NTP TECHNICAL REPORT

ON THE TOXICOLOGY AND

CARCINOGENESIS STUDIES OF

2-HYDROXY-

4-METHOXYBENZOPHENONE

(CASRN 131-57-7)

ADMINISTERED IN FEED

tO Sprague DaWley

(HSD:SPRAGUE DAWLEY ${ }^{\circledR}$ SD $^{\circledR}$ )

Rats AND B6C3F1/N MICE

NTP TR 597

MAY 2020 


\section{NTP Technical Report on the Toxicology and Carcinogenesis Studies of 2-Hydroxy-4-methoxybenzophenone (CASRN 131-57-7) Administered in Feed to Sprague Dawley (Hsd:Sprague Dawley ${ }^{\circledR} S D^{\circledR}$ ) Rats and B6C3F1/N Mice}

Technical Report 597

May 2020

National Toxicology Program

Public Health Service

U.S. Department of Health and Human Services ISSN: 2378-8925

Research Triangle Park, North Carolina, USA 


\section{Foreword}

The National Toxicology Program (NTP), established in 1978, is an interagency program within the Public Health Service of the U.S. Department of Health and Human Services. Its activities are executed through a partnership of the National Institute for Occupational Safety and Health (part of the Centers for Disease Control and Prevention), the Food and Drug Administration (primarily at the National Center for Toxicological Research), and the National Institute of Environmental Health Sciences (part of the National Institutes of Health), where the program is administratively located. NTP offers a unique venue for the testing, research, and analysis of agents of concern to identify toxic and biological effects, provide information that strengthens the science base, and inform decisions by health regulatory and research agencies to safeguard public health. NTP also works to develop and apply new and improved methods and approaches that advance toxicology and better assess health effects from environmental exposures.

The Technical Report series began in 1976 with carcinogenesis studies conducted by the National Cancer Institute. In 1981, this bioassay program was transferred to NTP. The studies described in the NTP Technical Report series are designed and conducted to characterize and evaluate the toxicological potential, including carcinogenic activity, of selected substances in laboratory animals (usually two species, rats and mice). Substances (e.g., chemicals, physical agents, and mixtures) selected for NTP toxicity and carcinogenicity studies are chosen primarily on the basis of human exposure, level of commercial production, and chemical structure. The interpretive conclusions presented in NTP Technical Reports are derived solely from the results of these NTP studies, and extrapolation of the results to other species, including characterization of hazards and risks to humans, requires analyses beyond the intent of these reports. Selection for study per se is not an indicator of a substance's carcinogenic potential.

NTP conducts its studies in compliance with its laboratory health and safety guidelines and the Food and Drug Administration Good Laboratory Practice Regulations and meets or exceeds all applicable federal, state, and local health and safety regulations. Animal care and use are in accordance with the Public Health Service Policy on Humane Care and Use of Laboratory Animals. Studies are subjected to retrospective quality assurance audits before they are presented for public review. Draft reports undergo external peer review before they are finalized and published.

The NTP Technical Reports are available free of charge on the NTP website and cataloged in PubMed, a free resource developed and maintained by the National Library of Medicine (part of the National Institutes of Health). Data for these studies are included in NTP's Chemical Effects in Biological Systems database.

For questions about the reports and studies, please email NTP or call 984-287-3211. 


\section{Table of Contents}

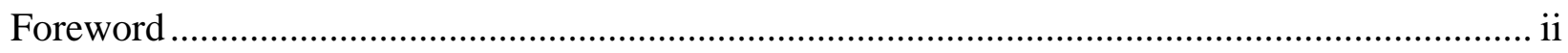

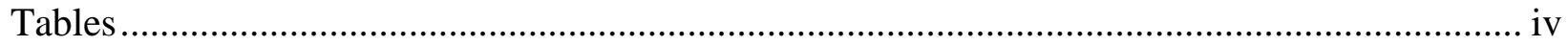

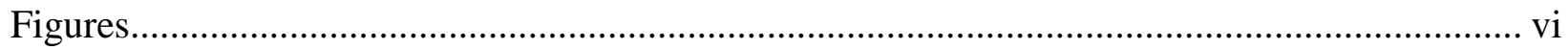

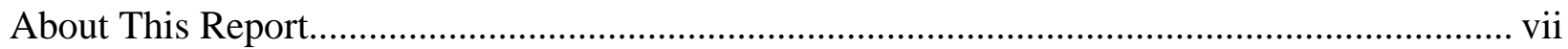

Explanation of Levels of Evidence of Carcinogenic Activity ................................................... xiii

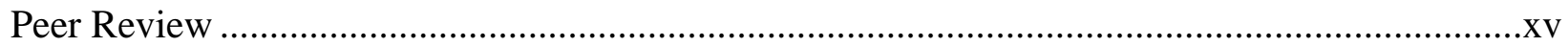

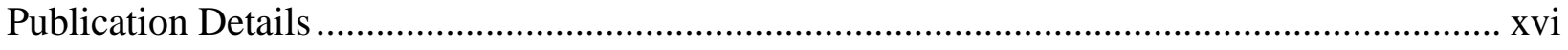

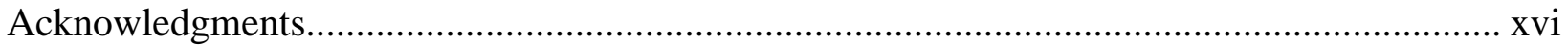

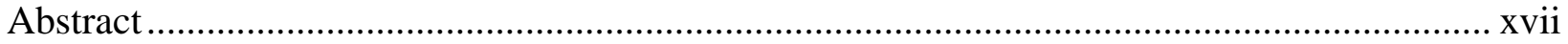

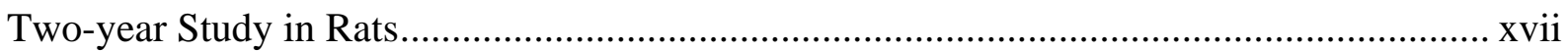

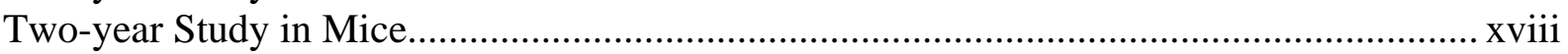

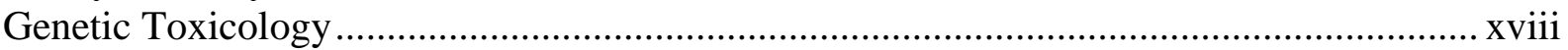

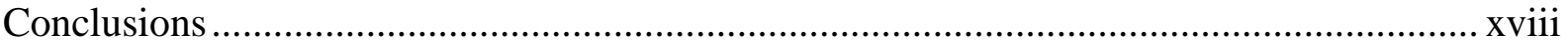

Overview

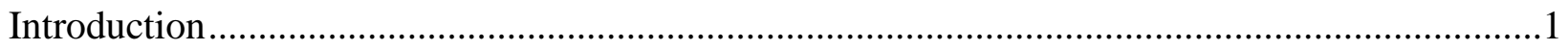

Chemical and Physical Properties .......................................................................................

Production, Use, and Human Exposure ……………...........................................................

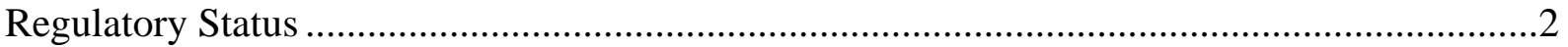

Absorption, Distribution, Metabolism, and Excretion ………...............................................

Experimental Animals .......................................................................................

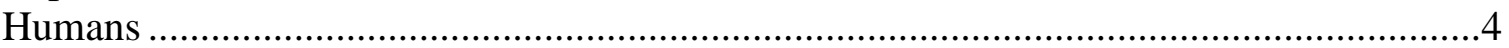

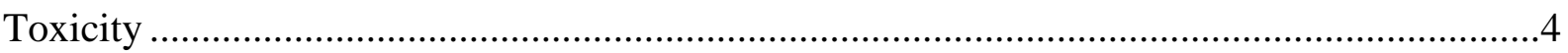

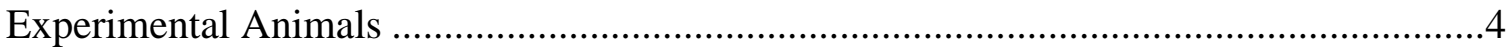

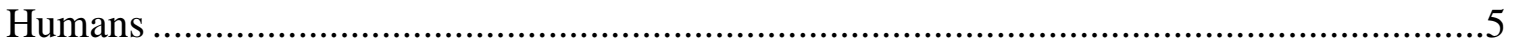

Reproductive and Developmental Toxicity .........................................................................

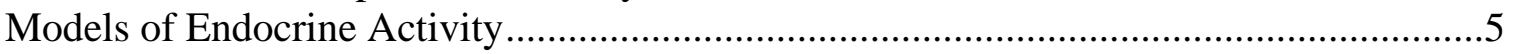

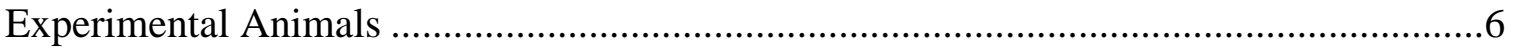

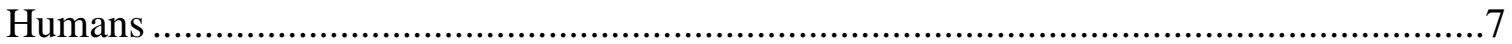

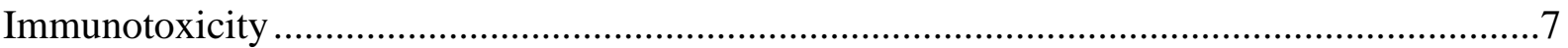

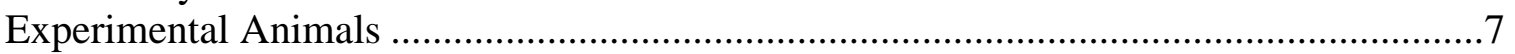

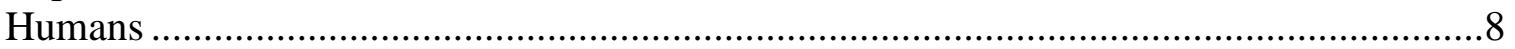

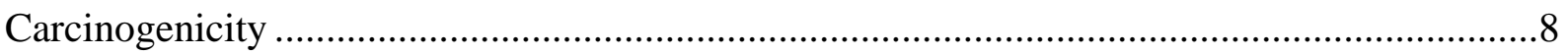

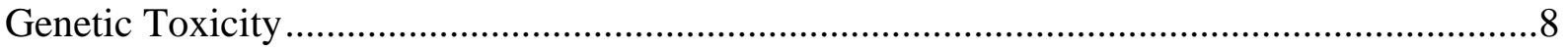

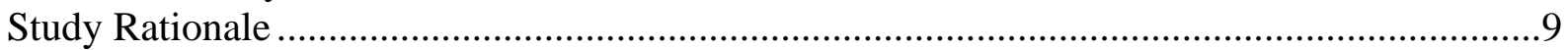

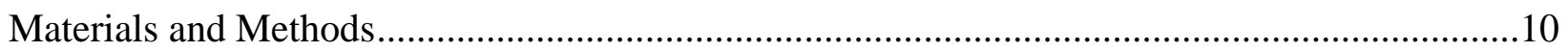

Procurement and Characterization of 2-Hydroxy-4-methoxybenzophenone ...........................10

Preparation and Analysis of Dose Formulations................................................................10

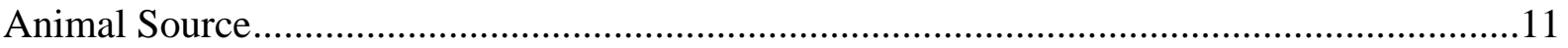

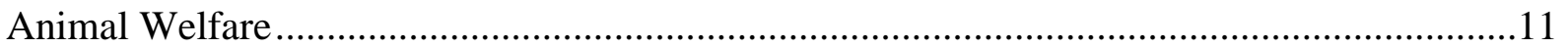




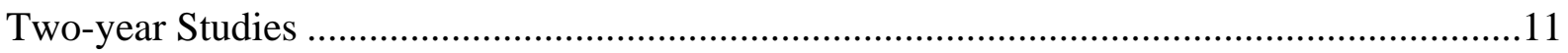

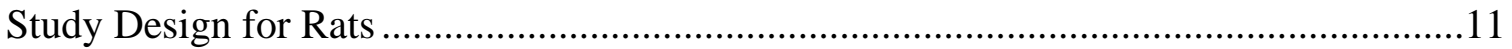

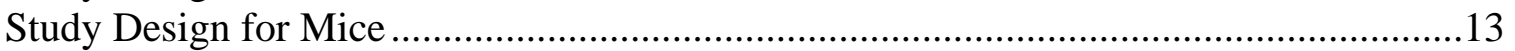

Clinical Examinations and Pathology ………..............................................................

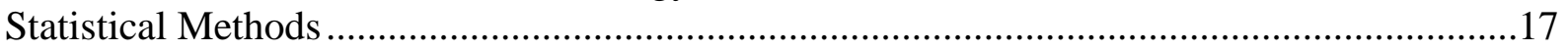

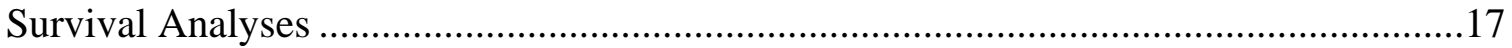

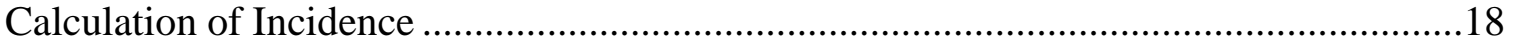

Analysis of Neoplasm and Nonneoplastic Lesion Incidence.............................................18

Analysis of Continuous Variables ...........................................................................19

Analysis of Gestational and Fertility Indices.............................................................20

Body Weight Adjustments ....................................................................................20

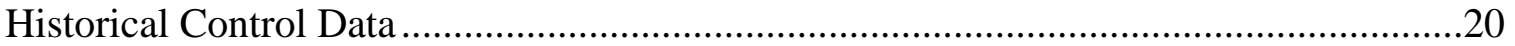

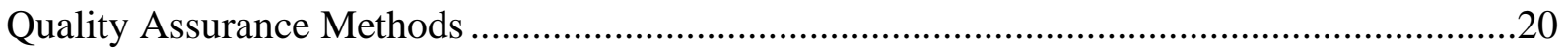

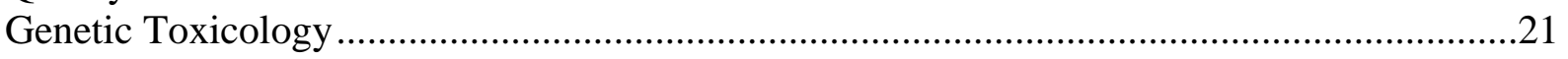

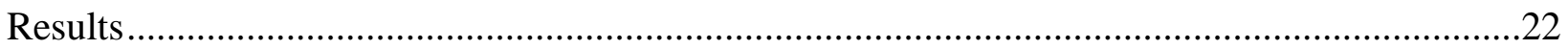

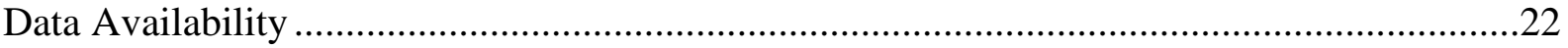

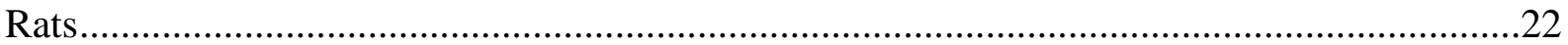

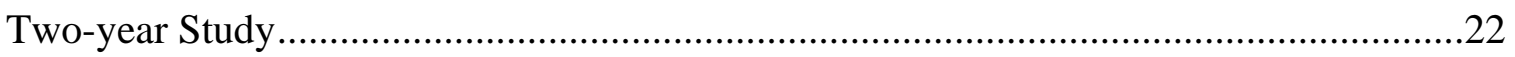

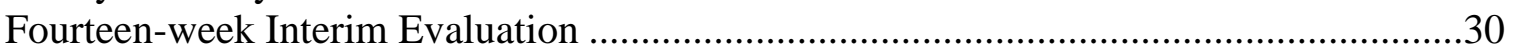

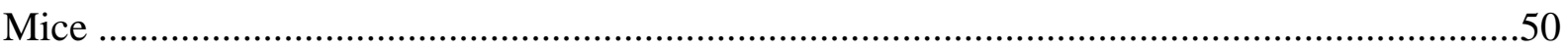

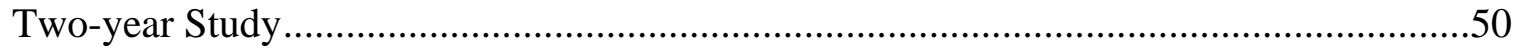

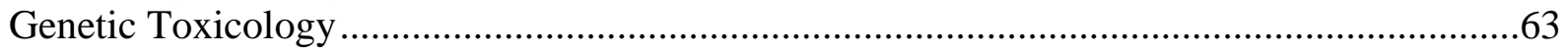

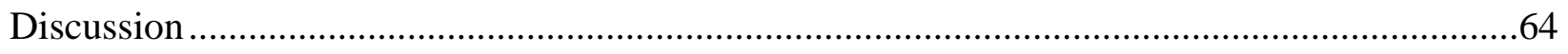

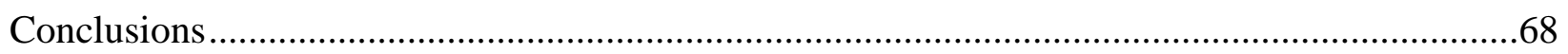

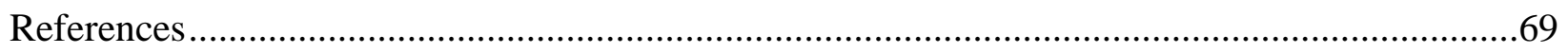

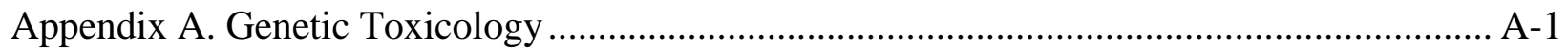

Appendix B. Chemical Characterization and Dose Formulation Studies ...................................... B-1

Appendix C. Ingredients, Nutrient Composition, and Contaminant Levels in NTP-2000

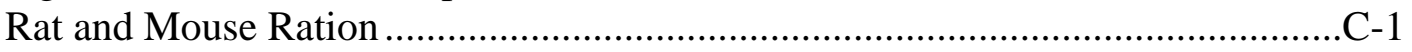

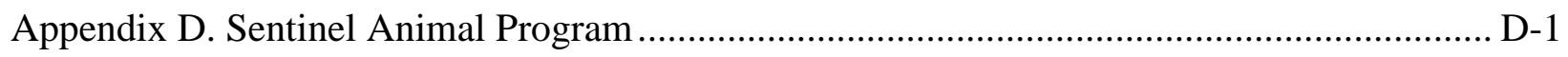

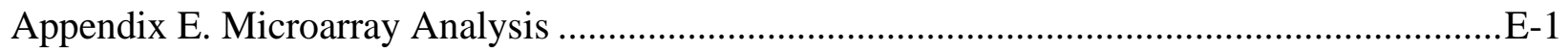

Appendix F. Endocrine Disruptor Screening Panel Studies ........................................................F-1

Appendix G. Summary of Peer Review Panel Comments ........................................................ G-1

Appendix H. Supplemental Data ………………….......................................................... H-1

\section{Tables}

Summary of the Perinatal and Two-year Carcinogenesis and Genetic Toxicology Studies of 2-Hydroxy-4-methoxybenzophenone ...................................................................... xix

Table 1. Experimental Design and Materials and Methods in the Perinatal and Two-year Feed Studies of 2-Hydroxy-4-methoxybenzophenone. 
Table 2. Mean Body Weights and Body Weight Changes of $F_{0}$ Female Rats Exposed to 2Hydroxy-4-methoxybenzophenone in Feed during Gestation and Lactation.

Table 3. Feed Consumption of $\mathrm{F}_{0}$ Female Rats Exposed to 2-Hydroxy-4methoxybenzophenone in Feed during Gestation and Lactation

Table 4. Summary of the Disposition of Rats during Perinatal Exposure and F1 Allocation in the Two-year Perinatal and Postnatal Feed Study of 2-Hydroxy-4methoxybenzophenone....

Table 5. Mean Number of Surviving $F_{1}$ Male and Female Rats during Lactation in the Two-year Perinatal and Postnatal Feed Study of 2-Hydroxy-4methoxybenzophenone.

Table 6. Preweaning Pup Body Weight of Rats Following Exposure during Gestation and Lactation in the Two-year Perinatal and Postnatal Feed Study of 2-Hydroxy-4methoxybenzophenone....

Table 7. Survival of Rats in the Perinatal and Two-year Feed Study of 2-Hydroxy-4methoxybenzophenone.

Table 8. Select Organ Weights, Organ-Weight-to-Body-Weight Ratios, and Histological Findings in Rats at the 14-week Interim of the Two-year Feed Study of 2Hydroxy-4-methoxybenzophenone

Table 9. Mean Body Weights and Survival of Male Rats in the Perinatal and Two-year Feed Study of 2-Hydroxy-4-methoxybenzophenone

Table 10. Mean Body Weights and Survival of Female Rats in the Perinatal and Twoyear Feed Study of 2-Hydroxy-4-methoxybenzophenone...

Table 11. Incidences of Neoplasms of the Brain in Male Rats in the Perinatal and Twoyear Feed Study of 2-Hydroxy-4-methoxybenzophenone

Table 12. Incidences of Neoplastic and Nonneoplastic Lesions of the Thyroid Gland in Female Rats in the Perinatal and Two-year Feed Study of 2-Hydroxy-4methoxybenzophenone.

Table 13. Incidences of Neoplastic and Nonneoplastic Lesions of the Uterus in Female Rats in the Perinatal and Two-year Feed Study of 2-Hydroxy-4methoxybenzophenone.

Table 14. Incidences of Nonneoplastic Lesions of the Testes, Pancreas, and Adrenal Cortex of Rats in the Perinatal and Two-year Feed Study of 2-Hydroxy-4methoxybenzophenone.

Table 15. Survival of Mice in the Two-year Feed Study of 2-Hydroxy-4methoxybenzophenone.

Table 16. Mean Body Weights and Survival of Male Mice in the Two-year Feed Study of 2-Hydroxy-4-methoxybenzophenone

Table 17. Mean Body Weights and Survival of Female Mice in the Two-year Feed Study of 2-Hydroxy-4-methoxybenzophenone.....

Table 18. Incidences of Nonneoplastic Lesions of the Bone Marrow, Spleen, Liver, and Kidney of Mice in the Two-year Feed Study of 2-Hydroxy-4methoxybenzophenone. 


\section{Figures}

Figure 1. 2-Hydroxy-4-methoxybenzophenone (CASRN 131-57-7; Chemical Formula:

$\mathrm{C}_{14} \mathrm{H}_{12} \mathrm{O}_{3}$; Molecular Weight: 228.25)

Figure 2. Metabolism of 2-Hydroxy-4-methoxybenzophenone in Rodents ................................4

Figure 3. Kaplan-Meier Survival Curves for Rats Exposed to 2-Hydroxy-4methoxybenzophenone in Feed for Two Years

Figure 4. Growth Curves for Rats Exposed to 2-Hydroxy-4-methoxybenzophenone in Feed for Two Years.

Figure 5. Malignant Meningioma in the Brain of a Male Sprague Dawley Rat Exposed to 1,000 ppm 2-Hydroxy-4-methoxybenzophenone for Two Years (H\&E).

Figure 6. Malignant Meningioma in the Brain of a Male Sprague Dawley Rat Exposed to 3,000 ppm 2-Hydroxy-4-methoxybenzophenone for Two Years (H\&E)

Figure 7. C-cell Adenoma in the Thyroid Gland of a Female Sprague Dawley Rat Exposed to 3,000 ppm 2-Hydroxy-4-methoxybenzophenone for Two Years (H\&E)....

Figure 8. Stromal Polyp in the Uterus of a Female Sprague Dawley Rat Exposed to 3,000 ppm 2-Hydroxy-4-methoxybenzophenone for Two Years (H\&E)

Figure 9. Stromal Sarcoma in the Uterus of Female Sprague Dawley Rat Exposed to 1,000 ppm 2-Hydroxy-4-methoxybenzophenone for Two Years (H\&E).

Figure 10. Atypical Hyperplasia of the Uterus in a Female Sprague Dawley Rat Exposed to 3,000 ppm 2-Hydroxy-4-methoxybenzophenone for Two Years (H\&E)

Figure 11. Focal Hypertrophy in the Adrenal Cortex from a Female Sprague Dawley Rat Exposed to 3,000 ppm 2-Hydroxy-4-methoxybenzophenone for Two Years (H\&E) ....

Figure 12. Kaplan-Meier Survival Curves for Mice Exposed to 2-Hydroxy-4methoxybenzophenone in Feed for Two Years

Figure 13. Growth Curves for Mice Exposed to 2-Hydroxy-4-methoxybenzophenone in Feed for Two Years ....

Figure 14. Pigment in the Bone Marrow from Female B6C3F1/N Mice Exposed to 0 or 10,000 ppm 2-Hydroxy-4-methoxybenzophenone for Two Years (H\&E)

Figure 15. Pigment in the Spleen from Female B6C3F1/N Mice Exposed to 0 or 10,000 ppm 2-Hydroxy-4-methoxybenzophenone for Two Years (H\&E)

Figure 16. Pigment in the Spleen from Female B6C3F1/N Mice Exposed to 0 or 10,000 ppm 2-Hydroxy-4-methoxybenzophenone for Two Years (Perl's Iron Stain)......

Figure 17. Syncytial Alteration in the Liver from a Male B6C3F1/N Mouse Exposed to 10,000 ppm 2-Hydroxy-4-methoxybenzophenone for Two Years (H\&E)

Figure 18. Renal Tubule Vacuolation in the Kidney from Male B6C3F1/N Mice Exposed to 0 or 10,000 ppm 2-Hydroxy-4-methoxybenzophenone for Two Years $(\mathrm{H} \& \mathrm{E})$ 


\section{About This Report}

National Toxicology Program ${ }^{1}$

${ }^{1}$ Division of the National Toxicology Program, National Institute of Environmental Health

Sciences, Research Triangle Park, North Carolina, USA

\section{Collaborators}

B.S. McIntyre, A.E. Brix, S.S. Auerbach, C.R. Blystone, S. Borghoff, P. Brown, M.A.

Buccellato, B.L. Burback, D.A. Contos, T.A. Cristy, M.J. DeVito, D.M. Fallacara, J.M. Fostel, P.M. Foster, H. Gong, S.W. Graves, M.R. Hejtmancik, C.A. Hobbs, M.J. Hooth, A. Hulett, C. Johnson, A.P. King-Herbert, G.E. Kissling, D.E. Malarkey, C. Martini, R.A. Miller, C. Myers, L. Recio, G.K. Roberts, V.G. Robinson, N. Sayers, C.C. Shackelford, M. Shaw, K.R. Shockley, A.W. Singer, S.L. Smith-Roe, N.L. South, M.D. Stout, C.D. Swartz, G.S. Travlos, H. Wagner, S. Waidyanatha, N.J. Walker, P. Wilga, J.A. Willoughby, G.A. Willson, K.L. Witt, R. Wittlesey, L. Zorrilla

Division of the National Toxicology Program, National Institute of Environmental Health Sciences, Research Triangle Park, North Carolina, USA

Evaluated and interpreted results and reported findings

B.S. McIntyre, Ph.D., Study Scientist

S.S. Auerbach., Ph.D.

C.R. Blystone, Ph.D.

M.J. DeVito, Ph.D.

P.M. Foster, Ph.D.

M.J. Hooth, Ph.D.

A.P. King-Herbert, D.V.M.

G.E. Kissling, Ph.D.

D.E. Malarkey, D.V.M., Ph.D.

G.K. Roberts, Ph.D.

V.G. Robinson, M.S.

K.R. Shockley, Ph.D.

S.L. Smith-Roe, Ph.D.

M.D. Stout, Ph.D.

G.S. Travlos, D.V.M.

S. Waidyanatha, Ph.D.

N.J. Walker, Ph.D.

K.L. Witt, M.S.

Provided oversight for data management

J.M. Fostel, Ph.D.

Experimental Pathology Laboratories, Inc., Research Triangle Park, North Carolina, USA Evaluated and interpreted results and reported findings

A.E. Brix, D.V.M., Ph.D., Study Pathologist 
Provided pathology review

R.A. Miller, D.V.M., Ph.D.

C.C. Shackelford, D.V.M., Ph.D.

G.A. Willson, B.V.M.S.

Coordinated NTP Pathology Working Groups on perinatal and 2-year rats (December 8, 2015)

and on 2-year mice (February 23, 2016)

G.A. Willson, B.V.M.S. (Rats)

C.C. Shackelford, D.V.M., Ph.D. (Mice)

Battelle, Columbus, Ohio, USA

Conducted studies and evaluated pathology findings

M.R. Hejtmancik, Ph.D., Principal Investigator

M.A. Buccellato, D.V.M., Ph.D.

D.M. Fallacara, Ph.D.

A.W. Singer, D.V.M.

Conducted prestart chemistry activities and dose formulations

S.W. Graves, B.S., Principal Investigator

B.L. Burback, Ph.D.

D.A. Contos, M.S.

T.A. Cristy, B.A.

N.L. South, B.S.

CeeTox, Inc., Kalamazoo, Michigan, USA

Conducted in vitro endocrine disruptor screening studies

A. Hulett, B.S.

H. Wagner, M.S.

P. Wilga, M.S.

J.A. Willoughby, Sr., Ph.D.

Integrated Laboratory Systems, Inc., Research Triangle Park, North Carolina, USA

Conducted in vivo endocrine disruptor screening studies

Susan Borghoff, Ph.D., Principal Investigator

Leah Zorrilla, Ph.D.

Conducted bacterial mutagenicity assays

L. Recio, Ph.D., Principal Investigator

C.A. Hobbs, Ph.D.

C.D. Swartz, D.V.M., Ph.D.

Pathology Associates International, A Charles River Company, Research Triangle Park, North Carolina, USA

Coordinated Pathology Peer Review on Uterine Lesions in Female Rats (April 26, 2016)

C. Johnson, D.V.M. 
ASRC Federal, Research Triangle Park, North Carolina, USA

Prepared data for report

P. Brown, B.S.

H. Gong, M.S.

C. Martini, B.S.

C. Myers, M.S.

N. Sayers, B.S.

M. Shaw, B.S.

R. Whittlesey, M.S.

\section{Contributors}

Division of the National Toxicology Program, National Institute of Environmental Health Sciences, Research Triangle Park, North Carolina, USA

Provided oversight of external peer review

E.A. Maull, Ph.D.

M.S. Wolfe, Ph.D.

Experimental Pathology Laboratories, Inc., Research Triangle Park, North Carolina, USA Supervised pathology review

M.H. Hamlin, II, D.V.M., Principal Investigator (Retired)

T.J. Steinbach, D.V.M., Principal Investigator

Coordinated NTP Pathology Peer Review of brain glial cell proliferative lesions in rats (April 18, 2016)

M. Gruebbel, D.V.M., Ph.D.

Coordinated NTP Pathology Peer Review of brain granular cell proliferative lesions and head/neck schwannomas/sarcomas in rats (April 18, 2016)

M. Gruebbel, D.V.M., Ph.D.

NTP Pathology Working Group, National Institute of Environmental Health Sciences, Research Triangle Park, North Carolina, USA

Participated in NTP Pathology Working Group on perinatal and 2-year rats (December 8, 2015)

A.E. Brix, D.V.M., Ph.D., Experimental Pathology Laboratories, Inc.

M.F. Cesta, D.V.M., Ph.D., National Toxicology Program

D. Dixon, D.V.M., Ph.D., National Toxicology Program

S.A. Elmore, D.V.M., National Toxicology Program

J.I. Everitt, D.V.M., GlaxoSmithKline

D.E. Malarkey, D.V.M., Ph.D., National Toxicology Program

Participated in NTP Pathology Working Group on 2-year mice (February 23, 2016)

A.E. Brix, D.V.M., Ph.D., Experimental Pathology Laboratories, Inc.

M.F. Cesta, D.V.M., Ph.D., National Toxicology Program

S.A. Elmore, D.V.M., National Toxicology Program

J.I. Everitt, D.V.M., GlaxoSmithKline

G.P. Flake, M.D., National Toxicology Program 
A.R. Pandiri, Ph.D., National Toxicology Program

D.E. Malarkey, D.V.M., Ph.D., National Toxicology Program

R.R. Maronpot, D.V.M., Experimental Pathology Laboratories, Inc.

T.J. Steinbach, D.V.M., Experimental Pathology Laboratories, Inc.

NTP Pathology Peer Review, National Institute of Environmental Health Sciences, Research Triangle Park, North Carolina, USA

Participated in NTP Pathology Peer Review of brain glial cell proliferative lesions in rats (April 18, 2016)

M.F. Cesta, D.V.M., Ph.D., National Toxicology Program

P. Little, D.V.M., Ph.D., Experimental Pathology Laboratories, Inc.

D.E. Malarkey, D.V.M., Ph.D., National Toxicology Program

Participated in NTP Pathology Peer Review of brain granular cell proliferative lesions and head/neck schwannomas/sarcomas in rats (April 18, 2016)

M.F. Cesta, D.V.M., Ph.D., National Toxicology Program

P. Little, D.V.M., Ph.D., Experimental Pathology Laboratories, Inc.

D.E. Malarkey, D.V.M., Ph.D., National Toxicology Program

Participated in NTP Pathology Peer Review of uterine lesions in female rats (April 26, 2016)

A.E. Brix, D.V.M., Ph.D., Experimental Pathology Laboratories, Inc.

K. Cimon, D.V.M., Experimental Pathology Laboratories, Inc.

D. Dixon, D.V.M., Ph.D., National Toxicology Program

S.A. Elmore, D.V.M., M.S., National Toxicology Program

G.A. Willson, B.V.M.S., Experimental Pathology Laboratories, Inc.

Participated in NTP Pathology Peer Review of hearts from control Harlan Sprague Dawley rats (April 14, 2016)

M.F. Cesta, D.V.M., Ph.D., National Toxicology Program

S.A. Elmore, D.V.M., M.S., National Toxicology Program

M. Jokinen, D.V.M., Integrated Laboratory Systems, Inc.

D.E. Malarkey, D.V.M., Ph.D., National Toxicology Program

Participated in NTP Pathology Peer Review of malignant meningiomas in male and female rats (June 20, 2017)

B. Bolon, D.V.M., Ph.D., Pathology Experts

G.A. Boorman, D.V.M., Ph.D., Covance, Inc.

M.C. Boyle, D.V.M., Ph.D., Amgen, Inc.

A.E. Brix, D.V.M., Ph.D., Experimental Pathology Laboratories, Inc.

M.T. Butt, D.V.M., Tox Path Specialists, LLC

M.F. Cesta, D.V.M., Ph.D., National Toxicology Program

M.R. Elwell, D.V.M., Ph.D., APEX TOXPATH, LLC

G. Flake, M.D., National Toxicology Program

R.H. Garman, D.V.M., Consultants in Veterinary Pathology, Inc.

R.A. Herbert, D.V.M., Ph.D., National Toxicology Program

K. Janardhan, Ph.D., Integrated Laboratory Systems, Inc.

R. Kovi, M.V.Sc., Ph.D., Experimental Pathology Laboratories, Inc. 
P. Little, D.V.M., Ph.D., Experimental Pathology Laboratories, Inc.

D.E. Malarkey, D.V.M., Ph.D., National Toxicology Program

J. Morrison, D.V.M., Charles River Laboratories, Inc.

A.R. Pandiri, Ph.D., National Toxicology Program

R.C. Sills, D.V.M., Ph.D., National Toxicology Program

J.M. Ward, D.V.M., Ph.D., Global VetPathology

C.J. Willson, D.V.M., Ph.D., Integrated Laboratory Systems, Inc.

CSS Corporation, Research Triangle Park, North Carolina, USA

Prepared quality assessment audits

S. Brecher, Ph.D., Principal Investigator

S. Iyer, B.S.

V.S. Tharakan, D.V.M.

Social \& Scientific Systems, Inc., Research Triangle Park, North Carolina, USA

Provided statistical analyses

S.J. McBride, Ph.D., Principal Investigator

L.J. Betz, M.S.

S.F. Harris, M.S.

J.D. Krause, Ph.D.

C.G. Leach, M.S.

M.V. Smith, Ph.D.

ICF, Durham, North Carolina, USA

Provided contract oversight

D.F. Burch, M.E.M., Principal Investigator

J.C. Cleland, M.E.M.

J.A. Wignall, M.S.P.H.

Prepared, edited, and formatted report

K.S. Duke, Ph.D.

J. Frye, M.S.

S.R. Gunnels, M.A.

T. Hamilton, M.S.

P. Hartman, M.E.M.

W. Mitchell, B.S.

K.A. Shipkowski, Ph.D.

Supported external peer review

C.N. Byrd, B.S.

S.A. Hearn, B.S.

S.J. Snow, Ph.D.

Biotechnical Services, Inc., North Little Rock, Arkansas, USA

Prepared report

S.R. Gunnels, M.A., Principal Investigator

P.A. Gideon, B.A. 
B.F. Hall, M.S.

L.M. Harper, B.S.

D.C. Serbus, Ph.D.

G.E. Simmons, M.A. 


\section{Explanation of Levels of Evidence of Carcinogenic Activity}

The National Toxicology Program describes the results of individual experiments on a chemical agent and notes the strength of the evidence for conclusions regarding each study. Negative results, in which the study animals do not have a greater incidence of neoplasia than control animals, do not necessarily mean that a chemical is not a carcinogen, in as much as the experiments are conducted under a limited set of conditions. Positive results demonstrate that a chemical is carcinogenic for laboratory animals under the conditions of the study and indicate that exposure to the chemical has the potential for hazard to humans. Other organizations, such as the International Agency for Research on Cancer, assign a strength of evidence for conclusions based on an examination of all available evidence, including animal studies such as those conducted by NTP, epidemiologic studies, and estimates of exposure. Thus, the actual determination of risk to humans from chemicals found to be carcinogenic in laboratory animals requires a wider analysis that extends beyond the purview of these studies.

Five categories of evidence of carcinogenic activity are used in the Technical Report series to summarize the strength of evidence observed in each experiment: two categories for positive results (clear evidence and some evidence); one category for uncertain findings (equivocal evidence); one category for no observable effects (no evidence); and one category for experiments that cannot be evaluated because of major flaws (inadequate study). These categories of interpretative conclusions were first adopted in June 1983 and then revised on March 1986 for use in the Technical Report series to incorporate more specifically the concept of actual weight of evidence of carcinogenic activity. For each separate experiment (male rats, female rats, male mice, female mice), one of the following five categories is selected to describe the findings. These categories refer to the strength of the experimental evidence and not to potency or mechanism.

- Clear evidence of carcinogenic activity is demonstrated by studies that are interpreted as showing a dose-related (i) increase of malignant neoplasms, (ii) increase of a combination of malignant and benign neoplasms, or (iii) marked increase of benign neoplasms if there is an indication from this or other studies of the ability of such tumors to progress to malignancy.

- Some evidence of carcinogenic activity is demonstrated by studies that are interpreted as showing a chemical-related increased incidence of neoplasms (malignant, benign, or combined) in which the strength of the response is less than that required for clear evidence.

- Equivocal evidence of carcinogenic activity is demonstrated by studies that are interpreted as showing a marginal increase of neoplasms that may be chemical related.

- No evidence of carcinogenic activity is demonstrated by studies that are interpreted as showing no chemical-related increases in malignant or benign neoplasms.

- Inadequate study of carcinogenic activity is demonstrated by studies that, because of major qualitative or quantitative limitations, cannot be interpreted as valid for showing either the presence or absence of carcinogenic activity.

For studies showing multiple chemical-related neoplastic effects that if considered individually would be assigned to different levels of evidence categories, the following convention has been 
adopted to convey completely the study results. In a study with clear evidence of carcinogenic activity at some tissue sites, other responses that alone might be deemed some evidence are indicated as "were also related" to chemical exposure. In studies with clear or some evidence of carcinogenic activity, other responses that alone might be termed equivocal evidence are indicated as "may have been" related to chemical exposure.

When a conclusion statement for a particular experiment is selected, consideration must be given to key factors that would extend the actual boundary of an individual category of evidence. Such consideration should allow for incorporation of scientific experience and current understanding of long-term carcinogenesis studies in laboratory animals, especially for those evaluations that may be on the borderline between two adjacent levels. These considerations should include:

- adequacy of the experimental design and conduct;

- occurrence of common versus uncommon neoplasia;

- progression (or lack thereof) from benign to malignant neoplasia as well as from preneoplastic to neoplastic lesions;

- some benign neoplasms have the capacity to regress but others (of the same morphologic type) progress. At present, it is impossible to identify the difference. Therefore, where progression is known to be a possibility, the most prudent course is to assume that benign neoplasms of those types have the potential to become malignant;

- combining benign and malignant tumor incidence known or thought to represent stages of progression in the same organ or tissue;

- latency in tumor induction;

- multiplicity in site-specific neoplasia;

- metastases;

- supporting information from proliferative lesions (hyperplasia) in the same site of neoplasia or other experiments (same lesion in another sex or species);

- presence or absence of dose relationships;

- statistical significance of the observed tumor increase;

- concurrent control tumor incidence as well as the historical control rate and variability for a specific neoplasm;

- $\quad$ survival-adjusted analyses and false positive or false negative concerns;

- structure-activity correlations; and

- in some cases, genetic toxicology. 


\section{Peer Review}

The members of the Peer Review Panel who evaluated the draft NTP Technical Report on the Toxicology and Carcinogenesis Studies of 2-Hydroxy-4-methoxybenzophenone (CASRN 131-577) Administered in Feed to Sprague Dawley (Hsd:Sprague Dawley ${ }^{\circledR} D^{\circledR}$ ) Rats and B6C3F1/N Mice on December 12, 2019, are listed below. Panel members served as independent scientists, not as representatives of any institution, company, or governmental agency. A summary of the Peer Review Panel's comments is provided in Appendix G.

In this capacity, panel members had five major responsibilities in reviewing the NTP studies:

- to ascertain that all relevant literature data have been adequately cited and interpreted,

- to determine if the design and conditions of the NTP studies were appropriate,

- to ensure that the Technical Report presents the experimental results and conclusions fully and clearly,

- to judge the significance of the experimental results by scientific criteria, and

- to assess the evaluation of the evidence of carcinogenic activity and other observed toxic responses.

\section{Peer Reviewers}

\section{Russell Cattley, V.M.D., Ph.D., Chairperson}

Auburn University

Auburn, Alabama, USA

Michael R. Elwell, D.V.M., Ph.D.

APEX TOXPATH, LLC

Apex, North Carolina, USA

Wendy Halpern, D.V.M., Ph.D.

Genentech, Inc.

San Francisco, California, USA

Gabriele Ludewig, Ph.D.

University of Iowa

Iowa City, Iowa, USA

\section{Kristini Miles, Ph.D.}

Venture Chemical Consulting LLC

Spelman College

Atlanta, Georgia, USA

Karen Regan, D.V.M.

Regan Pathology/Toxicology Service Inc.

Research Pathology Associates, LLC

Mansfield, Ohio, USA 


\section{Publication Details}

Publisher: National Toxicology Program

Publishing Location: Research Triangle Park, NC

ISSN: $2378-8925$

DOI: https://doi.org/10.22427/NTP-TR-597

Report Series: NTP Technical Report Series

Report Series Number: 597

Official citation: National Toxicology Program (NTP). 2020. NTP technical report on the toxicology and carcinogenesis studies of 2-hydroxy-4-methoxybenzophenone (CASRN 13157-7) administered in feed to Sprague Dawley (Hsd:Sprague Dawley ${ }^{\circledR} \mathrm{SD}^{\circledR}$ ) rats and B6C3F1/N mice. Research Triangle Park, NC: National Toxicology Program. Technical Report 597.

\section{Acknowledgments}

This work was supported by the Intramural Research Program (ES103316, ES103318, and ES103319) at the National Institute of Environmental Health Sciences, National Institutes of Health and performed for the National Toxicology Program, Public Health Service, U.S. Department of Health and Human Services under contracts HHSN273201800006C, HHSN273201600020C, HHSN273201600011C, GS00Q14OADU417 (Order No. HHSN273201600015U), HHSN273201500006C, HHSN273201500012C, HHSN273201500014C, HHSN273201400027C, HHSN273201300009C, HHSN316201200054W, HHSN273201000016C, HHS273200900002C, HHSN273200900005C, N01-ES-55551, N01-ES-55541, and N01-ES-55536. 


\section{Abstract}

2-Hydroxy-4-methoxybenzophenone (2H4MBP) is approved by the U.S. Food and Drug Administration for use in sunscreens and other personal products in concentrations of up to 6\% either alone or in combination formulations and as an indirect food additive in acrylic and modified acrylic plastics that come into contact with food. 2H4MBP was nominated to the National Toxicology Program by the National Cancer Institute due to widespread exposure via sunscreen use and lack of carcinogenicity data. $2 \mathrm{H} 4 \mathrm{MBP}$ was also nominated by a private individual to ascertain genotoxic potential. Male and female Sprague Dawley (Hsd:Sprague Dawley ${ }^{\circledR} \mathrm{SD}^{\circledR}$ ) rats (after weaning) and B6C3F1/N mice were exposed to 2H4MBP (greater than $99 \%$ pure) in feed for 2 years. Perinatal studies and 14-week interim evaluations were also conducted in rats. Genetic toxicology studies were conducted in Salmonella typhimurium and Escherichia coli.

\section{Two-year Study in Rats}

Beginning on gestation day (GD) 6 , groups of $42,35,35$, and $43 \mathrm{~F}_{0}$ time-mated female rats were fed diets containing 0, 1,000, 3,000, and 10,000 ppm 2H4MBP, respectively, for 39 days. Groups of $50\left(1,000\right.$ and 3,000 ppm) or $60(0$ and $10,000 \mathrm{ppm}) \mathrm{F}_{1}$ rats per sex continued on study after weaning and were fed diets containing the same exposure concentrations for 105 weeks; $10 \mathrm{~F}_{1}$ rats per sex from the 0 and 10,000 ppm groups were evaluated at 14 weeks. Dietary concentrations of $1,000,3,000$, and $10,000 \mathrm{ppm}$ resulted in average daily doses of approximately 58,168 , and $585 \mathrm{mg} 2 \mathrm{H} 4 \mathrm{MBP} / \mathrm{kg}$ body weight for males and 60, 180, and $632 \mathrm{mg} / \mathrm{kg}$ for females.

Survival of all exposed groups of $\mathrm{F}_{1}$ male and female rats was not significantly different from that of the control groups. Over the course of the study, mean body weights of $F_{1}$ males and females in the 10,000 ppm exposure groups were 10-25\% lower than those of the control groups. After week 77, $\mathrm{F}_{1}$ female mean body weights in the 3,000 ppm exposure group were $10 \%$ lower than those of the control group. Feed consumption by exposed groups of $F_{1}$ males and females was generally similar to that by the control group throughout the study.

In the brain, the occurrence of malignant meningiomas in males at the end of the 2-year study was $0 / 50,1 / 50,3 / 50$, and $0 / 50$. One male in the 3,000 ppm group had a malignant meningioma in the spinal cord.

In the thyroid gland, the incidence of C-cell adenoma in 3,000 ppm females was significantly greater than that in the control group at the end of the 2-year study.

In the uterus, the incidence of stromal polyp in 3,000 ppm females was significantly increased. A significantly increased incidence of atypical endometrium hyperplasia of the uterus also occurred at 3,000 ppm; however, the incidence of adenocarcinoma was significantly decreased in this group.

In the adrenal cortex, the incidences of focal hypertrophy were significantly increased in 1,000 and 3,000 ppm females at the end of the 2-year study.

In the testes, the incidence of interstitial cell hyperplasia occurred with a positive trend at the end of the 2-year study. 


\section{Two-year Study in Mice}

Groups of 50 male and 50 female mice were fed diets containing 0, 1,000, 3,000, or 10,000 ppm 2H4MBP (equivalent to average daily doses of approximately 113, 339, and 1,207 $\mathrm{mg}$ $2 \mathrm{H} 4 \mathrm{MBP} / \mathrm{kg}$ body weight for males and 109, 320, and 1,278 mg/kg for females) for 104 (females) or 105 (males) weeks. Survival of all exposed groups of male and female mice was not significantly different from that of the control groups. Mean body weights of 1,000 and 3,000 ppm males and females were within $10 \%$ of those of the control groups throughout the study. Mean body weights of 10,000 ppm males and females were at least $10 \%$ lower than those of the control groups generally after weeks 17 and 12, respectively. Feed consumption by exposed groups of males and females was not significantly different from that by the control groups.

The incidences of pigment in the bone marrow were significantly increased in 10,000 ppm males and females. The incidences of pigment in the spleen were significantly increased in 10,000 ppm males and 3,000 and 10,000 ppm females.

In the liver, the incidence of hepatocyte syncytial alteration was significantly increased in all exposed groups of males.

In the kidney, the incidence of renal tubule cytoplasmic alteration was significantly increased in $10,000 \mathrm{ppm}$ males. The incidence of osseous metaplasia was significantly increased in $10,000 \mathrm{ppm}$ females compared to the control group.

\section{Genetic Toxicology}

Results of bacterial mutagenicity tests conducted using standard testing approaches with the same lot of 2H4MBP tested in the 2-year studies were negative in TA98 and TA100, as well as in Escherichia coli strain WP2 uvrA pKM101, with and without rat liver S9.

\section{Conclusions}

Under the conditions of these 2-year studies, there was equivocal evidence of carcinogenic activity (see Explanation of Levels of Evidence of Carcinogenic Activity) of 2H4MBP exposure in male Hsd:Sprague Dawley ${ }^{\circledR} \mathrm{SD}^{\circledR}$ rats based on the occurrence of malignant meningiomas in the brain. There was equivocal evidence of carcinogenic activity in female Hsd:Sprague Dawley ${ }^{\circledR} \mathrm{SD}^{\circledR}$ rats based on the increased incidence of thyroid C-cell adenomas and the increased incidence of uterine stromal polyps. There was no evidence of carcinogenic activity in male or female B6C3F1/N mice at exposure concentrations of 1,000, 3,000, and 10,000 ppm.

Increases in the incidences of nonneoplastic lesions of the testis in male rats and of the uterus and adrenal cortex in female rats occurred with exposure to $2 \mathrm{H} 4 \mathrm{MBP}$. Increases in the incidences of nonneoplastic lesions of the bone marrow (males and females), spleen (males and females), kidney (males and females), and liver (males) in mice occurred with exposure to 2H4MBP.

Synonyms: Benzophenone-3; (2-hydroxy-4-methoxyphenyl)-phenylmethanoneoxybenzone; oxybenzone 
Summary of the Perinatal and Two-year Carcinogenesis and Genetic Toxicology Studies of 2-Hydroxy-4-methoxybenzophenone

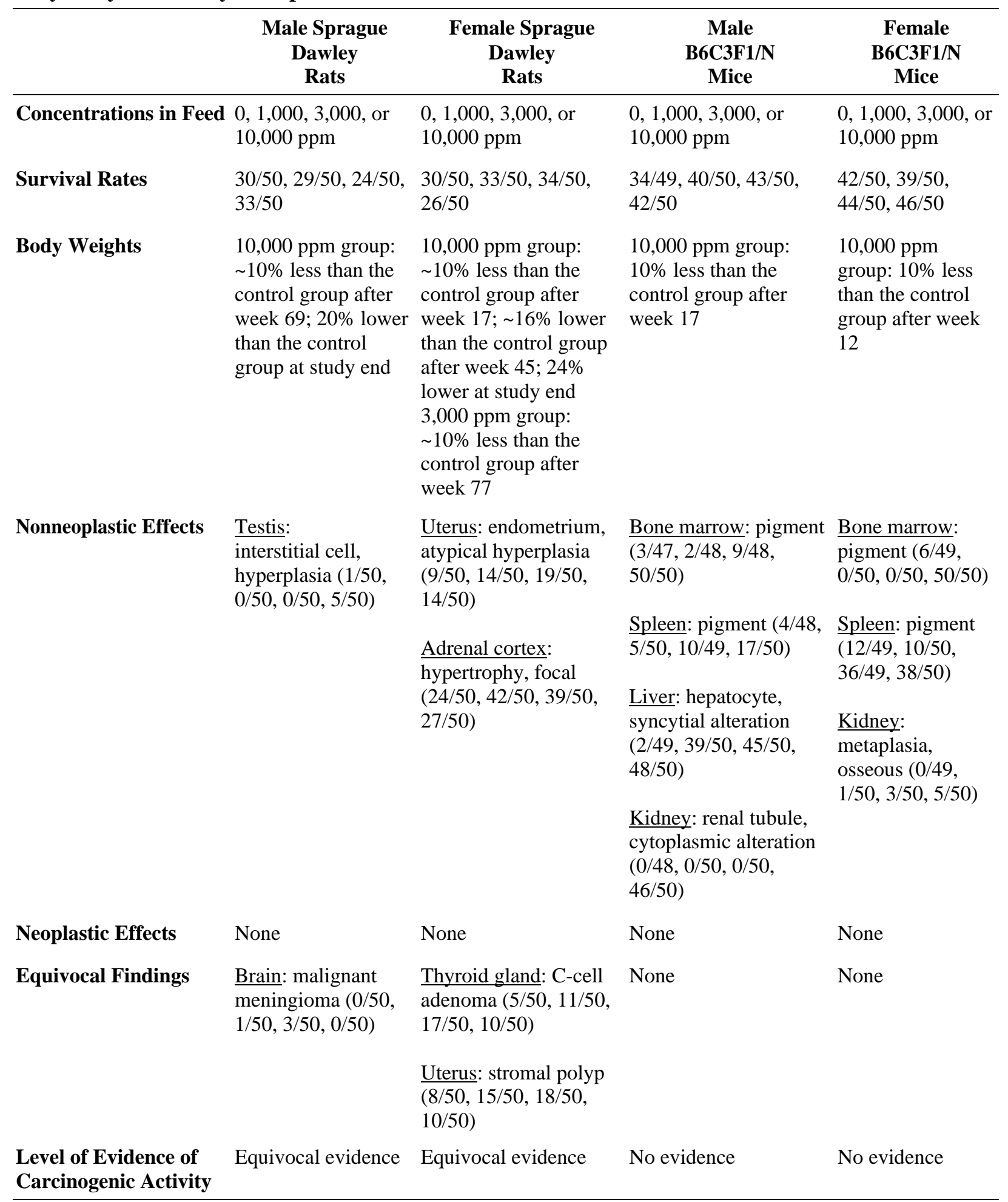

Genetic Toxicology

Bacterial Gene Mutations: Negative in Salmonella typhimurium strains TA98 and TA100 and Escherichia coli strain WP2 uvrA pKM101, with and without S9 


\section{Overview}

The National Toxicology Program (NTP) has assessed the potential adverse effects of sunscreens in human-relevant model systems; the data presented herein are part of that larger effort. The scope of 2-hydroxy-4-methoxybenzophenone (2H4MBP) studies includes the assessment of potential endocrine activity in the U.S. Environmental Protection Agency Endocrine Disruptor Screening Program Phase 1 studies (summary results of these data are provided in Appendix F), and characterization of the potential effects of continuous $2 \mathrm{H} 4 \mathrm{MBP}$ exposure over multiple generations using the NTP Modified One-Generation study design. In this study design, exposure to $2 \mathrm{H} 4 \mathrm{MBP}$ in the diet began on gestation day (GD) 6 . At weaning, one and two pups per sex per litter were allocated to prenatal and reproductive performance cohorts, respectively. In addition to an assessment of reproductive performance, $\mathrm{F}_{2}$ fetal outcomes (GD 21 fetal examinations) were assessed in one cohort and the potential effects on parturition and early growth of the $\mathrm{F}_{2}$ generation were assessed in the other cohort. Internal dose metrics were also assessed. Apical indicators sensitive to endocrine modulation were measured (e.g., anogenital distance, thoracic nipple retention, pubertal indices, reproductive tissue histology). The U.S. Food and Drug Administration's National Center for Toxicological Research (NCTR), in partnership under an Interagency Agreement, has also examined the effects of maternal and lactational exposure to $2 \mathrm{H} 4 \mathrm{MBP}$ on development and reproductive organs in male and female rat offspring, and on transcriptional changes in the testes and prostates of young rats. NCTR is also conducting fertility, embryo-fetal, and pre- and postnatal rat studies to characterize the potential effects of $2 \mathrm{H} 4 \mathrm{MBP}$ exposure. NTP previously conducted 2- and 13-week toxicity studies by dermal and oral routes and assessed the genotoxic potential of $2 \mathrm{H} 4 \mathrm{MBP}$. Potential effects of $2 \mathrm{H} 4 \mathrm{MBP}$ exposure on mouse reproduction were assessed using the Reproductive Assessment by Continuous Breeding protocol. 


\section{Introduction}<smiles>COc1ccc(C(=O)c2ccccc2)c(O)c1</smiles>

Figure 1. 2-Hydroxy-4-methoxybenzophenone (CASRN 131-57-7; Chemical Formula: $\mathrm{C}_{14} \mathrm{H}_{12} \mathrm{O}_{3}$; Molecular Weight: 228.25)

Synonyms: Benzophenone-3; (2-hydroxy-4-methoxyphenyl)-phenylmethanoneoxybenzone; oxybenzone.

\section{Chemical and Physical Properties}

2-Hydroxy-4-methoxybenzophenone (2H4MBP) is an off-white to light-yellow powder with a melting point of $62^{\circ} \mathrm{C}$ to $65^{\circ} \mathrm{C}$. $2 \mathrm{H} 4 \mathrm{MBP}$ is relatively insoluble in water $\left(69 \mathrm{mg} / \mathrm{kg}\right.$ at $\left.25^{\circ} \mathrm{C}\right)$ and is readily soluble in most organic solvents. $2 \mathrm{H} 4 \mathrm{MBP}$ absorbs ultraviolet (UV) A (320 to $400 \mathrm{~nm}$ ) and UVB (290 to $320 \mathrm{~nm}$ ) light and is photostable. ${ }^{1}$

\section{Production, Use, and Human Exposure}

2H4MBP is synthesized by condensation of benzoic acid with resorcinol monomethyl ether in the presence of heat, zinc chloride, and polyphosphoric acid or by the Friedel-Crafts reaction of benzoyl chloride with 3-hydroxyanisole. ${ }^{2}$

2H4MBP is commonly used in sunscreens and other personal care products at concentrations of up to $6 \%$ to protect the wearer from solar erythema. Per the Environmental Working Group's Guide to Sunscreens database, ${ }^{3}$ 2H4MBP is found in more than 1,000 products, including beach, sport, and baby sunscreens (619), moisturizers with SPF (150), and lip balms (109), often in combination with other sunscreens. $2 \mathrm{H} 4 \mathrm{MBP}$ has also been combined with the insecticide repellent $\mathrm{N}, \mathrm{N}$-diethyl-meta-toluamide (DEET). ${ }^{4}$ 2H4MBP is also used as a photostablizer for synthetic resins and polymers, including plastics $(0.05-0.5 \%)$ to prevent UV degradation. ${ }^{5-7}$ Exposure can occur when present in acrylic and modified acrylic plastics that come in contact with food. ${ }^{8}$

2H4MBP and its metabolites are typically excreted in urine. A study using National Health and Nutrition Examination Survey (NHANES) cycle data from 2004 to 2012 demonstrated more than $96 \%$ of the 10,232 samples (representing all populations) contained measurable urinary concentrations of $2 \mathrm{H} 4 \mathrm{MBP}$. Creatinine-adjusted urinary least square geometric mean concentrations ranged from 9 to $17 \mathrm{ng} / \mathrm{mL}$ in males, and 18 to $45 \mathrm{ng} / \mathrm{mL}$ in females. Children and adolescent concentrations ranged from 17 to 27 and 13 to $24 \mathrm{ng} / \mathrm{mL}$, respectively. ${ }^{9 ;}{ }^{10}$ Higher urinary concentrations of $2 \mathrm{H} 4 \mathrm{MBP}$ were observed in non-Hispanic whites and have been attributed to increased sunscreen use (28 versus $13 \mathrm{ng} / \mathrm{L}) .{ }^{11}$ Higher concentrations in females have been ascribed to the use of personal care products (e.g., lip balms, cosmetics) that often contain 2H4MBP. ${ }^{11}$ 


\section{Regulatory Status}

2H4MBP is approved by the U.S. Food and Drug Administration (FDA) for use as a sunscreen when present up to $6 \%$ either alone or in combination formulations and as an indirect food additive in acrylic and modified acrylic plastics that come into contact with food. ${ }^{12 ; 8} 2 \mathrm{H} 4 \mathrm{MBP}$ is also approved for use as a nonfood inert pesticide additive. ${ }^{13}$ Section 8 (a) of the Toxic Substances Control Act requires manufacturers of $2 \mathrm{H} 4 \mathrm{MBP}$ to report preliminary assessment information concerned with production, exposure, and use to the U.S. Environmental Protection Agency.

\section{Absorption, Distribution, Metabolism, and Excretion}

\section{Experimental Animals}

2H4MBP was well absorbed $(\geq 63.9 \%)$ following a single gavage administration of $\left[{ }^{14} \mathrm{C}\right] 2 \mathrm{H} 4 \mathrm{MBP}$ (3.01 to $2,570 \mathrm{mg} / \mathrm{kg}$ ) in male $\mathrm{F} 344 / \mathrm{N}$ rats, with the administered dose excreted primarily via urine $(63.9 \%$ to $72.9 \%)$ and feces $(19.3 \%$ to $41.7 \%$ ) by 72 hours postadministration. The radioactivity remaining in tissues 72 hours after administration was low $(\sim 0.1 \%)$ in all dose groups. ${ }^{14}$ Following dermal application of 51.6, 204, and $800 \mu \mathrm{g}$ $\left[{ }^{14} \mathrm{C}\right] 2 \mathrm{H} 4 \mathrm{MBP}$ (in ethanol) in male rats, the dose was excreted mainly via urine $(32.4 \%, 39.2 \%$, and $13.2 \%)$ and feces $(16.9 \%, 22.2 \%$, and $9.15 \%)$ by 72 hours postapplication. The dose excreted in urine and feces indicated that the applied dose absorbed was $49.3 \%, 61.4 \%$, and $22.4 \%$, respectively, for 51.6, 204, and $800 \mu \mathrm{g}\left[{ }^{14} \mathrm{C}\right] 2 \mathrm{H} 4 \mathrm{MBP}$. When the dose $(50 \mu \mathrm{g})$ was applied in a lotion vehicle, the dose absorbed (51.8\%) was similar to that in ethanol with $33.9 \%$ and $17.9 \%$ of the dose recovered in urine and feces, respectively. ${ }^{14}$

Absorption, distribution, metabolism, and excretion (ADME) were also investigated in male and female Sprague Dawley rats and B6C3F1/N mice following gavage administration or dermal application of $\left[{ }^{14} \mathrm{C}\right] 2 \mathrm{H} 4 \mathrm{MBP} .{ }^{15}$ Following a single gavage administration $(10,100$, or $500 \mathrm{mg} / \mathrm{kg}$ $\left.\left[{ }^{14} \mathrm{C}\right] 2 \mathrm{H} 4 \mathrm{MBP}\right)$ in rats, most of the administered dose was excreted in urine $(53 \%$ to $58 \%)$ and feces $(38 \%$ to $42 \%)$ by 72 hours postadministration with no observable sex difference in excretion. The radioactivity in urine indicated that $\geq 53 \%$ of the administered dose was absorbed. Following a single $100 \mathrm{mg} / \mathrm{kg}$ gavage dose in male mice, urinary $(\geq 34 \%)$ and fecal $(\geq 24 \%)$ excretion was similar to that of rats. However, mice (5\% to $15 \%)$ excreted a higher percentage of administered dose as exhaled $\mathrm{CO}_{2}$ compared to rats $(\sim 1 \%)$. The retention of dose in tissues was low at 72 hours $(<1 \%)$ in all gavage groups.

ADME of $2 \mathrm{H} 4 \mathrm{MBP}$ was investigated in rats and mice at 72 hours following dermal application of 0.1 or $10 \mathrm{mg} / \mathrm{kg}\left[{ }^{14} \mathrm{C}\right] 2 \mathrm{H} 4 \mathrm{MBP}$ formulated in several vehicles. In male rats, the highest absorption was observed following application in light paraffin oil (80\%). Absorption following application in ethanol, ethanol:coconut oil (1:1), or coconut oil was comparable to paraffin oil (64\% to $73 \%$ ). In contrast, the absorption of $2 \mathrm{H} 4 \mathrm{MBP}$ from the lotion vehicle (olive oil:emulsifying wax:water [15:15:70 v:v:v]) in male $(10 \mathrm{mg} / \mathrm{kg}, 46 \%)$ and female $(15 \mathrm{mg} / \mathrm{kg}$, $29 \%$ ) rats was lower relative to other vehicles. Both male and female mice absorbed approximately $60-69 \%$ of $10 \mathrm{mg} / \mathrm{kg}$ dose in ethanol or acetone and $37-46 \%$ of $10 \mathrm{mg} / \mathrm{kg}$ dose when formulated in the lotion vehicle. There was no dose-related effect in absorption ( 0.1 versus $10 \mathrm{mg} / \mathrm{kg}$ ) in either male rats or mice. ${ }^{15}$ 
Kinetics of disposition of 2H4MBP has been investigated in rats in limited studies. Following a single gavage dose of $100 \mathrm{mg} / \mathrm{kg} 2 \mathrm{H} 4 \mathrm{MBP}$ in male Sprague Dawley rats, the time ( $\left.\mathrm{T}_{\max }\right)$ to reach the maximum concentration, $\mathrm{C}_{\max }(21.21 \mu \mathrm{g} / \mathrm{mL})$, was 3 hours; the elimination of $2 \mathrm{H} 4 \mathrm{MBP}$ in plasma was biphasic with alpha and beta half-lives of 0.88 and 15.9 hours, respectively. Of the tissues examined, the liver had the highest concentration of 2H4MBP and conjugated 2H4MBP at 6 hours. ${ }^{16}$ In another study, following a $100 \mathrm{mg} / \mathrm{kg}$ gavage dose in male Sprague Dawley rats, similar $\mathrm{T}_{\max }(2.72$ hours $)$ and $\mathrm{C}_{\max }(21.21 \mu \mathrm{g} / \mathrm{mL})$ were observed, with a plasma elimination halflife of 4.58 hours. ${ }^{17}$ Following a single gavage dose of $10 \mathrm{mg} / \mathrm{kg}$ in male and female Harlan Sprague Dawley rats, $\mathrm{T}_{\max }$ and $\mathrm{C}_{\max }$ were 6.0 hours and $8.5 \mathrm{ng} / \mathrm{mL}$, respectively, for males and 2.3 hours and $2.9 \mathrm{ng} / \mathrm{mL}$ for females. The plasma elimination half-life for males was 6.4 hours and for females was 18.5 hours. The bioavailability of $2 \mathrm{H} 4 \mathrm{MBP}$ in male and female rats was $<1 \%$, demonstrating extensive first-pass metabolism of $2 \mathrm{H} 4 \mathrm{MBP}$ following gavage administration. ${ }^{15}$

2H4MBP was metabolized via numerous pathways in rodents, including demethylation, oxidation, glucuronidation, and sulfation. Products identified in bile and/or urine of rodents following administration of 2H4MBP were 2H4MBP, 2,4-dihydroxybenzophenone (DHB), 2,3,4-trihydroxybenzophenone (THB), 2,5-dihydroxy-4-methoxybenzophenone (D2H4MBP), and their corresponding glucuronide and sulfate conjugates (Figure 2). ${ }^{14 ; 16 ; 15 ; 18}$ Similar metabolites were also observed in vitro following incubation of $2 \mathrm{H} 4 \mathrm{MBP}$ with microsomes. ${ }^{19 ; 20}$ 2H4MBP and DHB have been quantified in serum from pregnant rats. ${ }^{21}$ In a recent National Toxicology Program (NTP) study, rats were exposed in utero and postnatally to $0,3,000,10,000$, and 30,000 parts per million (ppm) $2 \mathrm{H} 4 \mathrm{MBP}$ in the diet, and plasma concentrations of free (unconjugated analytes) and/or total (free and all conjugated forms) 2H4MBP, DHB, THB, and D2H4MBP were quantified (Figure 2). ${ }^{22}$ Free D2H4MBP and THB were not detected in plasma. Mean plasma concentrations of total $2 \mathrm{H} 4 \mathrm{MBP}$ and DHB were higher ( 100- to 300-fold) than the free $2 \mathrm{H} 4 \mathrm{MBP}$ and DHB concentrations demonstrating extensive conjugation of $2 \mathrm{H} 4 \mathrm{MBP}$ and its metabolites. The rank order of the total concentrations were $2 \mathrm{H} 4 \mathrm{MBP} \approx \mathrm{DHB}>$ D2H4MBP >> THB. Free and total analyte plasma concentrations were not sex-dependent in either PND 28 or PND 56 pup plasma. 


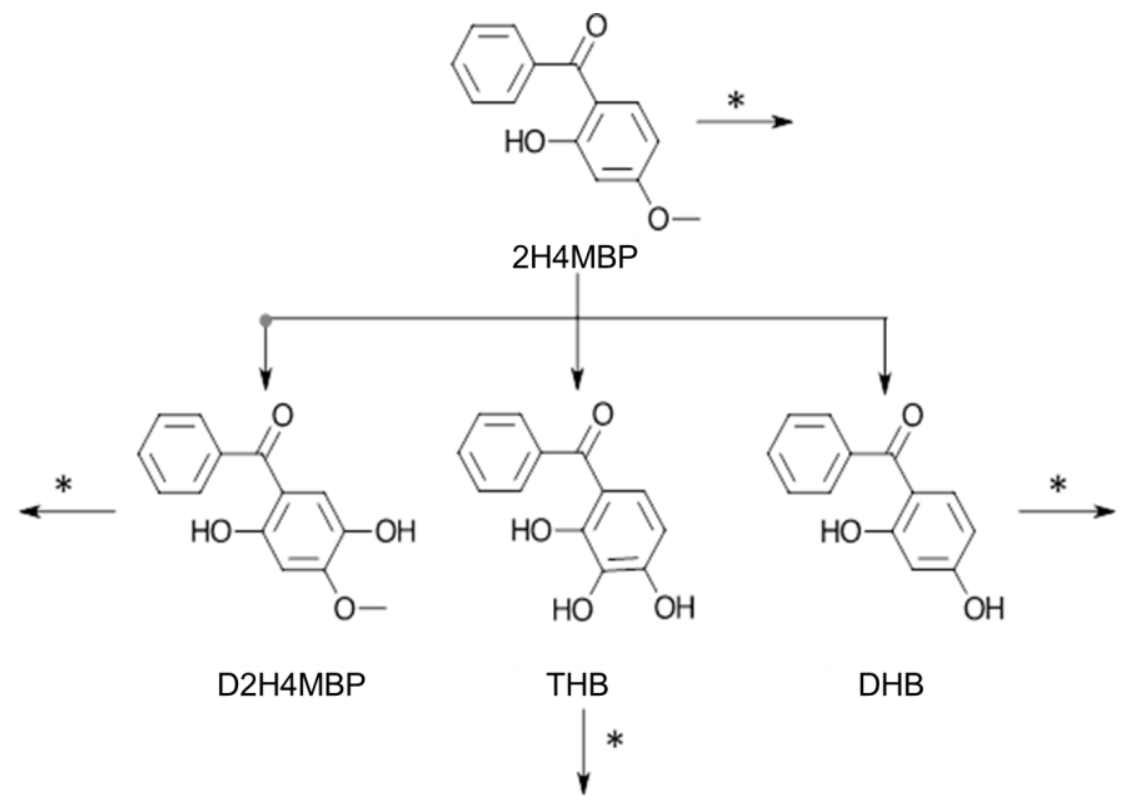

Figure 2. Metabolism of 2-Hydroxy-4-methoxybenzophenone in Rodents

2H4MBP = 2,4-dihydroxy-4-methoxybenzophenone; D2H4MBP = 2,5-dihydroxy-4-methoxybenzophenone; $\mathrm{THB}=$ trihydroxybenzophenone; $\mathrm{DHB}=$ dihydroxybenzophenone.

*Indicates glucuronide and sulfate conjugates.

\section{Humans}

ADME data on 2H4MBP in humans are limited. Human studies with sunscreens have demonstrated that $2 \mathrm{H} 4 \mathrm{MBP}$ is readily absorbed from the skin. ${ }^{23}$ A study that used excised human epidermis in Franz diffusion cells showed that approximately $10 \%$ of the dermally applied dose of $2 \mathrm{H} 4 \mathrm{MBP}$ is absorbed. ${ }^{24}$ When applied dermally, $2 \mathrm{H} 4 \mathrm{MBP}$ and the metabolites DHB and 2,2'-dihydroxy-4-methoxybenzophenone can be detected in serum and are excreted in urine. ${ }^{25 ; 26}$ A study examining the absorption of $2 \mathrm{H} 4 \mathrm{MBP}$, and subsequent irradiation with UV $\mathrm{A}$ and $\mathrm{B}$ rays, demonstrated that participants excreted $1.2-8.7 \%$ (mean $3.7 \%$ ) of the total applied dose in the urine. $2 \mathrm{H} 4 \mathrm{MBP}$ could be detected in the urine 3-5 days after application. UV irradiation did not affect the amount of $2 \mathrm{H} 4 \mathrm{MBP}$ excreted ${ }^{27}$ Frequency of sunscreen use is also related to urinary $2 \mathrm{H} 4 \mathrm{MBP}$ concentrations with frequent users having much higher urinary concentrations. ${ }^{28} 2 \mathrm{H} 4 \mathrm{MBP}$ has been detected in maternal urine and breast milk. ${ }^{29 ; 30}$

\section{Toxicity}

\section{Experimental Animals}

The acute rat dermal $\mathrm{LD}_{50}$ has been reported to be greater than $16 \mathrm{~g} / \mathrm{kg}$ body weight.

Concomitant local skin reactions consisting of mild to moderate erythema were observed in the absence of significant pathologic findings. ${ }^{6}$ The rat oral $\mathrm{LD}_{50}$ for $2 \mathrm{H} 4 \mathrm{MBP}$ has been reported to be greater than $12.8 \mathrm{~g} / \mathrm{kg} .{ }^{31}$ These authors also reported that administration of $0.5 \%$ or $1 \%$ $2 \mathrm{H} 4 \mathrm{MBP}$ in rat diet for 12 weeks was associated with growth depression. Upon examination at week 6 , female rats exposed to $0.5 \%$ or $1 \%$ displayed a leukocytosis with an increase in the lymphocyte count and a decrease in the neutrophil count, as well as a decrease in hemoglobin concentration. At week 12, rats exposed to either concentration displayed anemia and 
lymphocytosis with a reduction in granulocytes. The weights relative to brain of the pituitary gland, thymus, heart, adrenal gland, lung, and spleen were also reduced in both sexes. The $0.5 \%$ females showed an increase in the relative weight to brain of the thyroid gland and first stages of kidney degeneration. Degenerative nephrosis was diagnosed both macro- and microscopically in the kidneys of both sexes at $1 \%$.

NTP has reported the findings of studies conducted in F344 rats and B6C3F1 mice exposed to: (1) $0,3,125,6,250,12,500,25,000$, or 50,000 ppm 2H4MBP in feed for 2 or 13 weeks; (2) 0 , $1.25,2.5,5,10$, or $20 \mathrm{mg} / \mathrm{kg}$ body weight for 2 weeks dermally in acetone or lotion; and (3) 12.5, $25,50,100$, or $200 \mathrm{mg} / \mathrm{kg}$ body weight in acetone or lotion for 13 weeks duration. ${ }^{32}$ In rats and mice, dietary administration of $6,250 \mathrm{ppm}$ and higher concentrations of $2 \mathrm{H} 4 \mathrm{MBP}$ for 2 weeks were associated with increases in liver weights and with marked hepatocyte cytoplasmic vacuolization.

In the 13 -week rat dietary study, 50,000 ppm of 2H4MBP was associated with lower male and female body weight gains. Liver weights were increased at 3,125 ppm and higher, whereas kidney weights were increased at the $6,250 \mathrm{ppm}$ and higher dietary exposure concentrations. Males and females in the 50,000 ppm exposure groups also displayed lower weights of the heart, lungs, and thymus, and males in the 50,000 ppm exposure group displayed lower weights of the brain and testis. ${ }^{33}$ Histopathologic kidney findings primarily occurred in high-exposure rats, and included dilated tubules, tubular epithelial cell regeneration, papillary degeneration or necrosis, and inflammation. Although cytoplasmic vacuolization was not observed in the liver, liver enzymes remained elevated at 13 weeks.

In the 13-week mouse dietary study, there was an exposure-related decrease in body weight gains, mild increases in liver weights in both sexes, and variable increases in kidney weight in females. Histopathological findings were limited to kidneys of mice receiving 25,000 and $50,000 \mathrm{ppm}$ and included eosinophilic protein casts in dilated renal tubules, and mild inflammation. In the 2-week rat and mouse dermal studies, small and variable increases in liver and kidney weights were observed primarily in the higher dose groups. In the 13-week dermal studies, kidney weights were increased in dosed groups of female rats and variably increased in dosed male mice. These weight changes were not associated with any histopathological changes. ${ }^{33}$ A 4 -week dermal study in rats using $100 \mathrm{mg} / \mathrm{kg}$ of $2 \mathrm{H} 4 \mathrm{MBP}$ in petroleum jelly twice a day did not affect body weight; liver, kidney, or testes weight; or histopathology. ${ }^{34} 2 \mathrm{H} 4 \mathrm{MBP}$ exposure lowered rat blood glutathione- $S$-transferase levels.

\section{Humans}

Other than the human findings summarized in the Immunotoxicity section of this report, no other significant toxicity studies in humans were identified in the public domain.

\section{Reproductive and Developmental Toxicity}

\section{Models of Endocrine Activity}

2H4MBP has been reported to bind to and activate estrogen receptor alpha (ER $\alpha)$ with an IC50 ranging from 3 to $20 \times 10^{-6} \mathrm{M} .^{35-38} 2 \mathrm{H} 4 \mathrm{MBP}$ can also activate estrogen receptor beta (ER $\left.\beta\right),{ }^{39 ; 37}$ and reports indicate that $2 \mathrm{H} 4 \mathrm{MBP}$ can act as $\mathrm{ER} \alpha, \mathrm{ER} \beta$, and progesterone receptor antagonists. ${ }^{35}$; 39; 37 In NTP-sponsored ER binding and activation studies conducted under OPPTS 890.1250 and 
OPPTS $^{\text {a }} 890.1300$, maximal mean specific binding was $>75 \%$ (more than $75 \%$ of the radiolabeled estradiol remained bound), which categorizes $2 \mathrm{H} 4 \mathrm{MBP}$ as "non-interacting"; however, 2H4MBP was able to induce a luciferase response, albeit weak (>10\%, log EC $50 \mathrm{~s}-3.2$ and $-4.0 \mathrm{M}$ ) (Appendix F). ${ }^{40 ; 41} 2 \mathrm{H} 4 \mathrm{MBP}$ acts as an estrogen in stimulating MCF7 cell proliferation ( $\mathrm{IC}_{50} 3.4 \times 10^{-6}$ ). $2 \mathrm{H} 4 \mathrm{MBP}$ has been shown to induce a uterotrophic response (ED50: 1,000 to $1,500 \mathrm{mg} / \mathrm{kg}$ per day) in immature rats. ${ }^{42}$ However, $2 \mathrm{H} 4 \mathrm{MBP}$ did not cause a uterotrophic response in ovariectomized rats when tested up to $1 \mathrm{~g} / \mathrm{kg}$ in an NTP study (Appendix F). 2H4MBP was evaluated in quantitative (dose-response) high throughput screening assays by NTP in the Toxicology in the 21st Century (Tox21) program, and significant activity was observed in assays measuring stimulation of ER, progesterone receptor, constitutive androstane receptor, pregnane $\mathrm{X}$ receptor, retinoic acid receptor, and estrogen-related receptor signaling pathways. In addition, $2 \mathrm{H} 4 \mathrm{MBP}$ was shown to inhibit androgen receptor signaling (https://pubchem.ncbi.nlm.nih.gov/compound/4632\#section=BioAssayResults\&fullscreen=true).

2H4MBP exposure in male rainbow trout and Japanese medaka has been shown to induce vitellogenin production, an estrogenic response, and change the number of eggs produced and egg viability/hatching. ${ }^{43}$ 2H4MBP has also been shown to increase plasma concentrations of testosterone in male adult Japanese medaka and to decrease the estradiol to testosterone ratio in both male and female fish with concomitant downregulation of gonadal steroidogenic genes (star, Cypl 1a, Cyp17, Hsd3b, Hsd17b3, and Cyp19a). ${ }^{44}$

\section{Experimental Animals}

The potential for $2 \mathrm{H} 4 \mathrm{MBP}$ exposure to affect sperm density and vaginal cytology has been reported..$^{32}$ Rats and mice received $0,3,125,12,500$, or $50,000 \mathrm{ppm}$ in the diet for 90 days. Male rats exposed to $50,000 \mathrm{ppm}$ weighed $30 \%$ less than control animals and displayed lower epididymis (17\%) and caudal epididymis (22\%) weights and sperm density (27\%). Female rats displayed an increase in estrous cycle length in the 12,500 and 50,000 ppm groups (>1 day).

High-exposure male mice displayed a $27 \%$ decrease in sperm density and weighed $16 \%$ less than control mice. High-exposure female mice displayed a slight increase in estrous cycle length relative to control mice ( $>0.5$ day). NTP conducted a Reproductive Assessment by Continuous Breeding (RACB) study in mice at exposure concentrations of 12,500, 25,000, and 50,000 ppm in the diet. ${ }^{45}$ $2 \mathrm{H} 4 \mathrm{MBP}$ had no effect on $\mathrm{F}_{0}$ fertility, but the number of live pups per litter was significantly reduced in the 25,000 and 50,000 ppm groups, which was associated with lower parental body weights. There were no changes in sperm density or estrous cyclicity; however, the cumulative days to litter were increased in the 50,000 ppm group. 2H4MBP had minimal effects on fertility in the $F_{1}$ generation, but pup weights were significantly reduced. Collectively, it was concluded that $2 \mathrm{H} 4 \mathrm{MBP}$ caused systemic toxicity but had minimal effects on fertility and reproduction at the exposure concentrations studied. Another study examined the effects of 0,10 , 20,100 , or $400 \mathrm{mg} / \mathrm{kg}$ body weight of $2 \mathrm{H} 4 \mathrm{MBP}$ dermally applied to mice for 13 weeks. No

"Guidelines issued before April 22, 2010, refer to "OPPTS" because the office name changed from "Office of Prevention, Pesticides and Toxic Substances" to "Office of Chemical Safety and Pollution Prevention," or "OCSPP." 
effects on body weight, organ weights, sperm density, or testicular histopathology were attributed to $2 \mathrm{H} 4 \mathrm{MBP}$ exposure. ${ }^{46}$

The potential effects of maternal and lactational exposure to $2 \mathrm{H} 4 \mathrm{MBP}$ on $\mathrm{F}_{1}$ development and reproductive organs have been assessed. ${ }^{21}$ Sprague Dawley rats received 0, 1,000, 3,000, 10,000, 25,000 , or 50,000 ppm 2H4MBP in the diet from gestation day (GD) 6 until weaning on postnatal day (PND) 23. Exposure to $2 \mathrm{H} 4 \mathrm{MBP}$ was associated with increased liver and kidney weights in dams. Clinical pathology findings in the dams during GDs 10, 15, and 20 were elevation of glucose, alanine aminotransferase, alkaline phosphatase, cholesterol, total bile acids, and depression of aspartate aminotransferase, blood urea nitrogen, and creatinine. These findings occurred primarily in the higher dose groups and often at all time points. Alanine aminotransferase and cholesterol were elevated in the male and female offspring at the higher two exposure concentrations. No significant differences were observed in littering parameters. Male and female pups in the two highest dose groups displayed lower body weights. Male anogenital distance adjusted for body weight at PND 23 was decreased in the highest dose group. At necropsy on PND 23, female liver weights relative to body weight were higher at exposure concentrations $\geq 10,000 \mathrm{ppm}$. In the highest dose group, spermatocyte development was impaired and ovarian follicular development was delayed.

\section{Humans}

Maternal 2H4MBP exposure, determined primarily via third trimester urinary concentrations, was associated with lower birth weight of girls and the opposite in boys. ${ }^{47}$ In another study, maternal gestational urinary $2 \mathrm{H} 4 \mathrm{MBP}$ concentrations were positively associated with body weight and head circumference at birth. ${ }^{48}$ Maternal exposure to $2 \mathrm{H} 4 \mathrm{MBP}$ has been postulated to be involved in the development of Hirschsprung's disease (incidence of 1 in 5,000 newborns). ${ }^{49}$ One hypothesis is that this complex congenital disease is caused by gene-environment interactions that can lead to intestinal obstruction and chronic constipation in the offspring. Pregnant women that have higher $2 \mathrm{H} 4 \mathrm{MBP}$ concentrations in urine exhibit a higher odds ratio (2.4 to 2.6:1) of having a child with Hirschsprung's disease. ${ }^{50}$

In the 293T and SH-SY5Y cell migration model of Hirschsprung's disease, 2H4MBP suppressed migration and altered the levels of key migratory proteins at both the ribonucleic acid (RNA) and transcribed protein levels in the absence of cytotoxicity. ${ }^{51 ; 50}$ A study looking at the potential effect of 2H4MBP dermal application and serum hormone changes in young men and postmenopausal women concluded that the amount of $2 \mathrm{H} 4 \mathrm{MBP}$ absorbed did not alter the endogenous reproductive hormone homeostasis. ${ }^{23}$

\section{Immunotoxicity}

\section{Experimental Animals}

A study conducted per procedures outlined by the Federal Hazardous Substances Labeling Act (FSLA) for acute skin irritation and scored for irritation per the Draize method concluded that an occlusive patch containing $0.5 \mathrm{~mL}$ or $0.5 \mathrm{mg}$ at $2 \mathrm{H} 4 \mathrm{MBP}$ concentrations from $4 \%$ to $100 \%$ was nonirritating to intact and abraded albino rabbit skin. ${ }^{6} 2 \mathrm{H} 4 \mathrm{MBP}$ at $100 \%$ up to $100 \mathrm{mg}$ was found not to be irritating to the rabbit eye using the modified FSLA or Draize methods. A sunscreen containing $6 \% 2 \mathrm{H} 4 \mathrm{MBP}$ was found not to be photosensitizing in albino rabbits and 
was negative for sensitization potential in the Klingman Maximization Procedure ${ }^{6}$ and local lymph node assay. ${ }^{52}$

\section{Humans}

Some reports have indicated that $2 \mathrm{H} 4 \mathrm{MBP}$ might induce allergenic and sensitization responses. ${ }^{6}$ In a sunscreen sensitization study, researchers detected allergy and/or photoallergy to $2 \mathrm{H} 4 \mathrm{MBP}$ in $3.7 \%$ of the human subjects, which was attributed to application of moisturizing creams that contained $2 \mathrm{H} 4 \mathrm{MBP} .{ }^{53}$ A subsequent study sponsored by Schering-Plough HealthCare Products reported the results of the meta-analysis of 64 unpublished studies conducted at 10 independent clinical laboratories representing the results of 19,570 individuals subjected to human repeat insult patch tests and photoallergy studies between 1992 and 2006. ${ }^{54}$ These studies were aggregated and analyzed to evaluate the irritancy and sensitization potential of sunscreen products containing $2 \mathrm{H} 4 \mathrm{MBP}$ concentrations between $1 \%$ and $6 \%$. Forty-eight dermal responses were considered suggestive of sensitization or irritation with a mean rate of response of $0.26 \%$. The authors concluded that sunscreen products formulated with $1 \%$ to $6 \%$ oxybenzone do not possess a significant sensitization or irritation potential for the general public. $2 \mathrm{H} 4 \mathrm{MBP}$ was also negative in an in vitro phototoxicity assay using SkinEthic ${ }^{\mathrm{TM}}$, a human epidermis model. ${ }^{55}$

\section{Carcinogenicity}

No reports of studies that characterize the potential for $2 \mathrm{H} 4 \mathrm{MBP}$ to induce neoplasms were found in the literature.

\section{Genetic Toxicity}

$2 \mathrm{H} 4 \mathrm{MBP}$ was negative in tests screening for mutagenic agents in dental materials ${ }^{56}$ and in sunscreens. ${ }^{57 ; 58}$ However, as reported in NTP Toxicity Report 21, ${ }^{33}$ 2H4MBP showed weak mutagenic activity in Salmonella typimurium strains TA100 and TA97 when tested in the presence of $30 \%$ hamster liver S9 mix; results from a second bacterial mutation test that tested the compound with $10 \%$ hamster liver S9 mix were negative. 2H4MBP was also positive for induction of sister chromatid exchanges and chromosomal aberrations in Chinese hamster ovary cells when testing occurred in the presence of rat liver S9 mix. ${ }^{32}$ The parent structure, benzophenone, also was negative in an NTP bacterial mutagenicity assay in several strains of Salmonella typhimurium, with and without exogenous metabolic activation, ${ }^{59}$ but both 2,2'- dihydroxy-4-methoxybenzophenone and 4,4'-bis(dimethylamino)benzophenone (Michler's ketone) were mutagenic in bacterial assays conducted by NTP. Michler's ketone also was positive in the mouse lymphoma L5178Y cell mutation assay, and in tests for induction of chromosomal aberrations and sister chromatid exchanges in Chinese hamster ovary cells. ${ }^{60-64}$ In vivo assessments of genotoxic potential showed no activity in the Drosophila somatic mutation and recombination test following exposure of larva to feed containing 3,500 ppm 2H4MBP, and no induction of chromosomal aberrations in male Sprague Dawley rats treated with up to $5 \mathrm{~g} / \mathrm{kg}$ $2 \mathrm{H} 4 \mathrm{MBP}$ either as a single gavage treatment or after five once-daily gavage treatments. ${ }^{65}$ 2H4MBP was also negative for induction of micronucleated erythrocytes in male and female mice treated via dosed feed for 90 days. ${ }^{32}$ No activity in any of the Tox 21 deoxyribonucleic acid (DNA) damage assays was observed, consistent with the results in standard in vitro and in vivo assays for genotoxicity. 


\section{Study Rationale}

2H4MBP was nominated to NTP by the National Cancer Institute because of high exposure via use of $2 \mathrm{H} 4 \mathrm{MBP}$-containing sunscreen products and lack of carcinogenicity data. $2 \mathrm{H} 4 \mathrm{MBP}$ was also nominated by a private individual to ascertain genotoxic potential. NTP designed 2-year studies in rats and mice to evaluate the potential carcinogenic activity of $2 \mathrm{H} 4 \mathrm{MBP}$. The initiation of $F_{1}$ generation exposure on GD 6 (after expected implantation) in the 2-year rat study was selected to reflect potential human exposure to $2 \mathrm{H} 4 \mathrm{MBP}$, often present in sunscreens and cosmetics; exposure may occur at any human life stage, including in utero and early life. As the pattern of disposition is similar following oral and dermal exposure, 2H4MBP exposure via the diet was selected, rather than topical application, to sustain internal exposure. It was also recognized that if applied topically, internal dose would be influenced by intra- and inter-animal grooming behavior. 


\section{Materials and Methods}

\section{Procurement and Characterization of 2-Hydroxy-4- methoxybenzophenone}

2-Hydroxy-4-methoxybenzophenone (2H4MBP) was obtained from Ivy Fine Chemicals Corporation (Cherry Hill, NJ) in one lot (20080801) that was used in the perinatal and 2-year studies. Identity and purity analyses were conducted under the analytical chemistry laboratory and study laboratory at Battelle (Columbus, OH) (Appendix B). Reports on analyses performed in support of the 2H4MBP studies are on file at the National Institute of Environmental Health Sciences.

Lot 20080801 of the chemical, a light-yellow powder, was identified as 2H4MBP by infrared (IR) and proton and carbon-13 nuclear magnetic resonance (NMR) spectroscopy and gas chromatography (GC) with mass spectrometry (MS) detection. The IR spectrum was in good agreement with a reference spectrum ${ }^{66}$ and the structure of 2 H4MBP. Proton and carbon-13 NMR spectra were consistent with computer-predicted spectra and the structure of the test article. The mass spectrum of the major peak from the GC/MS analysis matched a reference spectrum ${ }^{67}$ for $2 \mathrm{H} 4 \mathrm{MBP}$.

The purity of lot 20080801 was determined using high-performance liquid chromatography (HPLC) with ultraviolet (UV) detection and using GC with flame ionization detection (FID). Lot 20080801 was screened for common residual volatile solvents using GC with electron capture detection (ECD) and FID. Differential scanning calorimetry (DSC) was used to determine the purity of the test article. In addition, Karl Fisher titration of lot 20080801 was performed by Galbraith Laboratories, Inc. (Knoxville, TN).

Purity assessment by HPLC/UV found no reportable impurities in lot 20080801. GC/FID analysis yielded a purity of $99.8 \%$ and found one impurity with an area of $0.17 \%$ of the total peak area. No significant halogenated or nonhalogenated volatile impurities were found in the bulk chemical. Purity by DSC was $99.2 \%$. Karl Fischer analysis indicated that no quantifiable water was present in the test article. The overall purity of lot 20080801 was determined to be greater than $99 \%$.

To ensure stability, the bulk chemical was stored at room temperature in sealed amber glass containers. Periodic reanalyses of the bulk chemical were performed during the perinatal and 2year studies by the study laboratory using HPLC/UV and no degradation of the bulk chemical was detected.

\section{Preparation and Analysis of Dose Formulations}

The dose formulations were prepared approximately monthly by mixing 2H4MBP with feed (Table B-1). Formulations were stored in sealed amber plastic bags at room temperature for up to 42 to 43 days.

Homogeneity studies of the 1,000 and 10,000 ppm dose formulations in NIH-07 and NTP-2000 feed were performed before the animal studies by the analytical chemistry and study laboratories. Additional homogeneity studies of the 1,000 and 10,000 ppm dose formulations in NTP-2000 
feed were performed during the chronic studies by the study laboratory. Stability studies of the 1,000 ppm dose formulation in NIH-07 and NTP-2000 feed were performed by the analytical chemistry laboratory using the same analytical method. Homogeneity was confirmed, and stability was confirmed for at least 42 days for dose formulations stored in sealed amber plastic bags at room temperature.

Periodic analyses of the dose formulations of $2 \mathrm{H} 4 \mathrm{MBP}$ were conducted by the study laboratory using HPLC/UV (Table B-2; Table B-3). Of the dose formulations analyzed, all were within $10 \%$ of the target concentrations; all animal room samples for rats and mice were within $10 \%$ of the target concentrations.

\section{Animal Source}

Time-mated $\left(\mathrm{F}_{0}\right)$ female Sprague Dawley (Hsd:Sprague Dawley $\left.{ }^{\circledR} \mathrm{SD}^{\circledR}\right)$ rats were obtained from Harlan Laboratories (now Envigo, Indianapolis, IN). Male and female B6C3F1/N mice were obtained from Taconic (Taconic Biosciences, Germantown, NY).

\section{Animal Welfare}

Animal care and use are in accordance with the Public Health Service Policy on Humane Care and Use of Animals. All animal studies were conducted in an animal facility accredited by AAALAC International. Studies were approved by the Battelle Columbus Operations (Columbus, $\mathrm{OH}$ ) Animal Care and Use Committee and conducted in accordance with all relevant National Institutes of Health (NIH) and National Toxicology Program (NTP) animal care and use policies and applicable federal, state, and local regulations and guidelines.

\section{Two-year Studies}

\section{Study Design for Rats}

Exposure concentration selection was based in part on Fischer 344/N rat studies reported in Toxicity Report $21 .{ }^{32}$ Rats were exposed to $0,3,125,6,250,12,500,25,000$, or 50,000 ppm $2 \mathrm{H} 4 \mathrm{MBP}$ in the diet for up to 13 weeks. After 13 weeks of $2 \mathrm{H} 4 \mathrm{MBP}$ exposure, males and females in the 25,000 ppm groups weighed approximately $10 \%$ less than rats in the control groups, whereas males and females exposed to 50,000 ppm weighed $32 \%$ and $14 \%$ less, respectively, than rats in the control groups. Both males and females in the 50,000 ppm groups had increased absolute and relative kidney weights and exhibited renal papillary necrosis and tubule dilatation. Renal tubule dilation was observed in $100 \%$ of the $25,000 \mathrm{ppm}$ male rats and in $30 \%$ of the males in the $12,500 \mathrm{ppm}$ group. Therefore, the $10,000 \mathrm{ppm}$ exposure concentration was selected for both male and female rats, anticipating that the system would be appropriately challenged and recognizing strain differences might exist.

Beginning on GD 6, groups of 42, 35, 35, or 43 Fo time-mated female rats were fed diets containing $0,1,000,3,000$, or $10,000 \mathrm{ppm} 2 \mathrm{H} 4 \mathrm{MBP}$, respectively, throughout gestation and lactation. Groups of $50(1,000$ and 3,000 ppm) or 60 (0 and 10,000 ppm) F1 rats per sex continued on in the study after weaning and were fed diets containing the same respective $2 \mathrm{H} 4 \mathrm{MBP}$ concentration for 105 weeks. An interim evaluation, using $10 \mathrm{~F}_{1}$ rats per sex from the 0 and 10,000 ppm groups, was conducted at 14 weeks. To evaluate transcriptional changes in the liver, liver tissue from five control and five 10,000 ppm $\mathrm{F}_{1}$ male rats from the 14-week interim 
evaluation was collected and processed for microarray analyses at the Battelle Biomedical Research Center (Columbus, OH) (Appendix E).

$\mathrm{F}_{0}$ female rats were 11 to 14 weeks old upon receipt. Evidence of mating is defined as GD 1; $\mathrm{F}_{0}$ females were received on GD 2 and held for 4 days. $F_{0}$ females were randomly assigned to exposure groups on GD 5. Randomization was performed by a body-weight-partitioning algorithm to produce similar group mean weights (PATH/TOX SYSTEM software, Xybion Medical Systems Co., Cedar Knolls, NJ).

$\mathrm{F}_{0}$ females were quarantined for 11 days after receipt. Ten nonmated females received with the time-mated females were designated for disease monitoring 11 days after arrival; samples were collected for serological analyses, and the rats were terminated, necropsied, and examined for the presence of disease or parasites. The health of the $\mathrm{F}_{1}$ rats was monitored during the study according to the protocols of the NTP Sentinel Animal Program (Appendix D). Pinworms (Syphacia spp.) were diagnosed in sentinel animals during routine health monitoring evaluations. Infected animals did not display clinical signs and no pathological lesions were noted in relation to the presence of the pinworms. Following this finding, NTP, in coordination with the testing laboratory, developed and implemented a successful plan of pinworm containment and eradication. NTP requires the testing laboratories to actively monitor animals to ensure the continued exclusion of pinworms from all studies going forward. All other test results were negative.

$\mathrm{F}_{0}$ female rats were housed individually during gestation and with their respective litters during lactation. $F_{0}$ females were weighed on GDs 5, 6, 9, 12, 15, 18, and 21 and on PNDs 1, 4, 7, 14, and 21. The day of parturition was considered to be PND 0. Total litter weight was collected on PND 1. Individual $F_{1}$ pups were weighed on PNDs 4, 7, 14, and 21. On apparent GD 27, all timemated female rats that did not deliver were euthanized and the uteruses were examined and stained for evidence of implantation. On PND 1, the number of live and dead $F_{1}$ pups, sex ratio, whole litter weights, and litter weights/sex were recorded.

$\mathrm{F}_{1}$ litters were standardized on PND 4 to eight pups/litter, with at least two pups of each sex and a preference for four males and four females each. Litters that did not meet the minimum of eight pups (or if they had fewer than two pups of either sex) were removed from the study. For continuation of exposure after weaning, two males and two females per litter from 30 litters in the 0 and 10,000 ppm groups and from 25 litters in the 1,000 and 3,000 ppm groups were randomly selected. During gestation and lactation, feed consumption was measured continuously by cage. On the day the last litter reached PND 18, litters were randomly selected and $\mathrm{F}_{1}$ pups from these litters were randomly selected for the 2-year study. On the day the last litter reached PND 21, the pups were weaned and the dams necropsied, and gross lesions collected. Weaning marked the beginning of the 2-year chronic phase of the study.

$\mathrm{F}_{1}$ pups were housed two (males) or four (females) per cage. Feed and water were available ad libitum. In the 2-year chronic phase of the rat study, feed consumption in $\mathrm{F}_{1}$ rats was measured initially, weekly for 13 weeks, then for one 7-day period every 4 weeks, and at the end of the study. Cages were changed weekly through PND 4, then changed every 2 weeks. Racks were changed and rotated every 2 weeks. Further details of animal maintenance are given in Table 1 . Information on feed composition and contaminants is provided in Appendix C. 


\section{Study Design for Mice}

Dose selection was based primarily on the 13-week B6C3F1/N mouse data presented in Toxicity Report $21 .^{32}$ Mice were exposed to $0,3,125,6,250,12,500,25,000$, or 50,000 ppm 2H4MBP in the diet. After 13 weeks of exposure, male and female mice in the 25,000 ppm groups displayed $14 \%$ and $8 \%$ lower body weights, respectively, relative to animals in the control groups. Absolute liver weights were higher in both the males and females exposed to $\geq 6,250 \mathrm{ppm}$, which was associated with cytoplasmic vacuolization of the hepatocytes. Therefore, $10,000 \mathrm{ppm}$ was selected as the high-exposure concentration for male and female mice.

Groups of 50 mice per sex were fed diets containing 0, 1,000, 3,000, or 10,000 ppm 2H4MBP for 104 (females) or 105 (males) weeks. Mice were quarantined for 14 days prior to study start. Mice were approximately 4 to 5 weeks old upon receipt and were randomly assigned to exposure groups using the same body-weight partitioning algorithm as was used for $\mathrm{F}_{0}$ female rats to produce similar group mean weights (PATH/TOX SYSTEM software).

Five male and five female mice were randomly selected for parasite evaluation and gross observation of disease. Mice were 6 to 7 weeks old on the first day of the study. The health of the mice was monitored during the study according to the protocol of the NTP Sentinel Animal Program (Appendix D). All test results were negative.

Mice were housed individually (males) or five (females) per cage. Feed and water were available ad libitum. Feed consumption was measured weekly for 13 weeks, then for one 7-day period every 4 weeks, and at the end of the study. Cages were changed once weekly (males) or twice weekly (females) and rotated every 2 weeks. Racks were changed and rotated every 2 weeks.

Further details of animal maintenance are given in Table 1. Information on feed composition and contaminants is given in Appendix C.

\section{Clinical Examinations and Pathology}

For the 2-year studies in rats and mice, animals were observed twice daily for morbidity and moribundity and were weighed initially, weekly for the first 13 weeks, then at 4-week intervals, and at study termination. Clinical findings were recorded every 4 weeks and at the end of the studies.

Complete necropsies and microscopic examinations were performed on $\mathrm{F}_{1}$ rats and mice. At the 14-week $F_{1}$ rat interim evaluation (control and 10,000 ppm, $n=10 /$ sex/group), the weights of the heart, right kidney, liver, lung, right testis, and thymus were collected. At necropsy, all organs and tissues were examined for grossly visible lesions and all major tissues were fixed and preserved in $10 \%$ neutral buffered formalin except for eyes, testes, vaginal tunics, and epididymides, which were first fixed in Davidson's solution or modified Davidson's solution. Spinal cord was only collected from animals that had clinical neurological signs. Tissues were processed and trimmed, embedded in paraffin, sectioned to a thickness of 4 to $6 \mu \mathrm{m}$, and stained with hematoxylin and eosin (H\&E) for microscopic examination. For all paired organs (e.g., adrenal gland, kidney, ovary), samples from each organ were examined. In the original evaluation of the uterus, a transverse section through each uterine horn, approximately $0.5 \mathrm{~cm}$ cranial to cervix, was collected for histopathology evaluation. During the pathology review process, a residual tissue evaluation of the uterus of rats was performed in which all remaining 
uterine tissue, including the cervix, and vaginal tissue was sectioned longitudinally, processed, and examined histologically. Results from the residual uterine evaluation were combined with those from the original, transverse sections of uterus. Tissues examined microscopically are listed in Table 1.

Microscopic evaluations were completed by the study laboratory pathologist, and the pathology data were entered into the Toxicology Data Management System. The report, slides, paraffin blocks, residual wet tissues, and pathology data were sent to the NTP Archives for inventory, slide/block match, wet tissue audit, and storage. The slides, individual animal data records, and pathology tables were evaluated by an independent quality assessment (QA) laboratory. The individual animal records and tables were compared for accuracy, the slide and tissue counts were verified, and the histotechnique was evaluated. For the 2-year studies, a QA pathologist evaluated slides from all neoplasms and all potential target organs, which included the kidney of rats and mice; the liver of male rats and male and female mice; the adrenal cortex and thyroid gland of rats; the epididymis, heart, pancreas, and testis of male rats; the uterus of female rats (including all the sections made from residual tissue); and the ovary of female mice.

The QA report and the reviewed slides were submitted to the NTP pathologist, who reviewed and addressed any inconsistencies in the diagnoses made by the laboratory and QA pathologist. The QA pathologist, who served as the coordinator of the Pathology Working Group (PWG), presented representative histopathology slides containing examples of lesions related to test agent administration, examples of disagreements in diagnoses between the laboratory and QA pathologist, or lesions of general interest to the PWG for review. The PWG consisted of the NTP pathologist and other pathologists experienced in rodent toxicologic pathology. When the PWG consensus differed from the opinion of the laboratory pathologist, the diagnosis was changed. Final diagnoses for reviewed lesions represent a consensus between the laboratory pathologist, QA pathologist, and the PWG. Details of these review procedures have been described, in part, by Maronpot and Boorman ${ }^{68}$ and Boorman et al. ${ }^{69}$ For subsequent analyses of the pathology data, the decision of whether to evaluate the diagnosed lesions for each tissue type separately or combined was generally based on the guidelines of Brix et al. ${ }^{70}$

An additional examination to confirm lesions recorded during the QA process in the longitudinal sections of uterus, cervix, and vagina was undertaken by a pathologist that had not previously examined the tissues.

A special pathology peer review panel was convened to examine all the diagnoses of malignant meningiomas, both in the brain and spinal cord. The consensus on the tumors (both brain and spinal cord) was that they were all malignant meningiomas, confirming the diagnoses made by the study pathologist and confirmed by the QA pathologist. In addition, digital scans of the spinal cord neoplasm were also sent, without knowledge of the chemical or dose group, to eight pathologists, including two neuropathologists. The general consensus on the spinal cord lesion, which included detailed input from the neuropathologists, was that it was a malignant meningioma. 
Table 1. Experimental Design and Materials and Methods in the Perinatal and Two-year Feed Studies of 2-Hydroxy-4-methoxybenzophenone

\begin{tabular}{|c|c|}
\hline Rats & Mice \\
\hline \multicolumn{2}{|l|}{ Study Laboratory } \\
\hline Battelle (Columbus, $\mathrm{OH}$ ) & Same as in rats \\
\hline \multicolumn{2}{|l|}{ Strain and Species } \\
\hline Sprague Dawley (Hsd:Sprague Dawley ${ }^{\circledR} \mathrm{SD}^{\circledR}$ ) & $\mathrm{B} 6 \mathrm{C} 3 \mathrm{~F} 1 / \mathrm{N}$ \\
\hline \multicolumn{2}{|l|}{ Animal Source } \\
\hline Harlan Laboratories (Indianapolis, IN), now Envigo & Taconic Farms (Germantown, NY) \\
\hline \multicolumn{2}{|l|}{ Time Held before Studies } \\
\hline \multirow[t]{2}{*}{ Fo females: 4 days } & Males: 16 days \\
\hline & Females: 15 days \\
\hline \multicolumn{2}{|l|}{ Average Age When Studies Began } \\
\hline$F_{0}$ females: 11 to 14 weeks & 6 to 7 weeks \\
\hline \multicolumn{2}{|l|}{ Date of First Exposure } \\
\hline $\mathrm{F}_{0}$ females: October 1, 2010 & Males: July 16, 2010 \\
\hline$F_{1}$ : November 8 (males) or 9 (females), 2010 & Females: July 15, 2010 \\
\hline \multicolumn{2}{|l|}{ Duration of Exposure } \\
\hline $\begin{array}{l}\text { Fo females: GD } 6 \text { to PND } 21 \\
\text { F1 (interim evaluation): } 14 \text { weeks }\end{array}$ & Males: 105 weeks \\
\hline $\mathrm{F}_{1}$ (2-year study): 105 weeks & Females: 104 weeks \\
\hline \multicolumn{2}{|l|}{ Date of Last Exposure } \\
\hline$F_{0}$ females: November 8, 2010 & Males: July 13, 2012 \\
\hline $\begin{array}{l}F_{1} \text { (14-week interim evaluation): February } 8 \text { (males) or } 9 \\
\text { (females), } 2011\end{array}$ & Females: July 11, 2012 \\
\hline \multicolumn{2}{|l|}{$\begin{array}{l}F_{1} \text { (2-year study): November } 5 \text { to } 7 \text { (males) or } 7 \text { to } 9 \\
\text { (females), } 2012\end{array}$} \\
\hline \multicolumn{2}{|l|}{ Necropsy Dates } \\
\hline \multirow{2}{*}{$\begin{array}{l}F_{1} \text { (2-year study): November } 5 \text { to } 7 \text { (males) or } 7 \text { to } 9 \\
\text { (females), } 2012\end{array}$} & Males: July 11-13, 2012 \\
\hline & Females: July 9-11, 2012 \\
\hline \multicolumn{2}{|l|}{ Size of Study Groups } \\
\hline $\begin{array}{l}\text { Fo females: } 42(0 \mathrm{ppm}), 35(1,000 \text { and } 3,000 \mathrm{ppm}) \text {, or } \\
43(10,000 \mathrm{ppm})\end{array}$ & $50 / \operatorname{sex}$ \\
\hline \multicolumn{2}{|l|}{$\begin{array}{l}\mathrm{F}_{1}: 60 / \mathrm{sex}(0 \text { and } 10,000 \mathrm{ppm}) \text { or } 50 / \mathrm{sex}(1,000 \text { and } \\
3,000 \mathrm{ppm})\end{array}$} \\
\hline \multicolumn{2}{|l|}{ Method of Distribution } \\
\hline $\begin{array}{l}\text { Animals were distributed randomly into groups of } \\
\text { approximately equal initial mean body weights }\end{array}$ & Same as in rats \\
\hline
\end{tabular}




\begin{tabular}{ll}
\hline Rats & Mice \\
\hline
\end{tabular}

\section{Animals per Cage}

Fo females: 1 (with litter)

$\mathrm{F}_{1}: 2$ (males) or 4 (females)
Males: 1

Females: 5

\section{Method of Animal Identification}

$\mathrm{F}_{0}$ females: Cage card and tail marking with permanent pen Tail tattoo

$\mathrm{F}_{1}$ : Cage card and tail tattoo

\section{Diet}

Irradiated NIH-07 meal feed (perinatal phase) or irradiated NTP-2000 meal feed (2-year study) (Zeigler Brothers, Inc., Gardners, PA), available ad libitum, changed twice weekly

Irradiated NTP-2000 meal feed (Zeigler Brothers, Inc., Gardners, PA), available ad libitum, changed once (males) or twice (females) weekly

\section{Water}

Tap water (Columbus municipal supply) via automatic watering system (Edstrom Industries, Inc., Waterford, WI), available ad libitum

\section{Cages}

Solid polycarbonate (Lab Products, Inc., Seaford, DE), Solid polycarbonate (Lab Products, Inc., Seaford, changed weekly through PND 4, then twice weekly, rotated every 2 weeks

Same as in rats

\section{Bedding}

Irradiated Sani-Chips ${ }^{\circledR}$ (P.J. Murphy Forest Products

Corporation, Montville, NJ) changed with cage changes

\section{Rack Filters}

Spun-bonded polyester (Snow Filtration Co., Cincinnati, $\mathrm{OH}$; National Filter Media, Olive Branch, MS), changed every 2 weeks

\section{Racks}

Stainless steel (Lab Products, Inc., Seaford, DE), changed and rotated every 2 weeks

\section{Animal Room Environment}

Temperature: $72^{\circ} \mathrm{F} \pm 3^{\circ} \mathrm{F}$

Relative humidity: $50 \% \pm 15 \%$

Room fluorescent light: 12 hours/day Room air changes: at least 10/hour

\section{Exposure Concentrations}

$0,1,000,3,000$, or $10,000 \mathrm{ppm}$ in feed

Same as in rats

Spun-bonded polyester (Snow Filtration Co., Cincinnati, $\mathrm{OH}$ ), changed every 2 weeks

Same as in rats

Same as in rats (females), rotated every 2 weeks

Same as in rats 


\section{Type and Frequency of Observation}

$\mathrm{F}_{0}$ females: Observed twice daily. Weighed on GDs 5, 6, 9, $12,15,18$, and 21 and on PNDs 1, 4, 7, 14, and 21. Feed consumption was measured continuously from GD 6 to PND 21.

$F_{1}$ rats: Observed twice daily. Litter data (litter count by sex, litter weights by sex, and litter observations) were recorded on PND 1. Pups per litter were recorded on PNDs 2 and 3. Pups were weighed on PNDs 4, 7, 14, and 21, weekly for 13 weeks, then every 4 weeks, and at the end of the study. Clinical findings were recorded every 4 weeks beginning at week 6 and at the end of the study. Feed consumption was recorded initially, continuously for 13 weeks, then for one 7-day period every 4 weeks.

\section{Method of Euthanasia}

Euthanasia solution and decapitation ( $\leq$ PND 10 pups and fetuses); exsanguination (interim rats); carbon dioxide ( $\geq$ PND 10 pups, $F_{0}$ females, and adult $F_{1}$ rats)

\section{Necropsy}

Necropsies were performed on all animals. Organs weighed Necropsies were performed on all animals. at the 14-week interim evaluation were heart, right kidney, liver, lung, right testis, and thymus.

\section{Microarray Analyses}

Liver tissue of five control and five $10,000 \mathrm{ppm} \mathrm{F}_{1}$ male rats was collected and processed to evaluate transcriptional changes in the liver at 14 weeks (Appendix E).

\section{Histopathology}

Complete histopathology was performed on all $\mathrm{F}_{1}$ rats. In addition to gross lesions and tissue masses, the following tissues were examined: adrenal gland, bone with marrow, brain, clitoral gland, esophagus, eyes, Harderian gland, heart, large intestine (cecum, colon, rectum), small intestine (duodenum, jejunum, ileum), kidney, liver, lung, lymph nodes (mandibular and mesenteric), mammary gland, nose, ovary, pancreas, parathyroid gland, pituitary gland, preputial gland, prostate gland, salivary gland, seminal vesicle, skin, spleen, stomach (forestomach and glandular), testis with epididymis, thymus, thyroid gland, trachea, urinary bladder, and uterus. An additional extended evaluation of the uterus was performed that included all remaining cervical, vaginal, and uterine tissue remnants.

\section{Carbon dioxide}

Observed twice daily. Weighed initially, weekly for 13 weeks, then every 4 weeks, and at the end of the studies. Clinical findings were recorded at week 5 then every 4 weeks. Feed consumption was measured initially, continuously for 13 weeks, then every 4 weeks for a 7-day period.
Complete histopathology was performed on all mice. In addition to gross lesions and tissue masses, the following tissues were examined: adrenal gland, bone with marrow, brain, clitoral gland, esophagus, eyes, Harderian gland, gallbladder, heart, large intestine (cecum, colon, rectum), small intestine (duodenum, jejunum, ileum), kidney, liver, lung, lymph nodes (mandibular and mesenteric), mammary gland, nose, ovary, pancreas, parathyroid gland, pituitary gland, preputial gland, prostate gland, salivary gland, seminal vesicle, skin, spleen, stomach (forestomach and glandular), testis with epididymis, thymus, thyroid gland, trachea, urinary bladder, and uterus.

\section{Statistical Methods}

\section{Survival Analyses}

The probability of survival was estimated by the product-limit procedure of Kaplan and Meier ${ }^{71}$ and is presented graphically. Animals surviving to the end of the observation period are treated 
as censored observations, as are animals dying from unnatural causes within the observation period. Animals dying from natural causes are included in analyses and are treated as uncensored observations. For the two-year mouse study, dose-related trends are identified with Tarone's lifetable test, ${ }^{72}$ and pairwise dose-related effects are assessed using Cox's ${ }^{73}$ method. For the rat perinatal study, dose-related trends and pairwise dose-related effects on survival are assessed using a Cox proportional hazards model ${ }^{73}$ with a random litter effect. All reported $\mathrm{p}$ values for the survival analyses are two-sided.

\section{Calculation of Incidence}

The incidence of neoplasms or nonneoplastic lesions (Appendix $\mathrm{H}$ ) is presented as the numbers of animals bearing such lesions at a specific anatomic site. For calculation of incidence rates (Appendix H), the denominator for most neoplasms and all nonneoplastic lesions is the number of animals where the site was examined microscopically. However, when macroscopic examination was required to detect neoplasms in certain tissues (e.g., mesentery, pleura, peripheral nerve, skeletal muscle, tongue, tooth, Zymbal's gland, and spinal cord) before microscopic evaluation, the denominator consists of the number of animals that had a gross abnormality. When neoplasms had multiple potential sites of occurrence (e.g., leukemia or lymphoma), the denominator consists of the number of animals on which a necropsy was performed. Additional study data (Appendix H) also give the survival-adjusted neoplasm rate for each group and each site-specific neoplasm. This survival-adjusted rate (based on the Poly-3 method described below) accounts for differential mortality by assigning a reduced risk of neoplasm, proportional to the third power of the fraction of time on study, only to site-specific, lesion-free animals that do not reach terminal euthanasia.

\section{Analysis of Neoplasm and Nonneoplastic Lesion Incidence}

Statistical analyses of neoplasm and nonneoplastic lesion incidence considered two features of the data. Some animals did not survive the entire 2 years of the study, so survival differences between groups had to be considered. Also, up to two rats per sex were randomly selected from each litter to participate in the study. The statistical analysis of lesion incidence used the Poly-3 test to account for survival differences, with a Rao-Scott adjustment for litter effects, as described below.

The Poly-k test ${ }^{74-76}$ was used to assess neoplasm and nonneoplastic lesion prevalence. This test is a survival-adjusted quantal-response procedure that modifies the Cochran-Armitage linear trend test to account for survival differences. More specifically, this method modifies the denominator in the quantal estimate of lesion incidence to approximate more closely the total number of animal years at risk. For analysis of a given site, each animal is assigned a risk weight. This value is 1 if the animal had a lesion at that site or if it survived until terminal euthanasia; if the animal died prior to terminal euthanasia and did not have a lesion at that site, its risk weight is the fraction of the entire study time that it survived, raised to the kth power.

This method yields a lesion prevalence rate that depends only on the choice of a shape parameter for a Weibull hazard function describing cumulative lesion incidence over time. ${ }^{74}$ Unless otherwise specified, a value of $\mathrm{k}=3$ was used in the analysis of site-specific lesions. This value was recommended by Bailer and Portier ${ }^{74}$ following an evaluation of neoplasm onset time distributions for a variety of site-specific neoplasms in control F344 rats and B6C3F1 mice. ${ }^{77}$ 
Bailer and Portier ${ }^{74}$ showed that the Poly- 3 test gave valid results if the true value of $\mathrm{k}$ was anywhere in the range from 1 to 5. A further advantage of the Poly-3 method is that it does not require lesion lethality assumptions. Variation introduced by the use of risk weights, which reflect differential mortality, was accommodated by adjusting the variance of the Poly-3 statistic as recommended by Bieler and Williams. ${ }^{78}$ Poly-3 tests used the continuity correction described by Nam. ${ }^{79}$

Littermates tend to be more like each other than like fetuses/pups in other litters. Failure to account for correlation within litters leads to underestimates of variance in statistical tests, resulting in higher probabilities of Type I errors ("false positives"). Because up to two pups per sex per litter were present in the core rat study, the Poly-3 test was modified to accommodate litter effects using the Rao-Scott approach. ${ }^{80}$ The Rao-Scott approach accounts for litter effects by estimating the ratio of the variance in the presence of litter effects to the variance in the absence of litter effects. This ratio is then used to adjust the sample size downward to yield the estimated variance in the presence of litter effects. The Rao-Scott approach was implemented in the Poly-3 test as recommended by Fung et al., ${ }^{81}$ formula $\bar{T}_{R S 2}$.

Tests of significance included pairwise comparisons of each dosed group with control groups and a test for an overall dose-related trend. Continuity-corrected Rao-Scott-adjusted Poly-3 tests were used in the analysis of lesion incidence and reported $p$ values are one-sided. The significance of a lower incidence or decreasing trend in lesions is represented as $1-\mathrm{p}$ with the letter $\mathrm{N}$ added (e.g., $\mathrm{p}=0.99$ is presented as $\mathrm{p}=0.01 \mathrm{~N}$ ). For neoplasms and nonneoplastic lesions observed without litter structure (e.g., at the interim evaluation), Poly-3 tests that included the continuity correction, but without adjustment for potential litter effects, were used for trend and pairwise comparisons to the control group.

To evaluate incidence rates by litter, the proportions of litters affected by each lesion type were tested among groups. Cochran-Armitage trend tests and Fisher exact tests ${ }^{82}$ were used to test for trends and pairwise differences from the control group, respectively.

\section{Analysis of Continuous Variables}

Before statistical analysis, extreme values identified by the outlier test of Dixon and Massey, ${ }^{83}$ for small samples $(\mathrm{n}<20)$, and Tukey's outer fences method, ${ }^{84}$ for large samples $(\mathrm{n} \geq 20)$, were examined by NTP personnel, and implausible values were eliminated from the analysis. Organ and body weight measurements, which historically have approximately normal distributions, were analyzed with the parametric multiple comparison procedures of Dunnett ${ }^{85}$ and Williams. ${ }^{86}$; ${ }^{87}$ Dam gestational and lactational feed consumption, litter sizes, pup survival, implantations, number of resorptions, and proportions of male pups per litter for all rat endpoints were analyzed using the nonparametric multiple comparison methods of Shirley ${ }^{88}$ [as modified by Williams ${ }^{89}$ ] and Dunn ${ }^{90}$ given that these endpoints typically have skewed distributions. For all quantitative endpoints unaffected by litter structure, Jonckheere's test ${ }^{91}$ was used to assess the significance of the dose-related trends and to determine at the 0.01 level of significance, whether a trendsensitive test (Williams' or Shirley's test) was more appropriate for pairwise comparisons than a test that does not assume a monotonic dose-related trend (Dunnett's or Dunn's test).

Postweaning body weights were measured on two pups per sex per litter in the 2-year study; more than two pups per sex per litter were possible in preweaning body weight measurements. 
The analyses of pup body weights and body weights adjusted for litter size (described below) of these animals took litter effects into account using a mixed model, where litters were the random effect. To adjust for multiple comparisons in these models, a Dunnett-Hsu adjustment was used. $^{92}$ Dam body weights during gestation and lactation were analyzed with the parametric multiple comparison procedures of Dunnett ${ }^{85}$ and Williams, ${ }^{86 ; 87}$ depending on whether Jonckheere's test indicated the use of a trend-sensitive test. P values for these analyses are twosided.

\section{Analysis of Gestational and Fertility Indices}

Cochran-Armitage trend tests were used to test the significance of trends in gestational and fertility indices across dose groups. The Fisher exact test was used to conduct pairwise comparisons of each dosed group with the control group. P values for these analyses are twosided.

\section{Body Weight Adjustments}

Preweaning pup body weights were adjusted for live litter size as follows: A linear model was fit to body weights as a function of dose and litter size. The estimated coefficient of litter size was then used to adjust each pup body weight on the basis of the difference between its litter size and the mean litter size. Prestandardization PND 4 body weights were adjusted for PND 1 litter size, and body weights measured between PND 4 poststandardization and PND 21 were adjusted for PND 4 poststandardization litter size. Following adjustment, body weights were analyzed with a linear mixed model with a random litter effect.

\section{Historical Control Data}

The concurrent control group represents the most valid comparison to the treated groups and is the only control group analyzed statistically in NTP bioassays. However, historical control data are often helpful in interpreting potential treatment-related effects, particularly for uncommon or rare neoplasm types. For meaningful comparisons, the conditions for studies in the historical control data must be generally similar. Significant factors affecting the background incidence of neoplasms at a variety of sites are diet, sex, strain/stock, vehicle and route of exposure. The NTP historical control database contains all 2-year studies for each species, sex, and strain/stock with histopathology findings in control animals completed within the most recent 5-year period, ${ }^{93-95}$ including the concurrent control groups for comparison across multiple technical reports. Due to the sectioning of residual tissues for the rat uteri, the historical control for this organ consists of three studies at this time: Indole-3-carbinol, perfluorooctanoic acid, and this study. In general, the historical control data for a given study includes studies using the same route of administration, and the overall incidence of neoplasms in control groups for all routes of administration are included for comparison, including the current study.

\section{Quality Assurance Methods}

The 2-year studies were conducted in compliance with FDA Good Laboratory Practice Regulations. ${ }^{96}$ In addition, the 2-year study reports were audited retrospectively by an independent QA contractor against study records submitted to the NTP Archives. Separate audits covered completeness and accuracy of the pathology data, pathology specimens, final pathology tables, and a draft of this NTP Technical Report. Audit procedures and findings are presented in 
the reports and are on file at NIEHS. The audit findings were reviewed and assessed by NTP staff, and all comments were resolved or otherwise addressed during the preparation of this Technical Report.

\section{Genetic Toxicology}

The genetic toxicity of $2 \mathrm{H} 4 \mathrm{MBP}$ was assessed by testing the ability of the chemical to induce mutations in various strains of Salmonella typhimurium and Escherichia coli. The protocol for these studies and the results are given in Appendix A.

The genetic toxicity studies have evolved from an earlier effort by NTP to develop a comprehensive database permitting a critical anticipation of a chemical's carcinogenicity in experimental animals based on numerous considerations, including the molecular structure of the chemical and its observed effects in short-term in vitro and in vivo genetic toxicity tests (structure-activity relationships). The short-term tests were originally developed to clarify proposed mechanisms of chemical-induced DNA damage on the basis of the relationship between electrophilicity and mutagenicity ${ }^{97}$ and the somatic mutation theory of cancer. ${ }^{98 ; 99}$ However, it should be noted that not all cancers arise through genotoxic mechanisms.

DNA reactivity combined with Salmonella mutagenicity is highly correlated with induction of carcinogenicity in multiple species/sexes of rodents and at multiple tissue sites. ${ }^{100}$ A positive response in the Salmonella test was shown to be the most predictive in vitro indicator for rodent carcinogenicity (89\% of the Salmonella mutagens are rodent carcinogens). ${ }^{101 ; 102}$ Additionally, no battery of tests that included the Salmonella test improved the predictivity of the Salmonella test alone. However, these other tests can provide useful information on the types of DNA and chromosomal damage induced by the chemical under investigation. 


\section{Results}

\section{Data Availability}

The National Toxicology Program (NTP) evaluated all study data. Data relevant for evaluating toxicological findings are presented here. All study data are available in the NTP Chemical Effects in Biological Systems (CEBS) database: https://doi.org/10.22427/NTP-DATA-TR-597. ${ }^{\text {b }}$

\section{Rats}

\section{Two-year Study}

\section{Perinatal Exposure}

Gestation body weights of dams receiving 10,000 ppm 2H4MBP in the diet were slightly lower $(\sim 3 \%)$ than those of the control group and showed statistically significant differences. Dams receiving 3,000 or 10,000 ppm 2H4MBP in the diet displayed slight decreases in GD 6-21 body weight gain $(\sim 10 \%)$ relative to the control group that attained statistical significance (Table 2). Lower body weight gain over the GD 6-9 (10,000 ppm) and 18-21 (3,000 and 10,000 ppm) intervals, which was associated with slightly lower feed consumption over the GD 18-21 interval (Table 3), likely contributed to this response. These collective effects are minimal and would not be expected to affect normal development of the offspring. Dietary concentrations of 1,000, 3,000 , and 10,000 ppm 2H4MBP resulted in average daily doses of approximately 70, 206, and $660 \mathrm{mg} 2 \mathrm{H} 4 \mathrm{MBP} / \mathrm{kg}$ body weight/day during gestation, and 157, 478, and 1,609 mg/kg/day over lactation days (LD) 1-14 (Appendix H).

\footnotetext{
${ }^{b}$ National Toxicology Program (NTP). TR-597: Pathology tables, survival and growth curves from NTP long-term, genetic toxicology studies. Research Triangle Park, NC. 2020. https://doi.org/10.22427/NTP-DATA-TR-597
} 
Table 2. Mean Body Weights and Body Weight Changes of $F_{0}$ Female Rats Exposed to 2-Hydroxy-4-methoxybenzophenone in Feed during Gestation and Lactation

\begin{tabular}{ccccc}
\hline Parameter $^{\mathbf{a}}$ & $\mathbf{0 ~} \mathbf{p p m}$ & $\mathbf{1 , 0 0 0} \mathbf{~ p p m}$ & $\mathbf{3 , 0 0 0} \mathbf{~ p m}$ & $\mathbf{1 0 , 0 0 0} \mathbf{~ p p m}$ \\
\hline Gestation Day & & & & \\
6 & $231.4 \pm 1.9[40]$ & $231.1 \pm 2.5[34]$ & $232.1 \pm 1.5[32]$ & $231.7 \pm 2.3[36]$ \\
9 & $246.3 \pm 2.4^{*}[40]$ & $248.6 \pm 1.9[34]$ & $246.0 \pm 1.4[32]$ & $239.7 \pm 1.8^{*}[36]$ \\
12 & $262.5 \pm 1.6^{*}[40]$ & $263.2 \pm 1.9[34]$ & $260.3 \pm 1.6[32]$ & $258.8 \pm 1.8[36]$ \\
15 & $281.3 \pm 1.7^{*}[40]$ & $282.1 \pm 2.1[34]$ & $278.2 \pm 1.8[32]$ & $276.4 \pm 2.2[36]$ \\
18 & $321.9 \pm 1.8^{*}[40]$ & $322.1 \pm 2.6[34]$ & $316.0 \pm 2.8[32]$ & $314.0 \pm 2.8^{*}[36]$ \\
21 & $366.0 \pm 2.4^{*}[40]$ & $364.7 \pm 3.5[34]$ & $353.7 \pm 4.9^{*}[32]$ & $353.8 \pm 3.8^{*}[36]$
\end{tabular}

Gestation Weight Change

$\begin{array}{ccccc}6-9 & 14.9 \pm 1.7^{* *[40]} & 17.5 \pm 1.3[34] & 13.9 \pm 0.7[32] & 8.0 \pm 1.3^{* *[36]} \\ 9-12 & 16.3 \pm 1.6^{* *[40]} & 14.6 \pm 0.6[34] & 14.3 \pm 0.5[32] & 19.0 \pm 0.8[36] \\ 12-15 & 18.8 \pm 0.7[40] & 19.0 \pm 0.5[34] & 17.9 \pm 0.8[32] & 17.6 \pm 0.8[36] \\ 15-18 & 40.6 \pm 1.0^{*}[40] & 40.0 \pm 1.0[34] & 37.8 \pm 1.5[32] & 37.6 \pm 1.0[36] \\ 18-21 & 44.1 \pm 1.1^{*}[40] & 42.6 \pm 1.4[34] & 37.6 \pm 2.6^{*}[32] & 39.9 \pm 1.4[36] \\ 6-21 & 134.6 \pm 2.4^{* *[40]} & 133.6 \pm 2.9[34] & 121.6 \pm 4.4^{* *[32]} & 122.1 \pm 3.2^{* *[36]}\end{array}$

Lactation Day

$\begin{array}{ccccc}1 & 276.3 \pm 1.6^{* *[40]} & 274.1 \pm 2.1[34] & 269.0 \pm 2.3^{*}[32] & 264.5 \pm 2.2^{* *[36]} \\ 4 & 289.7 \pm 1.8^{* *[40]} & 287.8 \pm 2.3[34] & 279.8 \pm 2.6^{* *[32]} & 274.1 \pm 2.2^{* *[36]} \\ 7 & 295.9 \pm 1.8[35] & 295.4 \pm 2.5[30] & 289.2 \pm 3.6[27] & 285.6 \pm 2.5^{* *[33]} \\ 14 & 312.9 \pm 2.1^{*}[35] & 312.7 \pm 2.7[30] & 306.9 \pm 3.0[27] & 304.2 \pm 3.0^{*}[33] \\ 21 & 304.8 \pm 2.3^{*}[35] & 300.6 \pm 2.6[30] & 295.4 \pm 2.4^{*}[27] & 298.8 \pm 2.7[33]\end{array}$

Lactation Weight Change

$\begin{array}{ccccc}1-4 & 13.4 \pm 1.2 *[40] & 13.7 \pm 1.1[34] & 10.8 \pm 2.0[32] & 9.6 \pm 1.0[36] \\ 4-7 & 7.5 \pm 1.2[35] & 6.3 \pm 1.3[30] & 8.6 \pm 1.5[27] & 10.3 \pm 1.0[33] \\ 7-14 & 17.0 \pm 1.4[35] & 17.3 \pm 1.7[30] & 17.7 \pm 2.5[27] & 18.6 \pm 1.6[33] \\ 14-21 & -8.1 \pm 1.5[35] & -12.0 \pm 1.7[30] & -11.6 \pm 2.1[27] & -5.4 \pm 2.1[33] \\ 4-21 & 16.4 \pm 1.7 *[35] & 11.6 \pm 1.5[30] & 14.7 \pm 2.3[27] & 23.5 \pm 1.9 *[33]\end{array}$

Statistical significance for a treatment group indicates a significant pairwise test compared to the vehicle control group. Statistical significance for the control group indicates a significant trend test.

$*$ Statistically significant at $\mathrm{p} \leq 0.05 ; * * \mathrm{p} \leq 0.01$.

'Each dietary concentration was compared to the control with Williams' test when a trend was present $(\mathrm{p} \leq 0.01$ from Jonckheere's trend test) or with Dunnett's test when no trend was present. Body weight data are presented in grams. 
Table 3. Feed Consumption of $F_{0}$ Female Rats Exposed to 2-Hydroxy-4-methoxybenzophenone in Feed during Gestation and Lactation

\begin{tabular}{ccccc}
\hline Parameter $^{\mathbf{a}}$ & $\mathbf{0 ~ p p m}$ & $\mathbf{1 , 0 0 0} \mathbf{~ p p m}$ & $\mathbf{3 , 0 0 0} \mathbf{~ p p m}$ & $\mathbf{1 0 , 0 0 0} \mathbf{~ p p m}$ \\
\hline Gestation Day & & & & \\
$6-9$ & $17.7 \pm 0.5^{* *}[41]$ & $17.9 \pm 0.2[34]$ & $17.2 \pm 0.3^{*}[33]$ & $13.3 \pm 0.4^{* *}[36]$ \\
$9-12$ & $18.2 \pm 0.2[41]$ & $18.6 \pm 0.3[34]$ & $18.3 \pm 0.3[33]$ & $19.0 \pm 0.3[36]$ \\
$12-15$ & $18.6 \pm 0.2[41]$ & $18.6 \pm 0.2[34]$ & $18.2 \pm 0.3[33]$ & $18.5 \pm 0.2[36]$ \\
$15-18$ & $21.1 \pm 0.2^{*}[41]$ & $21.3 \pm 0.2[34]$ & $21.0 \pm 0.3[33]$ & $20.2 \pm 0.3[36]$ \\
$18-21$ & $21.4 \pm 0.2^{* *}[41]$ & $21.3 \pm 0.2[34]$ & $20.2 \pm 0.5 *[33]$ & $19.9 \pm 0.3 * *[36]$ \\
$6-21$ & $19.4 \pm 0.2^{* *}[41]$ & $19.6 \pm 0.2[34]$ & $19.0 \pm 0.3[33]$ & $18.2 \pm 0.2^{* *[36]}$ \\
Lactation Day & & & & \\
$0-4$ & $35.2 \pm 0.6[40]$ & $35.0 \pm 0.7[34]$ & $33.7 \pm 1.3[32]$ & $37.4 \pm 1.5[35]$ \\
$4-7$ & $41.6 \pm 0.6[35]$ & $41.4 \pm 0.4[30]$ & $41.8 \pm 1.0[27]$ & $41.3 \pm 0.7[33]$ \\
$7-10$ & $49.6 \pm 0.8[35]$ & $48.4 \pm 0.6[30]$ & $48.5 \pm 1.2[27]$ & $47.9 \pm 1.1[33]$ \\
$10-14$ & $58.2 \pm 0.8[34]$ & $58.4 \pm 0.6[30]$ & $57.0 \pm 1.1[27]$ & $55.6 \pm 1.1[33]$ \\
$14-17$ & $61.4 \pm 1.1[35]$ & $62.6 \pm 0.6[30]$ & $62.8 \pm 0.7[27]$ & $59.7 \pm 1.5[33]$ \\
$17-21$ & $69.6 \pm 1.1[35]$ & $69.4 \pm 1.3[30]$ & $70.7 \pm 1.0[27]$ & $69.7 \pm 1.4[33]$ \\
$1-14$ & $47.1 \pm 0.5[34]$ & $46.9 \pm 0.4[30]$ & $46.5 \pm 0.8[27]$ & $46.5 \pm 0.7[32]$ \\
\hline
\end{tabular}

Statistical significance for a treatment group indicates a significant pairwise test compared to the vehicle control group. Statistical significance for the control group indicates a significant trend test.

$*$ Statistically significant at $\mathrm{p} \leq 0.05 ; * * \mathrm{p} \leq 0.01$.

aEach dietary concentration was compared to the control group with Shirley's test when a trend was present or with Dunn's test when no trend was present. Feed consumption data are presented as g/animal/day.

Administration of $2 \mathrm{H} 4 \mathrm{MBP}$ had no effects on the percentage of mated females producing pups, litter size, pup sex distribution, or numbers of male or female pups (Table 4; Table 5). The apparent decrease in the percentage of females pregnant in the 10,000 ppm group can be attributed to the seven animals that had no evidence of pregnancy as shown by the absence of implantation sites. Therefore, the lower pregnancy rate was not exposure-related given that exposure began after implantation. Dams receiving 2H4MBP did not display any adverse clinical findings before or after parturition. Litter size of the 10,000 ppm 2H4MBP group was slightly lower on PNDs 7 and 10 (Table 5). 
Table 4. Summary of the Disposition of Rats during Perinatal Exposure and $F_{1}$ Allocation in the Two-year Perinatal and Postnatal Feed Study of 2-Hydroxy-4-methoxybenzophenone

\begin{tabular}{|c|c|c|c|c|}
\hline & 0 ppm & $1,000 \mathrm{ppm}$ & $3,000 \mathrm{ppm}$ & 10,000 ppm \\
\hline \multicolumn{5}{|l|}{ Reproductive Performance } \\
\hline Time-mated Females (GD 6) & 42 & 35 & 35 & 43 \\
\hline Females Pregnant $(\%)^{\mathrm{a}}$ & $41(98 \%)^{* *}$ & $34(97 \%)$ & $33(94 \%)$ & $36(84 \%)$ \\
\hline Females Not Pregnant (\%) & $1(2 \%)$ & $1(3 \%)$ & $2(6 \%)$ & $7(16 \%)$ \\
\hline Dams Not Delivering with Evidence of Pregnancy (\%) & $1^{\mathrm{b}}$ & 0 & $1^{\mathrm{c}}$ & 0 \\
\hline Dams with Litters on PND $0(\%)$ & $40(98 \%)$ & $34(100 \%)$ & $32(97 \%)$ & $36(100 \%)$ \\
\hline Litters Poststandardization (PND 4) ${ }^{\mathrm{d}}$ & 35 & 30 & 27 & 33 \\
\hline \multicolumn{5}{|l|}{ Postweaning Allocation } \\
\hline $\mathrm{F}_{1}$ Males - Chronic (Litters) ${ }^{\mathrm{e}}$ & $50(30)$ & $50(25)$ & $50(25)$ & $50(30)$ \\
\hline $\mathrm{F}_{1}$ Males - Interim $(\text { Litters })^{\mathrm{f}}$ & $10(9)$ & - & - & $10(8)$ \\
\hline $\mathrm{F}_{1}$ Females - Chronic (Litters) ${ }^{\mathrm{e}}$ & $50(30)$ & $50(25)$ & $50(25)$ & $50(30)$ \\
\hline $\mathrm{F}_{1}$ Females - Interim $(\text { Litters })^{\mathrm{f}}$ & $10(9)$ & - & - & $10(9)$ \\
\hline
\end{tabular}

Statistical significance for the control group indicates a significant trend test.

$* *$ Statistically significant at $\mathrm{p} \leq 0.01$.

$\mathrm{GD}=$ gestation day; PND = postnatal day .

aStatistical analysis performed by Cochran-Armitage (trend) and Fisher Exact (pairwise) tests.

${ }^{\text {b}}$ Found dead on GD 23 (no adverse clinical signs) with a single fetus and no other apparent resorption sites.

'Undelivered (2 implantations/0 resorptions).

${ }^{\mathrm{d}}$ Standardization to eight pups per litter (four pups/sex).

${ }^{\mathrm{e}}$ Total number of $\mathrm{F}_{1}$ rats included in the 105-week evaluation (number of litters from which they originated).

${ }^{\mathrm{f}}$ Number of $\mathrm{F}_{1}$ rats euthanized at the 14-week interim evaluation (number of litters from which they originated).

Table 5. Mean Number of Surviving $F_{1}$ Male and Female Rats during Lactation in the Two-year Perinatal and Postnatal Feed Study of 2-Hydroxy-4-methoxybenzophenone

\begin{tabular}{lcccc}
\hline & $\mathbf{0 ~} \mathbf{p p m}$ & $\mathbf{1 , 0 0 0} \mathbf{~ p p m}$ & $\mathbf{3 , 0 0 0} \mathbf{~ p p m}$ & $\mathbf{1 0 , 0 0 0} \mathbf{~ p p m}$ \\
\hline PND 1, & & & & \\
Total & $12.55 \pm 0.35[40]$ & $12.65 \pm 0.41[34]$ & $11.63 \pm 0.65[32]$ & $12.53 \pm 0.41[36]$ \\
Live & $12.45 \pm 0.36[40]$ & $12.50 \pm 0.41[34]$ & $11.44 \pm 0.66[32]$ & $12.33 \pm 0.43[36]$ \\
\% Male per Litter & $51.23 \pm 2.29[40]$ & $50.20 \pm 2.34[34]$ & $45.84 \pm 2.89[32]$ & $51.66 \pm 2.54[36]$ \\
\% Male, & $52[498]$ & $50[425]$ & $47[366]$ & $52[444]$ \\
PND 4 Prestandardization & $\mathbf{1 2 . 4 3} \pm \mathbf{0 . 3 6}[\mathbf{4 0}]$ & $\mathbf{1 2 . 4 1} \pm \mathbf{0 . 4 1}[\mathbf{3 4}]$ & $\mathbf{1 1 . 3 8} \pm \mathbf{0 . 6 5}[\mathbf{3 2}]$ & $\mathbf{1 2 . 2 5} \pm \mathbf{0 . 4 3}[\mathbf{3 6}]$ \\
\hline Male & & & & \\
PND 1 & & & $5.41 \pm 0.40[32]$ & $6.39 \pm 0.38[36]$ \\
PND 4 Prestandardization & $6.45 \pm 0.35[40]$ & $6.24 \pm 0.36[34]$ & $5.28 \pm 0.40[32]$ & $6.39 \pm 0.39[36]$ \\
PND 4 Poststandardization & $4.00 \pm 0.00[35]$ & $4.00 \pm 0.05[30]$ & $3.89 \pm 0.08[27]$ & $4.12 \pm 0.08[33]$ \\
\hline
\end{tabular}




\begin{tabular}{|c|c|c|c|c|}
\hline & O ppm & 1,000 ppm & 3,000 ppm & 10,000 ppm \\
\hline \multicolumn{5}{|l|}{ Female $^{\mathbf{a}, \mathrm{b}}$} \\
\hline PND 1 & $6.00 \pm 0.32[40]$ & $6.21 \pm 0.36[34]$ & $6.03 \pm 0.45[32]$ & $5.94 \pm 0.36[36]$ \\
\hline PND 4 Prestandardization & $5.98 \pm 0.33[40]$ & $6.18 \pm 0.35[34]$ & $6.09 \pm 0.46[32]$ & $5.86 \pm 0.34[36]$ \\
\hline PND 4 Poststandardization & $4.00 \pm 0.00[35]$ & $4.00 \pm 0.05[30]$ & $4.11 \pm 0.08[27]$ & $3.88 \pm 0.08[33]$ \\
\hline \multicolumn{5}{|l|}{ Male and Female ${ }^{a, b}$} \\
\hline PND 4 Poststandardization & $8.00 \pm 0.00[35]$ & $8.00 \pm 0.00[30]$ & $8.00 \pm 0.00[27]$ & $8.00 \pm 0.00[33]$ \\
\hline PND 7 & $8.00 \pm 0.00 *[35]$ & $8.00 \pm 0.00[30]$ & $8.00 \pm 0.00[27]$ & $7.82 \pm 0.13^{*}[33]$ \\
\hline PND 10 & $8.00 \pm 0.00 *[35]$ & $8.00 \pm 0.00[30]$ & $8.00 \pm 0.00[27]$ & $7.82 \pm 0.13 *[33]$ \\
\hline PND 14 & $7.94 \pm 0.04[35]$ & $7.97 \pm 0.03[30]$ & $7.96 \pm 0.04[27]$ & $7.82 \pm 0.13[33]$ \\
\hline PND 17 & $7.94 \pm 0.04[35]$ & $7.97 \pm 0.03[30]$ & $7.96 \pm 0.04[27]$ & $7.82 \pm 0.13[33]$ \\
\hline PND 21 & $7.91 \pm 0.05[35]$ & $7.97 \pm 0.03[30]$ & $7.93 \pm 0.07[27]$ & $7.82 \pm 0.13[33]$ \\
\hline \multicolumn{5}{|l|}{ Survival per Litter } \\
\hline Total Dead: PND 1-4 & $5[40]$ & $8[34]$ & $8[32]$ & $10[36]$ \\
\hline Total Dead: PND 5-21 & $3[35]$ & $1[30]$ & $2[27]$ & $6[33]$ \\
\hline Dead: PND 1-4 & $0.125 \pm 0.064[40]$ & $0.235 \pm 0.095[34]$ & $0.250 \pm 0.162[32]$ & $0.278 \pm 0.102[36]$ \\
\hline Dead: PND 4-21 $1^{\mathrm{b}, \mathrm{f}, \mathrm{g}}$ & $0.086 \pm 0.048[35]$ & $0.033 \pm 0.033[30]$ & $0.074 \pm 0.074[27]$ & $0.182 \pm 0.127[33]$ \\
\hline Survival Ratio: PND 1-4,g,h & $0.998 \pm 0.002[40]$ & $0.993 \pm 0.004[34]$ & $0.996 \pm 0.003[32]$ & $0.994 \pm 0.005[36]$ \\
\hline Survival Ratio: PND 4-21 & $0.989 \pm 0.006[35]$ & $0.996 \pm 0.004[30]$ & $0.991 \pm 0.009[27]$ & $0.977 \pm 0.016[33]$ \\
\hline
\end{tabular}

Statistical significance for a treatment group indicates a significant pairwise test compared to the vehicle control group. Statistical significance for the control group indicates a significant trend test.

*Statistically significant at $\mathrm{p} \leq 0.05$.

PND = postnatal day.

aEach dietary concentration was compared to the control group with Shirley's test when a trend was present or with Dunn's test when no trend was present.

${ }^{b}$ Mean \pm standard error [number of dams].

${ }^{c} 100 \times$ [number of live males in dietary exposure group]/[number of live males and females in dietary exposure group].

${ }^{\mathrm{d}}$ No statistics done on this endpoint.

eTotal dead in dietary concentration group [number of dams].

${ }_{\mathrm{f}}$ Number dead per litter.

gEach dietary concentration was compared to the control group with Shirley's test when a trend is present ( $p \leq 0.01$ from Jonckheere's trend test), otherwise Dunn's test is applied.

hurvival per litter: Number of pups prestandardization on PND 4/total live pups on PND 1.

iSurvival per litter: Number of live pups on PND 21/number of live pups poststandardization on PND 4.

Male, female, and combined pup body weights were not significantly different across the exposure groups on PND 1. However, on PND 4, pup body weights (male, female, and both) in the $10,000 \mathrm{ppm}$ exposure groups were approximately $10 \%$ lower than those of the control groups, and this response was generally observed over subsequent preweaning weights (Table 6).

Pups were weaned on PND 21, which was considered day 1 of the 2-year exposure period. 
Table 6. Preweaning Pup Body Weight of Rats Following Exposure during Gestation and Lactation in the Two-year Perinatal and Postnatal Feed Study of 2-Hydroxy-4-methoxybenzophenone

\begin{tabular}{|c|c|c|c|c|}
\hline & 0 ppm & 1,000 ppm & 3,000 ppm & 10,000 ppm \\
\hline \multicolumn{5}{|c|}{ Pup Body Weights (g)a } \\
\hline \multicolumn{5}{|l|}{ Male } \\
\hline PND $1^{b, c, d}$ & $7.32 \pm 0.07[40]$ & $7.38 \pm 0.07[34]$ & $7.22 \pm 0.09[31]$ & $7.11 \pm 0.08[35]$ \\
\hline PND $4^{e, f, g}$ & $10.65 \pm 0.12 * *[258 / 40]$ & $10.95 \pm 0.12[212 / 34]$ & $10.54 \pm 0.13[169 / 31]$ & $10.02 \pm 0.18 * *[231 / 35]$ \\
\hline PND $7^{e, h}$ & $16.66 \pm 0.26^{*}[140 / 35]$ & $16.44 \pm 0.26[120 / 30]$ & $16.29 \pm 0.35[105 / 27]$ & $15.72 \pm 0.28 *[135 / 33]$ \\
\hline PND $14^{\mathrm{e}, \mathrm{h}}$ & $33.72 \pm 0.47 * *[139 / 35]$ & $33.79 \pm 0.38[120 / 30]$ & $32.83 \pm 0.52[104 / 27]$ & $30.99 \pm 0.40 * *[135 / 33]$ \\
\hline PND $21^{\mathrm{e}, \mathrm{h}}$ & $53.36 \pm 0.84 * *[136 / 34]$ & $52.85 \pm 0.75[120 / 30]$ & $52.61 \pm 0.77[104 / 27]$ & $48.47 \pm 0.74 * *[135 / 33]$ \\
\hline \multicolumn{5}{|l|}{ Female } \\
\hline PND $1^{b, c, d}$ & $6.95 \pm 0.07[40]$ & $7.00 \pm 0.08[34]$ & $6.86 \pm 0.09[32]$ & $6.80 \pm 0.07[36]$ \\
\hline PND $4^{e, f, g}$ & $10.08 \pm 0.12 * *[239 / 40]$ & $10.42 \pm 0.12[210 / 34]$ & $9.94 \pm 0.17[195 / 32]$ & $9.51 \pm 0.17 *[210 / 36]$ \\
\hline PND $7^{e, h}$ & $15.56 \pm 0.28 *[140 / 35]$ & $15.58 \pm 0.26[119 / 30]$ & $15.46 \pm 0.35[111 / 27]$ & $14.73 \pm 0.24[123 / 33]$ \\
\hline PND $14^{\mathrm{e}, \mathrm{h}}$ & $32.27 \pm 0.41 * *[138 / 35]$ & $32.06 \pm 0.38[119 / 30]$ & $31.37 \pm 0.51[111 / 27]$ & $29.78 \pm 0.33 * *[123 / 33]$ \\
\hline PND $21^{\mathrm{e}, \mathrm{h}}$ & $49.49 \pm 0.72 * *[138 / 35]$ & $49.24 \pm 0.79[119 / 30]$ & $49.17 \pm 0.79[110 / 27]$ & $45.70 \pm 0.55 * *[123 / 33]$ \\
\hline \multicolumn{5}{|c|}{ Male and Female } \\
\hline PND $1^{\mathrm{b}, \mathrm{c}, \mathrm{d}}$ & $7.13 \pm 0.07 *[40]$ & $7.20 \pm 0.07[34]$ & $7.01 \pm 0.08[32]$ & $6.95 \pm 0.07[36]$ \\
\hline PND $4^{e, f, g}$ & $10.36 \pm 0.12 * *[497 / 40]$ & $10.70 \pm 0.10[422 / 34]$ & $10.16 \pm 0.16[364 / 32]$ & $9.79 \pm 0.17 * *[441 / 36]$ \\
\hline PND $7^{e, h}$ & $16.11 \pm 0.26^{*}[280 / 35]$ & $16.02 \pm 0.25[239 / 30]$ & $15.88 \pm 0.33[216 / 27]$ & $15.23 \pm 0.26[258 / 33]$ \\
\hline PND $14^{\mathrm{e}, \mathrm{h}}$ & $32.99 \pm 0.42 * *[277 / 35]$ & $32.94 \pm 0.34[239 / 30]$ & $32.10 \pm 0.49[215 / 27]$ & $30.40 \pm 0.35 * *[258 / 33]$ \\
\hline PND $21^{\mathrm{e}, \mathrm{h}}$ & $51.39 \pm 0.73 * *[274 / 35]$ & $51.07 \pm 0.71[239 / 30]$ & $50.90 \pm 0.70[214 / 27]$ & $47.21 \pm 0.62 * *[258 / 33]$ \\
\hline $\begin{array}{l}\text { Statistical si } \\
\text { significance } \\
\text { *Statistically } \\
\text { PND = postn } \\
\text { a'Statistical a } \\
\text { Dunnett-Hsu } \\
\text { bMean } \pm \text { star } \\
\text { 'Each dietary } \\
\text { Jonckheere's } \\
\text { dTotal pup w } \\
\text { eMean of dar } \\
\text { fPND 4 prest } \\
\text { 'Individual p }\end{array}$ & $\begin{array}{l}\text { nce for a treatment group ind } \\
\text { control group indicates a sig } \\
\text { ficant at } \mathrm{p} \leq 0.05 ; * * \mathrm{p} \leq 0.01 \\
\text { ay. } \\
\text { w was performed using mixed } \\
\text { tment for multiple compariso } \\
\text { error [number of dams]. } \\
\text { entration was compared to th } \\
\text { test) or with Dunnett's test } \\
\text { at PND } 1 \text { divided by number } \\
\text { in } \pm \text { standard error [number o } \\
\text { dization. } \\
\text { ights first adjusted for live lit }\end{array}$ & $\begin{array}{l}\text { models with random litter } \\
\text { s. } \\
\text { control group with Williar } \\
\text { hen no trend was present. } \\
\text { f live pups at PND } 1 . \\
\text { pups/number of dams]. }\end{array}$ & ms' test when a trend was & $\begin{array}{l}\text { airwise tests, using the } \\
\text { present }(\mathrm{p} \leq 0.01 \text { from }\end{array}$ \\
\hline
\end{tabular}




\section{Postnatal Exposure}

\section{Survival}

Estimates of 2-year survival probabilities for male and female rats are shown in Table 7 and in the Kaplan-Meier survival curves (Figure 3). Survival of all exposed groups of male and female rats was not significantly different from that of the control groups.

Table 7. Survival of Rats in the Perinatal and Two-year Feed Study of 2-Hydroxy-4-methoxybenzophenone

\begin{tabular}{|c|c|c|c|c|}
\hline & 0 ppm & 1,000 ppm & $3,000 \mathrm{ppm}$ & $10,000 \mathrm{ppm}$ \\
\hline \multicolumn{5}{|l|}{ Male } \\
\hline Animals Initially in Study & 60 & 50 & 50 & 60 \\
\hline 14-week Interim Evaluation ${ }^{\mathrm{a}}$ & 10 & 0 & 0 & 10 \\
\hline Moribund & 12 & 15 & 18 & 10 \\
\hline Natural Deaths & 8 & 6 & 8 & 7 \\
\hline Animals Surviving to Study Termination & $30^{\mathrm{b}}$ & 29 & 24 & 33 \\
\hline Percent Probability of Survival at End of Study ${ }^{c}$ & 60 & 58 & 48 & 66 \\
\hline Mean Survival (Days) ${ }^{\mathrm{d}}$ & 705 & 675 & 678 & 678 \\
\hline Survival Analysis ${ }^{\mathrm{e}}$ & $\mathrm{p}=0.486 \mathrm{~N}$ & $\mathrm{p}=0.672$ & $p=0.203$ & $\mathrm{p}=0.706 \mathrm{~N}$ \\
\hline \multicolumn{5}{|l|}{ Female } \\
\hline Animals Initially in Study & 60 & 50 & 50 & 60 \\
\hline 14-week Interim Evaluation ${ }^{\mathrm{a}}$ & 10 & 0 & 0 & 10 \\
\hline Moribund & 15 & 13 & 10 & 16 \\
\hline Natural Deaths & 5 & 4 & 6 & 8 \\
\hline Animals Surviving to Study Termination & 30 & 33 & 34 & 26 \\
\hline Percent Probability of Survival at End of Study ${ }^{c}$ & 60 & 66 & 68 & 52 \\
\hline Mean Survival (Days) ${ }^{\mathrm{d}}$ & 659 & 682 & 692 & 658 \\
\hline Survival Analysis ${ }^{\mathrm{e}}$ & $\mathrm{p}=0.231$ & $\mathrm{p}=0.385 \mathrm{~N}$ & $\mathrm{p}=0.238 \mathrm{~N}$ & $\mathrm{p}=0.603$ \\
\hline
\end{tabular}

${ }^{\mathrm{a}}$ Excluded from survival analysis.

b Includes one animal that died during the last week of the study.

${ }^{\mathrm{c}}$ Kaplan-Meier determinations.

${ }^{\mathrm{d}}$ Mean of litter means of all deaths (uncensored, censored, and study termination).

${ }^{\mathrm{e}}$ The result of the Cox proportional hazards trend tes ${ }^{\mathrm{t} 67}$ is in the control column, and the results of the proportional hazards pairwise comparisons with the control groups are in the exposed group columns. A negative trend or lower mortality in an exposure group is indicated by $\mathrm{N}$. 

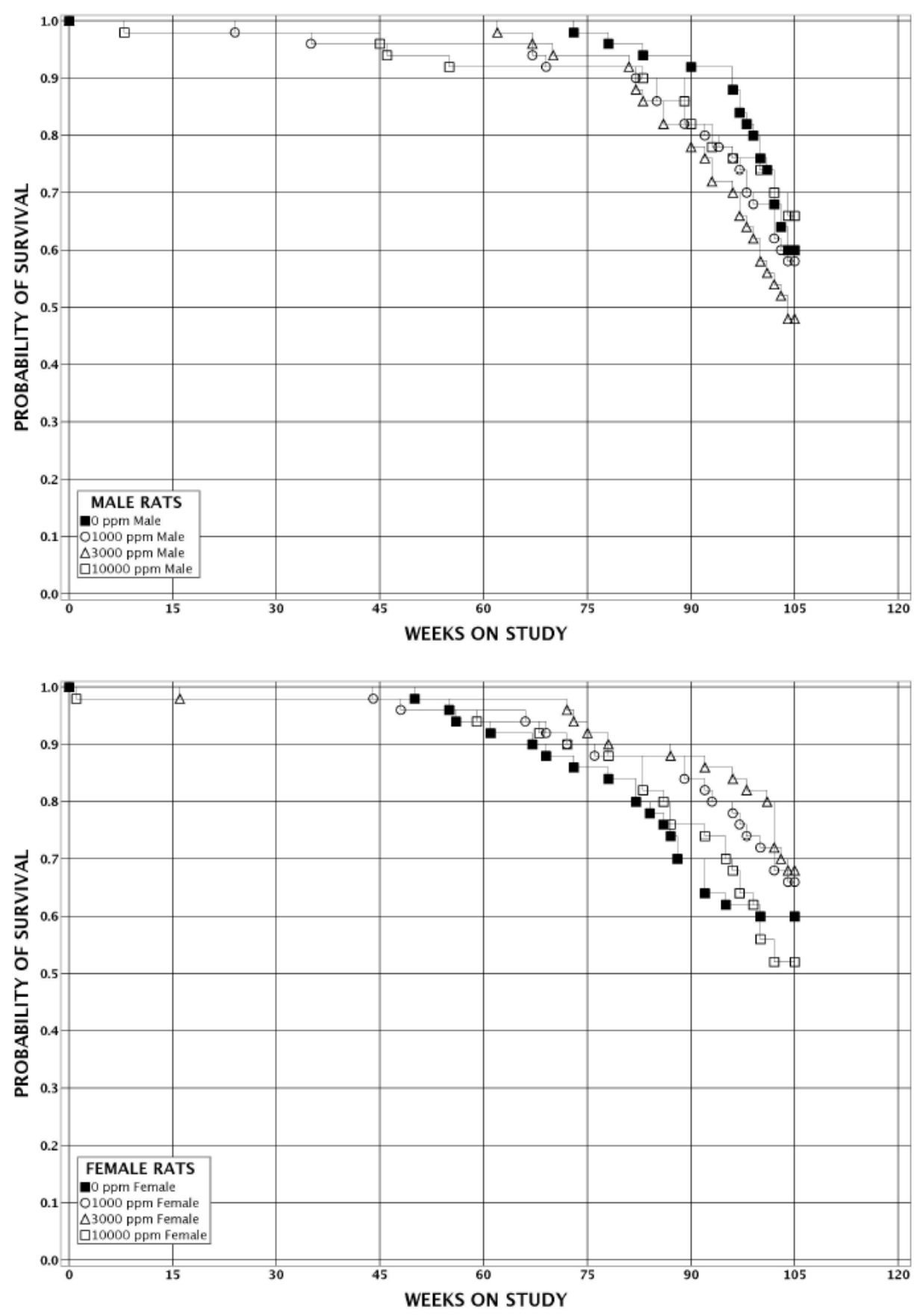

Figure 3. Kaplan-Meier Survival Curves for Rats Exposed to 2-Hydroxy-4-methoxybenzophenone in Feed for Two Years 


\section{Fourteen-week Interim Evaluation}

Groups of 10 male and 10 female rats were exposed to 0 or 10,000 ppm 2H4MBP for 14 weeks. At the 14-week interim evaluation, the mean body weight of the $10,000 \mathrm{ppm}$ males was not significantly different from that of the control males, but the mean body weight of the 10,000 ppm females was significantly decreased and was approximately $87 \%$ that of the control group (Table 8). In males, the absolute and relative liver and right kidney weights were increased in the 10,000 ppm group compared to the control group. In females, the absolute kidney weight was significantly decreased, and the relative liver weight was significantly increased relative to the control group (Table 8).

The incidence of mixed-cell cellular infiltration in the liver was significantly increased in $10,000 \mathrm{ppm}$ males relative to the control group (Table 8; Appendix $\mathrm{H}$ ). These cellular infiltrates were composed of mononuclear cells with scarce neutrophils and had no specific predisposition to a specific area of the liver lobule. It is unlikely that the cellular infiltrates, which were all of minimal severity, would be responsible for the changes in the liver weights observed in male rats at this time point (Table 8; Appendix H). No other histologic findings were observed to explain the differences in organ weights, but in the females, body weight changes could have influenced the absolute kidney weight decrease and the relative liver weight increase. However, the increase in relative liver weight in exposed females was accompanied by a nonsignificant absolute liver weight increase, so it is unlikely that body weight was responsible for the liver weight changes (Table 8).

As a part of the 14-week interim evaluation in the $\mathrm{F}_{1}$ rat study, transcriptome analysis was performed on RNA extracted from microarray study male rat livers from the $10,000 \mathrm{ppm}$ and control groups. The observed effects on transcription were consistent with a mild induction of xenobiotic metabolism-related processes that is likely related to the observed liver weight increases. Analysis of a subset of estrogen-responsive genes showed no change in response to 2H4MBP (Appendix E). 
Table 8. Select Organ Weights, Organ-Weight-to-Body-Weight Ratios, and Histological Findings in Rats at the 14-week Interim of the Two-year Feed Study of 2-Hydroxy-4-methoxybenzophenone

\begin{tabular}{lcc}
\hline & $\mathbf{0 ~ p p m}$ & $\mathbf{1 0 , 0 0 0 ~ p p m ~}$ \\
\hline $\mathbf{n}$ & 10 & 10
\end{tabular}

\section{Male}

Necropsy Body Wt. (g) ${ }^{\mathrm{a}}$

$394.6 \pm 7.9$

$386.8 \pm 6.8$

R. Kidney ${ }^{\mathrm{a}}$
Absolute (g)
$1.18 \pm 0.03 * *$
$1.37 \pm 0.03 * *$
Relative $(\mathrm{mg} / \mathrm{g})^{\mathrm{b}}$
$3.00 \pm 0.06 * *$
$3.54 \pm 0.07 * *$

Liver $^{\mathrm{a}}$
Absolute (g)
$13.94 \pm 0.49 * *$
$16.41 \pm 0.46^{* *}$
Relative (mg/g)
$35.25 \pm 0.68 * *$
$42.38 \pm 0.75^{* *}$

Histological Findings ${ }^{c}$

Liver $^{\mathrm{d}}$

10

10

Infiltration cellular, mixed cell ${ }^{\mathrm{e}}$

$2(1.0)^{\mathrm{f}}$

$8 * *(1.0)$

\section{Female}

Necropsy Body Wt. (g)

$261.7 \pm 6.3 * *$

$228.7 \pm 4.9 * *$

R. Kidney
Absolute (g)
$0.79 \pm 0.01 *$
$0.71 \pm 0.02 * *$
Relative (mg/g)
$3.01 \pm 0.04$
$3.09 \pm 0.08$

Liver
Absolute (g)
$8.77 \pm 0.38$
$9.64 \pm 0.28$
Relative (mg/g)
$33.43 \pm 0.91 * *$
$42.15 \pm 0.68 * *$

Histological Findings

Liver

Infiltration cellular, mixed cell

$2(1.0)$

Statistical significance for a treatment group indicates a significant pairwise test compared to the vehicle control group. Statistical significance for the control group indicates a significant trend test.

$*$ Statistically significant at $\mathrm{p} \leq 0.05 ; * * \mathrm{p} \leq 0.01$.

aData are displayed as mean \pm SEM $(\mathrm{N})$. Statistical analysis performed by Jonckheere's (trend) and Williams' or Dunnett's (pairwise) tests.

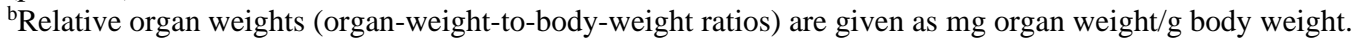

${ }^{\mathrm{c} S t a t i s t i c a l ~ a n a l y s i s ~ f o r ~ h i s t o l o g i c a l ~ f i n d i n g s ~ p e r f o r m e d ~ u s i n g ~ t h e ~ P o l y-3 ~ t e s t . ~}$

dNumber of animals examined microscopically.

eNumber of animals with lesion.

${ }_{\mathrm{f}}$ Average severity grade of lesion in affected animals: $1=$ minimal; $2=$ mild; $3=$ moderate; $4=$ marked. 


\section{Chronic Exposure}

\section{Body Weights, Feed and Compound Consumption, and Clinical Observations}

Male rats exposed to $10,000 \mathrm{ppm} 2 \mathrm{H} 4 \mathrm{MBP}$ displayed consistently lower mean body weights $(\sim 10 \%)$ after week 69 relative to the control group and were $20 \%$ lower than the control group mean at study end (Table 9; Figure 4). Females exposed to 10,000 ppm 2H4MBP displayed a similar response ( 10\% lower than the control group mean after week 17), but after week 45 this group displayed mean body weights that were approximately $16 \%$ lower than the control group, and mean body weights were $24 \%$ lower than the control group mean at study end. Mean body weights of females exposed to 3,000 ppm 2H4MBP were lower than the control group mean after week $77(\sim 10 \%)$ (Table 10).

Feed consumption by $2 \mathrm{H} 4 \mathrm{MBP}$-exposed male and female rats was not significantly different from that by the control groups throughout the study (Appendix $\mathrm{H}$ ). Dietary concentrations of $1,000,3,000$, and 10,000 ppm resulted in average daily doses of approximately 58,168 , and $585 \mathrm{mg} 2 \mathrm{H} 4 \mathrm{MBP} / \mathrm{kg}$ body weight for males and 60,180 , and $632 \mathrm{mg} / \mathrm{kg}$ for females. No clinical findings in exposed groups of male or female rats were considered to be related to $2 \mathrm{H} 4 \mathrm{MBP}$ exposure (Appendix H). 
Table 9. Mean Body Weights and Survival of Male Rats in the Perinatal and Two-year Feed Study of 2-Hydroxy-4-methoxybenzophenone

\begin{tabular}{|c|c|c|c|c|c|c|c|c|c|c|c|}
\hline \multirow[b]{2}{*}{ Day } & \multicolumn{2}{|c|}{0 ppm } & \multicolumn{3}{|c|}{$1,000 \mathrm{ppm}$} & \multicolumn{3}{|c|}{ 3,000 ppm } & \multicolumn{3}{|c|}{10,000 ppm } \\
\hline & $\begin{array}{c}\text { Av. Wt. } \\
\text { (g) }\end{array}$ & $\begin{array}{l}\text { No. of } \\
\text { Litters }\end{array}$ & $\begin{array}{c}\text { Av. Wt. } \\
\text { (g) }\end{array}$ & $\begin{array}{l}\text { Wt. (\% of } \\
\text { Controls) }\end{array}$ & $\begin{array}{l}\text { No. of } \\
\text { Litters }\end{array}$ & $\begin{array}{c}\text { Av. Wt. } \\
\text { (g) }\end{array}$ & $\begin{array}{l}\text { Wt. (\% of } \\
\text { Controls) }\end{array}$ & $\begin{array}{l}\text { No. of } \\
\text { Litters }\end{array}$ & $\begin{array}{l}\text { Av. Wt. } \\
\text { (g) }\end{array}$ & $\begin{array}{l}\text { Wt. (\% of } \\
\text { Controls) }\end{array}$ & $\begin{array}{l}\text { No. of } \\
\text { Litters }\end{array}$ \\
\hline 1 & 56.2 & 30 & 56.2 & 100 & 25 & 56.0 & 100 & 25 & 51.1 & 91 & 30 \\
\hline 8 & 85.5 & 30 & 85.1 & 100 & 25 & 84.2 & 99 & 25 & 74.5 & 87 & 30 \\
\hline 15 & 130.9 & 30 & 127.4 & 97 & 25 & 125.2 & 96 & 25 & 109.6 & 84 & 30 \\
\hline 22 & 177.3 & 30 & 173.5 & 98 & 25 & 170.8 & 96 & 25 & 151.7 & 86 & 30 \\
\hline 29 & 224.2 & 30 & 218.2 & 97 & 25 & 217.2 & 97 & 25 & 194.5 & 87 & 30 \\
\hline 36 & 270.4 & 30 & 262.5 & 97 & 25 & 260.8 & 96 & 25 & 236.9 & 88 & 30 \\
\hline 43 & 304.2 & 30 & 295.3 & 97 & 25 & 297.4 & 98 & 25 & 272.0 & 89 & 30 \\
\hline 50 & 332.6 & 30 & 324.4 & 98 & 25 & 324.6 & 98 & 25 & 299.4 & 90 & 30 \\
\hline 57 & 350.4 & 30 & 342.7 & 98 & 25 & 343.4 & 98 & 25 & 321.3 & 92 & 30 \\
\hline 64 & 368.3 & 30 & 361.0 & 98 & 25 & 358.8 & 97 & 25 & 337.4 & 92 & 30 \\
\hline 71 & 382.9 & 30 & 372.8 & 97 & 25 & 370.9 & 97 & 25 & 351.7 & 92 & 30 \\
\hline 78 & 395.7 & 30 & 387.2 & 98 & 25 & 384.1 & 97 & 25 & 364.4 & 92 & 30 \\
\hline 85 & 407.4 & 30 & 398.2 & 98 & 25 & 394.7 & 97 & 25 & 374.1 & 92 & 30 \\
\hline 92 & 416.6 & 30 & 408.0 & 98 & 25 & 404.1 & 97 & 25 & 383.1 & 92 & 30 \\
\hline 120 & 443.8 & $29^{a}$ & 429.8 & 97 & 25 & 428.4 & 97 & 25 & 401.2 & 90 & $28^{\mathrm{a}}$ \\
\hline 148 & 469.2 & 29 & 447.8 & 95 & 25 & 453.6 & 97 & 25 & 423.9 & 90 & 28 \\
\hline 176 & 482.1 & 29 & 467.6 & 97 & 25 & 467.9 & 97 & 25 & 439.1 & 91 & 28 \\
\hline 204 & 502.2 & 29 & 490.0 & 98 & 25 & 481.8 & 96 & 25 & 458.2 & 91 & 28 \\
\hline 232 & 511.4 & 29 & 495.2 & 97 & 25 & 496.0 & 97 & 25 & 462.8 & 91 & 28 \\
\hline 260 & 522.1 & 29 & 512.2 & 98 & 25 & 509.5 & 98 & 25 & 479.5 & 92 & 28 \\
\hline 288 & 538.5 & 29 & 524.4 & 97 & 25 & 518.9 & 97 & 25 & 489.0 & 91 & 28 \\
\hline 316 & 548.5 & 29 & 533.2 & 97 & 25 & 529.2 & 97 & 25 & 495.1 & 90 & 28 \\
\hline 344 & 555.0 & 29 & 538.3 & 97 & 25 & 541.8 & 98 & 25 & 502.8 & 91 & 28 \\
\hline 372 & 570.2 & 29 & 551.9 & 97 & 25 & 557.0 & 98 & 25 & 521.0 & 91 & 28 \\
\hline 400 & 579.2 & 29 & 561.6 & 97 & 25 & 563.0 & 97 & 25 & 526.5 & 91 & 28 \\
\hline 428 & 585.1 & 29 & 557.5 & 96 & 25 & 576.1 & 99 & 25 & 531.8 & 91 & 28 \\
\hline 456 & 594.5 & 29 & 570.4 & 96 & 25 & 587.9 & 99 & 25 & 536.8 & 90 & 28 \\
\hline 484 & 606.6 & 29 & 575.2 & 95 & 24 & 592.7 & 98 & 25 & 543.1 & 90 & 28 \\
\hline 512 & 610.7 & 29 & 581.6 & 95 & 24 & 598.1 & 98 & 25 & 546.2 & 89 & 28 \\
\hline 540 & 608.6 & 29 & 573.9 & 94 & 24 & 598.7 & 98 & 25 & 543.0 & 89 & 28 \\
\hline 568 & 613.1 & 29 & 577.9 & 94 & 24 & 597.7 & 98 & 25 & 537.9 & 88 & 28 \\
\hline 596 & 617.6 & 29 & 590.5 & 96 & 24 & 599.1 & 97 & 23 & 538.6 & 87 & 27 \\
\hline 624 & 613.2 & 29 & 584.4 & 95 & 23 & 594.6 & 97 & 23 & 533.1 & 87 & 27 \\
\hline 652 & 601.5 & 28 & 584.7 & 97 & 23 & 592.9 & 99 & 22 & 528.6 & 88 & 25 \\
\hline 680 & 590.3 & 26 & 572.0 & 97 & 23 & 590.8 & 100 & 21 & 510.1 & 86 & 25 \\
\hline 708 & 592.2 & 23 & 547.4 & 92 & 20 & 584.5 & 99 & 21 & 486.7 & 82 & 24 \\
\hline EOS & 603.4 & 21 & 556.3 & 92 & 19 & 575.9 & 96 & 18 & 480.3 & 80 & 23 \\
\hline
\end{tabular}

EOS $=$ end of study.

${ }^{\text {a}}$ Fourteen-week interim necropsy occurred between this day and the previous scheduled weigh day. 
Table 10. Mean Body Weights and Survival of Female Rats in the Perinatal and Two-year Feed Study of 2-Hydroxy-4-methoxybenzophenone

\begin{tabular}{|c|c|c|c|c|c|c|c|c|c|c|c|}
\hline \multirow[b]{2}{*}{ Day } & \multicolumn{2}{|c|}{ O ppm } & \multicolumn{3}{|c|}{1,000 ppm } & \multicolumn{3}{|c|}{$3,000 \mathrm{ppm}$} & \multicolumn{3}{|c|}{10,000 ppm } \\
\hline & $\begin{array}{c}\text { Av. Wt. } \\
\text { (g) }\end{array}$ & $\begin{array}{l}\text { No. of } \\
\text { Litters }\end{array}$ & $\begin{array}{c}\text { Av. Wt. } \\
\text { (g) }\end{array}$ & $\begin{array}{l}\text { Wt. (\% of } \\
\text { Controls) }\end{array}$ & $\begin{array}{l}\text { No. of } \\
\text { Litters }\end{array}$ & $\begin{array}{l}\text { Av. Wt. } \\
\text { (g) }\end{array}$ & $\begin{array}{l}\text { Wt. (\% of } \\
\text { Controls) }\end{array}$ & $\begin{array}{l}\text { No. of } \\
\text { Litters }\end{array}$ & $\begin{array}{c}\text { Av. Wt. } \\
\text { (g) }\end{array}$ & $\begin{array}{l}\text { Wt. (\% of } \\
\text { Controls) }\end{array}$ & $\begin{array}{l}\text { No. of } \\
\text { Litters }\end{array}$ \\
\hline 1 & 53.7 & 30 & 54.5 & 102 & 25 & 55.1 & 103 & 25 & 49.4 & 92 & 30 \\
\hline 8 & 80.5 & 30 & 81.0 & 101 & 25 & 80.5 & 100 & 25 & 71.6 & 89 & 30 \\
\hline 15 & 115.3 & 30 & 114.5 & 99 & 25 & 114.0 & 99 & 25 & 100.5 & 87 & 30 \\
\hline 22 & 145.7 & 30 & 145.0 & 100 & 25 & 143.0 & 98 & 25 & 128.8 & 88 & 30 \\
\hline 29 & 162.6 & 30 & 165.3 & 102 & 25 & 162.8 & 100 & 25 & 151.0 & 93 & 30 \\
\hline 36 & 182.3 & 30 & 183.9 & 101 & 25 & 180.3 & 99 & 25 & 168.8 & 93 & 30 \\
\hline 43 & 199.9 & 30 & 198.5 & 99 & 25 & 195.0 & 98 & 25 & 181.6 & 91 & 30 \\
\hline 50 & 212.7 & 30 & 212.0 & 100 & 25 & 209.1 & 98 & 25 & 193.6 & 91 & 30 \\
\hline 57 & 221.0 & 30 & 223.3 & 101 & 25 & 216.7 & 98 & 25 & 200.4 & 91 & 30 \\
\hline 64 & 229.7 & 30 & 229.8 & 100 & 25 & 225.1 & 98 & 25 & 207.8 & 91 & 30 \\
\hline 71 & 235.0 & 30 & 236.2 & 101 & 25 & 230.7 & 98 & 25 & 213.5 & 91 & 30 \\
\hline 78 & 240.2 & 30 & 239.9 & 100 & 25 & 234.4 & 98 & 25 & 218.0 & 91 & 30 \\
\hline 85 & 246.0 & 30 & 246.9 & 100 & 25 & 238.8 & 97 & 25 & 223.5 & 91 & 30 \\
\hline 92 & 251.2 & 30 & 250.5 & 100 & 25 & 243.8 & 97 & 25 & 227.9 & 91 & 30 \\
\hline 120 & 266.0 & $29^{\mathrm{a}}$ & 262.2 & 99 & 25 & 254.3 & 97 & 25 & 237.9 & 89 & $29^{\mathrm{a}}$ \\
\hline 148 & 276.1 & 29 & 275.0 & 100 & 25 & 269.3 & 98 & 25 & 245.8 & 89 & 29 \\
\hline 176 & 282.7 & 29 & 280.4 & 99 & 25 & 273.8 & 97 & 25 & 252.4 & 89 & 29 \\
\hline 204 & 293.3 & 29 & 283.6 & 97 & 25 & 278.9 & 95 & 25 & 257.4 & 88 & 29 \\
\hline 232 & 300.6 & 29 & 291.0 & 97 & 25 & 286.7 & 95 & 25 & 260.8 & 87 & 29 \\
\hline 260 & 306.7 & 29 & 296.6 & 97 & 25 & 291.3 & 95 & 25 & 264.7 & 86 & 29 \\
\hline 288 & 311.5 & 29 & 300.5 & 97 & 25 & 294.2 & 94 & 25 & 267.6 & 86 & 29 \\
\hline 316 & 316.7 & 29 & 303.0 & 96 & 25 & 295.8 & 93 & 25 & 267.0 & 84 & 29 \\
\hline 344 & 323.2 & 29 & 307.9 & 95 & 25 & 301.5 & 93 & 25 & 269.9 & 84 & 29 \\
\hline 372 & 333.3 & 29 & 312.4 & 94 & 25 & 305.7 & 92 & 25 & 275.6 & 83 & 29 \\
\hline 400 & 342.0 & 29 & 318.9 & 93 & 25 & 310.4 & 91 & 25 & 279.1 & 82 & 28 \\
\hline 428 & 339.2 & 28 & 321.5 & 95 & 25 & 313.9 & 93 & 25 & 281.7 & 83 & 28 \\
\hline 456 & 348.1 & 28 & 326.9 & 94 & 25 & 318.4 & 92 & 25 & 286.5 & 82 & 28 \\
\hline 484 & 355.6 & 28 & 329.0 & 93 & 25 & 322.6 & 91 & 25 & 286.6 & 81 & 27 \\
\hline 512 & 358.6 & 28 & 332.4 & 93 & 25 & 325.6 & 91 & 25 & 287.8 & 80 & 27 \\
\hline 540 & 368.4 & 28 & 334.0 & 91 & 24 & 327.0 & 89 & 25 & 292.6 & 79 & 27 \\
\hline 568 & 373.4 & 27 & 341.0 & 91 & 24 & 331.0 & 89 & 25 & 297.5 & 80 & 27 \\
\hline 596 & 378.2 & 27 & 348.0 & 92 & 24 & 333.6 & 88 & 25 & 295.9 & 78 & 27 \\
\hline 624 & 386.2 & 27 & 351.0 & 91 & 24 & 336.6 & 87 & 25 & 303.1 & 79 & 26 \\
\hline 652 & 380.1 & 24 & 352.0 & 93 & 24 & 330.2 & 87 & 25 & 311.1 & 82 & 26 \\
\hline 680 & 386.1 & 23 & 359.0 & 93 & 23 & 335.8 & 87 & 25 & 307.0 & 80 & 24 \\
\hline 708 & 384.0 & 23 & 371.1 & 97 & 23 & 335.9 & 88 & 25 & 306.9 & 80 & 21 \\
\hline EOS & 401.4 & 23 & 367.1 & 92 & 22 & 346.0 & 87 & 25 & 303.7 & 76 & 19 \\
\hline
\end{tabular}

EOS $=$ end of study.

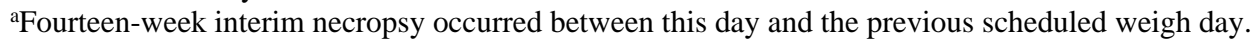



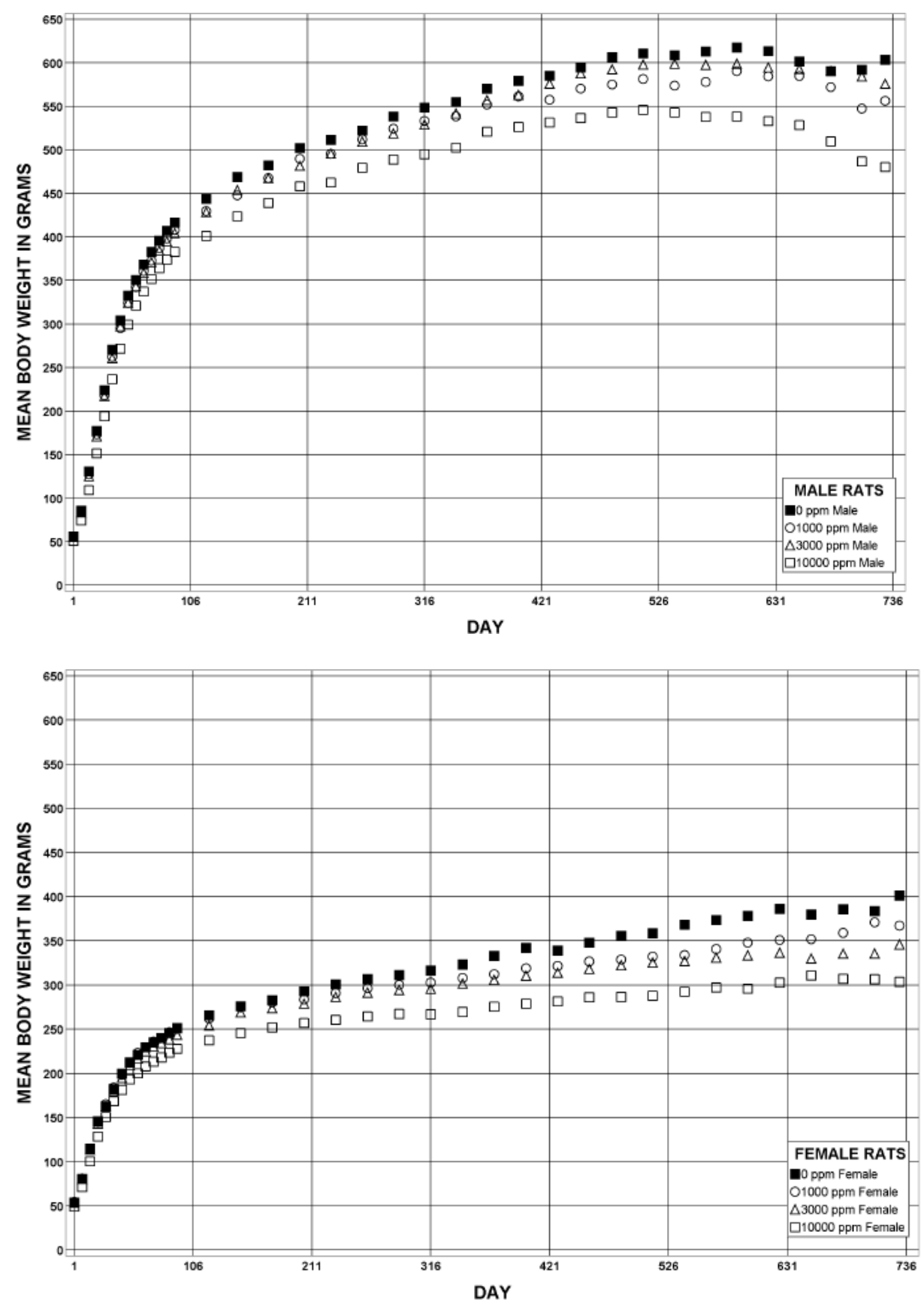

Figure 4. Growth Curves for Rats Exposed to 2-Hydroxy-4-methoxybenzophenone in Feed for Two Years 


\section{Pathology and Statistical Analyses}

This section describes the statistically significant or biologically noteworthy changes in the incidence of neoplasms and nonneoplastic lesions of the brain and spinal cord, thyroid gland, uterus, adrenal cortex, testis, pancreas, and mammary gland. Summaries of the incidence of neoplasms and nonneoplastic lesions and statistical analyses of primary neoplasms are presented in Appendix $\mathrm{H}$.

Brain: Malignant meningiomas occurred only in treated animals, with incidences in males at the end of the 2-year study of 0/50, 1/50,3/50, and 0/50 (Table 11; Appendix $\mathrm{H}$ ). In addition, there was one malignant meningioma in the spinal cord of a 3,000 ppm animal (which did not have a meningioma in the brain). The spinal cord was examined only when an animal displayed clinical neurological signs, so the actual incidence of meningiomas in the spinal cord may be

underrepresented. In females, there was one malignant meningioma (in the brain of a 3,000 ppm animal).

Malignant meningiomas in the brain varied somewhat in appearance, both between neoplasms and within a single neoplasm. All of the neoplasms were poorly delineated, cellular neoplasms that were either invading into the brain parenchyma directly, or following along the meninges and vessels deep into the brain (Figure 5 and Figure 6). One neoplasm also involved the pituitary gland, and another involved the trigeminal ganglion. Within a single neoplasm, there was some variability in cell size and shape, with some of the neoplasms displaying more anisocytosis and pleomorphism than others. In some areas, neoplasms had a more sarcomatous appearance, consisting of interlacing bundles of spindle-shaped cells with indistinct cell borders. Cells in these areas tended to have indistinct cell borders, eosinophilic fibrillary cytoplasm, and oval vesicular nuclei. Other areas were characterized by sheets of cells, with round, open-faced nuclei and vacuolated cytoplasm (Figure 5 and Figure 6). In still other areas, the cells were arranged in whorls; these areas tended to have elongated nuclei and indistinct cell borders. Within some neoplasms, there were focal areas of hemorrhage and coagulative necrosis. Mitotic figures were not common in most areas of the lesions, but 1-2 per high power field could be found in some sections of a couple of the tumors. In the one case involving the spinal cord, the neoplasm appeared to be based within the meninges, with infiltration into the underlying spinal cord and spinal nerves. The neoplastic cells within the meninges appeared more epithelial than sarcomatous, although both types were present. 
Table 11. Incidences of Neoplasms of the Brain in Male Rats in the Perinatal and Two-year Feed Study of 2-Hydroxy-4-methoxybenzophenone

\begin{tabular}{lcccc}
\hline & $\mathbf{0 ~} \mathbf{p p m}$ & $\mathbf{1 , 0 0 0} \mathbf{~ p p m}$ & $\mathbf{3 , 0 0 0} \mathbf{~ p p m}$ & $\mathbf{1 0 , 0 0 0} \mathbf{~ p p m}$ \\
\hline $\mathbf{n}^{\mathrm{a}}$ & 50 & 50 & 50 & 50 \\
\hline Meningioma, Malignant $^{\mathrm{b}}$ & & & & \\
Overall rate $^{\mathrm{c}}$ & $0 / 50(0 \%)$ & $1 / 50(2 \%)$ & $3 / 50(6 \%)$ & $0 / 50(0 \%)$ \\
Rate per litters $^{\mathrm{d}}$ & $0 / 29(0 \%)$ & $1 / 25(4 \%)$ & $2 / 25(8 \%)$ & $0 / 28(0 \%)$ \\
Adjusted rate $^{\mathrm{e}}$ & $0 \%$ & $2.3 \%$ & $7 \%$ & $0 \%$ \\
Terminal rate $^{\mathrm{f}}$ & $0 / 30(0 \%)$ & $0 / 29(0 \%)$ & $1 / 24(4 \%)$ & $0 / 33(0 \%)$ \\
First incidence (days) & - & 162 & 430 & - \\
Rao-Scott-adjusted Poly-3 test $^{\mathrm{g}}$ & $\mathrm{p}=0.583 \mathrm{~N}$ & $\mathrm{p}=0.706$ & $\mathrm{p}=0.291$ & $(\mathrm{e})$ \\
\hline
\end{tabular}

(e) = value of statistic could not be computed.

${ }^{a}$ Number of animals with tissue examined microscopically.

${ }^{b}$ Historical control incidence for all routes of 2-year studies: 0/340.

${ }^{c}$ Number of animals with neoplasm per number of animals necropsied.

${ }^{\mathrm{d} N u m b e r}$ of litters with neoplasm-bearing animals per number of litters examined at site.

ePoly-3 estimated neoplasm incidence after adjustment for intercurrent mortality.

fObserved incidence at study termination.

${ }^{g}$ Beneath the control incidence is the $\mathrm{p}$ value associated with the trend test. Beneath the exposed group incidence are the $\mathrm{p}$ values corresponding to pairwise comparisons between the control group and that exposed group. The Rao-Scott test adjusts the Poly-3 test (which accounts for differential mortality in animals that do not reach terminal euthanasia) for within-litter correlation. A negative trend or a lower incidence in an exposure group is indicated by $\mathrm{N}$. 
A)

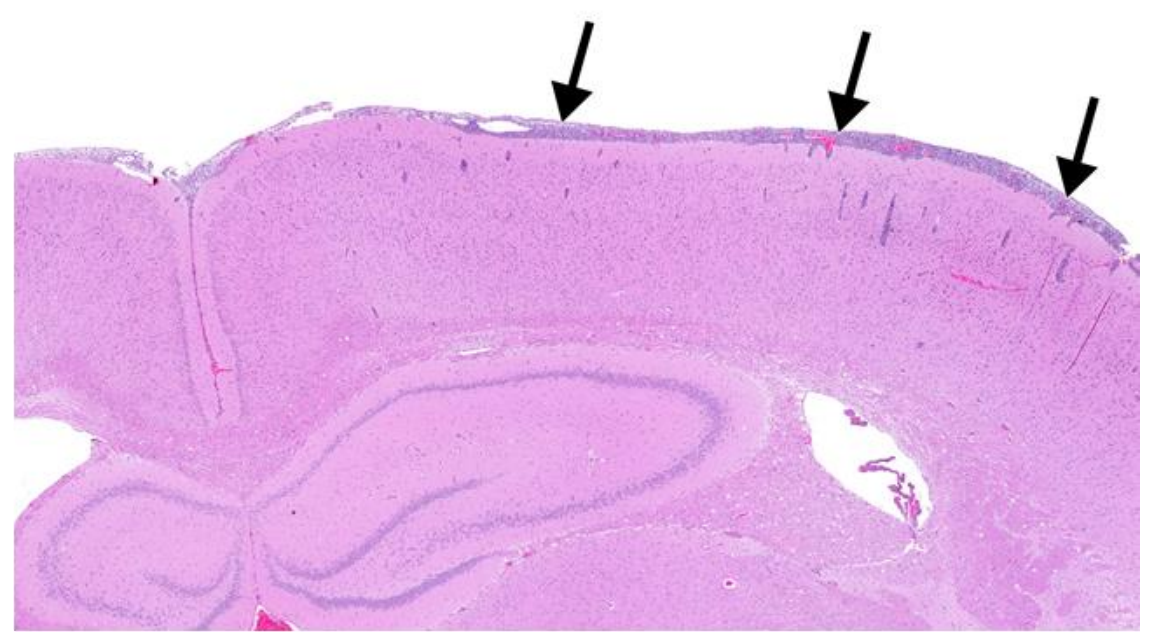

B)

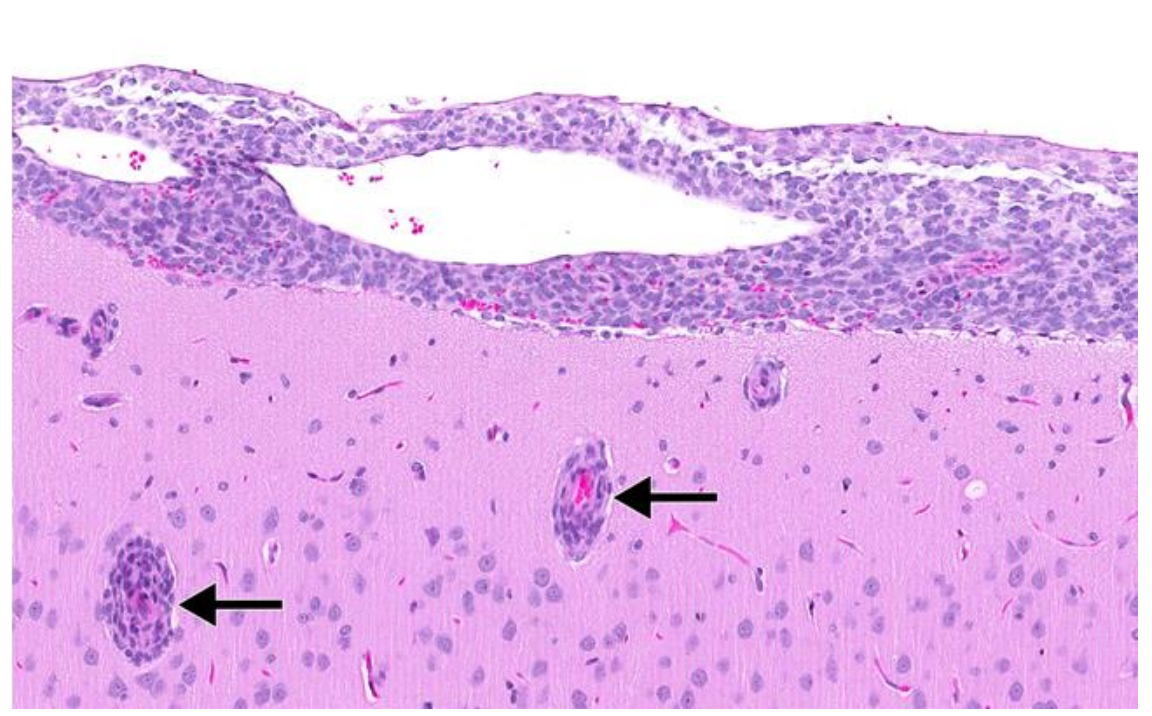

Figure 5. Malignant Meningioma in the Brain of a Male Sprague Dawley Rat Exposed to 1,000 ppm 2-Hydroxy-4-methoxybenzophenone for Two Years (H\&E)

This animal was humanely euthanized on study day 162. A) Widespread thickening of the meninges can be observed and is due to a highly cellular neoplasm (arrows). B) Higher magnification of panel A shows closely packed cells with oval nuclei and indistinct borders. The cells contain wispy, lightly eosinophilic cytoplasm and surround small vessels within the brain (arrows). 
A)

B)
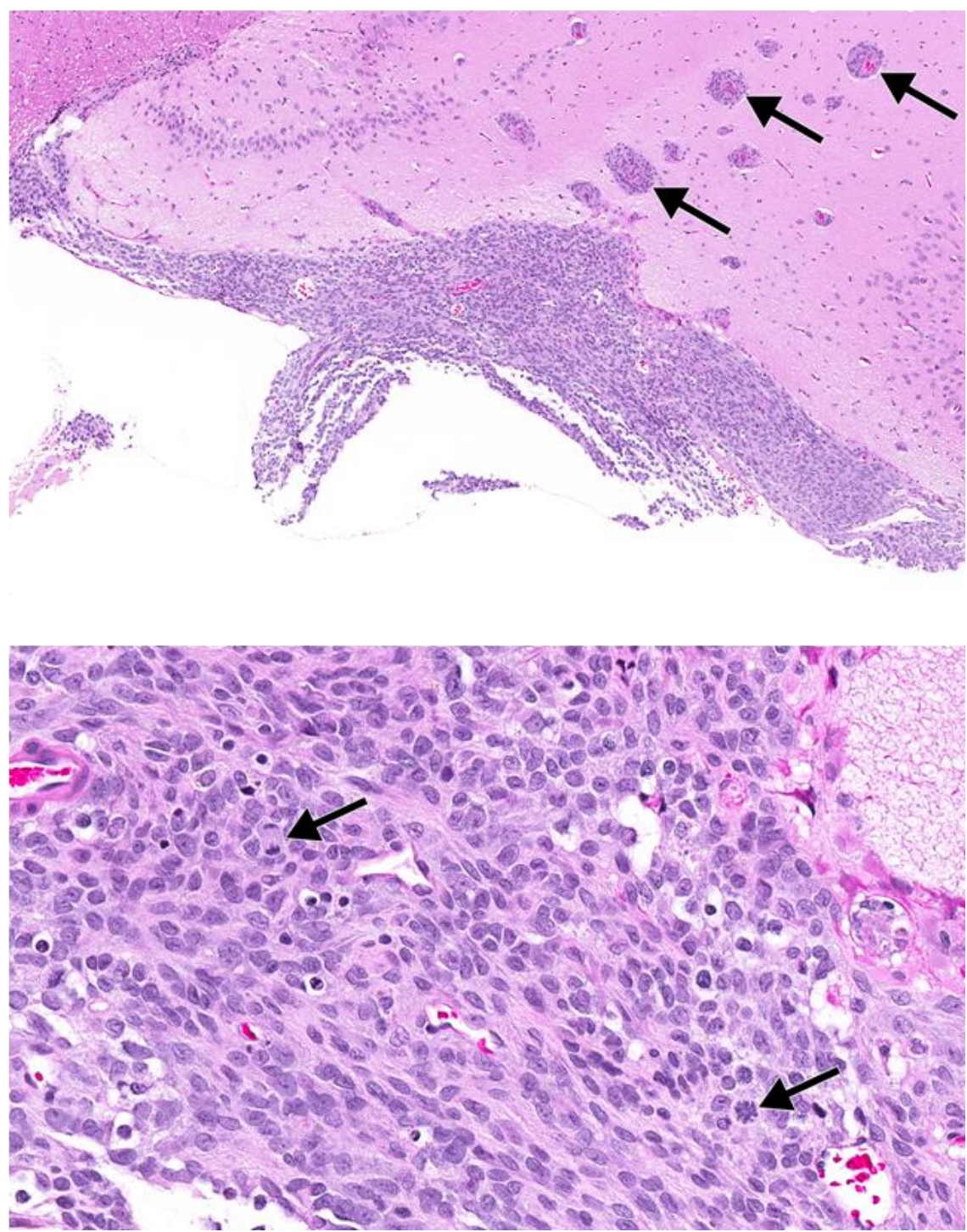

Figure 6. Malignant Meningioma in the Brain of a Male Sprague Dawley Rat Exposed to 3,000 ppm 2-Hydroxy-4-methoxybenzophenone for Two Years (H\&E)

A) Another example of a malignant meningioma, this one is from a male Sprague Dawley rat exposed to 3,000 ppm 2H4MBP. As in Figure 5, within the meninges is a dense proliferation of cells that can be seen surrounding blood vessels deep within the brain (arrows). B) A higher magnification of the neoplasm in panel A shows mitotic figures (arrows) among the neoplastic cells. 
Thyroid gland: The incidence of C-cell adenomas in 3,000 ppm females was significantly greater than that in the control group at the end of the 2-year study (Table 12; Appendix H). Only one female rat, in the 10,000 ppm group, had bilateral C-cell adenomas; the rest were unilateral lesions. One animal (in the 1,000 ppm group) had both a C-cell adenoma and a C-cell carcinoma (in the opposite gland) but otherwise, all C-cell lesions occurred in unique animals. The incidences of C-cell carcinomas and hyperplasia in exposed groups of female rats were similar to those in the control group. There was no significant exposure concentration-related difference in the incidence of C-cell adenomas in male rats $(0 \mathrm{ppm}, 7 / 50 ; 1,000 \mathrm{ppm}, 10 / 50 ; 3,000 \mathrm{ppm}, 8 / 50$; $10,000 \mathrm{ppm} 8 / 50$ ) when compared to the control group. C-cell adenomas were discrete masses of C-cells, typically larger than five thyroid gland follicles in diameter (Figure 7). The neoplasms caused some compression of adjacent follicles, but did not invade the thyroid gland capsule, and were composed of round-to-oval cells with pale cytoplasm and round nuclei. The cells were arranged in nests and clusters that were separated by a delicate fibrovascular stroma (Figure 7). 
Table 12. Incidences of Neoplastic and Nonneoplastic Lesions of the Thyroid Gland in Female Rats in the Perinatal and Two-year Feed Study of 2-Hydroxy-4-methoxybenzophenone

\begin{tabular}{lcccc}
\hline & $\mathbf{0 ~ p p m}$ & $\mathbf{1 , 0 0 0} \mathbf{~ p p m}$ & $\mathbf{3 , 0 0 0} \mathbf{~ p p m}$ & $\mathbf{1 0 , 0 0 0} \mathbf{~ p p m}$ \\
\hline $\mathbf{n}^{\mathbf{a}}$ & 50 & 50 & 50 & 50 \\
\hline C-cell, Hyperplasia $^{\mathrm{b}}$ & $11(2.0) \mathrm{c}$ & $11(2.4)$ & $9(1.9)$ & $9(2.4)$ \\
C-cell, Adenoma $^{\mathrm{d}}$ & & & & \\
Overall rate $^{\mathrm{e}}$ & $5 / 50(10 \%)$ & $11 / 50(22 \%)$ & $17 / 50(34 \%)$ & $10 / 50(20 \%)$ \\
Rate per litters $^{\mathrm{f}}$ & $5 / 29(17 \%)$ & $10 / 25(40 \%)$ & $15 / 25(60 \%)$ & $9 / 29(31 \%)$ \\
Adjusted rate $^{\mathrm{g}}$ & $12.4 \%$ & $25.1 \%$ & $37.2 \%$ & $24.3 \%$ \\
Terminal rate $^{\mathrm{h}}$ & $3 / 30(10 \%)$ & $9 / 33(27 \%)$ & $12 / 34(35 \%)$ & $6 / 26(23 \%)$ \\
First incidence (days) & 582 & 529 & 540 & 581 \\
Rao-Scott-adjusted Poly-3 test $^{\mathrm{i}}$ & $\mathrm{p}=0.326$ & $\mathrm{p}=0.108$ & $\mathrm{p}=0.008$ & $\mathrm{p}=0.128$ \\
C-cell, Carcinoma $^{\mathrm{j}}$ & & & & \\
Overall rate & $1 / 50(2 \%)$ & $1 / 50(2 \%)$ & $0 / 50(0 \%)$ & $1 / 50(2 \%)$ \\
Rate per litter & $1 / 29(3 \%)$ & $1 / 25(4 \%)$ & $0 / 25(0 \%)$ & $1 / 29(3 \%)$ \\
Adjusted rate & $2.6 \%$ & $2.3 \%$ & $0 \%$ & $2.5 \%$ \\
Terminal rate $_{\text {First incidence (days) }}$ & $1 / 30(3 \%)$ & $1 / 33(3 \%)$ & $0 / 34(0 \%)$ & $1 / 26(4 \%)$ \\
Rao-Scott-adjusted Poly-3 test $^{2}$ & $730(\mathrm{~T})$ & $730(\mathrm{~T})$ & $-{ }^{\mathrm{k}}$ & $730(\mathrm{~T})$ \\
\hline
\end{tabular}

$(\mathrm{T})=$ terminal euthanasia; $(\mathrm{n})=$ no statistical test run.

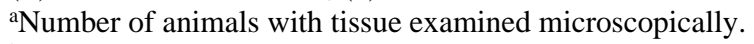

${ }^{b}$ Number of animals with lesion.

${ }^{\mathrm{c}}$ Average severity grade of lesions in affected animals: $1=$ minimal, $2=$ mild, $3=$ moderate, $4=$ marked.

${ }^{\mathrm{d}}$ Historical control incidence for all routes of 2-year studies (mean \pm standard deviation): $38 / 339(11.85 \% \pm 7.01 \%)$; range: $4 \%$ to $22 \%$.

${ }^{\mathrm{e}}$ Number of animals with neoplasm per number of animals necropsied.

${ }^{\mathrm{f} N u m b e r}$ of litters with neoplasm-bearing animals per number of litters examined at site.

'Poly-3 estimated neoplasm incidence after adjustment for intercurrent mortality.

hobserved incidence at study termination.

${ }^{i}$ Beneath the control incidence is the $p$ value associated with the trend test. Beneath the exposed group incidence are the $p$ values corresponding to pairwise comparisons between the control group and that exposed group. The Rao-Scott test adjusts the Poly-3 test (which accounts for differential mortality in animals that do not reach terminal euthanasia) for within-litter correlation. A negative trend or a lower incidence in an exposure group is indicated by $\mathrm{N}$.

${ }^{\mathrm{j} H i s t o r i c a l}$ control incidence: $4 / 339(1.33 \% \pm 1.63 \%)$; range: $0 \%$ to $4 \%$.

kNot applicable; no neoplasms in animal group. 
A)

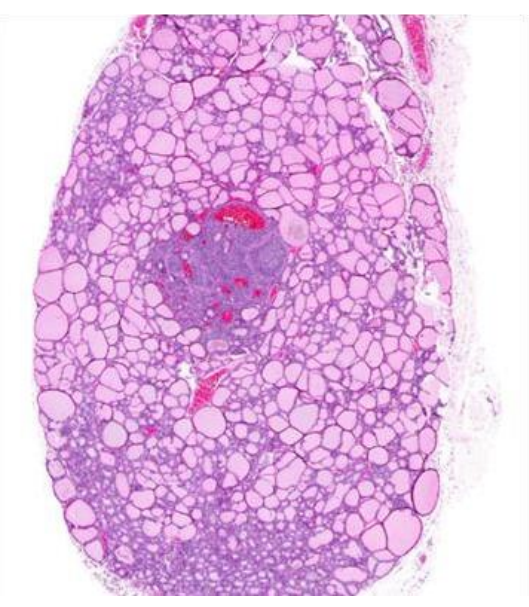

B)

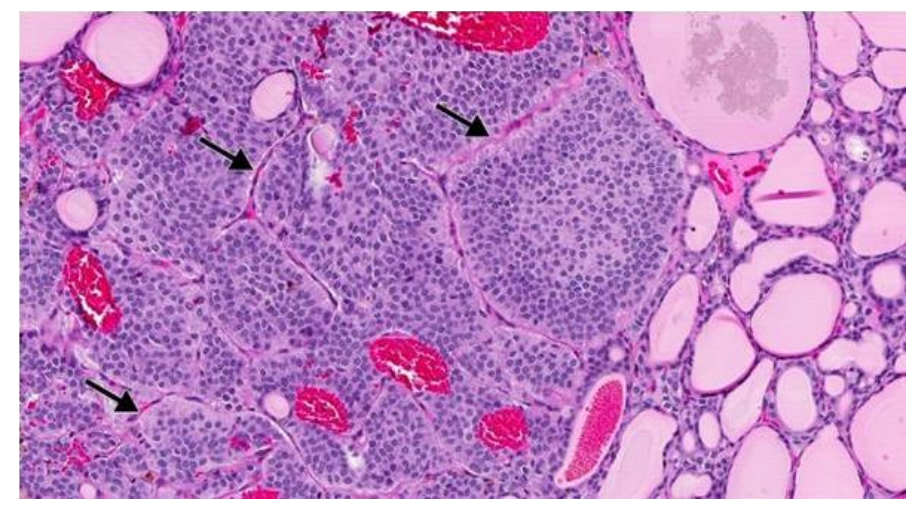

Figure 7. C-cell Adenoma in the Thyroid Gland of a Female Sprague Dawley Rat Exposed to 3,000 ppm 2-Hydroxy-4-methoxybenzophenone for Two Years (H\&E)

A) The C-cell adenoma is a discrete mass of several nests, or clusters, of cells separated by a delicate fibrovascular stroma. B) Higher magnification of the C-cell adenoma; at this magnification, the fibrovascular stroma that separates the nests of C-cells is more apparent (arrows). The cells that make up the adenoma have round nuclei and pale staining cytoplasm.

Uterus: At 2 years, a significantly increased incidence of stromal polyp occurred in 3,000 ppm females when compared to the control group (Table 13; Appendix H). Incidences of stromal sarcoma, which can occasionally arise within stromal polyps, ${ }^{103}$ were not significantly increased relative to the control group in exposed females, and only occurred in the 1,000 and 3,000 ppm groups (Table 13; Appendix H). Stromal polyps typically were sessile or pedunculated masses of loosely organized stromal cells observed within the uterine lumen (Figure 8). Blood vessels and variable numbers of glands could be found within the polyps, which were covered by a single layer of cuboidal or columnar epithelium. A few polyps were partially lined by squamous epithelium; this was observed when the polyp arose in areas of moderate to marked squamous metaplasia of the uterus. Stromal sarcomas were poorly demarcated, highly cellular neoplasms composed of pleomorphic spindle cells with indistinct borders (Figure 9). If a stromal sarcoma arises within a stromal polyp, only the stromal sarcoma is diagnosed. In the two cases in which both were diagnosed in the same rat, the polyp and the sarcoma were considered separate, unique neoplasms.

Compared to the control group, there was a significantly increased incidence of atypical endometrium hyperplasia of the uterus in 3,000 ppm females (Table 13; Appendix H). Atypical hyperplasia is considered a preneoplastic lesion of the uterine epithelium, ${ }^{51}$ but 3,000 ppm females had a significantly decreased incidence of adenocarcinoma of the uterus (Table 13; Appendix H). Atypical hyperplasia involved both the endometrial glands and the surface epithelium (Figure 10). Affected endometrial glands were characterized by clusters of enlarged glands lined by disorganized, stratified, large epithelial cells displaying pleomorphism and anisokaryosis; thickened papillary projections and infoldings often contained clear vacuoles within the cells or spaces reminiscent of glandular lumen formation (Figure 10). Atypical hyperplasia affecting the surface epithelium consisted of branching, frond-like projections of epithelial cells on a fibrovascular stalk extending into the uterine lumen. 
Table 13. Incidences of Neoplastic and Nonneoplastic Lesions of the Uterus in Female Rats in the Perinatal and Two-year Feed Study of 2-Hydroxy-4-methoxybenzophenone

\begin{tabular}{|c|c|c|c|c|}
\hline & O ppm & 1,000 ppm & $3,000 \mathrm{ppm}$ & 10,000 ppm \\
\hline $\mathbf{n}^{\mathrm{a}}$ & 50 & 50 & 50 & 50 \\
\hline Endometrium, Atypical Hyperplasia ${ }^{\mathrm{b}}$ & $9(2.0)^{\mathrm{c}}$ & $14(1.5)$ & $19 *(1.4)$ & $14(2.1)$ \\
\hline \multicolumn{5}{|l|}{ Adenocarcinoma $^{\mathrm{d}}$} \\
\hline Overall rate ${ }^{\mathrm{e}}$ & $5 / 50(10 \%)$ & $3 / 50(6 \%)$ & $0 / 50(0 \%)$ & $4 / 50(8 \%)$ \\
\hline Rate per litters ${ }^{\mathrm{f}}$ & $5 / 29(17 \%)$ & $3 / 25(12 \%)$ & $0 / 25(0 \%)$ & $4 / 29(14 \%)$ \\
\hline Adjusted rate ${ }^{\mathrm{g}}$ & $12.6 \%$ & $7.0 \%$ & $0.0 \%$ & $9.9 \%$ \\
\hline Terminal rate ${ }^{\mathrm{h}}$ & $4 / 30(13 \%)$ & $3 / 33(9 \%)$ & $0 / 34(0 \%)$ & $4 / 26(15 \%)$ \\
\hline First incidence (days) & 644 & $730(\mathrm{~T})$ & $-{ }^{\mathrm{i}}$ & $730(\mathrm{~T})$ \\
\hline Rao-Scott-adjusted Poly-3 test ${ }^{\mathrm{j}}$ & $\mathrm{p}=0.555$ & $\mathrm{p}=0.325 \mathrm{~N}$ & $\mathrm{p}=0.036 \mathrm{~N}$ & $\mathrm{p}=0.486 \mathrm{~N}$ \\
\hline Stromal Polyp, Multiple & 1 & 3 & 3 & 0 \\
\hline \multicolumn{5}{|l|}{ Stromal Polyp (includes multiple) ${ }^{\mathrm{k}}$} \\
\hline Overall rate & $8 / 50(16 \%)$ & $15 / 50(30 \%)$ & $18 / 50(36 \%)$ & $10 / 50(20 \%)$ \\
\hline Rate per litters & $8 / 29(28 \%)$ & $12 / 25(48 \%)$ & $16 / 25(64 \%)$ & $10 / 29(34 \%)$ \\
\hline Adjusted rate & $20.4 \%$ & $33.9 \%$ & $39.9 \%$ & $24.4 \%$ \\
\hline Terminal rate & $8 / 30(27 \%)$ & $12 / 33(36 \%)$ & $14 / 34(41 \%)$ & $7 / 26(27 \%)$ \\
\hline First incidence (days) & $730(\mathrm{~T})$ & 529 & 681 & 599 \\
\hline Rao-Scott-adjusted Poly-3 test & $\mathrm{p}=0.415 \mathrm{~N}$ & $\mathrm{p}=0.132$ & $\mathrm{p}=0.049$ & $\mathrm{p}=0.424$ \\
\hline Stromal Sarcoma & 0 & 1 & 2 & 0 \\
\hline \multicolumn{5}{|c|}{ Stromal Polyp or Stromal Sarcoma (Combined) $)^{1}$} \\
\hline Overall rate & $8 / 50(16 \%)$ & $15 / 50(30 \%)$ & $19 / 50(38 \%)$ & $10 / 50(20 \%)$ \\
\hline Rate per litters & $8 / 29(28 \%)$ & $12 / 25(48 \%)$ & $17 / 25(68 \%)$ & $10 / 29(34 \%)$ \\
\hline Adjusted rate & $20.4 \%$ & $33.9 \%$ & $41.5 \%$ & $24.4 \%$ \\
\hline Terminal rate & $8 / 30(27 \%)$ & $12 / 33(36 \%)$ & $14 / 34(41 \%)$ & $7 / 26(27 \%)$ \\
\hline First incidence (days) & $730(\mathrm{~T})$ & 529 & 525 & 599 \\
\hline Rao-Scott-adjusted Poly-3 test & $\mathrm{p}=0.409 \mathrm{~N}$ & $\mathrm{p}=0.132$ & $\mathrm{p}=0.035$ & $\mathrm{p}=0.424$ \\
\hline
\end{tabular}

*Significantly different $(\mathrm{p} \leq 0.05)$ from the control group by the Rao-Scott-adjusted Poly-3 test.

$(\mathrm{T})=$ terminal euthanasia.

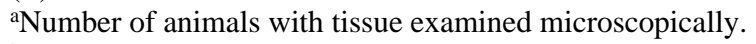

${ }^{b}$ Number of animals with lesion.

${ }^{\mathrm{c}}$ Average severity grade of lesions in affected animals: $1=$ minimal, $2=$ mild, $3=$ moderate, $4=$ marked.

${ }^{\mathrm{d}}$ Historical control incidence for all routes of 2-year studies (mean \pm standard deviation): $11 / 150$ (7.33\% $\pm 4.62 \%$ ); range: $2 \%$ to $10 \%$.

eNumber of animals with neoplasm per number of animals necropsied.

${ }^{\mathrm{f}}$ Number of litters with neoplasm-bearing animals per number of litters examined at site.

gPoly-3 estimated neoplasm incidence after adjustment for intercurrent mortality.

${ }^{\mathrm{h}}$ Observed incidence at terminal euthanasia.

${ }^{\mathrm{i} N o t}$ applicable; no neoplasms in animal group.

${ }^{j}$ Beneath the control incidence is the $\mathrm{p}$ value associated with the trend test. Beneath the exposed group incidence are the $\mathrm{p}$ values corresponding to pairwise comparisons between the control group and that exposed group. The Rao-Scott test adjusts the Poly-3 test (which accounts for differential mortality in animals that do not reach terminal euthanasia) for within-litter correlation. A negative trend or a lower incidence in an exposure group is indicated by $\mathrm{N}$.

${ }^{\mathrm{k}}$ Historical control incidence: $34 / 150(22.67 \% \pm 8.33 \%)$; range: $16 \%$ to $32 \%$.

${ }^{1}$ Historical control incidence: $36 / 150(24 \% \pm 8 \%)$; range: $16 \%$ to $32 \%$. 


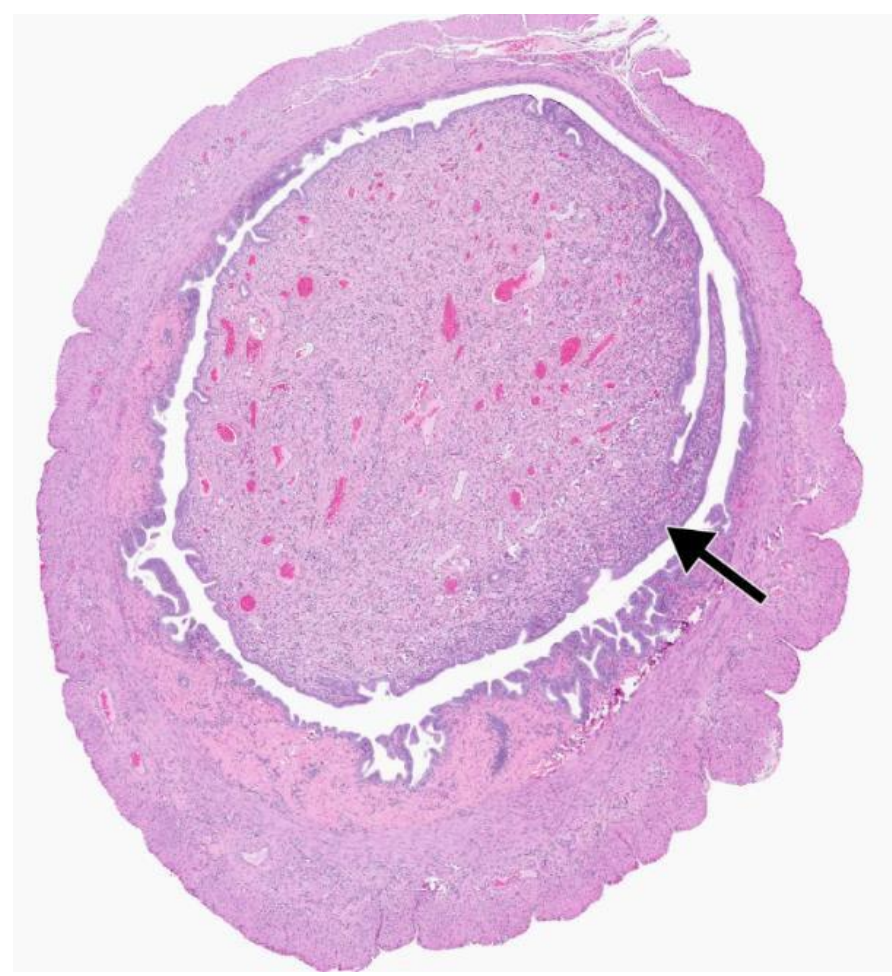

Figure 8. Stromal Polyp in the Uterus of a Female Sprague Dawley Rat Exposed to 3,000 ppm 2Hydroxy-4-methoxybenzophenone for Two Years (H\&E)

A cross section of a stromal polyp is visible within the lumen of the uterus. This polyp (arrow) is primarily composed of connective tissue with few glands; some polyps contain more glands. 
A)

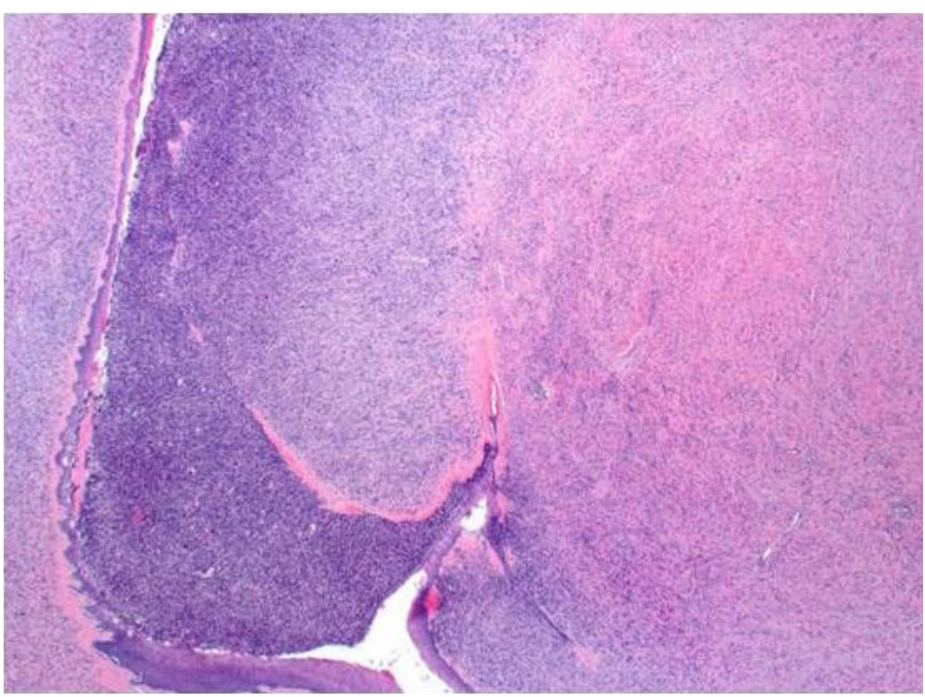

B)

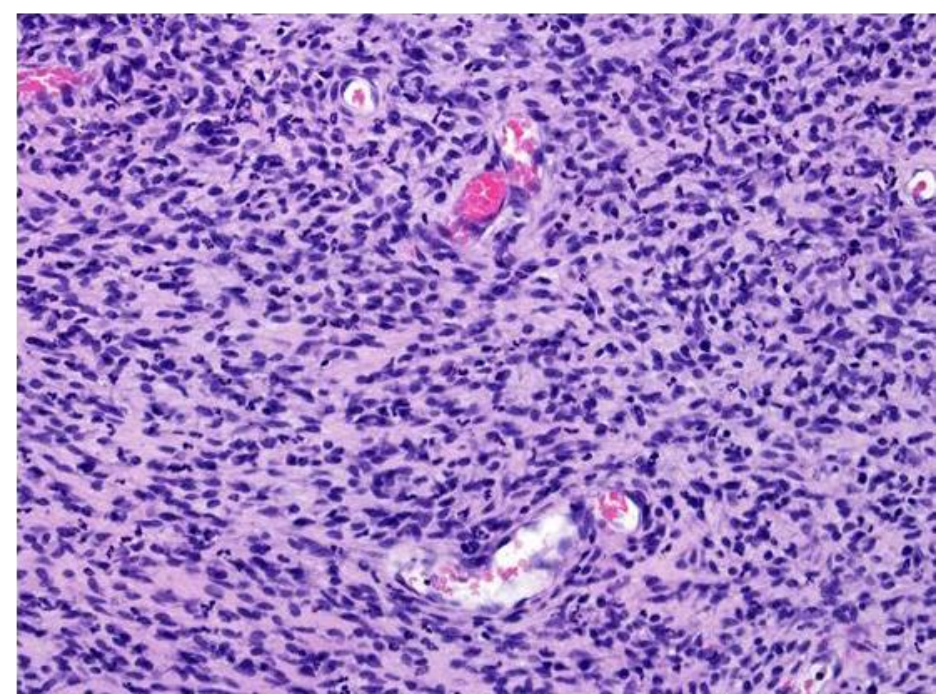

Figure 9. Stromal Sarcoma in the Uterus of Female Sprague Dawley Rat Exposed to 1,000 ppm 2-Hydroxy-4-methoxybenzophenone for Two Years (H\&E)

A) The sarcoma is a poorly demarcated, highly cellular mass. B) Magnification of panel A. A dense population of neoplastic cells is evident with oval to elongated nuclei and indistinct cell borders. 
A)

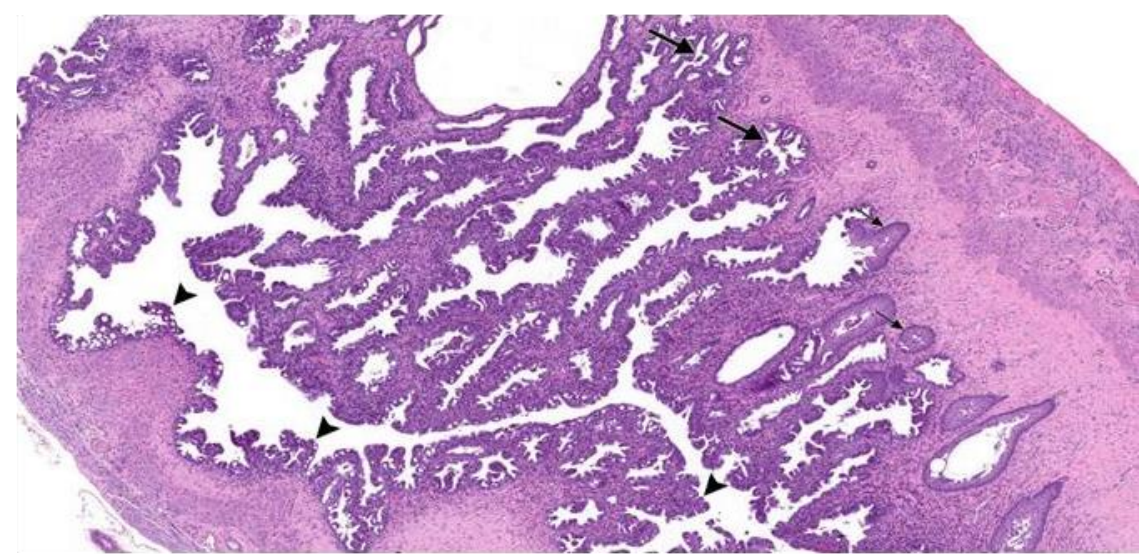

B)

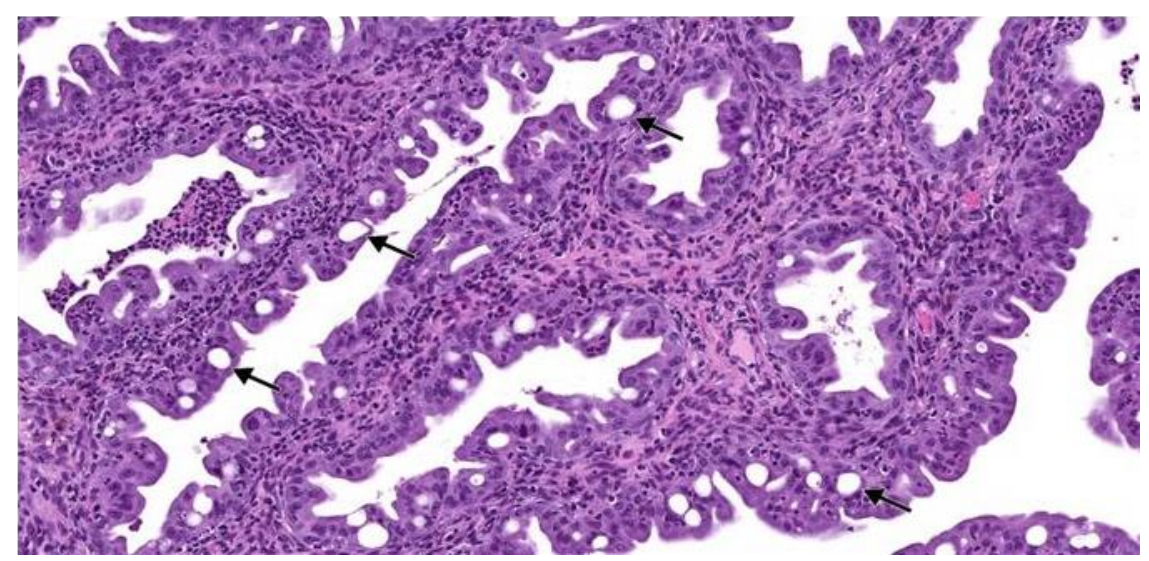

Figure 10. Atypical Hyperplasia of the Uterus in a Female Sprague Dawley Rat Exposed to 3,000 ppm 2-Hydroxy-4-methoxybenzophenone for Two Years (H\&E)

A) Atypical hyperplasia affected both the luminal surface epithelium (arrowheads) and the glandular epithelium (large arrows). This animal also had squamous metaplasia of the epithelium in some glands (small arrows). B) Higher magnification of hyperplasia imaged in panel A; glands are lined by enlarged, stratified, disorganized, and pleomorphic cells that frequently contain large vacuoles (arrows).

Adrenal cortex: The incidences of focal hypertrophy were significantly increased in 1,000 and 3,000 ppm females compared to the control group at the end of the 2-year study (Table 14; Appendix H). Hypertrophy in the cortex was characterized by a focal area of enlarged cells, without a concomitant increase in cell numbers. Affected cells had increased amounts of pale to brightly eosinophilic cytoplasm. Minimal to mild lesions often involved the zona glomerulosa with extension into the zona fasciculata, although some were observed only in the zona fasciculata (Figure 11). Larger lesions seemed to involve the entire thickness of the cortex, and the cells often displayed cytoplasmic vacuolation (Figure 11). One control female had bilateral lesions; all others were unilateral. 
Table 14. Incidences of Nonneoplastic Lesions of the Testes, Pancreas, and Adrenal Cortex of Rats in the Perinatal and Two-year Feed Study of 2-Hydroxy-4-methoxybenzophenone

\begin{tabular}{|c|c|c|c|c|}
\hline & 0 ppm & 1,000 ppm & 3,000 ppm & 10,000 ppm \\
\hline Male $^{a}$ & 50 & 50 & 50 & 50 \\
\hline \multicolumn{5}{|l|}{ Testes } \\
\hline Arteriole, necrosis, fibrinoid ${ }^{\mathrm{b}}$ & $16^{*}(2.3)^{\mathrm{c}}$ & $19(2.6)$ & $16(2.6)$ & $25 *(2.4)$ \\
\hline Interstitial cell, hyperplasia & $1 *(1.0)$ & 0 & 0 & $5(2.0)$ \\
\hline \multicolumn{5}{|l|}{ Pancreas } \\
\hline Arteriole, inflammation, chronic active & $4(1.5)$ & $15^{*}(1.2)$ & $10(1.4)$ & $11(1.3)$ \\
\hline Female $^{\mathrm{a}}$ & 50 & 50 & 50 & 50 \\
\hline \multicolumn{5}{|l|}{ Adrenal Cortex } \\
\hline Hypertrophy, focal & $24(2.0)$ & $42 * *(1.8)$ & $39 *(1.6)$ & $27(1.7)$ \\
\hline
\end{tabular}

Statistical significance for a treatment group indicates a significant pairwise test compared to the vehicle control group. Statistical significance for the vehicle control indicates a significant trend test.

$*$ Statistically significant at $\mathrm{p} \leq 0.05$ by the Rao-Scott test; **p $\leq 0.01$.

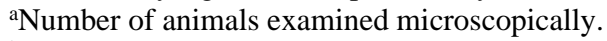

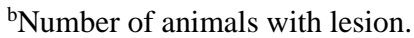

${ }^{\mathrm{c}}$ Average severity grade of observed lesion in affected animals; $1=$ minimal; $2=$ mild; $3=$ moderate; $4=$ marked). 
A)

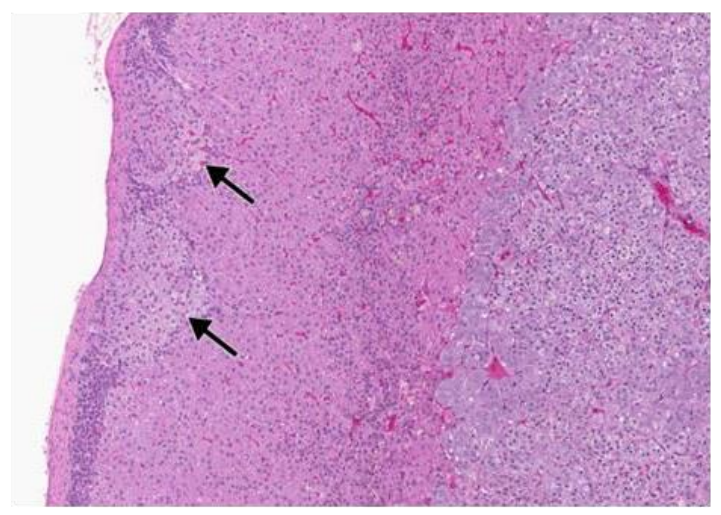

C)

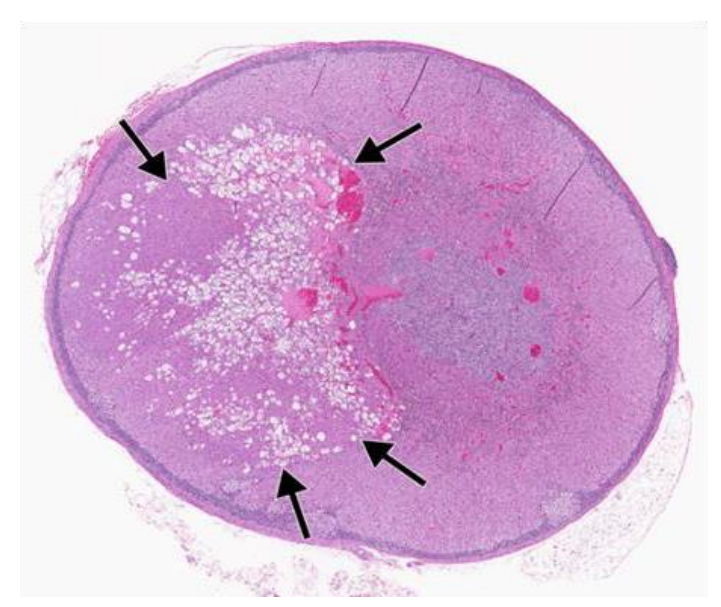

B)

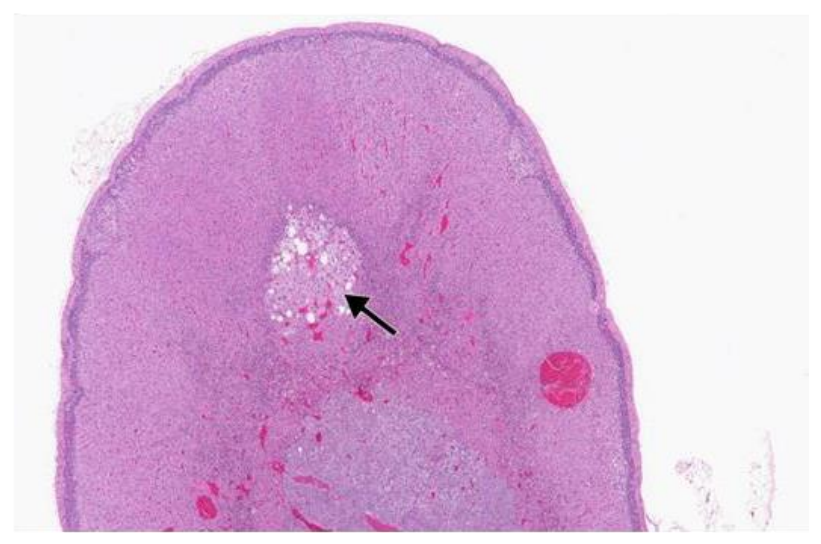

Figure 11. Focal Hypertrophy in the Adrenal Cortex from a Female Sprague Dawley Rat Exposed to 3,000 ppm 2-Hydroxy-4-methoxybenzophenone for Two Years $(\mathrm{H} \& \mathrm{E})$

A) Minimal focal hypertrophy of the adrenal cortex (arrows) is present, which involves the zona glomerulosa with extension into the zona fasciculata. B) This minimal focus of hypertrophy (arrow) was confined to the zona fasciculata. C) A large area of hypertrophy (arrows) is evident; many of the hypertrophied cells also have pronounced vacuolation.

Testes: The incidence of interstitial cell hyperplasia showed a statistically significant positive trend, but there were no significant pairwise comparisons of the exposed groups to the control group (Table 14; Appendix H). Interstitial cell hyperplasia consisted of focal proliferations of interstitial cells that did not cause compression of surrounding seminiferous tubules. Minimal lesions were typically smaller than the size of one seminiferous tubule, whereas mild lesions were somewhat larger, but still did not cause compression. All lesions were unilateral and no interstitial cell adenomas were observed in this study.

The incidence of fibrinoid necrosis of the arterioles was significantly increased in 10,000 ppm males compared to the control group (Table 14; Appendix H). Arteriole fibrinoid necrosis was characterized by vessels with a tunica media thickened by amorphous eosinophilic material. Severity grading was based on the percentage of arterioles having fibrinoid necrosis of the vessel walls: Grade 1 (minimal) was used when up to $25 \%$ of the arterioles in the testes were affected; Grade 2 (mild) when 25-50\% of the arterioles were affected; Grade 3 (moderate) when 50-75\% of the arterioles were affected, and Grade 4 (marked) when greater than $75 \%$ of the 
arterioles in the testes had fibrinoid necrosis of the vascular walls. Fibrinoid necrosis of these blood vessels was often accompanied by a mixed inflammatory cell infiltrate and was frequently found in vessels in other tissues as well. Polyarteritis nodosa involving necrosis and inflammation of arterioles and arteries is a common spontaneous age-related lesion in several strains of rats. ${ }^{104}$

Pancreas: The incidence of chronic active inflammation affecting the arterioles was significantly increased in 1,000 ppm males compared to the control group at the end of the 2-year study (Table 14; Appendix H). This lesion was not considered to be a primary pancreatic lesion, but rather, part of the syndrome of inflammation and necrosis of the arteries and arterioles (polyarteritis nodosa) that develops in certain strains of rats. Arteries and arterioles commonly involved in polyarteritis nodosa include those in the pancreas, mesentery, and testes. ${ }^{105}$ In this particular case, although the incidences of chronic active inflammation of the arterioles were increased in the 1,000 and 10,000 ppm males, the incidence of chronic active inflammation of the pancreatic arteries was not statistically different from the control group in any exposed group. The arteries, larger than the arterioles, would be easier to observe in sections of tissue and because almost every male rat that had inflammation recorded in the arterioles of the pancreas also had inflammation of the arteries of the pancreas (the exception being three $1,000 \mathrm{ppm}$ males) the differences in the incidences of arteriole inflammation might simply reflect fewer observed cross sections of the smaller arterioles in some rats.

Mammary gland: The incidences of mammary gland fibroadenoma and carcinoma were significantly decreased, relative to the control group, in 10,000 ppm females at the end of the 2year study (fibroadenoma: 32/50, 30/50, 27/50, 18/50; carcinoma: 7/50, 5/50, 7/50, 1/50; Appendix H). 


\section{Mice}

\section{Two-year Study}

\section{Survival}

Estimates of 2-year survival probabilities for male and female mice are shown in Table 15 and in the Kaplan-Meier survival curves (Figure 12). Survival of all exposed groups of male and female mice was not significantly different from that of the control groups.

Table 15. Survival of Mice in the Two-year Feed Study of 2-Hydroxy-4-methoxybenzophenone

\begin{tabular}{|c|c|c|c|c|}
\hline & O ppm & 1,000 ppm & 3,000 ppm & 10,000 ppm \\
\hline \multicolumn{5}{|l|}{ Male } \\
\hline Animals Initially in Study & 50 & 50 & 50 & 50 \\
\hline Missing $^{\mathrm{a}}$ & 1 & 0 & 0 & 0 \\
\hline Moribund & 2 & 1 & 2 & 0 \\
\hline Natural Deaths & 13 & 9 & 5 & 8 \\
\hline Animals Surviving to Study Termination & 34 & 40 & 43 & 42 \\
\hline Percent Probability of Survival at End of Study ${ }^{b}$ & 69 & 80 & 86 & 84 \\
\hline Mean Survival (Days) ${ }^{c}$ & 691 & 715 & 701 & 688 \\
\hline Survival Analysis $^{\mathrm{d}}$ & $\mathrm{p}=0.266 \mathrm{~N}$ & $\mathrm{p}=0.251 \mathrm{~N}$ & $\mathrm{p}=0.094 \mathrm{~N}$ & $\mathrm{p}=0.155 \mathrm{~N}$ \\
\hline \multicolumn{5}{|l|}{ Female } \\
\hline Animals Initially in Study & 50 & 50 & 50 & 50 \\
\hline Moribund & 1 & 5 & 2 & 1 \\
\hline Natural Deaths & 7 & 6 & 4 & 3 \\
\hline Animals Surviving to Study Termination & 42 & $39^{\mathrm{e}}$ & 44 & 46 \\
\hline Percent Probability of Survival at End of Study ${ }^{b}$ & 84 & 78 & 88 & 92 \\
\hline Mean Survival (Days) ${ }^{c}$ & 716 & 696 & 720 & 717 \\
\hline Survival Analysis ${ }^{\mathrm{d}}$ & $\mathrm{p}=0.135 \mathrm{~N}$ & $\mathrm{p}=0.492$ & $\mathrm{p}=0.724 \mathrm{~N}$ & $\mathrm{p}=0.369 \mathrm{~N}$ \\
\hline
\end{tabular}

${ }^{\mathrm{a} C e n s o r e d ~ i n ~ t h e ~ s u r v i v a l ~ a n a l y s i s . ~}$

${ }^{b}$ Kaplan-Meier determinations.

${ }^{\mathrm{c}}$ Mean of all deaths (uncensored, censored, and study termination).

${ }^{\mathrm{d}}$ The result of the life-table trend test ${ }^{72}$ is in the control column, and the results of the life-table pairwise comparisons ${ }^{73}$ with the control group are in the exposed group columns. A negative trend or lower mortality in an exposure group is indicated by $\mathrm{N}$.

'Includes one animal that died during the last week of the study. 
2-Hydroxy-4-methoxybenzophenone, NTP TR 597
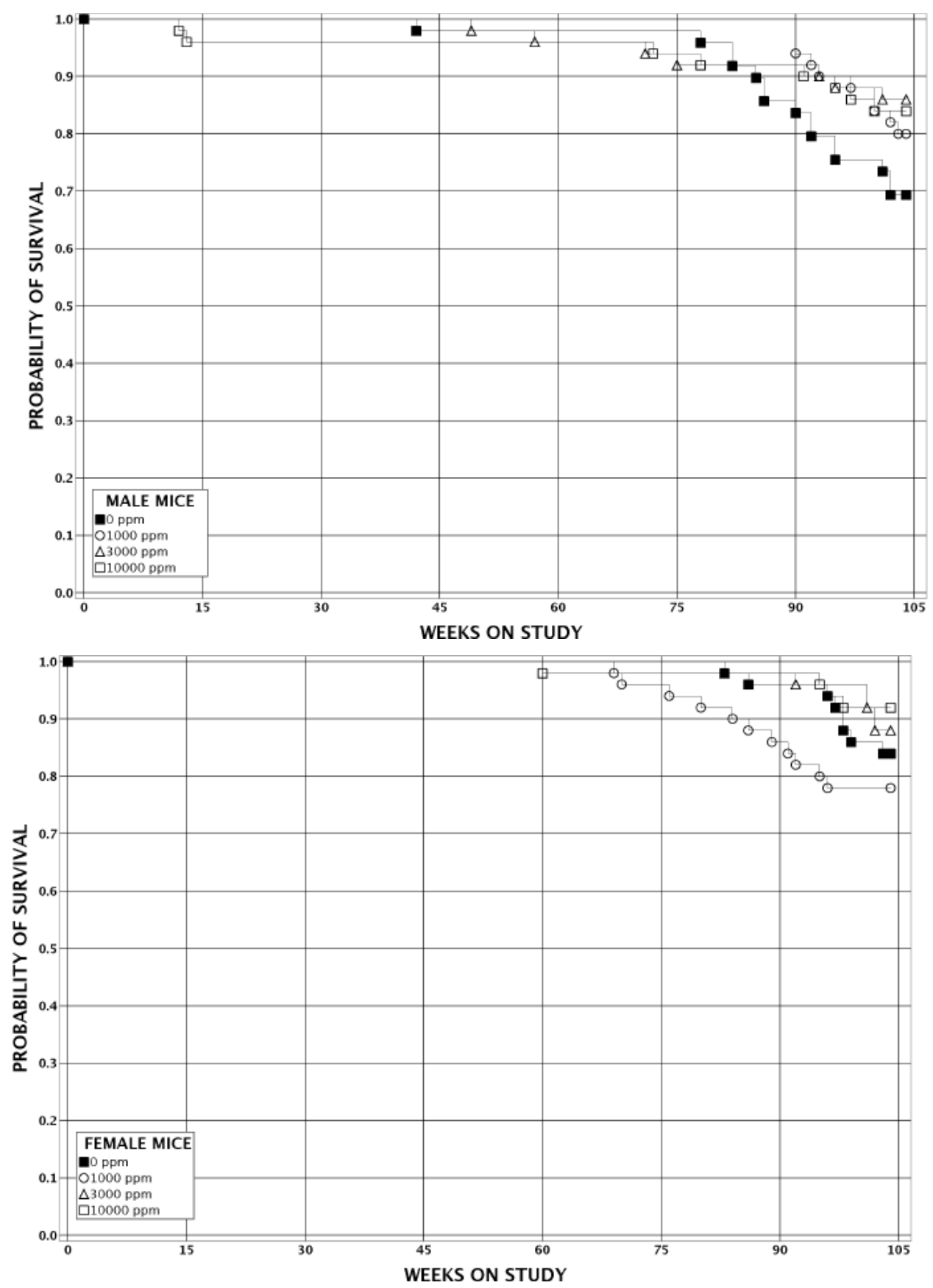

Figure 12. Kaplan-Meier Survival Curves for Mice Exposed to 2-Hydroxy-4-methoxybenzophenone in Feed for Two Years 


\section{Body Weights, Feed and Compound Consumption, and Clinical Observations}

Mean body weights of 1,000 and 3,000 ppm males and females were within $10 \%$ of those of the control groups throughout the study (Table 16, Table 17; Figure 13). Mean body weights of $10,000 \mathrm{ppm}$ males and females were at least $10 \%$ less than those of the control groups generally at weeks 17 and 12, respectively. Feed consumption by exposed groups of males and females was not significantly different from that by the control groups (Appendix H). Dietary concentrations of $1,000,3,000$, and 10,000 ppm resulted in average daily doses of approximately 113,339 , and $1,207 \mathrm{mg} 2 \mathrm{H} 4 \mathrm{MBP} / \mathrm{kg}$ body weight for males and 109,320 , and $1,278 \mathrm{mg} / \mathrm{kg}$ for females. No clinical findings in exposed groups of male or female mice were considered to be related to 2H4MBP exposure (Appendix $\mathrm{H}$ ). 
Table 16. Mean Body Weights and Survival of Male Mice in the Two-year Feed Study of 2-Hydroxy-4-methoxybenzophenone

\begin{tabular}{|c|c|c|c|c|c|c|c|c|c|c|c|}
\hline \multirow[b]{2}{*}{ Day } & \multicolumn{2}{|c|}{ O ppm } & \multicolumn{3}{|c|}{1,000 ppm } & \multicolumn{3}{|c|}{ 3,000 ppm } & \multicolumn{3}{|c|}{10,000 ppm } \\
\hline & $\begin{array}{c}\text { Av. } \\
\text { Wt. (g) }\end{array}$ & $\begin{array}{c}\text { No. of } \\
\text { Survivors }\end{array}$ & $\begin{array}{c}\text { Av. } \\
\text { Wt. (g) }\end{array}$ & $\begin{array}{l}\text { Wt. (\% of } \\
\text { Controls) }\end{array}$ & $\begin{array}{c}\text { No. of } \\
\text { Survivors }\end{array}$ & $\begin{array}{c}\text { Av. } \\
\text { Wt. (g) }\end{array}$ & $\begin{array}{l}\text { Wt. (\% of } \\
\text { Controls) }\end{array}$ & $\begin{array}{c}\text { No. of } \\
\text { Survivors }\end{array}$ & $\begin{array}{c}\text { Av. } \\
\text { Wt. (g) }\end{array}$ & $\begin{array}{l}\text { Wt. (\% of } \\
\text { Controls) }\end{array}$ & $\begin{array}{c}\text { No. of } \\
\text { Survivors }\end{array}$ \\
\hline 1 & 21.8 & 50 & 21.8 & 100 & 50 & 21.9 & 100 & 50 & 21.9 & 100 & 50 \\
\hline 8 & 22.6 & 50 & 22.3 & 99 & 50 & 22.4 & 99 & 50 & 21.9 & 97 & 50 \\
\hline 15 & 23.0 & 50 & 22.9 & 100 & 50 & 23.0 & 100 & 50 & 22.4 & 97 & 50 \\
\hline 22 & 23.4 & 50 & 23.4 & 100 & 50 & 23.3 & 100 & 50 & 22.5 & 96 & 50 \\
\hline 29 & 24.2 & 50 & 24.4 & 101 & 50 & 23.9 & 99 & 50 & 23.1 & 95 & 50 \\
\hline 36 & 25.0 & 50 & 25.4 & 102 & 50 & 24.8 & 99 & 50 & 23.7 & 95 & 50 \\
\hline 43 & 25.5 & 50 & 26.0 & 102 & 50 & 25.3 & 99 & 50 & 24.2 & 95 & 50 \\
\hline 50 & 26.5 & 50 & 26.7 & 101 & 50 & 25.8 & 97 & 50 & 24.9 & 94 & 50 \\
\hline 57 & 27.1 & 50 & 27.3 & 101 & 50 & 26.3 & 97 & 50 & 25.3 & 93 & 50 \\
\hline 64 & 27.9 & 50 & 28.3 & 101 & 50 & 26.9 & 97 & 50 & 25.9 & 93 & 50 \\
\hline 71 & 28.4 & 50 & 28.8 & 101 & 50 & 27.8 & 98 & 50 & 26.7 & 94 & 50 \\
\hline 78 & 29.1 & 50 & 29.4 & 101 & 50 & 28.3 & 97 & 50 & 26.6 & 92 & 49 \\
\hline 85 & 28.9 & 50 & 29.3 & 101 & 50 & 27.9 & 97 & 50 & 26.5 & 92 & 49 \\
\hline 92 & 30.0 & 50 & 30.2 & 101 & 50 & 28.4 & 95 & 50 & 27.2 & 91 & 48 \\
\hline 120 & 33.3 & 50 & 33.4 & 100 & 50 & 31.6 & 95 & 50 & 29.4 & 88 & 48 \\
\hline 148 & 35.3 & 50 & 35.0 & 99 & 50 & 33.2 & 94 & 50 & 30.0 & 85 & 48 \\
\hline 176 & 37.5 & 50 & 37.6 & 100 & 50 & 35.0 & 93 & 50 & 31.4 & 84 & 48 \\
\hline 204 & 40.4 & 50 & 40.6 & 100 & 50 & 37.8 & 94 & 50 & 33.5 & 83 & 48 \\
\hline 232 & 42.5 & 50 & 42.2 & 99 & 50 & 39.8 & 94 & 50 & 35.1 & 83 & 48 \\
\hline 260 & 43.6 & 50 & 43.2 & 99 & 50 & 41.0 & 94 & 50 & 35.9 & 83 & 48 \\
\hline 288 & 43.6 & 49 & 42.9 & 98 & 50 & 42.0 & 96 & 50 & 36.8 & 84 & 48 \\
\hline 316 & 45.5 & 49 & 44.4 & 98 & 50 & 43.1 & 95 & 50 & 37.6 & 83 & 48 \\
\hline 344 & 46.3 & 49 & 45.9 & 99 & 50 & 44.1 & 95 & 49 & 38.6 & 83 & 48 \\
\hline 372 & 45.6 & 49 & 44.9 & 99 & 50 & 43.4 & 95 & 49 & 38.1 & 84 & 48 \\
\hline 400 & 46.7 & 49 & 46.6 & 100 & 50 & 44.7 & 96 & 48 & 39.3 & 84 & 48 \\
\hline 428 & 46.0 & 49 & 46.2 & 100 & 50 & 44.6 & 97 & 48 & 39.0 & 85 & 48 \\
\hline 456 & 46.4 & 49 & 46.7 & 101 & 50 & 44.7 & 96 & 48 & 38.9 & 84 & 48 \\
\hline 484 & 45.9 & 49 & 46.2 & 101 & 50 & 44.7 & 97 & 48 & 38.9 & 85 & 48 \\
\hline 512 & 46.9 & 49 & 46.5 & 99 & 50 & 45.5 & 97 & 47 & 39.1 & 83 & 47 \\
\hline 540 & 47.4 & 49 & 47.4 & 100 & 50 & 46.6 & 98 & 46 & 40.7 & 86 & 47 \\
\hline 568 & 47.2 & 48 & 46.8 & 99 & 50 & 45.9 & 97 & 46 & 40.1 & 85 & 46 \\
\hline 596 & 47.6 & 45 & 47.1 & 99 & 50 & 46.6 & 98 & 46 & 40.6 & 85 & 46 \\
\hline 624 & 47.2 & 42 & 45.7 & 97 & 48 & 45.0 & 96 & 46 & 39.2 & 83 & 46 \\
\hline 652 & 46.6 & 39 & 46.1 & 99 & 45 & 45.0 & 97 & 45 & 39.1 & 84 & 45 \\
\hline 680 & 46.8 & 37 & 43.9 & 94 & 44 & 45.3 & 97 & 44 & 38.7 & 83 & 43 \\
\hline 708 & 45.8 & 36 & 44.6 & 97 & 42 & 45.5 & 99 & 43 & 38.8 & 85 & 42 \\
\hline \multicolumn{12}{|c|}{ Mean for Weeks } \\
\hline $1-13$ & 25.6 & - & 25.8 & 101 & - & 25.2 & 98 & - & 24.3 & 95 & - \\
\hline $14-52$ & 39.8 & - & 39.5 & 99 & - & 37.6 & 94 & - & 33.6 & 85 & - \\
\hline 53-102 & 46.6 & - & 46.1 & 99 & - & 45.2 & 97 & - & 39.3 & 84 & - \\
\hline
\end{tabular}


Table 17. Mean Body Weights and Survival of Female Mice in the Two-year Feed Study of 2-Hydroxy-4-methoxybenzophenone

\begin{tabular}{|c|c|c|c|c|c|c|c|c|c|c|c|}
\hline \multirow[b]{2}{*}{ Day } & \multicolumn{2}{|c|}{ 0 ppm } & \multicolumn{3}{|c|}{$1,000 \mathrm{ppm}$} & \multicolumn{3}{|c|}{ 3,000 ppm } & \multicolumn{3}{|c|}{10,000 ppm } \\
\hline & $\begin{array}{c}\text { Av. Wt. } \\
\text { (g) }\end{array}$ & $\begin{array}{c}\text { No. of } \\
\text { Survivors } \\
\end{array}$ & $\begin{array}{c}\text { Av. Wt. } \\
\text { (g) }\end{array}$ & $\begin{array}{l}\text { Wt. (\% of } \\
\text { Controls) }\end{array}$ & $\begin{array}{c}\text { No. of } \\
\text { Survivors }\end{array}$ & $\begin{array}{c}\text { Av. Wt. } \\
\text { (g) }\end{array}$ & $\begin{array}{l}\text { Wt. (\% of } \\
\text { Controls) }\end{array}$ & $\begin{array}{c}\text { No. of } \\
\text { Survivors }\end{array}$ & $\begin{array}{c}\text { Av. Wt. } \\
\text { (g) }\end{array}$ & $\begin{array}{l}\text { Wt. (\% of } \\
\text { Controls) }\end{array}$ & $\begin{array}{c}\text { No. of } \\
\text { Survivors }\end{array}$ \\
\hline 1 & 18.0 & 50 & 17.7 & 98 & 50 & 17.9 & 99 & 50 & 17.7 & 99 & 50 \\
\hline 8 & 19.0 & 50 & 18.7 & 98 & 50 & 18.8 & 99 & 50 & 18.1 & 96 & 50 \\
\hline 15 & 20.0 & 50 & 19.6 & 98 & 50 & 19.6 & 98 & 50 & 19.0 & 95 & 50 \\
\hline 22 & 20.8 & 50 & 20.6 & 99 & 50 & 20.3 & 98 & 50 & 19.4 & 94 & 50 \\
\hline 29 & 21.7 & 50 & 21.3 & 98 & 50 & 20.8 & 96 & 50 & 20.2 & 93 & 50 \\
\hline 36 & 22.5 & 50 & 22.1 & 98 & 50 & 21.9 & 97 & 50 & 20.9 & 93 & 50 \\
\hline 43 & 22.9 & 50 & 22.5 & 98 & 50 & 22.6 & 99 & 50 & 21.2 & 93 & 50 \\
\hline 50 & 23.6 & 50 & 22.9 & 97 & 50 & 23.0 & 98 & 50 & 21.8 & 93 & 50 \\
\hline 57 & 24.5 & 50 & 23.9 & 98 & 50 & 23.9 & 97 & 50 & 22.6 & 92 & 50 \\
\hline 64 & 24.8 & 50 & 24.3 & 98 & 50 & 24.7 & 100 & 50 & 22.8 & 92 & 50 \\
\hline 71 & 25.7 & 50 & 25.3 & 98 & 50 & 24.9 & 97 & 50 & 23.1 & 90 & 50 \\
\hline 78 & 25.5 & 50 & 25.4 & 100 & 50 & 25.3 & 99 & 50 & 23.3 & 91 & 50 \\
\hline 85 & 26.5 & 50 & 25.9 & 98 & 50 & 26.1 & 98 & 50 & 23.8 & 90 & 50 \\
\hline 92 & 27.1 & 50 & 26.0 & 96 & 50 & 26.3 & 97 & 50 & 23.8 & 88 & 50 \\
\hline 120 & 29.8 & 50 & 29.2 & 98 & 50 & 28.6 & 96 & 50 & 25.1 & 84 & 50 \\
\hline 148 & 31.9 & 50 & 30.7 & 96 & 50 & 31.1 & 98 & 50 & 26.3 & 82 & 50 \\
\hline 176 & 34.0 & 50 & 33.3 & 98 & 50 & 32.2 & 95 & 50 & 26.9 & 79 & 50 \\
\hline 204 & 36.8 & 50 & 35.1 & 96 & 50 & 36.0 & 98 & 50 & 27.6 & 75 & 50 \\
\hline 232 & 38.6 & 50 & 37.0 & 96 & 50 & 37.1 & 96 & 50 & 29.7 & 77 & 50 \\
\hline 260 & 39.9 & 50 & 38.9 & 97 & 50 & 39.6 & 99 & 50 & 30.5 & 76 & 50 \\
\hline 288 & 42.3 & 50 & 40.3 & 95 & 50 & 40.8 & 96 & 50 & 31.5 & 75 & 50 \\
\hline 316 & 44.3 & 50 & 42.6 & 96 & 50 & 42.4 & 96 & 50 & 33.2 & 75 & 50 \\
\hline 344 & 45.2 & 50 & 44.3 & 98 & 50 & 43.9 & 97 & 50 & 34.2 & 76 & 50 \\
\hline 372 & 46.0 & 50 & 44.3 & 96 & 50 & 45.1 & 98 & 50 & 34.7 & 75 & 50 \\
\hline 400 & 47.7 & 50 & 45.8 & 96 & 50 & 46.9 & 98 & 50 & 36.1 & 76 & 50 \\
\hline 428 & 48.7 & 50 & 47.2 & 97 & 50 & 46.5 & 95 & 50 & 36.7 & 75 & 49 \\
\hline 456 & 48.9 & 50 & 47.9 & 98 & 50 & 46.6 & 95 & 50 & 36.7 & 75 & 49 \\
\hline 484 & 52.0 & 50 & 49.4 & 95 & 48 & 49.5 & 95 & 50 & 37.7 & 72 & 49 \\
\hline 512 & 53.2 & 50 & 49.2 & 93 & 48 & 50.5 & 95 & 50 & 38.4 & 72 & 49 \\
\hline 540 & 54.5 & 50 & 51.4 & 94 & 47 & 51.8 & 95 & 50 & 39.3 & 72 & 49 \\
\hline 568 & 54.3 & 50 & 51.7 & 95 & 46 & 50.9 & 94 & 50 & 39.3 & 72 & 49 \\
\hline 596 & 54.7 & 48 & 51.6 & 94 & 45 & 49.5 & 91 & 49 & 39.2 & 72 & 49 \\
\hline 624 & 54.2 & 48 & 51.2 & 94 & 43 & 50.3 & 93 & 49 & 39.3 & 72 & 49 \\
\hline 652 & 52.3 & 48 & 50.2 & 96 & 41 & 49.8 & 95 & 48 & 38.9 & 74 & 49 \\
\hline 680 & 52.5 & 46 & 51.0 & 97 & 39 & 50.1 & 96 & 48 & 39.5 & 75 & 47 \\
\hline 708 & 52.5 & 43 & 50.3 & 96 & 39 & 47.2 & 90 & 46 & 39.2 & 75 & 46 \\
\hline \multicolumn{12}{|c|}{ Mean for Weeks } \\
\hline $1-13$ & 22.7 & - & 22.3 & 98 & - & 22.3 & 98 & - & 21.1 & 93 & - \\
\hline $14-52$ & 37.0 & - & 35.7 & 97 & - & 35.8 & 97 & - & 28.9 & 79 & - \\
\hline 53-102 & 51.7 & - & 49.3 & 96 & - & 48.8 & 95 & - & 38.1 & 74 & - \\
\hline
\end{tabular}



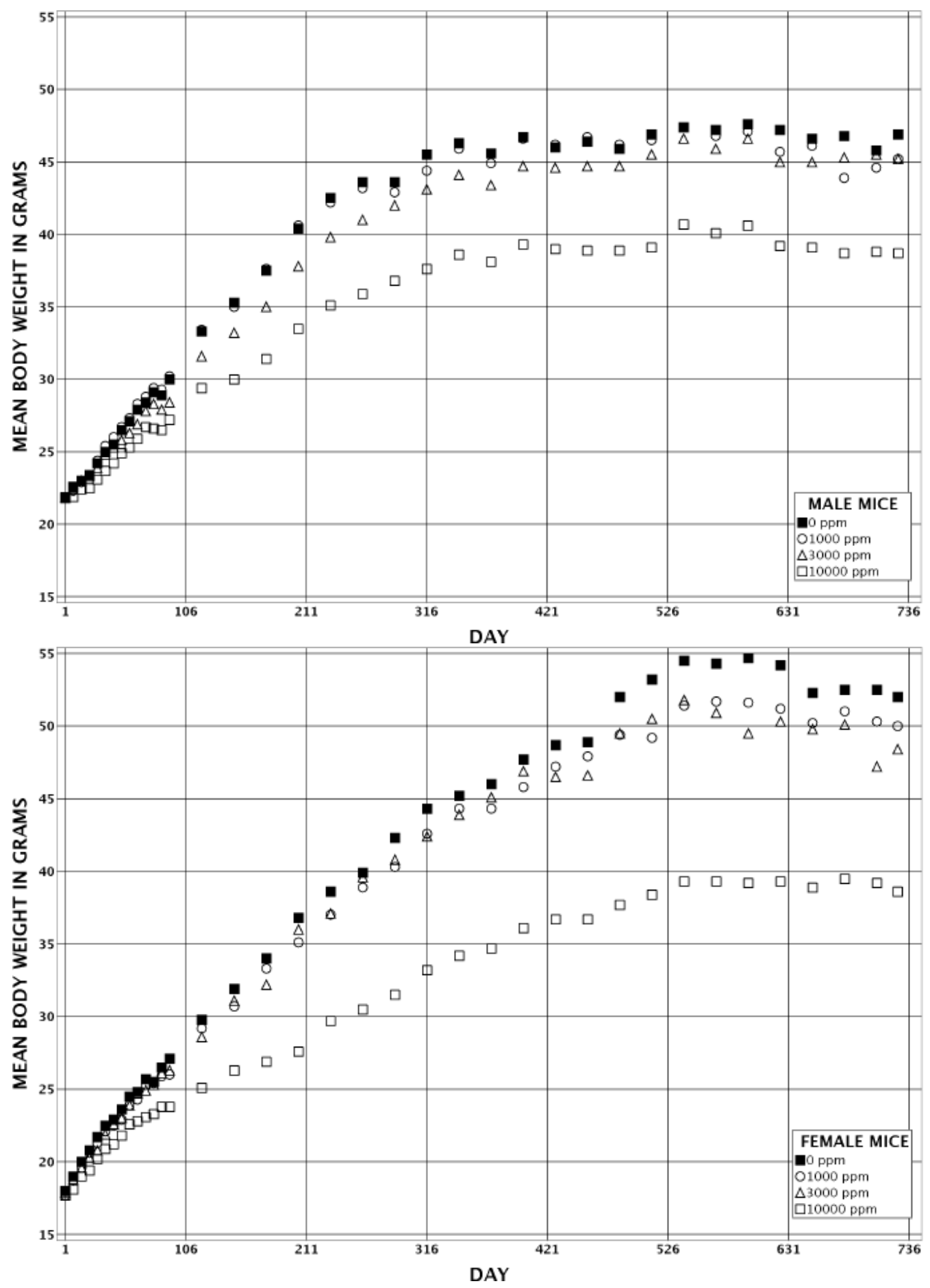

Figure 13. Growth Curves for Mice Exposed to 2-Hydroxy-4-methoxybenzophenone in Feed for Two Years 


\section{Pathology and Statistical Analyses}

This section describes the statistically significant or biologically noteworthy changes in the incidence of neoplasms and nonneoplastic lesions of the hematopoietic tissues (bone marrow and spleen), liver, kidney, Harderian gland, pituitary gland (pars distalis), thyroid gland, pancreatic islets, and adrenal cortex. Summaries of the incidence of neoplasms and nonneoplastic lesions and statistical analyses of primary neoplasms are presented in Appendix $\mathrm{H}$.

Hematopoietic tissues (bone marrow and spleen): The incidences of pigment in the bone marrow were significantly increased in $10,000 \mathrm{ppm}$ males and females when compared to their respective control group (Table 18; Appendix H). Also relative to their respective control group, the incidences of pigment in the spleen were significantly increased in 10,000 ppm males and 3,000 and 10,000 ppm females (Table 18; Appendix H). In both the bone marrow and spleen, the pigment was characterized by a golden-brown to brown granular material found within the cytoplasm of macrophages (Figure 14 and Figure 15). It was consistent with hemosiderin, and the presence of iron was confirmed using a Perl's stain on spleens from several animals (Figure 16). Some amount of pigment could be found in most animals, but pigment was only recorded as a change when it was above the threshold of that which was considered a normal background level. Typically, pigment was recorded when there were increased numbers of pigment-containing macrophages, often present in clusters of up to 10 or more macrophages, and the macrophages individually contained more pigment than what was observed at background levels. All findings of pigment in the bone marrow were of minimal severity. The majority of lesions in the spleen were of minimal severity, with only one animal each having lesions of mild or moderate severity. Mild and moderate pigment was based on a subjective increase in the amount of pigment compared to observations of minimal severity. 
Table 18. Incidences of Nonneoplastic Lesions of the Bone Marrow, Spleen, Liver, and Kidney of Mice in the Two-year Feed Study of 2-Hydroxy-4-methoxybenzophenone

\begin{tabular}{|c|c|c|c|c|}
\hline & O ppm & 1,000 ppm & 3,000 ppm & $10,000 \mathrm{ppm}$ \\
\hline \multicolumn{5}{|l|}{ Male } \\
\hline Bone Marrow ${ }^{\mathrm{a}}$ & 47 & 48 & 48 & 50 \\
\hline Pigment $^{\mathrm{b}}$ & $3^{* *}(1.0)^{\mathrm{c}}$ & $2(1.0)$ & $9(1.0)$ & $50 * *(1.0)$ \\
\hline Spleen & 48 & 50 & 49 & 50 \\
\hline Pigment & $4 * *(1.0)$ & $5(1.0)$ & $10(1.0)$ & $17 * *(1.0)$ \\
\hline Liver & 49 & 50 & 50 & 50 \\
\hline Hepatocyte, syncytial alteration & $2 * *(1.0)$ & $39 * *(1.0)$ & $45^{* *}(1.5)$ & $48 * *(1.8)$ \\
\hline Kidney & 48 & 50 & 50 & 50 \\
\hline Renal tubule, cytoplasmic alteration & $0 * *$ & 0 & 0 & $46 * *(2.0)$ \\
\hline Infiltration cellular, lymphocyte & $40 *(1.0)$ & $40(1.0)$ & $43(1.0)$ & $46 *(1.0)$ \\
\hline Nephropathy, chronic progressive & $41 *(1.1)$ & $48(1.1)$ & $48 *(1.0)$ & $50 *(1.1)$ \\
\hline \multicolumn{5}{|l|}{ Female } \\
\hline Bone Marrow & 49 & 50 & 50 & 50 \\
\hline Pigment & $6 * *(1.0)$ & $0 *$ & $0 *$ & $50 * *(1.0)$ \\
\hline Spleen & 49 & 50 & 49 & 50 \\
\hline Pigment & $12 * *(1.0)$ & $10(1.0)$ & $36^{* *}(1.0)$ & $38 * *(1.0)$ \\
\hline Kidney & 49 & 50 & 50 & 50 \\
\hline Metaplasia, osseous & $0^{*}$ & 1 & 3 & $5^{*}$ \\
\hline \multicolumn{5}{|c|}{$\begin{array}{l}\text { Statistical significance for a treatment group indicates a significant pairwise test compared to the vehicle control group. Statistica } \\
\text { significance for the vehicle control group indicates a significant trend test. } \\
* \text { Statistically significant at } \mathrm{p} \leq 0.05 \text { by the Poly }-3 \text { test; } * * \mathrm{p} \leq 0.01 \text {. } \\
\text { aNumber of animals examined microscopically. } \\
\text { bumber of animals with lesion. }\end{array}$} \\
\hline
\end{tabular}


A)

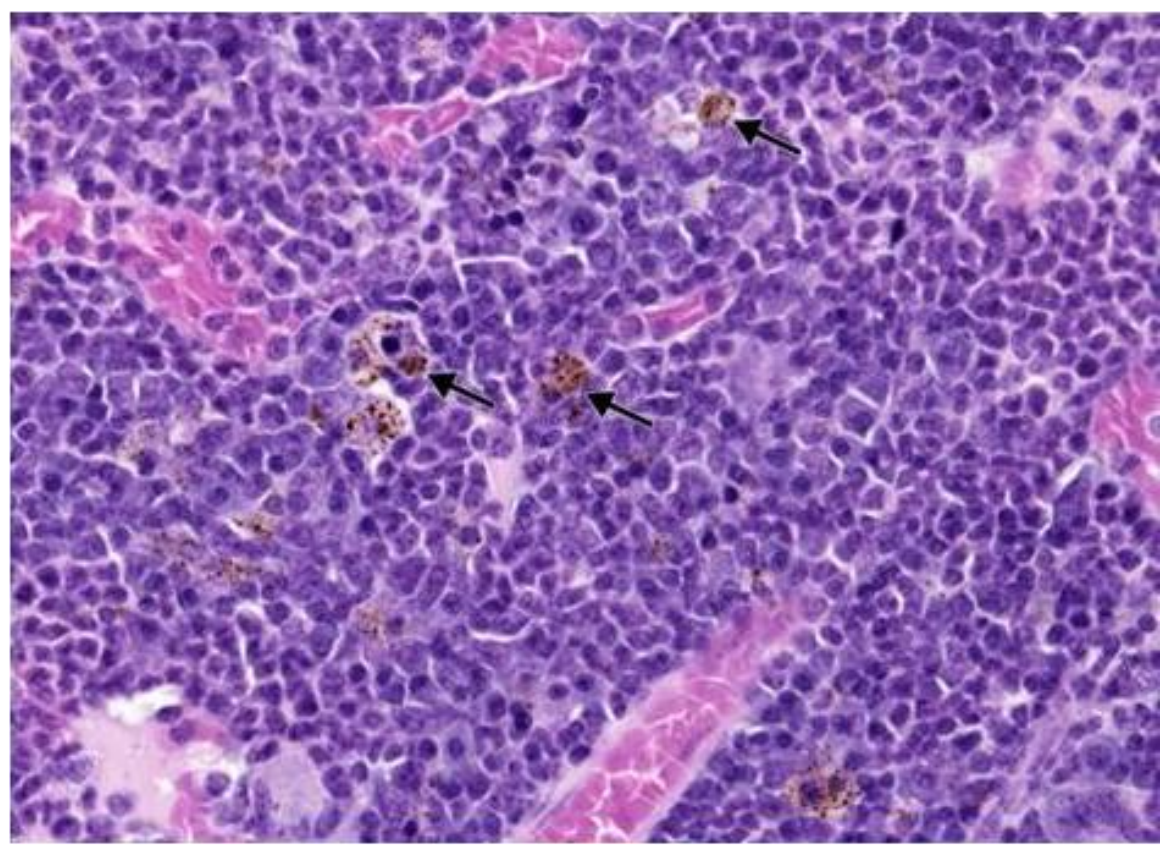

B)

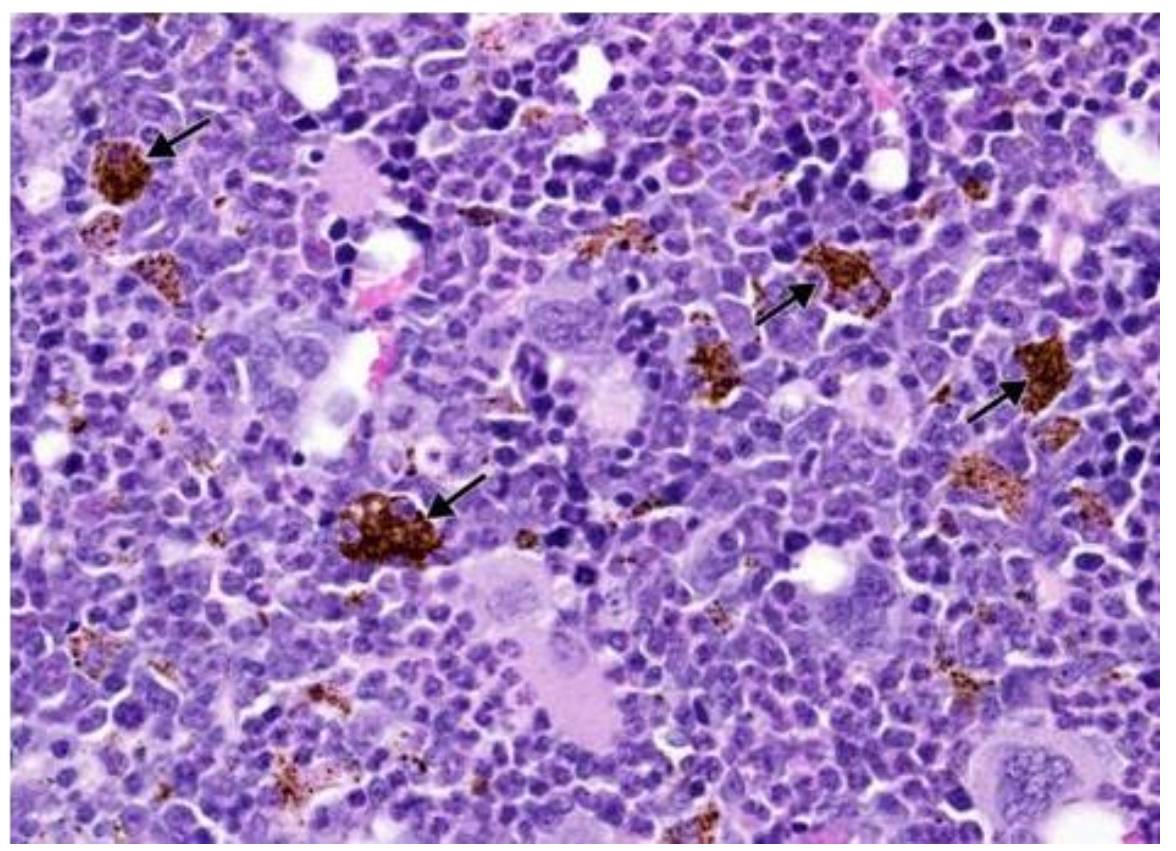

Figure 14. Pigment in the Bone Marrow from Female B6C3F1/N Mice Exposed to 0 or 10,000 ppm 2-Hydroxy-4-methoxybenzophenone for Two Years (H\&E)

A) A background level of pigment appears within macrophages in the bone marrow (arrows) of a control mouse. B) In a female mouse exposed to 10,000 ppm 2-hydroxy-4-methoxybenzophenone, an increased amount of pigment in the macrophages in the bone marrow (arrows) is apparent. 
A)

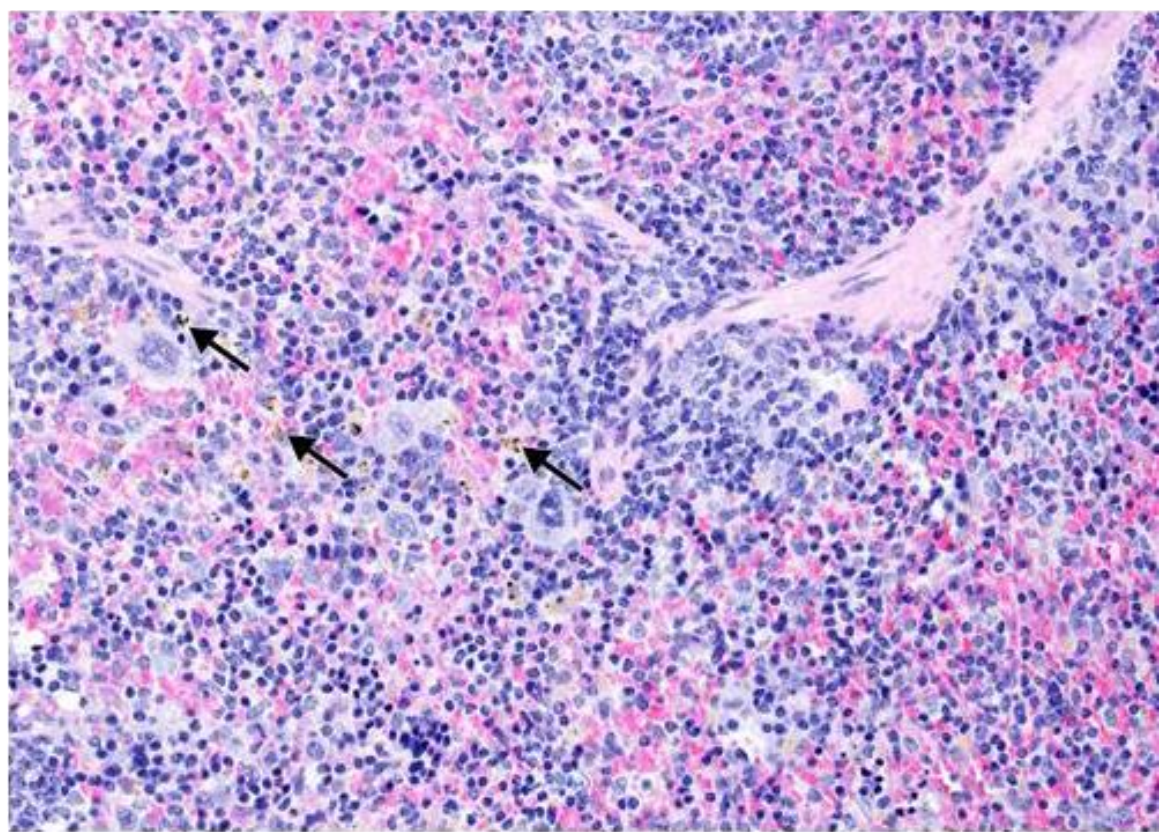

B)

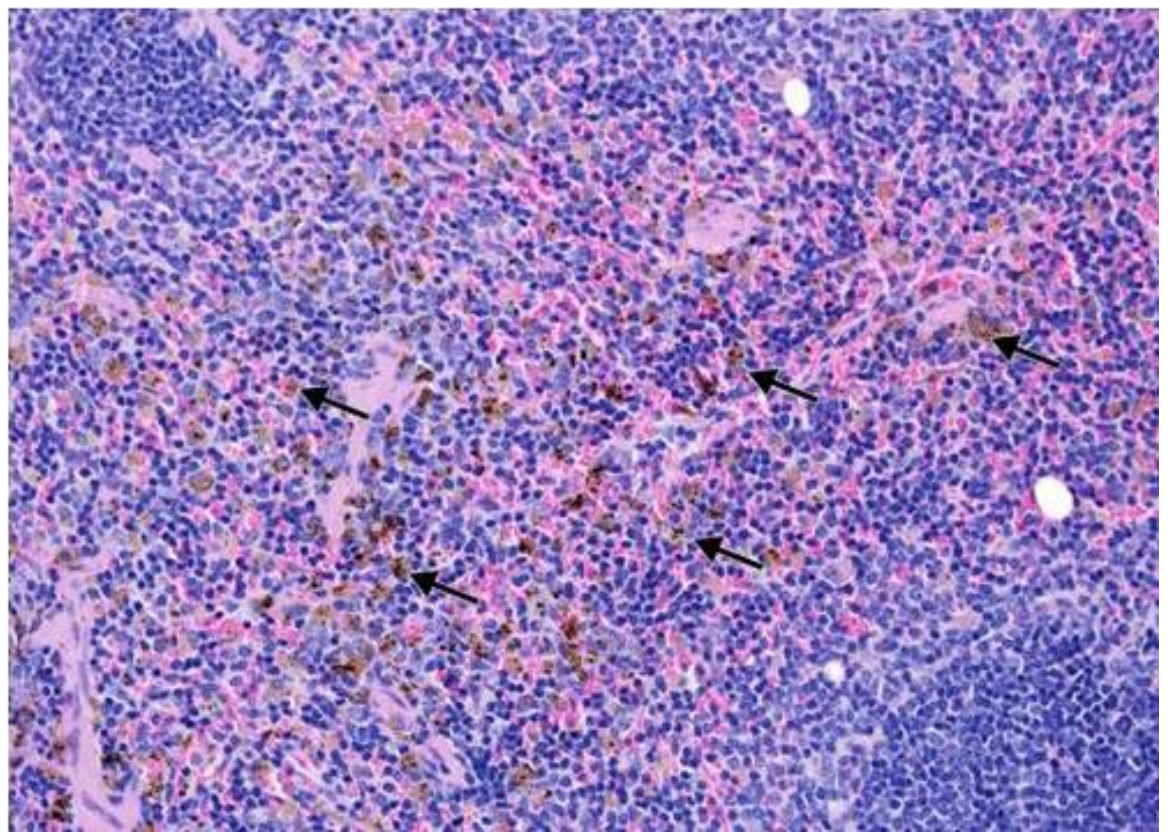

Figure 15. Pigment in the Spleen from Female B6C3F1/N Mice Exposed to 0 or 10,000 ppm 2-Hydroxy-4-methoxybenzophenone for Two Years (H\&E)

A) Similar to what was seen in the bone marrow, some pigment is present in control animals as a background observation (arrows). B) An increased amount of pigment is evident in the spleen (arrows) in a female mouse exposed to 10,000 ppm 2-hydroxy-4-methoxybenzophenone when compared to the spleen from the control mouse. 
A)

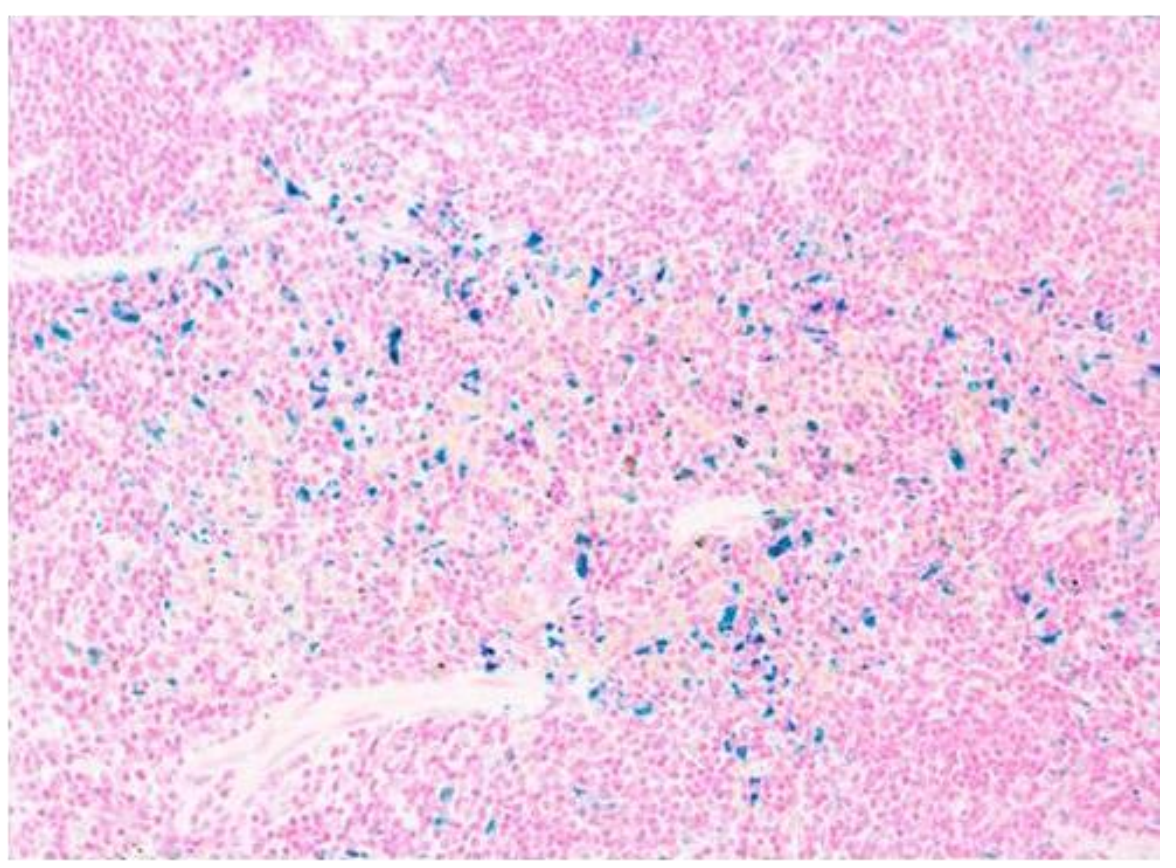

B)

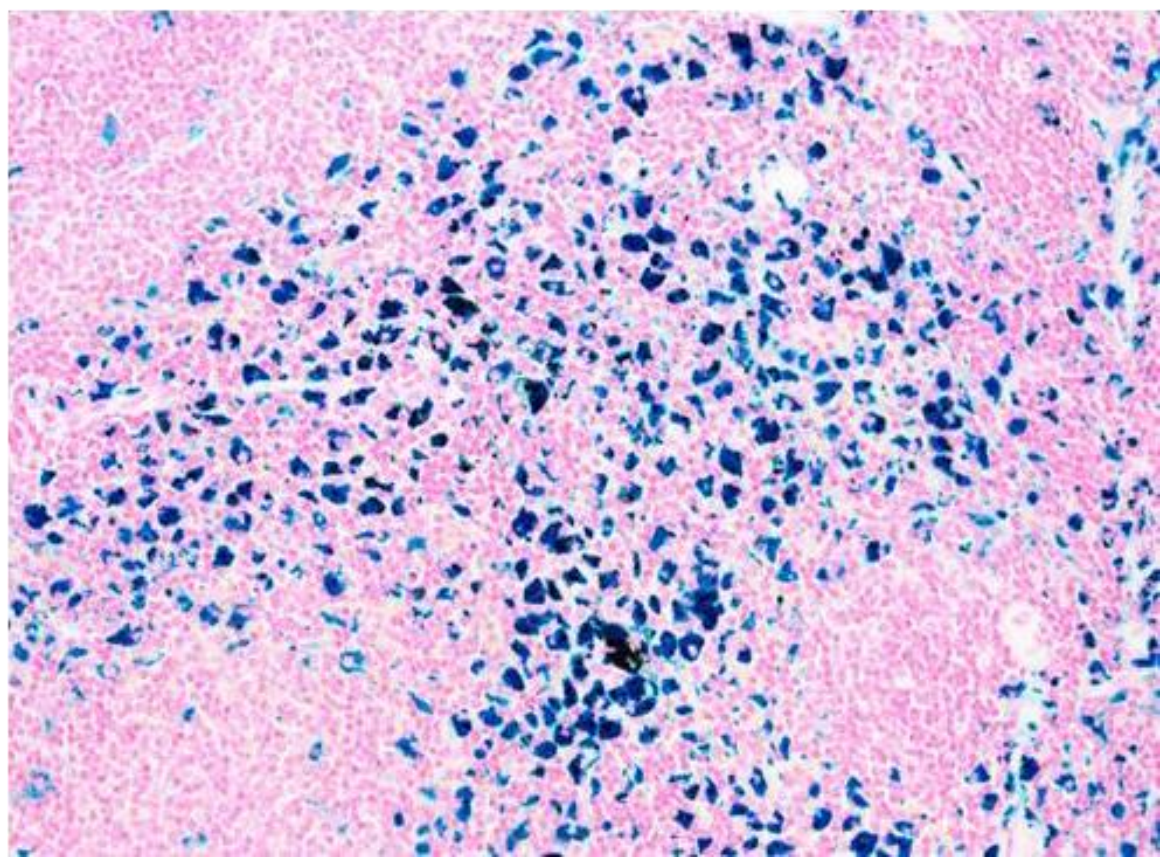

Figure 16. Pigment in the Spleen from Female B6C3F1/N Mice Exposed to 0 or $10,000 \mathrm{ppm}$ 2-Hydroxy-4-methoxybenzophenone for Two Years (Perl's Iron Stain)

A) The positive (blue) staining indicates that the pigment in the spleen contains iron, which is consistent with hemosiderin from a control group mouse. B) Increased iron-containing pigment in spleen of female mouse exposed to 10,000 ppm 2-hydroxy-4methoxybenzophenone; compare the amount of positive (blue) staining in this photomicrograph to that in panel A. 
Liver: The incidences of hepatocyte syncytial alteration were significantly increased in all exposed groups of males compared to the control group (Table 18; Appendix H).

Hepatocytes with two or three nuclei are common in old mice and were not included in the diagnosis of syncytial alteration. Hepatocytes recorded with syncytial alteration had four to seven or more nuclei. Affected hepatocytes were larger than normal, but the individual nuclei were typically small and densely basophilic (Figure 17). Severity grading was based upon the number of altered hepatocytes observed within a section of liver, with minimal (1) being recorded when one to three such hepatocytes were observed; mild (2) severity being recorded when four to 10 syncytial cells were observed; and moderate (3) severity being recorded when $>10$ were observed. No marked lesions were recorded.

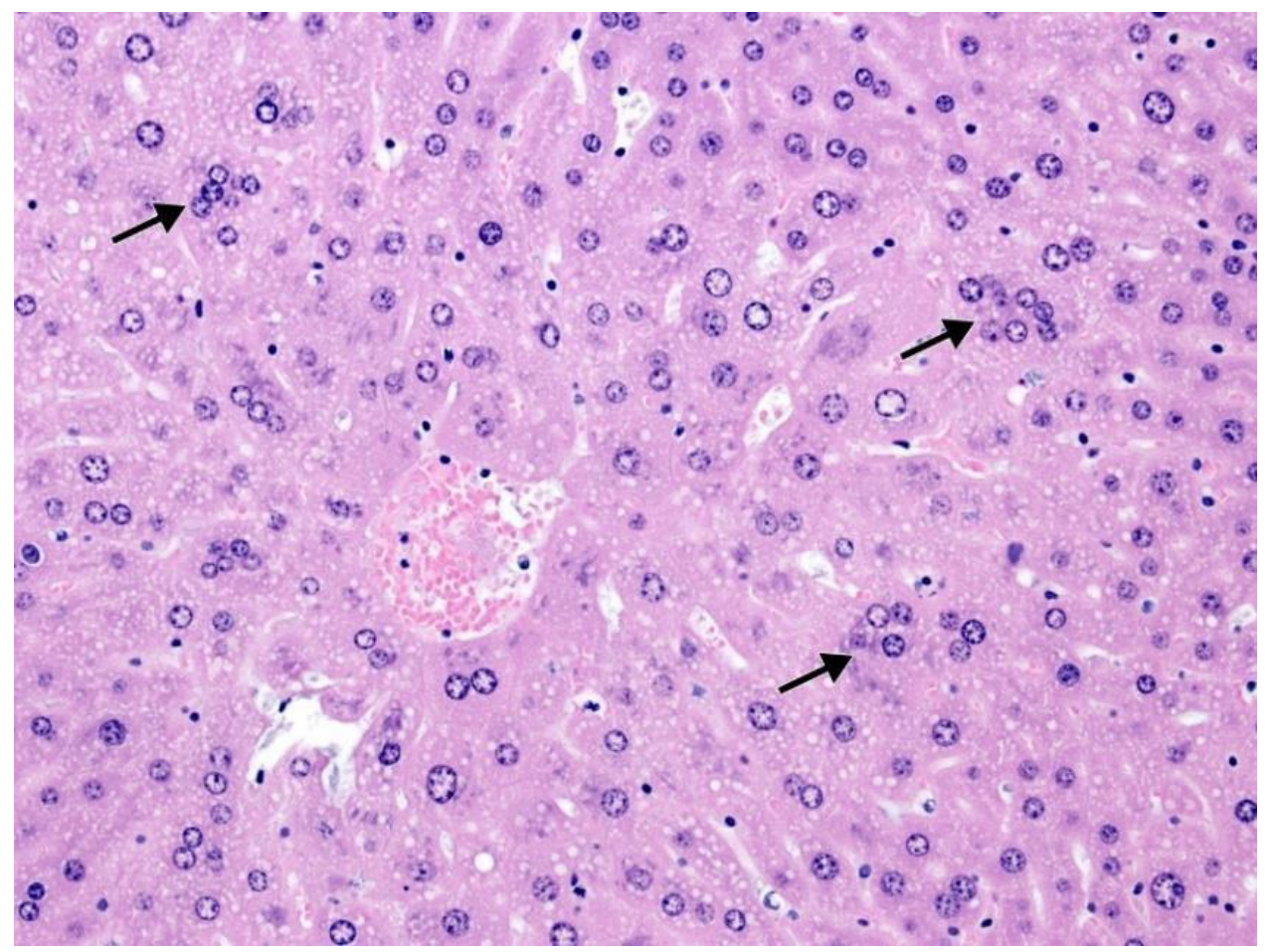

Figure 17. Syncytial Alteration in the Liver from a Male B6C3F1/N Mouse Exposed to 10,000 ppm 2-Hydroxy-4-methoxybenzophenone for Two Years (H\&E)

This animal died on day 545 of the 2-year study. Enlarged hepatocytes contain multiple nuclei (arrows).

Kidney: The incidence of renal tubule cytoplasmic alteration was significantly increased in the 10,000 ppm males compared to the control group (Table 18; Appendix H). Vacuolation of the renal tubules, typically in the outer cortex, is a normal background finding in male mice (Figure 18). The presence of these vacuoles is not recorded as a lesion; however, when a decrease in the vacuolation of the renal tubules is noted, it is typically recorded. In the current study, the normal background vacuolation decreased in renal tubules in the 10,000 ppm males, and this was recorded as an increased incidence of cytoplasmic alteration. (Figure 18).

Incidences of chronic progressive nephropathy were significantly increased in 3,000 and $10,000 \mathrm{ppm}$ males compared to the control group In addition, the incidence of lymphocytic cellular infiltration were significantly increased in 10,000 ppm males compared to the control 
group (Table 18; Appendix H). Lymphocytic cellular infiltration was characterized by increased numbers of lymphocytes within the interstitium of the kidney.

Lymphocytic infiltrates are very common in aged mouse kidneys, and lymphocytes can also be associated with chronic progressive nephropathy. Therefore, lymphocytic cellular infiltration was not diagnosed unless there were larger accumulations of lymphocytes than is typically seen as a background change or what one would expect associated with chronic progressive nephropathy. Early and minimal chronic progressive nephropathy was characterized by basophilic, hyperplastic tubules with thickened basement membranes (Figure 18). Later and more severe changes were interstitial infiltrations of mononuclear cells (predominantly lymphocytes), hyaline casts, dilated tubules, and interstitial fibrosis. The vast majority of the occurrences of chronic progressive nephropathy were of minimal severity, with only a few mild or moderate (and one marked occurrence) scattered among the exposure groups.

The incidence of osseous metaplasia was significantly increased in 10,000 ppm females compared to the control group (Table 18; Appendix H). This lesion consisted of small areas of mature bone within the cortex of the kidney. Osseous metaplasia is regarded as a spontaneous lesion with unknown pathological significance.

A)

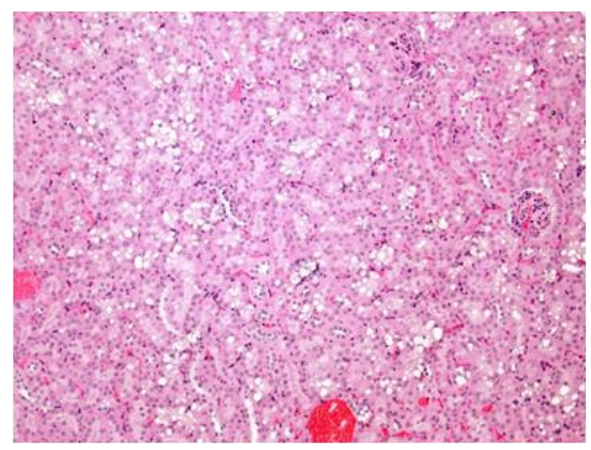

B)

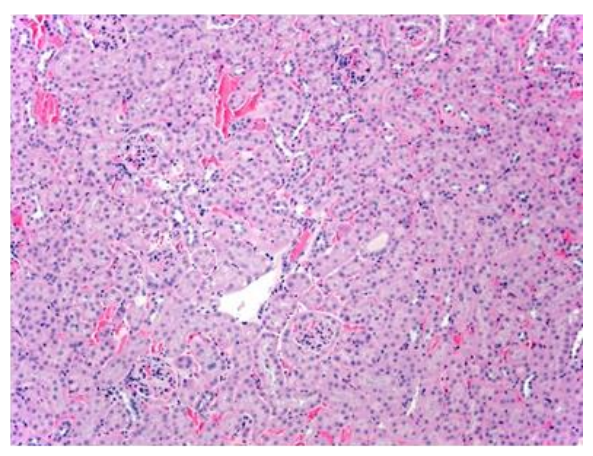

C)

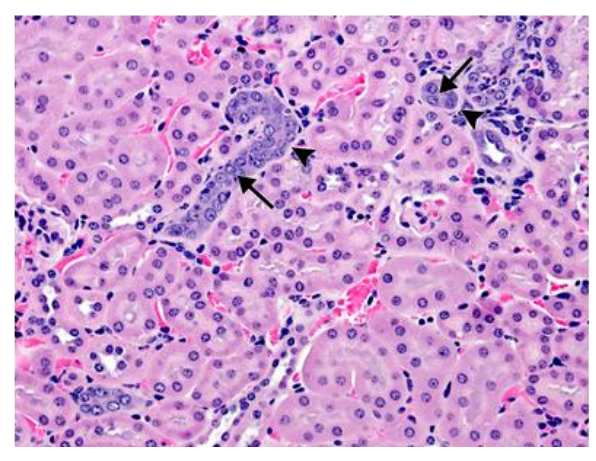

Figure 18. Renal Tubule Vacuolation in the Kidney from Male B6C3F1/N Mice Exposed to 0 or 10,000 ppm 2-Hydroxy-4-methoxybenzophenone for Two Years (H\&E)

Vacuolation of the renal tubules, typically in the outer cortex, is a normal background finding in control male mice. B) The renal tubules of a male mouse exposed to 10,000 ppm 2-hydroxy-4-methoxybenzophenone show a lack of vacuoles (cytoplasmic vacuolation) compared to what is typically seen in male mice. C) Basophilic tubules (arrows) with thickened basement membranes (arrowheads) are evidence of minimal chronic progressive nephropathy in a male mouse exposed to $10,000 \mathrm{ppm}$ 2-hydroxy-4-methoxybenzophenone. In addition, the normal vacuoles seen in the renal tubules of male mice are not present (cytoplasmic alteration). 
Other tissues: In the Harderian gland, the incidence of adenoma was significantly increased in $1,000 \mathrm{ppm}$ females compared to the control group $(1 / 50,6 / 50,4 / 50,3 / 50$; Appendix H). None of these values was outside the historical control range (33/640; range: $2 \%$ to $18 \%$ ),

Relative to the control group, significantly increased incidences of focal hyperplasia in the pituitary gland (pars distalis) $(15 / 47,24 / 49,14 / 47,17 / 50)$ and follicular degeneration in the thyroid gland $(20 / 48,30 / 49,18 / 48,20 / 48)$ occurred in 1,000 ppm females (Appendix H).

In the pancreatic islets, significantly decreased incidences of hyperplasia occurred in 10,000 ppm males $(29 / 47,31 / 50,25 / 48,20 / 50)$ and 1,000 and $3,000 \mathrm{ppm}$ females compared to their respective control group $(11 / 49,3 / 49,4 / 49,7 / 49)$ (Appendix H).

In the adrenal cortex, the incidences of accessory adrenal cortical nodules in 1,000 and $3,000 \mathrm{ppm}$ females were significantly less than that in the control group $(9 / 50,2 / 50,2 / 50,4 / 50$; Appendix H).

None of these lesions was considered toxicologically significant.

\section{Genetic Toxicology}

2H4MBP (20 to 6,000 $\mu \mathrm{g} / \mathrm{plate}$ ) was not mutagenic in Salmonella typhimurium strains TA98 or TA100 or Escherichia coli strain WP2 uvrA/pKM101 when tested with and without $10 \%$ rat liver metabolic activation enzymes (S9) (Table A-1). 


\section{Discussion}

These National Toxicology Program (NTP) dietary studies evaluated the toxic and carcinogenic potential of 2H4MBP. Two-year studies in Hsd:Sprague Dawley ${ }^{\circledR} \mathrm{SD}^{\circledR}$ rats, with exposure beginning in utero, and in $\mathrm{B} 6 \mathrm{C} 3 \mathrm{~F} 1 / \mathrm{N}$ mice were conducted at exposure concentrations of 0 , $1,000,3,000$, and 10,000 ppm 2H4MBP in feed. The initiation of $\mathrm{F}_{1}$ generation exposure on GD 6 (after expected implantation) in the 2-year rat study was selected to reflect potential human exposure to $2 \mathrm{H} 4 \mathrm{MBP}$, often present in sunscreens and cosmetics, which can occur at all human life stages, including in utero and early life. ${ }^{106}$ Information from previous NTP studies ${ }^{107 ; 32}$ was used to aid in selection of exposure concentrations for the 2-year study. An interim evaluation at 14 weeks on a subset of rats in the control and 10,000 ppm exposure groups was conducted to confirm expected responses. The oral route of administration was selected on the basis of NTP studies that used radiolabeled $2 \mathrm{H} 4 \mathrm{MBP}$ and that demonstrated disposition is similar between oral and dermal administration. ${ }^{15 ; 22}$ Moreover, given the pragmatic challenges of topical application in young small rodents, which requires the shaving of fur, and inter- and intra-animal grooming, exposure via dietary feed was selected.

Postweaning dietary $2 \mathrm{H} 4 \mathrm{MBP}$ was well tolerated in rats and did not adversely affect survival. Consumption of $2 \mathrm{H} 4 \mathrm{MBP}$ in the 1,000, 3,000, and 10,000 ppm groups resulted in average daily 2H4MBP doses of approximately 58, 168, and $585 \mathrm{mg} 2 \mathrm{H} 4 \mathrm{MBP} / \mathrm{kg}$ body weight for males and 60,180 , and $632 \mathrm{mg} / \mathrm{kg}$ for females. These doses translate to a range of 348 to $3,792 \mathrm{mg} / \mathrm{m}^{2}$, using a $\mathrm{K}_{\mathrm{m}}$ (body weight $[\mathrm{kg}] /$ surface area $\left[\mathrm{m}^{2}\right]$ ) value of 6 for rats ${ }^{108}$ and are only 5 - to 57 -fold higher than those used in a repeated dermal application study $\left(20 \mathrm{~g} / \mathrm{m}^{2}\right)$ study in postmenopausal women. ${ }^{109}$ NTP studies have shown previously that using plasma concentrations of $2 \mathrm{H} 4 \mathrm{MBP}$ in rats following feed exposure of 3,000-30,000 ppm compared to humans following repeated dermal application of $20 \mathrm{~g} / \mathrm{m}^{2}$ rat: human dose multiples were 0.1 to $4 .^{22}$ Human geometric mean maximum plasma concentrations of $2 \mathrm{H} 4 \mathrm{MBP}$ have been shown to be approximately $200 \mathrm{ng} / \mathrm{mL}$ when topically applied. This exceeds the FDA guidance of $0.5 \mathrm{ng} / \mathrm{mL}$ that would necessitate the conduct of additional nonclinical toxicity studies. ${ }^{110}$ Collectively, these data demonstrate similar external (5- to 57-fold) and internal (0.1- to 4-fold) exposure of 2H4MBP in rats and humans. However, the effects on body weight observed in both rats and mice precluded any higher dose levels in a chronic study.

The 14-week interim evaluation was conducted to ensure that there were no unexpected strain differences in response to $2 \mathrm{H} 4 \mathrm{MBP}$ in feed; this interim evaluation observed similar magnitude of 2H4MBP-induced effects on female body weight in Sprague Dawley rats exposed to $10,000 \mathrm{ppm} 2 \mathrm{H} 4 \mathrm{MBP}$ compared to that observed in female $\mathrm{F} 344 / \mathrm{N}$ rats exposed to $12,500 \mathrm{ppm}$ $2 \mathrm{H} 4 \mathrm{MBP}$ in the diet (12\% versus $11 \%$, respectively). ${ }^{32} \mathrm{~F} 334 / \mathrm{N}$ male rat body weights were not affected at 12,500 ppm 2H4MBP, consistent with what was observed in Sprague Dawley males in the current study (Appendix H). ${ }^{32}$ The observed increases in absolute and relative kidney weights in male Sprague Dawley rats and decrease in absolute kidney weight in female Sprague Dawley rats exposed to $10,000 \mathrm{ppm} 2 \mathrm{H} 4 \mathrm{MBP}$ were not observed in the F344/N rats exposed to 12,500 ppm 2H4MBP (Appendix H). ${ }^{32}$ However, increases in absolute and relative kidney weights were observed in male $\mathrm{F} 344 / \mathrm{N}$ rats exposed to 50,000 ppm 2H4MBP, and females exposed to 25,000 or $50,000 \mathrm{ppm} 2 \mathrm{H} 4 \mathrm{MBP}$ in feed. ${ }^{32}$ The absence of histopathological findings in the kidneys of Sprague Dawley rats at the interim evaluation is also consistent with what was 
previously observed at 12,500 ppm in F344/N male and female rats (Appendix H). ${ }^{32}$ The observed increase ( $20 \%)$ in absolute and relative male Sprague Dawley rat liver weights is fairly consistent with what was previously observed in male $\mathrm{F} 344 / \mathrm{N}$ rats $(26 \%$ and $31 \%$, respectively) exposed to $12,500 \mathrm{ppm}$ (Appendix $\mathrm{H}) .{ }^{32}$ The increase in relative liver weight was comparable to that observed in the female F334/N rats exposed to $12,500 \mathrm{ppm}$ (Appendix $\mathrm{H}$ ). ${ }^{32}$ In general, 2H4MBP-induced responses in the Sprague Dawley rats were consistent with those observed previously in the $\mathrm{F} 344 / \mathrm{N}$ rats.

At the 14-week interim evaluation in rats, the observed increase in liver weight in males exposed to $10,000 \mathrm{ppm} 2 \mathrm{H} 4 \mathrm{MBP}$ occurred concomitantly with a significantly increased incidence of mixed-cell cellular infiltration. However, it is unlikely that the cellular infiltrates, which were all of minimal severity, would be responsible for the changes in the liver weights observed in male rats at this time point. $2 \mathrm{H} 4 \mathrm{MBP}$ exposure has been shown to increase hepatic Cyplal and Cyp4a expression the magnitude of which is consistent with enzyme induction and moderate increase in tissue weight. In the NTP Modified One-Generation (MOG) ${ }^{111}$ study, focal inflammation was observed in all $\mathrm{F}_{1}$ male exposure groups in the reproductive performance cohort $(\sim 8-25 \%)$, including the control group (7\%), with the low exposure group of 3,000 ppm displaying the highest incidence (10/40). The incidence in $\mathrm{F}_{1}$ females was $5 \%$ at $30,000 \mathrm{ppm}$, the only $2 \mathrm{H} 4 \mathrm{MBP}$ exposure group examined.

The absence of appreciable alterations in the kidneys after 14 weeks of 2H4MBP exposure was somewhat unexpected given the previous reports of 2H4MBP-induced kidney histopathology in male $\mathrm{F} 344 / \mathrm{N}$ rats at exposure concentrations $\geq 12,500 \mathrm{ppm}$ in the diet. ${ }^{32}$ This could be a function of dose, given that in the NTP MOG study, a dietary concentration of $10,000 \mathrm{ppm}$ - the highest concentration used in the current study - did not result in apparent 2H4MBP-related adverse histopathological kidney findings following a similar duration of exposure. However, rats exposed to 30,000 ppm in the MOG study did display 2H4MBP-related kidney findings in renal tubules and pelvises (concretions, epithelial degeneration, and dilatation).

In the 2-year study, the incidences of malignant meningiomas in the brain in male rats were higher in the 1,000 and 3,000 ppm groups (1/50 [1/25 litters]; 3/50 [2/25 litters]) than in the control group (0/50 [0/29 litters]) or in the $10,000 \mathrm{ppm}$ group (0/50 [0/28 litters]). In addition, one malignant meningioma was diagnosed in the spinal cord of a male rat in the $3,000 \mathrm{ppm}$ group. Spinal cords were only examined from animals displaying clinical neurologic signs, however, so it is possible that the true incidence of spinal cord neoplasms was underreported. Although not dose responsive, these incidences of malignant meningiomas exceeded previous historical control incidences (none was observed in the control groups from six previously conducted studies) and therefore was considered equivocal evidence of carcinogenic activity. This conclusion is consistent with conclusions summarized in a previous NTP technical report (TR 356 - Toxicology and Carcinogenesis Studies of Furosemide) that found three meningiomas, all in male rats from the low-dose group, and this was considered equivocal evidence of carcinogenic activity. ${ }^{112}$

Although the malignant meningiomas observed in the brain in this study lacked features resembling granular cells tumors sometimes seen in benign meningiomas, the possibility that some meningiomas and granular cell tumors share a common progenitor is noteworthy. However, whereas benign granular cell tumors have been recorded in the historical controls for this study, malignant meningiomas have not. Therefore, although it may be beneficial to consider 
the combination of granular cell tumors and meningiomas, it is also necessary to consider malignant meningiomas on their own for the interpretation of the data in this study.

The incidences of thyroid gland C-cell adenoma in all groups of female rats exposed to dietary 2H4MBP for 2 years were higher than that in the control group, but the occurrences were not related to exposure concentration, and the higher incidence was only statistically significant at 3,000 ppm: 5/50 (5/29 litters) in the control group; 11/50 (10/25 litters); 17/50 (15/25 litters); and $10 / 50$ (9/29 litters) in the 1,000,3,000, and 10,000 ppm groups, respectively. This incidence exceeded the historical control incidence of recent NTP studies (38/339; range: $4 \%$ to $22 \%$ ).

Along with the lack of a dose response, there were no increases in the incidences of thyroid gland C-cell hyperplasia or C-cell carcinomas when compared to the control group, nor was there any support from the males concerning proliferative lesions of the $\mathrm{C}$-cells. Therefore, it was considered that thyroid gland $\mathrm{C}$-cell adenomas in female rats may have been related to 2H4MBP exposure.

Female rats exposed to all dietary concentrations of $2 \mathrm{H} 4 \mathrm{MBP}$ for 2 years had increased incidences of uterine stromal polyps (15/50 [12/25 litters]; 18/50 [16/25 litters]; 10/50 [10/29 litters]) relative to the control group (8/50 [8/29 litters]); the 3,000 ppm group was the only group that displayed a statistically significant difference from the control group. While stromal sarcomas only occurred in $2 \mathrm{H} 4 \mathrm{MBP}$ exposed groups and not in the control group, the numbers of stromal sarcomas were not significantly different between the control group and any of the exposed groups; hence, it was considered that the increased incidences of uterine stromal polyps may have been related to $2 \mathrm{H} 4 \mathrm{MBP}$ exposure.

The 3,000 ppm females also had a significantly higher incidence of atypical endometrial hyperplasia relative to the control group, which is considered a preneoplastic lesion of the uterine epithelium. However, that exposure group had a significantly lower incidence of uterine adenocarcinomas. These findings are inconsistent with the purported 2H4MBP estrogenic activity given that ultra-low doses (2-50 parts per billion [ppb]) of ethinyl estradiol have shown to be associated with increased incidences of both atypical uterine focal hyperplasia $(6 / 51,14 / 50$, $16 / 49,20 / 50)$ and squamous metaplasia $(2 / 51,6 / 50,8 / 49,13 / 50)$ in female Sprague Dawley rats. $^{113}$

In the 2-year rat study, the incidence of mammary gland fibroadenoma in the female $10,000 \mathrm{ppm}$ group (18/50 [18/29 litters]) was significantly lower than the control incidence (32/50 [23/29 litters]). Similarly, the $10,000 \mathrm{ppm}$ group displayed a lower incidence of mammary gland carcinoma (1/50 [1/29 litters]) than did the control group (7/50 [6/29 litters]). The concurrent control incidence of fibroadenomas is higher than recent historical control incidences (195/340; range: $40 \%$ to $70 \%$ ). The incidence of mammary gland carcinomas in the concurrent control is also higher than recent historical control incidences (30/340; range: $4 \%$ to $14 \%$ ). The 10,000 ppm females had a mean body weight at terminal sacrifice that was $76 \%$ of the control group, and this lower body weight might have contributed to the lower incidences of mammary gland carcinomas and fibroadenomas in this group. ${ }^{114}$ These $2 \mathrm{H} 4 \mathrm{MBP}$ findings are also inconsistent with the purported $2 \mathrm{H} 4 \mathrm{MBP}$ estrogenic activity. Exposure to ultra-low dose (2$50 \mathrm{ppb}$ ) ethinyl estradiol has been reported to be associated with an increased incidence of mammary alveolar or ductal hyperplasia in male Sprague Dawley rats (1/44, 4/45, 8/47, 
21/44). ${ }^{113}$ No changes in the incidences of mammary gland lesions were observed in males exposed to $2 \mathrm{H} 4 \mathrm{MBP}$.

At the end of the 2-year study, the incidences of focal hypertrophy within the adrenal cortex were significantly higher in females exposed to $1,000(42 / 50)$ or $3,000 \mathrm{ppm}(39 / 50) 2 \mathrm{H} 4 \mathrm{MBP}$ relative to the control group (24/50). These findings were not associated with an increased incidence of adrenocortical neoplasia.

In male rats, there was an increase in the incidence of interstitial cell hyperplasia of the testes in the 10,000 ppm group, but the increase was not statistically different from controls with a pairwise comparison. No interstitial cell adenomas were observed in male rats of any group in the study.

The 2-year study was conducted in $\mathrm{B} 6 \mathrm{C} 3 \mathrm{~F} 1 / \mathrm{N}$ mice at dietary exposure concentrations of 0 , $1,000,3,000$, and 10,000 ppm, which resulted in average daily doses of approximately 113, 339, and $1,207 \mathrm{mg} 2 \mathrm{H} 4 \mathrm{MBP} / \mathrm{kg}$ body weight for males and 109,320 , and $1,278 \mathrm{mg} / \mathrm{kg}$ for females. 2H4MBP exposure did not affect survival of either sex. After several months of 2H4MBP exposure, both males and females in the 10,000 ppm groups displayed lower body weights $(>10 \%)$. No 2H4MBP-related increases in the incidences of neoplastic lesions were observed in the 2-year study.

Increased incidences of bone marrow pigment (hemosiderin) were observed in both male and female mice exposed to $10,000 \mathrm{ppm} 2 \mathrm{H} 4 \mathrm{MBP}$ for 2 years. The incidences of pigment in the spleen were higher in males and females exposed to 3,000 and 10,000 ppm 2H4MBP. Increased levels of hemosiderin in the spleen of mice can be associated with increased erythrocyte turnover. ${ }^{115}$ In the current study there was no other evidence of an increase in the turnover of erythrocytes, such as changes in the cellularity of the bone marrow, or increased extramedullary hematopoiesis in the spleen. Additionally, there were no changes in hematology parameters or bone marrow histology in a 13 -week dosed feed 2 H4MBP mouse study. ${ }^{32}$

The incidences of hepatocyte syncytial alteration were significantly increased in all 2H4MBPexposed groups of male mice. Ethylbenzene induced a similar response in the male mouse, ${ }^{32}$ and these compounds share some structural similarities. ${ }^{32}$ As with $2 \mathrm{H} 4 \mathrm{MBP}$ no association was found between the syncytial cells and hepatocellular neoplasia in male mice in the ethylbenzene study, although there were increased incidences of hepatocellular tumors in female mice.

2H4MBP dietary exposure in male mice was associated with an increased incidence of renal tubule cytoplasmic alteration at 10,000 ppm. Vacuolation of the renal tubules, typically in the outer cortex, is a normal background finding in male mice. ${ }^{116}$ The presence of these vacuoles is not recorded as a lesion; however, when a decrease in the vacuolation of the renal tubules is noted, it is typically recorded. In the current study, the normal background vacuolation decreased in renal tubules in the $10,000 \mathrm{ppm}$ males, and this was recorded as an increased incidence of cytoplasmic alteration. 


\section{Conclusions}

Under the conditions of these 2-year studies, there was equivocal evidence of carcinogenic activity ${ }^{c}$ of $2 \mathrm{H} 4 \mathrm{MBP}$ exposure in male Hsd:Sprague Dawley ${ }^{\circledR} \mathrm{SD}^{\circledR}$ rats based on the occurrence of malignant meningiomas in the brain. There was equivocal evidence of carcinogenic activity in female Hsd:Sprague Dawley ${ }^{\circledR} \mathrm{SD}^{\circledR}$ rats based on the increased incidence of thyroid C-cell adenomas and the increased incidence of uterine stromal polyps. There was no evidence of carcinogenic activity in male or female $\mathrm{B} 6 \mathrm{C} 3 \mathrm{~F} 1 / \mathrm{N}$ mice at exposure concentrations of 1,000 , 3,000 , and 10,000 ppm.

Increases in the incidences of nonneoplastic lesions of the testis in male rats and of the uterus and adrenal cortex in female rats occurred with exposure to $2 \mathrm{H} 4 \mathrm{MBP}$. Increases in the incidences of nonneoplastic lesions of the bone marrow (males and females), spleen (males and females), kidney (males and females), and liver (males) in mice occurred with exposure to 2H4MBP.

${ }^{\mathrm{c} S e e}$ Explanation of Levels of Evidence of Carcinogenic Activity. 


\section{References}

1. Tarras-Wahlberg N, Rosén A, Stenhagen G, Larkö O, Wennberg A-M, Wennerström O. Changes in ultraviolet absorption of sunscreens after ultraviolet irradiation. J Invest Dermatol. 1999; 113(4):547-553.

2. Hazardous Substances Data Bank (HSDB). 2-Hydroxy-4-methoxybenzophenone. Bethesda, MD: National Library of Medicine, Toxnet; 2018. http://toxnet.nlm.nih.gov/cgibin/sis/search2/r?dbs+hsdb: @ term+@DOCNO+4503 [Accessed: July 11, 2018]

3. Environmental Working Group (EWG). EWG's guide to sunscreen. 2017. https://www.ewg.org/sunscreen/ [Accessed: July, 2017 ]

4. Iguana LLC. Sunsect insect repellent sunscreen-octinoxate, oxybenzone, octisalate loction. 2015. https://dailymed.nlm.nih.gov/dailymed/getFile.cfm?setid=6ccdc093-8af9-4bd8-84b0$\underline{\text { f229fccd } 2 \mathrm{f} 1 \mathrm{c} \& \mathrm{type}=\mathrm{pdf}}$

5. BASF AG. Technical inforation, Uvinul, T-Lite and Z-Cote grades, MEMC 050103e-00. 2005.

6. Christian M. Final report on the safety assessment of benzophenones-1,-3,-4,-5,-9, and-11. J Am College Toxicol. 1983; 2:35-73.

7. Yousif E, Haddad R. Photodegradation and photostabilization of polymers, especially polystyrene. SpringerPlus. 2013; 2(1):398.

8. Code of Federal Regulations (CFR). 21:§177.1010.

9. Han C, Lim Y-H, Hong Y-C. Ten-year trends in urinary concentrations of triclosan and benzophenone-3 in the general US population from 2003 to 2012. Environ Pollut. 2016; 208:803-810.

10. Wang L, Kannan K. Characteristic profiles of benzonphenone-3 and its derivatives in urine of children and adults from the United States and China. Environ Sci Technol. 2013; 47(21):12532-12538.

11. Calafat AM, Wong L-Y, Ye X, Reidy JA, Needham LL. Concentrations of the sunscreen agent benzophenone-3 in residents of the United States: National Health and Nutrition Examination Survey 2003-2004. Environ Health Perspect. 2008; 116(7):893-897.

12. Code of Federal Regulations (CFR). 21:Part 352.

13. U.S. Environmental Protection Agency (USEPA). Methanone, (2-hydroxy-4methoxyphenyl)phenyl-. 2020.

https://iaspub.epa.gov/apex/pesticides/f?p=INERTFINDER:3:::NO::P3_ID:7568

14. El Dareer SM, Kalin JR, Tillery KF, Hill DL. Disposition of 2-hydroxy-4methoxybenzophenone in rats dosed orally, intravenously, or topically. J Toxicol Environ Health. 1986; 19(4):491-502. 
15. Mutlu E, Garner CE, Wegerski CJ, McDonald JD, McIntyre BS, Doyle-Eisele M, Waidyanatha S. Metabolism and disposition of 2-hydroxy-4-methoxybenzophenone, a sunscreen ingredient, in Harlan Sprague Dawley rats and B6C3F1/N mice; a species and route comparison. Xenobiotica. 2019; 31:1-16. 10.1080/00498254.2019.1680906. [Epub ahead of print]

16. Kadry AM, Okereke CS, Abdel-Rahman MS, Friedman MA, Davis RA. Pharmacokinetics of benzophenone-3 after oral exposure in male rats. J Appl Toxicol. 1995; 15(2):97-102.

17. Jeon H-K, Sarma SN, Kim Y-J, Ryu J-C. Toxicokinetics and metabolisms of benzophenonetype UV filters in rats. Toxicology. 2008; 248(2-3):89-95.

18. Okereke CS, Abdel-Rhaman MS, Friedman MA. Disposition of benzophenone-3 after dermal administration in male rats. Toxicol Lett. 1994; 73(2):113-122.

19. Kamikyouden N, Sugihara K, Watanabe Y, Uramaru N, Murahashi T, Kuroyanagi M, Sanoh S, Ohta S, Kitamura S. 2, 5-Dihydroxy-4-methoxybenzophenone: A novel major in vitro metabolite of benzophenone-3 formed by rat and human liver microsomes. Xenobiotica. 2013; 43(6):514-519.

20. Nakagawa Y, Suzuki T. Metabolism of 2-hydroxy-4-methoxybenzophenone in isolated rat hepatocytes and xenoestrogenic effects of its metabolites on MCF-7 human breast cancer cells. Chem Biol Interact. 2002; 139(2):115-128.

21. Nakamura N, Inselman AL, White GA, Chang CW, Trbojevich RA, Sephr E, Voris KL, Patton RE, Bryant MS, Harrouk W. Effects of Maternal and Lactational Exposure to 2-Hydroxy4-Methoxybenzone on Development and Reproductive Organs in Male and Female Rat Offspring. Birth Defects Res B: Dev Reprod Toxicol. 2015; 104(1):35-51.

22. Mutlu E, Pierfelice J, McIntyre BS, Cunny HC, Kissling GE, Burback B, Waidyanatha S. Simultaneous quantitation of 2-hydroxy-4-methoxybenzophenone, a sunscreen ingredient, and its metabolites in Harlan Sprague Dawley rat plasma following perinatal dietary exposure. J Anal Toxicol. 2017; 41(9):744-754.

23. Janjua N, Kongshoj B, Andersson AM, Wulf HC. Sunscreens in human plasma and urine after repeated whole-body topical application. J Eur Acad Dermatol Venereol. 2008; 22(4):456461.

24. Jiang R, Roberts M, Collins D, Benson H. Absorption of sunscreens across human skin: An evaluation of commercial products for children and adults. Br J Clin Pharmacol. 1999; 48:635637.

25. Gonzalez H, Farbrot A, Larkö O. Percutaneous absorption of benzophenone-3, a common component of topical sunscreens. Clin Exp Dermatol. 2002; 27(8):691-694.

26. Tarazona I, Chisvert A, Salvador A. Determination of benzophenone-3 and its main metabolites in human serum by dispersive liquid-liquid microextraction followed by liquid chromatography tandem mass spectrometry. Talanta. 2013; 116:388-395.

27. Gonzalez H, Farbrot A, Larkö O, Wennberg AM. Percutaneous absorption of the sunscreen benzophenone-3 after repeated whole-body applications, with and without ultraviolet irradiation. Br J Dermatol. 2006; 154(2):337-340. 
28. Zamoiski RD, Cahoon EK, Freedman DM, Linet MS. Self-reported sunscreen use and urinary benzophenone-3 concentrations in the United States: NHANES 2003-2006 and 20092012. Environ Res. 2015; 142:563-567.

29. Hines EP, Mendola P, von Ehrenstein OS, Ye X, Calafat AM, Fenton SE. Concentrations of environmental phenols and parabens in milk, urine and serum of lactating North Carolina women. Reprod Toxicol. 2015; 54:120-128.

30. Rodríguez-Gómez R, Zafra-Gómez A, Camino-Sánchez F, Ballesteros O, Navalón A. Gas chromatography and ultra high performance liquid chromatography tandem mass spectrometry methods for the determination of selected endocrine disrupting chemicals in human breast milk after stir-bar sorptive extraction. J Chromatogr. 2014; 1349:69-79.

31. Lewerenz H-J, Lewerenz G, Plass R. Akute und subchronische toxizitätsuntersuchungen des UV-absorbers MOB an ratten [In German]. Food Cosmet Toxicol. 1972; 10(1):41-50.

32. National Toxicology Program (NTP). NTP technical report on toxicity studies of 2-hydroxy4-methoxybenzophenone (CAS number: 131-57-7) administered topically and in dosed feed to F344/N rats and B6C3F1 mice. Research Triangle Park, NC: United States Department of Health and Human Services, Public Health Service, National Institutes of Health; 1992. Toxicity Report 21. NIH Publication No. 92-3344.

33. National Toxicology Program (NTP). 2-Hydroxy-4-methoxybenzophenone: Administered topically and in dosed feed to F344/N Rats and B6C3F 1 mice. Research Triangle Park, NC: U.S. Department of Health and Human Services, Public Health Service, National Toxicology Program; 1992. https://ntp.niehs.nih.gov/ntp/htdocs/st_rpts/tox021.pdf

34. Okereke CS, Barat SA, Abdel-Rahman MS. Safety evaluation of benzophenone-3 after dermal administration in rats. Toxicol Lett. 1995; 80(1-3):61-67.

35. Kunz PY, Fent K. Multiple hormonal activities of UV filters and comparison of in vivo and in vitro estrogenic activity of ethyl-4-aminobenzoate in fish. Aquat Toxicol. 2006; 79(4):305324.

36. Miller D, Wheals BB, Beresford N, Sumpter JP. Estrogenic activity of phenolic additives determined by an in vitro yeast bioassay. Environ Health Perspect. 2001; 109(2):133-138.

37. Schreurs RH, Sonneveld E, Jansen JH, Seinen W, van der Burg B. Interaction of polycyclic musks and UV filters with the estrogen receptor (ER), androgen receptor (AR), and progesterone receptor (PR) in reporter gene bioassays. Toxicol Sci. 2004; 83(2):264-272.

38. Suzuki T, Kitamura S, Khota R, Sugihara K, Fujimoto N, Ohta S. Estrogenic and antiandrogenic activities of 17 benzophenone derivatives used as UV stabilizers and sunscreens. Toxicol Appl Pharmacol. 2005; 203(1):9-17.

39. Schreurs R, Lanser P, Seinen W, van der Burg B. Estrogenic activity of UV filters determined by an in vitro reporter gene assay and an in vivo transgenic zebrafish assay. Arch Toxicol. 2002; 76(5-6):257-261.

40. U.S. Environmental Protection Agency (USEPA). Endocrine disruptor screening program test guidelines-OPPTS 890.1250: Estrogen receptor binding assay using rat uterine cytosol (ER- 
RUC) [EPA 740-C-09-005]. EPA Docket ID: EPA-HQ-OPPT-2009-0576-0005. 2009. https://www.regulations.gov/document?D=EPA-HQ-OPPT-2009-0576-0005

41. U.S. Environmental Protection Agency (USEPA). Endocrine distruptor screening program test guidelines-OPPTS 890.1300: Estrogen receptor transcriptional activation (human cell line (HeLa-9903)) [EPA 740-C-09-006]. EPA Docket ID: EPA-HQ-OPPT-2009-0576-0006. 2009. https://www.regulations.gov/document?D=EPA-HQ-OPPT-2009-0576-0006

42. Schlumpf M, Cotton B, Conscience M, Haller V, Steinmann B, Lichtensteiger W. In vitro and in vivo estrogenicity of UV screens. Environ Health Perspect. 2001; 109(3):239-244.

43. Coronado M, De Haro H, Deng X, Rempel MA, Lavado R, Schlenk D. Estrogenic activity and reproductive effects of the UV-filter oxybenzone (2-hydroxy-4-methoxyphenyl-methanone) in fish. Aquat Toxicol. 2008; 90(3):182-187.

44. Kim S, Jung D, Kho Y, Choi K. Effects of benzophenone-3 exposure on endocrine disruption and reproduction of Japanese medaka (Oryzias latipes) - A two generation exposure study. Aquat Toxicol. 2014; 155:244-252.

45. National Toxicology Program (NTP). Final report on the reproductive toxicity of 2-hydroxy4-methoxybenzophenone in CD-1 Swiss mice. Research Triangle Park, NC: U.S. Department of Health and Human Services, Public Health Service, National Institutes of Health; 1990. RACB88076. https://ntp.niehs.nih.gov/testing/types/repro/abstracts/racb88076/index-63.html

46. Daston GP, Gettings SD, Carlton BD, Chudkowski M, Davis RA, Kraus AL, Luke CF, Oellette RE, Re TA, Hoberman AM. Assessment of the reproductive toxic potential of dermally applied 2-hydroxy-4-methoxybenzophenone to male B6C3F1 mice. Toxicol Sci. 1993; 20(1):120-124.

47. Wolff MS, Engel SM, Berkowitz GS, Ye X, Silva MJ, Zhu C, Wetmur J, Calafat AM. Prenatal phenol and phthalate exposures and birth outcomes. Environ Health Perspect. 2008; 116(8):1092-1097.

48. Philippat C, Mortamais M, Chevrier C, Petit C, Calafat AM, Ye X, Silva MJ, Brambilla C, Pin I, Charles M-A. Exposure to phthalates and phenols during pregnancy and offspring size at birth. Environ Health Perspect. 2011; 120(3):464-470.

49. U.S. National Library of Medicine (NLM). Hirschsprung disease. 2020. https://ghr.nlm.nih.gov/condition/hirschsprung-disease\#statistics

50. Huo W, Cai P, Chen M, Li H, Tang J, Xu C, Zhu D, Tang W, Xia Y. The relationship between prenatal exposure to BP-3 and Hirschsprung's disease. Chemosphere. 2016; 144:10911097.

51. Dinardo JC, Downs CA. Can oxybenzone cause Hirschsprung's disease? Reprod Toxicol. 2019. 10.1016/j.reprotox.2019.02.014

52. European Chemical Agency (ECHA). Entry for: Oxybenzone (CAS No. 131-57-7). 2017. https://echa.europa.eu/registration-dossier/-/registered-dossier/5515/7/5/1 
53. Trevisi P, Vincenzi C, Chieregato C, Guerra L, Tosti A. Sunscreen sensitization: A threeyear study. Dermatology. 1994; 189(1):55-57.

54. Agin PP, Ruble K, Hermansky SJ, McCarthy TJ. Rates of allergic sensitization and irritation to oxybenzone-containing sunscreen products: a quantitative meta-analysis of 64 exaggerated use studies. Photodermatol Photoimmunol Photomed. 2008; 24(4):211-217.

55. Bernard F, Barrault C, Deguercy A, De Wever B, Rosdy M. Development of a highly sensitive in vitro phototoxicity assay using the SkinEthicTM reconstructed human epidermis. Cell Biol Toxicol. 2000; 16(6):391-400.

56. Jonsen J, Jacobsen N, Hensten-Pettersen A. Bacterial muragenesis (Ames Test) as a screening method for carcinogenic substances of dental materials In: Winter GD, Leroy JL, De Groot K, editors. Evaluation of Biomaterials. London, UK: John Wiley \& Sons, Ltd; 1980. p. 333-339.

57. Bonin A, Arlauskas A, Angus D, Baker R, Gallagher C, Greenoak G, Brown ML, MeherHomji K, Reeve V. UV-absorbing and other sun-protecting substances: Genotoxicity of 2ethylhexyl P-methoxycinnamate. Mutat Res Lett. 1982; 105(5):303-308.

58. Morita K, Ishigaki M, Abe T. Mutagenicity of materials related with cosmetics. J Soc Cosmet Chem Jpn. 1981; 15(3):243-253.

59. Mortelmans K, Haworth S, Lawlor T, Speck W, Tainer B, Zeiger E. Salmonella mutagenicity tests: II. Results from the testing of 270 chemicals. Environ Mutagen. 1986; 8(S7 S7):56-119.

60. Dunkel VC, Zeiger E, Brusick D, McCoy E, McGregor D, Mortelmans K, Rosenkranz HS, Simmon VF. Reproducibility of microbial mutagenicity assays: II. Testing of carcinogens and noncarcinogens in Salmonella typhimurium and Escherichia coli. Environ Mutagen. 1985; 7(S5):1-19.

61. Mitchell AD, Rudd CJ, Caspary WJ. Evaluation of the L5178Y mouse lymphoma cell mutagenesis assay: Intralaboratory results for sixty-three coded chemicals tested at SRI International. Environ Mutagen. 1988; 12(S13):37-101.

62. Myhr BC, Caspary WJ. Evaluation of the L5178Y mouse lymphoma cell mutagenesis assay: Intralaboratory results for sixty-three coded chemicals tested at Litton Bionetics, Inc. Environ Mutagen. 1988; 12(S13):103-194.

63. National Cancer Institute (NCI). Bioassay of Michler's ketone for possible carcinogenicity. CAS No. 90-94-8. Bethesda, MD: U.S. Department of Health, Education, and Welfare, Public Health Services, National Institutes of Health; 1979. NCI-CG-TR-181. NIH Publication No. 791737.

64. Zeiger E, Anderson B, Haworth S, Lawlor T, Mortelmans K. Salmonella mutagenicity tests: V. Results from the testing of 311 chemicals. Environ Mol Mutag. 1992; 19(S21):2-141.

65. Robison SH, Odio MR, Thompson ED, Aardema MJ, Kraus AL. Assessment of the in vivo genotoxicity of 2-hydroxy 4-methoxybenzophenone. Environ Mol Mutag. 1994; 23(4):312-317. 
66. Sadtler Scholl Polymer Processing Chemicals Library. HS No. 5801. Hercules, CA. Bio-Rad Laboratories; [date unknown].

67. National Institute of Advanced Industrial Science and Technology (NIAIST). Spectral Database for Organic Compunds (SDOC): Spectrum No. 5800. Tokyo, Japan; 1999. https://sdbs.db.aist.go.jp/sdbs/cgi-bin/direct_frame_top.cgi

68. Maronpot R, Boorman G. Interpretation of rodent hepatocellular proliferative alterations and hepatocellular tumors in chemical safety assessment. Toxicol Pathol. 1982; 10(2):71-78.

69. Boorman GA, Montgomery CA, Jr., Eustis SL, Wolfe MJ, McConnell EE, Hardisty JF. Quality assurance in pathology for rodent carcinogenicity studies In: Milman HA, Weisburger EK, editors. Handbook of Carcinogen Testing. Park Ridge, NJ: Noyes Publications; 1985. p. $345-357$.

70. Brix AE, Hardisty JF, McConnell EE. Combining neoplasms for evaluation of rodent carcinogenesis studies In: Hsu C-H, Stedeford T, editors. Cancer Risk Assessment. Hoboken, NJ: John Wiley \& Sons, Inc.; 2010. p. 699-715.

71. Kaplan EL, Meier P. Nonparametric estimation from incomplete observations. J Am Stat Assoc. 1958; 53(282):457-481.

72. Tarone RE. Tests for trend in life table analysis. Biometrika. 1975; 62(3):679-690.

73. Cox DR. Regression models and life-tables. J R Stat Soc. 1972; 34(2):187-202.

74. Bailer AJ, Portier CJ. Effects of treatment-induced mortality and tumor-induced mortality on tests for carcinogenicity in small samples. Biometrics. 1988:417-431.

75. Piegorsch WW, Bailer AJ. Statistics for Environmental Biology and Toxicology, Section 6.3.2. London, UK: Chapman and Hall; 1997.

76. Portier C, Bailer A. Testing for increased carcinogenicity using a survival-adjusted quantal response test. Toxicol Sci. 1989; 12(4):731-737.

77. Portier CJ, Hedges JC, Hoel DG. Age-specific models of mortality and tumor onset for historical control animals in the National Toxicology Program's carcinogenicity experiments. Cancer Res. 1986; 46(9):4372-4378.

78. Bieler GS, Williams RL. Ratio estimates, the delta method, and quantal response tests for increased carcinogenicity. Biometrics. 1993:793-801.

79. Nam J-M. A simple approximation for calculating sample sizes for detecting linear trend in proportions. Biometrics. 1987:701-705.

80. Rao J, Scott A. A simple method for the analysis of clustered binary data. Biometrics. 1992:577-585.

81. Fung K, Krewski D, Rao J, Scott A. Tests for trend in developmental toxicity experiments with correlated binary data. Risk Anal. 1994; 14(4):639-648. 
82. Gart JJ, Chu KC, Tarone RE. Statistical issues in interpretation of chronic bioassay tests for carcinogenicity. J Natl Cancer Inst. 1979; 62(4):957-974.

83. Dixon WJ, Massey FJ, Jr. Introduction to statistical analysis, 2nd ed. New York, NY: McGraw-Hill Book Company; 1957. p. 276-278, 412.

84. Tukey JW. Easy summaries - numerical and graphical. Reading, MA: Addison-Wesley; 1977.

85. Dunnett CW. A multiple comparison procedure for comparing several treatments with a control. J Am Stat Assoc. 1955; 50(272):1096-1121.

86. Williams D. A test for differences between treatment means when several dose levels are compared with a zero-dose control. Biometrics. 1971; 27:103-117.

87. Williams D. The comparison of several dose levels with a zero dose control. Biometrics. 1972:519-531.

88. Shirley E. A non-parametric equivalent of Williams' test for contrasting increasing dose levels of a treatment. Biometrics. 1977; 33(2):386-389.

89. Williams DA. A note on Shirley's nonparametric test for comparing several dose levels with a zero-dose control. Biometrics. 1986:183-186.

90. Dunn OJ. Multiple comparisons using rank sums. Technometrics. 1964; 6(3):241-252. $10.2307 / 1266041$

91. Jonckheere AR. A distribution-free k-sample test against ordered alternatives. Biometrika. 1954; 41(1/2):133-145.

92. Hsu JC. The factor analytic approach to simultaneous inference in the general linear model. J Comput Graph Stat. 1992; 1(2):151-168.

93. Haseman J. Value of historical controls in the interpretation of rodent tumor data. Drug Inf J. 1992; 26(2):191-200.

94. Haseman JK. Data analysis: Statistical analysis and use of historical control data. Regul Toxicol Pharmacol. 1995; 21(1):52-59.

95. Haseman JK, Rao GN. Effects of corn oil, time-related changes, and inter-laboratory variability on tumor occurrence in control Fischer 344 (F344/N) rats. Toxicol Pathol. 1992; 20(1):52-60.

96. Code of Federal Regulations (CFR). 21:Part 58.

97. Miller JA, Miller EC. Ultimate chemical carcinogens as reactive mutagenic electrophiles In: Hiatt HH, Watson JD, Winsten JA, editors. Origins of Human Cancer. Cold Spring Harbor, NY: Cold Spring Harbor Laboratory; 1977. p. 605-627.

98. Crawford BD. Perspectives on the somatic mutation model of carcinogenesis In: Mehlman MA, Flamm WG, Lorentzen RJ, editors. Advances in Modern Environmental Toxicology 
Mechanisms and Toxicity of Chemical Carcinogens and Mutagens. Princeton, NJ: Princeton Scientific Publishing Co. Inc; 1985. p. 13-59.

99. Straus DS. Somatic mutation, cellular differentiation, and cancer causation. J Natl Cancer Inst. 1981; 67:233-241.

100. Ashby J, Tennant RW. Definitive relationships among chemical structure, carcinogenicity and mutagenicity for 301 chemicals tested by the US NTP. Mutat Res. 1991; 257(3):229-306.

101. Tennant RW, Margolin BH, Shelby MD, Zeiger E, Haseman JK, Spalding J, Caspary W, Resnick M, Stasiewicz S, Anderson B. Prediction of chemical carcinogenicity in rodents from in vitro genetic toxicity assays. Science. 1987; 236(4804):933-941.

102. Zeiger E, Haseman JK, Shelby MD, Margolin BH, Tennant RW, Holden H. Evaluation of four in vitro genetic toxicity tests for predicting rodent carcinogenicity: Confirmation of earlier results with 41 additional chemicals. Environ Mol Mutag. 1990; 16(S18):1-14.

103. Leininger JR, Jokinen MP. Oviduct, uterus, and vagina In: Boorman GA, Eustis SL, Elwell MR, Montgomery CA, Jr., MacKenzie WF, editors. Pathology of the Fischer Rat: Reference and Atlas. San Diego, CA: Academic Press Inc; 1990. p. 443-459.

104. Creasy D, Bube A, Rijk Ed, Kandori H, Kuwahara M, Masson R, Nolte T, Reams R, Regan $\mathrm{K}$, Rehm S et al. Proliferative and Nonproliferative Lesions of the Rat and Mouse Male Reproductive System. Toxicol Pathol. 2012; 40(6_suppl):40S-121S.

$10.1177 / 0192623312454337$

105. Jokinen MP, Walker NJ, Brix AE, Sells DM, Haseman JK, Nyska A. Increase in cardiovascular pathology in female Sprague-Dawley rats following chronic treatment with 2, 3, 7, 8-tetrachlorodibenzo-p-dioxin and 3, 3', 4, 4', 5-pentachlorobiphenyl. Cardiovasc Toxicol. 2003; 3(4):299.

106. Centers for Disease Control and Prevention (CDC). Fourth national report on human exposure to environmental chemicals: Updated tables, January 2019, volume one. Atlanta, GA: U.S. Department of Health and Human Services, National Center for Environmental Health; 2019. https://www.cdc.gov/exposurereport/pdf/FourthReport_UpdatedTables_Volume1_Jan2019508.pdf

107. National Toxicology Program (NTP). Abstract for RACB88076: 2-hydroxy-4methoxybenzophenone: Reproductive toxicity in CD-1 Swiss mice; dose 1.25, 2.5 \& 5\% in feed. Research Triangle Park: U.S. Department of Health and Human Services, Public Health Service, National Toxicology Program; 1990. NTIS\# PB91158477.

108. Reagan-Shaw S, Nihal M, Ahmad N. Dose translation from animal to human studies revisited. FASEB J. 2008; 22(3):659-661. 10.1096/fj.07-9574LSF

109. Janjua NR, Mogensen B, Andersson AM, Petersen JH, Henriksen M, Skakkebaek NE, Wulf HC. Systemic absorption of the sunscreens benzophenone-3, octyl-methoxycinnamate, and 3-(4methyl-benzylidene) camphor after whole-body topical application and reproductive hormone levels in humans. J Invest Dermatol. 2004; 123(1):57-61. 10.1111/j.0022-202X.2004.22725.x 
110. Matta MK, Zusterzeel R, Pilli NR, Patel V, Volpe DA, Florian J, Oh L, Bashaw E, Zineh I, Sanabria $\mathrm{C}$ et al. Effect of sunscreen application under maximal use conditions on plasma concentration of sunscreen active ingredients. A randomized clinical trial. JAMA. 2019; 321(21):2082-2091. 10.1001/jama.2019.5586

111. National Toxicology Program (NTP). DART-05: 2-Hydroxy-4-methoxybenzophenone: Growth and clinical finding tables (I), pathology tables (PA), developmental and reproductive tables (R) from NTP modified one generation dose range finding study and modified one generation main study studies. Research Triangle Park, NC: U.S. Department of Health and Human Services, Public Health Service, National Toxicology Program; 2019. https://tools.niehs.nih.gov/cebs3/views/?action=main.dataReview\&bin_id=14485

112. National Toxicology Program (NTP). NTP techical report on the toxicology and carcinogenesis studies of furosemide (CAS No. 54-31-9) in F344/N rats and B6C3F1 mice (feed studies). Research Triangle Park, NC: National Toxicology Program, U.S. Department of Health and Human Services, Public Health Service, National Institutes of Health; 1989. NTP TR 356. https://ntp.niehs.nih.gov/publications/reports/tr/300s/tr356/index.html?utm_source=direct\&utm

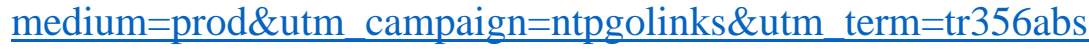

113. National Toxicology Program (NTP). NTP technical report on the toxicology and carcinogenesis study of ethinyl estradiol (CAS No. 57-63-6) in Sprague-Dawley rats (feed study). Research Triangle Park, NC: U.S. Department of Health and Human Services, Public Health Service, National Toxicology Program; 2010. Toxicity Report 548. NIH Publication No. 10-5889. https://ntp.niehs.nih.gov/ntp/htdocs/lt_rpts/tr548.pdf

114. Haseman JK, Young E, Eustis SL, Hailey JR. Body weight-tumor incidence correlations in long-term rodent carcinogenicity studies. Toxicology Pathology. 1997; 25(3):256-263. https://doi.org/10.1177/019262339702500302

115. Ward J, Mann P, Morishima H, Frith C. Thymus, spleen, and lymph nodes In: Maronpot R, editor. Pathology of the Mouse. Vienna, IL: Cache River Press; 1999. p. 333-360.

116. Seely J, Brix A. Kidney, renal tubule - Cytoplasmic alteration In: Cesta M, Herbert R, Brix A, Malarkey D, Sills R, editors. National Toxicology Program Nonneoplastic Lesion Atlas. Research Triangle Park, NC: National Toxicology Program; 2019.

117. Wilson CL, Miller CJ. Simpleaffy: A BioConductor package for Affymetrix Quality Control and data analysis. Bioinformatics. 2005; 21(18):3683-3685.

118. Irizarry RA, Bolstad BM, Collin F, Cope LM, Hobbs B, Speed TP. Summaries of Affymetrix GeneChip probe level data. Nucleic Acids Res. 2003; 31(4):e15-e15.

119. Ganter B, Tugendreich S, Pearson CI, Ayanoglu E, Baumhueter S, Bostian KA, Brady L, Browne LJ, Calvin JT, Day G-J. Development of a large-scale chemogenomics database to improve drug candidate selection and to understand mechanisms of chemical toxicity and action. J Biotechnol. 2005; 119(3):219-244.

120. Igarashi Y, Nakatsu N, Yamashita T, Ono A, Ohno Y, Urushidani T, Yamada H. Open TGGATEs: A large-scale toxicogenomics database. Nucleic Acids Res. 2014; 43(D1):D921-D927. 
121. Kupershmidt I, Su QJ, Grewal A, Sundaresh S, Halperin I, Flynn J, Shekar M, Wang H, Park J, Cui W. Ontology-based meta-analysis of global collections of high-throughput public data. PLoS One. 2010; 5(9):e13066.

122. Code of Federal Regulations (CFR). 9:1-4.

123. U.S. Environmental Protection Agency (USEPA). Endocrine disruptor screening program test guidelines-OPPTS 890.1600: Uterotrophic assay [EPA 740-C-09-0010]. EPA Docket ID: EPA-HQ-OPPT-2009-0576-0012. 2009. https://www.regulations.gov/document?D=EPA-HQOPPT-2009-0576-0012

124. National Research Council (US) Committee for the Update of the Guide for the Care and Use of Laboratory Animals. Guide for the care and use of laboratory animals. Washington D.C.: National Academies Press; 2011. 10.17226/12910

125. U.S. Environmental Protection Agency (USEPA). Endocrine distuptor screening program test guidelines-OPPTS 890.1150: Androgen receptor binding (rat prostate cytosol) [EPA 640-C09-003]. EPA Docket ID: EPA-HQ-OPPT-2009-0576-0003. 2009.

https://www.regulations.gov/document?D=EPA-HQ-OPPT-2009-0576-0003

126. U.S. Environmental Protection Agency (USEPA). Endocrine disruptor screening program test guidelines-OPPTS 890.1400: Hershberger bioassay [EPA 740-C09-008]. EPA Docket ID: EPA-HQ-OPPT-2009-0576-0008. 2009. https://www.regulations.gov/document?D=EPA-HQOPPT-2009-0576-0008

127. Organisation for Economic Cooperation and Development (OECD). OECD guideline for the testing of chemicals: Hershberger bioassay in rats: A short-term screening assay for (anti)androgenic properties Paris, France: OECD; 2009. OECD Guideline 441. https://ntp.niehs.nih.gov/iccvam/suppdocs/feddocs/oecd/oecd-tg441.pdf

128. U.S. Environmental Protection Agency (USEPA). Endocrine disruptor screening program test guidelines-OPPTS 890.1200: Aromatase (human recombinant) [EPA 740-C-09-004]. EPA Docket ID: EPA-HQ-OPPT-2009-0576-0004. 2009.

https://www.regulations.gov/document?D=EPA-HQ-OPPT-2009-0576-0004 


\section{Appendix A. Genetic Toxicology}

\section{Table of Contents}

A.1. Bacterial Mutagenicity Test Protocol ........................................................................ A-2

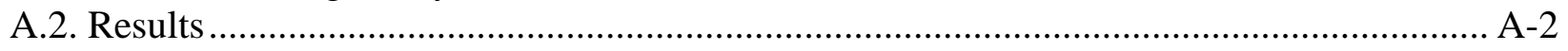

\section{Tables}

Table A-1. Mutagenicity of 2-Hydroxy-4-methoxybenzophenone in Bacterial Tester 


\section{A.1. Bacterial Mutagenicity Test Protocol}

Testing procedures were modified from those originally reported by Zeiger et al. ${ }^{64}$ Coded samples of 2-hydroxy-4-methoxybenzophenone (2H4MBP) (the same chemical lot that was used in the 2-year bioassays) were incubated with the Salmonella typhimurium (TA98, TA100) or Escherichia coli (WP2 uvrA pKM101) tester strains either in buffer or S9 mix (metabolic activation enzymes and cofactors from phenobarbital/benzoflavone-induced male Sprague Dawley rat liver) for 20 minutes at $37^{\circ} \mathrm{C}$. Top agar supplemented with L-histidine (or tryptophan for the E. coli strain) and d-biotin was added, and the contents of the tubes were mixed and poured onto the surfaces of minimal glucose agar plates. Histidine- or tryptophan-independent mutant colonies arising on these plates were counted following incubation for 2 days at $37^{\circ} \mathrm{C}$.

Each trial consisted of triplicate plates of concurrent positive and negative controls and at least five doses of $2 \mathrm{H} 4 \mathrm{MBP}$. The highest concentration tested was limited by toxicity in strain TA100; the other two strains were tested up to the assay limit dose of $6,000 \mu \mathrm{g} /$ plate. All trials were repeated.

In this assay, a positive response is defined as a reproducible, dose-related increase in histidineindependent (revertant) colonies in any one strain/activation combination. An equivocal response is defined as an increase in revertants that is not related to dose, not reproducible, or not of sufficient magnitude to support a determination of mutagenicity. A negative response is obtained when no increase in revertant colonies is observed following chemical treatment. No minimum percentage or fold increase is required for a chemical to be judged positive or weakly positive, although positive calls are typically reserved for increases in mutant colonies that are at least twofold over background.

\section{A.2. Results}

2H4MBP (20 to 6,000 $\mu \mathrm{g} / \mathrm{plate}$ ) was not mutagenic in $S$. typhimurium strains TA98 or TA100 or E. coli strain WP2 uvrA pKM101 when tested with and without $10 \%$ rat liver metabolic activation enzymes (S9) (Table A-1). 
Table A-1. Mutagenicity of 2-Hydroxy-4-methoxybenzophenone in Bacterial Tester Strains ${ }^{\text {a }}$

\begin{tabular}{|c|c|c|c|c|c|}
\hline Strain & $\begin{array}{c}\text { Concentration } \\
(\mu g / \text { plate })\end{array}$ & Without S9 & Without S9 & $\begin{array}{c}\text { With } 10 \% \text { Rat } \\
\text { S9 }\end{array}$ & $\begin{array}{c}\text { With } 10 \% \text { Rat } \\
\text { S9 }\end{array}$ \\
\hline \multicolumn{6}{|l|}{ TA100 } \\
\hline & 0 & $92.7 \pm 4.1$ & $111.7 \pm 10.7$ & $101.7 \pm 1.3$ & $156.3 \pm 3.3$ \\
\hline & 20 & $95.0 \pm 9.2$ & $120.3 \pm 9.8$ & - & - \\
\hline & 50 & $86.7 \pm 2.9$ & $115.0 \pm 6.0$ & $99.7 \pm 1.9$ & $157.7 \pm 7.9$ \\
\hline & 125 & $82.3 \pm 4.9$ & $126.0 \pm 4.6$ & $88.0 \pm 9.6$ & $147.3 \pm 10.3$ \\
\hline & 250 & $80.7 \pm 4.3$ & $83.3 \pm 1.9^{c}$ & $76.7 \pm 2.0$ & $128.0 \pm 15.2$ \\
\hline & 500 & $56.0 \pm 4.0$ & $51.3 \pm 6.0^{c}$ & $58.3 \pm 1.3$ & $84.7 \pm 6.7^{\mathrm{c}}$ \\
\hline & 1,000 & $14.3 \pm 1.9^{\mathrm{c}}$ & $54.3 \pm 16.3^{c}$ & $25.7 \pm 3.3^{\mathrm{c}}$ & $55.7 \pm 3.3^{\mathrm{c}}$ \\
\hline & 3,000 & - & - & $30.3 \pm 3.0^{\mathrm{c}}$ & $56.3 \pm 3.4^{\mathrm{c}}$ \\
\hline Trial Summary & & Negative & Negative & Negative & Negative \\
\hline Positive Control $^{\mathrm{b}}$ & & $658.3 \pm 14.4$ & $573.3 \pm 10.4$ & $542.0 \pm 9.5$ & $554.0 \pm 20.1$ \\
\hline \multicolumn{6}{|l|}{ TA98 } \\
\hline & 0 & $16.7 \pm 2.9$ & $17.7 \pm 3.3$ & $23.7 \pm 4.6$ & $22.0 \pm 1.0$ \\
\hline & 125 & $9.0 \pm 1.7$ & $10.3 \pm 3.7$ & $14.7 \pm 2.4$ & $27.0 \pm 2.3$ \\
\hline & 250 & $9.7 \pm 0.7$ & $15.7 \pm 1.9$ & $14.7 \pm 0.7$ & $17.7 \pm 0.7$ \\
\hline & 500 & $6.0 \pm 1.5$ & $10.3 \pm 1.9$ & $11.3 \pm 2.3$ & $14.3 \pm 0.9$ \\
\hline & 1,000 & $2.7 \pm 0.3^{c}$ & $3.3 \pm 0.3^{\mathrm{c}}$ & $12.0 \pm 2.3$ & $13.0 \pm 1.7^{\mathrm{c}}$ \\
\hline & 3,000 & $2.0 \pm 0.6^{\mathrm{c}}$ & $2.3 \pm 1.3^{\mathrm{c}}$ & $4.7 \pm 1.5^{\mathrm{c}}$ & $12.3 \pm 1.8^{\mathrm{c}}$ \\
\hline & 6,000 & $2.3 \pm 0.3^{\mathrm{c}}$ & $9.7 \pm 1.5^{\mathrm{c}}$ & $10.7 \pm 4.4^{\mathrm{c}}$ & $17.3 \pm 0.3^{\mathrm{c}}$ \\
\hline Trial Summary & & Negative & Negative & Negative & Negative \\
\hline Positive Control & & $537.7 \pm 9.8$ & $519.0 \pm 24.6$ & $1,485.7 \pm 67.2$ & $2,016.7 \pm 34.7$ \\
\hline \multicolumn{6}{|c|}{ Escherichia coli WP2 uvrA/pKM101 } \\
\hline & 0 & $116.0 \pm 11.5$ & $109.3 \pm 9.5$ & $155.0 \pm 9.3$ & $152.7 \pm 4.2$ \\
\hline & 125 & $106.0 \pm 7.1$ & $127.7 \pm 10.3$ & $161.0 \pm 3.1$ & $153.0 \pm 6.1$ \\
\hline & 250 & $118.7 \pm 8.1$ & $119.7 \pm 9.2$ & $145.3 \pm 11.9$ & $166.3 \pm 11.7$ \\
\hline & 500 & $99.7 \pm 5.5$ & $111.7 \pm 6.2$ & $137.3 \pm 12.0$ & $139.0 \pm 9.5$ \\
\hline & 1,000 & $90.3 \pm 2.8$ & $106.0 \pm 5.6$ & $117.0 \pm 8.0$ & $109.7 \pm 17.1^{\mathrm{c}}$ \\
\hline & 3,000 & $86.0 \pm 2.3^{c}$ & $101.0 \pm 7.2^{\mathrm{c}}$ & $105.3 \pm 1.7$ & $122.7 \pm 5.0^{c}$ \\
\hline & 6,000 & $102.0 \pm 11.2^{\mathrm{c}}$ & $116.0 \pm 12.5^{\mathrm{c}}$ & $110.3 \pm 16.4^{\mathrm{c}, \mathrm{d}}$ & $97.3 \pm 9.6^{c}$ \\
\hline Trial Summary & & Negative & Negative & Negative & Negative \\
\hline Positive Control & & $1,751.3 \pm 68.7$ & $1,984.0 \pm 82.4$ & $1,391.3 \pm 37.1$ & $1,178.0 \pm 35.4$ \\
\hline
\end{tabular}




\section{Appendix B. Chemical Characterization and Dose Formulation Studies}

\section{Table of Contents}

B.1. Procurement and Characterization of 2-Hydroxy-4-methoxybenzophenone ......................

B.2. Preparation and Analysis of Dose Formulations .............................................................

\section{Tables}

Table B-1. Preparation and Storage of Dose Formulations in the Perinatal and Two-year Feed Studies of 2-Hydroxy-4-methoxybenzophenone

Table B-2. Results of Analyses of Dose Formulations Administered to Rats in the Perinatal and Two-year Feed Study of 2-Hydroxy-4-methoxybenzophenone

Table B-3. Results of Analyses of Dose Formulations Administered to Mice in the Twoyear Feed Study of 2-Hydroxy-4-methoxybenzophenone

\section{Figures}

Figure B-1. Infrared Absorption Spectrum of 2-Hydroxy-4-methoxybenzophenone B-10 


\section{B.1. Procurement and Characterization of 2-Hydroxy-4- methoxybenzophenone}

2-Hydroxy-4-methoxybenzophenone (2H4MBP) was obtained from Ivy Fine Chemicals Corporation (Cherry Hill, NJ) in one lot (20080801) that was used in the perinatal and 2-year studies. Identity and purity analyses were conducted under the analytical chemistry laboratory and study laboratory at Battelle (Columbus, $\mathrm{OH}$ ). Reports on analyses performed in support of the 2H4MBP studies are on file at the National Institute of Environmental Health Sciences.

Lot 20080801 of the chemical, a light-yellow powder, was identified as 2H4MBP by infrared (IR) and proton and carbon-13 nuclear magnetic resonance (NMR) spectroscopy and gas chromatography (GC) with mass spectrometry (MS) detection. The IR spectrum was in good agreement with a reference spectrum ${ }^{66}$ and the structure of 2 H4MBP. Proton and carbon-13 NMR spectra were consistent with computer-predicted spectra and the structure of the test article. The mass spectrum of the major peak from the GC/MS analysis matched a reference spectrum $^{67}$ for $2 \mathrm{H} 4 \mathrm{MBP}$. A representative IR spectrum is presented in Table B-1 and Figure B-1.

The purity of lot 20080801 was determined using high-performance liquid chromatography (HPLC) with ultraviolet (UV) detection by system A and using GC with flame ionization detection (FID) by system B. Lot 20080801 was screened for common residual volatile solvents using GC system $\mathrm{C}$ with electron capture detection (ECD) and FID. Differential scanning calorimetry (DSC) was used to determine the purity of the test article using a PerkinElmer (Shelton, CT) Diamond differential scanning calorimeter scanning $1^{\circ} \mathrm{C}$ per minute over the range of $40^{\circ} \mathrm{C}$ to $75^{\circ} \mathrm{C}$. In addition, Karl Fisher titration of lot 20080801 was performed by Galbraith Laboratories, Inc. (Knoxville, TN).

(A)For HPLC/UV analysis, the system included an Agilent 110 high-performance liquid chromatograph (Agilent Technologies, Inc., Santa Clara, CA) with UV detection $(289 \mathrm{~nm})$; a Synergi ${ }^{\mathrm{TM}}$ Fusion-RP column $(100 \mathrm{~mm} \times 3 \mathrm{~mm}, 2.5 \mu \mathrm{m}$ particle size or $100 \mathrm{~mm} \times 4.6 \mathrm{~mm}, 4 \mu \mathrm{m}$ particle size; Phenomenex, Torrance, CA); and an isocratic mobile phase of acetonitrile:ASTM Type 1 water (40:60) at a flow rate of $0.8 \mathrm{~mL} / \mathrm{minute}$.

(B) For GC/FID analysis of initial bulk chemical purity, the system included an Agilent 6890 gas chromatograph (Agilent Technologies, Inc., Santa Clara, CA) with FID; a Rtx-5, $30 \mathrm{~m} \times 0.32 \mathrm{~mm}, 1.0 \mu \mathrm{m}$ film thickness column (Restek, Bellefonte, PA), helium carrier gas at a flow rate of $3 \mathrm{~mL} /$ minute; and an oven temperature program of $80^{\circ} \mathrm{C}$ for 1 minute, then $20^{\circ} \mathrm{C} /$ minute to $200^{\circ} \mathrm{C}$, then $10^{\circ} \mathrm{C} /$ minute to $280^{\circ} \mathrm{C}$, held for 10 minutes.

(C) For GC analysis of residual volatiles in the test article, the system included an Agilent 6890 instrument (Agilent Technologies, Inc., Santa Clara, CA) with either ECD for halogenated volatiles or FID for non-halogenated volatiles; a Restek Rtx-624, $30 \mathrm{~m} \times 0.53 \mathrm{~mm}, 3 \mu \mathrm{m}$ film thickness column, helium carrier gas at a flow rate of $5 \mathrm{~mL} /$ minute; and an oven temperature program of $35^{\circ} \mathrm{C}$ for 14 minutes, then $15^{\circ} \mathrm{C} /$ minute to $40^{\circ} \mathrm{C}$, held for 3 minutes, then $15^{\circ} \mathrm{C} /$ minute to $240^{\circ} \mathrm{C}$, held for 2 minutes. 
Purity assessment by HPLC/UV system A found no reportable impurities in lot 20080801. GC/FID analysis by system B yielded a purity of $99.8 \%$ and found one impurity with an area of $0.17 \%$ of the total peak area. No significant halogenated or nonhalogenated volatile impurities were found in the bulk chemical using GC/ECD or GC/FID by system C, respectively. Purity by DSC was $99.2 \%$. Karl Fischer analysis indicated that no quantifiable water was present in the test article. The overall purity of lot 20080801 was determined to be greater than $99 \%$.

To ensure stability, the bulk chemical was stored at room temperature, in sealed amber glass containers. Periodic reanalyses of the bulk chemical were performed during the perinatal and 2year studies by the study laboratory using HPLC/UV by system A and no degradation of the bulk chemical was detected.

\section{B.2. Preparation and Analysis of Dose Formulations}

The dose formulations were prepared approximately monthly by mixing 2H4MBP with feed (Table B-1). Formulations were stored in sealed amber plastic bags at room temperature for up to 43 days.

Homogeneity studies of the 1,000 and 10,000 ppm dose formulations in NIH-07 and NTP-2000 feed were performed before the animal studies by the analytical chemistry and study laboratories with HPLC/UV by system A. Additional homogeneity studies of the 1,000 and 10,000 ppm dose formulations in NTP-2000 feed were performed during the chronic studies by the study laboratory with the same HPLC/UV system. Stability studies of the 1,000 ppm dose formulation in NIH-07 and NTP-2000 feed were performed by the analytical chemistry laboratory using the same analytical method. Homogeneity was confirmed, and stability was confirmed for at least 42 days for dose formulations stored in sealed amber plastic bags at room temperature.

Periodic analyses of the dose formulations of $2 \mathrm{H} 4 \mathrm{MBP}$ were conducted by the study laboratory using HPLC/UV system A. During the perinatal and 2-year studies, the dose formulations were analyzed 14 times; animal room samples were also analyzed (Table B-2; Table B-3). Of the dose formulations analyzed, all 65 for rats and all 67 for mice were within $10 \%$ of the target concentrations; all 18 animal room samples for rats and all 15 for mice were within $10 \%$ of the target concentrations. 
Table B-1. Preparation and Storage of Dose Formulations in the Perinatal and Two-year Feed Studies of 2-Hydroxy-4-methoxybenzophenone

\begin{tabular}{|c|c|}
\hline Rats & Mice \\
\hline \multicolumn{2}{|l|}{ Preparation } \\
\hline $\begin{array}{l}\text { A premix of NIH- } 07 \text { or NTP- } 2000 \text { meal feed and 2- } \\
\text { hydroxy-4-methoxybenzophenone was prepared in a } \\
\text { Hobart processor, then layered into the remaining feed } \\
\text { and blended in a Patterson Kelly twin-shell blender for } \\
\text { approximately } 15 \text { minutes. The dose formulations were } \\
\text { prepared approximately every } 4 \text { weeks. }\end{array}$ & $\begin{array}{l}\text { Same as rats except that dose formulations were only } \\
\text { prepared in NTP- } 2000 \text { feed }\end{array}$ \\
\hline \multicolumn{2}{|l|}{ Chemical Lot Number } \\
\hline 20080801 & 20080801 \\
\hline \multicolumn{2}{|l|}{ Maximum Storage Time } \\
\hline 42 days & 43 days \\
\hline \multicolumn{2}{|l|}{ Storage Conditions } \\
\hline Stored in sealed amber plastic bags at room temperature & Stored in sealed amber plastic bags at room temperature \\
\hline \multicolumn{2}{|l|}{ Study Laboratory } \\
\hline Battelle (Columbus, OH) & Battelle (Columbus, $\mathrm{OH}$ ) \\
\hline
\end{tabular}

Table B-2. Results of Analyses of Dose Formulations Administered to Rats in the Perinatal and Two-year Feed Study of 2-Hydroxy-4-methoxybenzophenone

\begin{tabular}{ccccc}
\hline Date Prepared & Date Analyzed & $\begin{array}{c}\text { Target } \\
\text { Concentration (ppm) }\end{array}$ & $\begin{array}{c}\text { Determined } \\
\text { Concentration } \\
(\mathbf{p p m})\end{array}$ & $\begin{array}{c}\text { Difference from } \\
\text { Target (\%) }\end{array}$ \\
\hline September 22, 2010 & September 24, 2010 & 1,000 & 981 & -2 \\
& October 26, 2010 & 3,000 & 2,920 & -3 \\
& & 10,000 & 9,910 & -1 \\
October 7, 2010 & 1,000 & 945 & -6 \\
& October 8, 2010 & 3,000 & 2,740 & -9 \\
& & 10,000 & 9,550 & -5 \\
& & 1,000 & 1,000 & 0 \\
& & 1,000 & 989 & -1 \\
& & 3,000 & 3,020 & 1 \\
& & 3,000 & 3,020 & 1 \\
& & 10,000 & 10,000 & 0 \\
\hline
\end{tabular}


2-Hydroxy-4-methoxybenzophenone, NTP TR 597

\begin{tabular}{|c|c|c|c|c|}
\hline Date Prepared & Date Analyzed & $\begin{array}{c}\text { Target } \\
\text { Concentration (ppm) }\end{array}$ & $\begin{array}{c}\text { Determined } \\
\text { Concentration }^{\mathrm{a}} \\
(\mathbf{p p m})\end{array}$ & $\begin{array}{c}\text { Difference from } \\
\text { Target }(\%)\end{array}$ \\
\hline & & 3,000 & 2,840 & -5 \\
\hline & & 10,000 & 9,450 & -6 \\
\hline \multirow[t]{6}{*}{ December 2, 2010} & December 3, 2010 & 1,000 & 1,040 & 4 \\
\hline & & 1,000 & 1,030 & 3 \\
\hline & & 3,000 & 3,050 & 2 \\
\hline & & 3,000 & 3,070 & 2 \\
\hline & & 10,000 & 10,200 & 2 \\
\hline & & 10,000 & 10,100 & 1 \\
\hline \multirow[t]{7}{*}{ January 26, 2011} & January 26, 2011 & 1,000 & 998 & 0 \\
\hline & & 3,000 & 2,940 & -2 \\
\hline & & 3,000 & 2,950 & -2 \\
\hline & & 10,000 & 9,820 & -2 \\
\hline & March 11, 2011 b & 1,000 & 971 & -3 \\
\hline & & 3,000 & 3,020 & +1 \\
\hline & & 10,000 & 9,550 & -5 \\
\hline \multirow[t]{6}{*}{ April 15, 2011} & April 18, 2011 & 1,000 & 996 & 0 \\
\hline & & 1,000 & 992 & -1 \\
\hline & & 3,000 & 2,970 & -1 \\
\hline & & 3,000 & 2,960 & -1 \\
\hline & & 10,000 & 9,860 & -1 \\
\hline & & 10,000 & 9,890 & -1 \\
\hline \multirow[t]{9}{*}{ June 10, 2011} & June 14, 2011 & 1,000 & 1,010 & 1 \\
\hline & & 1,000 & 1,010 & 1 \\
\hline & & 3,000 & 2,970 & -1 \\
\hline & & 3,000 & 3,020 & 1 \\
\hline & & 10,000 & 9,890 & -1 \\
\hline & & 10,000 & 9,790 & -2 \\
\hline & July $25,2011^{\mathrm{b}}$ & 1,000 & 967 & -3 \\
\hline & & 3,000 & 2,790 & -7 \\
\hline & & 10,000 & 9,140 & -9 \\
\hline \multirow[t]{2}{*}{ September 7, 2011} & September 9, 2011 & 1,000 & 1,020 & 2 \\
\hline & & 1,000 & 1,010 & 1 \\
\hline
\end{tabular}


2-Hydroxy-4-methoxybenzophenone, NTP TR 597

\begin{tabular}{|c|c|c|c|c|}
\hline Date Prepared & Date Analyzed & $\begin{array}{c}\text { Target } \\
\text { Concentration (ppm) }\end{array}$ & $\begin{array}{c}\text { Determined } \\
\text { Concentration }^{\mathrm{a}} \\
\quad(\mathbf{p p m})\end{array}$ & $\begin{array}{l}\text { Difference from } \\
\text { Target }(\%)\end{array}$ \\
\hline & & 3,000 & 2,910 & -3 \\
\hline & & 3,000 & 2,960 & -2 \\
\hline & & 10,000 & 9,830 & -2 \\
\hline & & 10,000 & 9,730 & -3 \\
\hline \multirow[t]{6}{*}{ October 28, 2011} & October 28, 2011 & 1,000 & 988 & -1 \\
\hline & & 1,000 & 993 & -1 \\
\hline & & 3,000 & 2,950 & -2 \\
\hline & & 3,000 & 2,900 & -3 \\
\hline & & 10,000 & 9,710 & -3 \\
\hline & & 10,000 & 9,800 & -2 \\
\hline \multirow[t]{9}{*}{ January 20, 2012} & January 20, 2012 & 1,000 & 1,010 & 1 \\
\hline & & 1,000 & 1,020 & 2 \\
\hline & & 3,000 & 2,960 & -1 \\
\hline & & 3,000 & 2,930 & -2 \\
\hline & & 10,000 & 9,750 & -3 \\
\hline & & 10,000 & 9,730 & -3 \\
\hline & March 6, 2012 & 1,000 & 929 & -7 \\
\hline & & 3,000 & 2,850 & -5 \\
\hline & & 10,000 & 9,370 & -6 \\
\hline \multirow[t]{6}{*}{ March 16, 2012} & March 16, 2012 & 1,000 & 1,030 & 3 \\
\hline & & 1,000 & 996 & 0 \\
\hline & & 3,000 & 3,020 & 1 \\
\hline & & 3,000 & 3,050 & 2 \\
\hline & & 10,000 & 9,960 & 0 \\
\hline & & 10,000 & 9,990 & 0 \\
\hline \multirow[t]{6}{*}{ June 8, 2012} & June 11, 2012 & 1,000 & 974 & -3 \\
\hline & & 1,000 & 990 & -1 \\
\hline & & 3,000 & 3,030 & 1 \\
\hline & & 3,000 & 2,950 & -2 \\
\hline & & 10,000 & 9,960 & 0 \\
\hline & & 10,000 & 9,880 & -1 \\
\hline August 31,2012 & August 31, 2012 & 1,000 & 984 & -2 \\
\hline
\end{tabular}




\begin{tabular}{|c|c|c|c|c|}
\hline Date Prepared & Date Analyzed & $\begin{array}{c}\text { Target } \\
\text { Concentration (ppm) }\end{array}$ & $\begin{array}{l}\text { Determined } \\
\text { Concentration } \\
\quad(\mathbf{p p m})\end{array}$ & $\begin{array}{l}\text { Difference from } \\
\text { Target }(\%)\end{array}$ \\
\hline & \multirow{6}{*}{ October $16,2012^{b}$} & 3,000 & 3,010 & 0 \\
\hline & & 10,000 & 10,300 & 3 \\
\hline & & 10,000 & 10,200 & 2 \\
\hline & & 1,000 & 974 & -3 \\
\hline & & 3,000 & 2,860 & -5 \\
\hline & & 10,000 & 9,600 & -4 \\
\hline
\end{tabular}

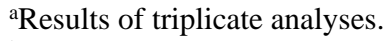

${ }^{\mathrm{b}}$ Animal room samples.

Table B-3. Results of Analyses of Dose Formulations Administered to Mice in the Two-year Feed Study of 2-Hydroxy-4-methoxybenzophenone

\begin{tabular}{|c|c|c|c|c|}
\hline Date Prepared & Date Analyzed & $\begin{array}{c}\begin{array}{c}\text { Target } \\
\text { Concentration } \\
(\mathbf{p p m})\end{array} \\
\end{array}$ & $\begin{array}{c}\begin{array}{c}\text { Determined } \\
\text { Concentration } \\
(\mathbf{p p m})\end{array} \\
\end{array}$ & $\begin{array}{c}\text { Difference from } \\
\text { Target }(\%)\end{array}$ \\
\hline \multirow[t]{6}{*}{ June 17, 2010} & June 19, 2010 & 1,000 & 1,030 & +3 \\
\hline & & 3,000 & 2,940 & -2 \\
\hline & & 10,000 & 9,600 & -4 \\
\hline & July $27,2010^{\mathrm{b}}$ & 1,000 & 951 & -5 \\
\hline & & 3,000 & 2,770 & -8 \\
\hline & & 10,000 & 9,120 & -9 \\
\hline \multirow[t]{6}{*}{ July 15,2010} & July 16, 2010 & 1,000 & 997 & 0 \\
\hline & & 1,000 & 993 & -1 \\
\hline & & 3,000 & 2,920 & -3 \\
\hline & & 3,000 & 2,930 & -2 \\
\hline & & 10,000 & 9,770 & -2 \\
\hline & & 10,000 & 9,770 & -2 \\
\hline \multirow[t]{6}{*}{ October 7, 2010} & October 8, 2010 & 1,000 & 1,000 & 0 \\
\hline & & 1,000 & 989 & -1 \\
\hline & & 3,000 & 3,020 & 1 \\
\hline & & 3,000 & 3,020 & 1 \\
\hline & & 10,000 & 10,000 & 0 \\
\hline & & 10,000 & 9,730 & -3 \\
\hline December 2, 2010 & December 3, 2010 & 1,000 & 1,040 & 4 \\
\hline
\end{tabular}


2-Hydroxy-4-methoxybenzophenone, NTP TR 597

\begin{tabular}{|c|c|c|c|c|}
\hline Date Prepared & Date Analyzed & $\begin{array}{c}\text { Target } \\
\text { Concentration } \\
(\mathbf{p p m})\end{array}$ & $\begin{array}{c}\text { Determined } \\
\text { Concentration } \\
(\mathbf{p p m})\end{array}$ & $\begin{array}{c}\text { Difference from } \\
\text { Target }(\%)\end{array}$ \\
\hline & & 1,000 & 1,030 & 3 \\
\hline & & 3,000 & 3,050 & 2 \\
\hline & & 3,000 & 3,070 & 2 \\
\hline & & 10,000 & 10,200 & 2 \\
\hline & & 10,000 & 10,100 & 1 \\
\hline & January $13,2011^{\mathrm{b}}$ & 1,000 & 943 & -6 \\
\hline & & 3,000 & 2,760 & -8 \\
\hline & & 10,000 & 9,260 & -7 \\
\hline \multirow[t]{7}{*}{ January 26, 2011} & January 26, 2011 & 1,000 & 998 & 0 \\
\hline & & 3,000 & 2,940 & -2 \\
\hline & & 3,000 & 2,950 & -2 \\
\hline & & 10,000 & 9,820 & -2 \\
\hline & March $11,2011^{\mathrm{b}}$ & 1,000 & 977 & -2 \\
\hline & & 3,000 & 2,910 & -3 \\
\hline & & 10,000 & 9,920 & -1 \\
\hline \multirow[t]{6}{*}{ April 15, 2011} & April 18, 2011 & 1,000 & 996 & 0 \\
\hline & & 1,000 & 992 & -1 \\
\hline & & 3,000 & 2,970 & -1 \\
\hline & & 3,000 & 2,960 & -1 \\
\hline & & 10,000 & 9,860 & -1 \\
\hline & & 10,000 & 9,890 & -1 \\
\hline \multirow[t]{9}{*}{ June 10, 2011} & June 14, 2011 & 1,000 & 1,010 & 1 \\
\hline & & 1,000 & 1,010 & 1 \\
\hline & & 3,000 & 2,970 & -1 \\
\hline & & 3,000 & 3,020 & 1 \\
\hline & & 10,000 & 9,890 & -1 \\
\hline & & 10,000 & 9,790 & -2 \\
\hline & July $25,2011^{\mathrm{b}}$ & 1,000 & 967 & -3 \\
\hline & & 3,000 & 2,870 & -4 \\
\hline & & 10,000 & 9,560 & -4 \\
\hline
\end{tabular}


2-Hydroxy-4-methoxybenzophenone, NTP TR 597

\begin{tabular}{|c|c|c|c|c|}
\hline Date Prepared & Date Analyzed & $\begin{array}{c}\text { Target } \\
\text { Concentration } \\
(\mathbf{p p m})\end{array}$ & $\begin{array}{c}\text { Determined } \\
\text { Concentration }^{\mathrm{a}} \\
(\mathrm{ppm})\end{array}$ & $\begin{array}{c}\text { Difference from } \\
\text { Target }(\%)\end{array}$ \\
\hline \multirow[t]{6}{*}{ September 7, 2011} & September 9, 2011 & 1,000 & 1,020 & 2 \\
\hline & & 1,000 & 1,010 & 1 \\
\hline & & 3,000 & 2,910 & -3 \\
\hline & & 3,000 & 2,960 & -2 \\
\hline & & 10,000 & 9,830 & -2 \\
\hline & & 10,000 & 9,730 & -3 \\
\hline \multirow[t]{6}{*}{ October 28, 2011} & October 28, 2011 & 1,000 & 988 & -1 \\
\hline & & 1,000 & 993 & -1 \\
\hline & & 3,000 & 2,950 & -2 \\
\hline & & 3,000 & 2,900 & -3 \\
\hline & & 10,000 & 9,710 & -3 \\
\hline & & 10,000 & 9,800 & -2 \\
\hline \multirow[t]{9}{*}{ January 20, 2012} & January 20, 2012 & 1,000 & 1,010 & 1 \\
\hline & & 1,000 & 1,020 & 2 \\
\hline & & 3,000 & 2,960 & -1 \\
\hline & & 3,000 & 2,930 & -2 \\
\hline & & 10,000 & 9,750 & -3 \\
\hline & & 10,000 & 9,730 & -3 \\
\hline & March 6, 2012 & 1,000 & 975 & -3 \\
\hline & & 3,000 & 2,840 & -5 \\
\hline & & 10,000 & 9,360 & -6 \\
\hline \multirow[t]{6}{*}{ March 16, 2012} & March 16, 2012 & 1,000 & 1,030 & 3 \\
\hline & & 1,000 & 996 & 0 \\
\hline & & 3,000 & 3,020 & 1 \\
\hline & & 3,000 & 3,050 & 2 \\
\hline & & 10,000 & 9,960 & 0 \\
\hline & & 10,000 & 9,990 & 0 \\
\hline \multirow[t]{3}{*}{ June 8, 2012} & June 11, 2012 & 1,000 & 974 & -3 \\
\hline & & 1,000 & 990 & -1 \\
\hline & & 3,000 & 3,030 & 1 \\
\hline
\end{tabular}


2-Hydroxy-4-methoxybenzophenone, NTP TR 597

\begin{tabular}{|c|c|c|c|c|}
\hline Date Prepared & Date Analyzed & $\begin{array}{c}\text { Target } \\
\text { Concentration } \\
(\mathbf{p p m})\end{array}$ & $\begin{array}{c}\text { Determined } \\
\text { Concentration } \\
(\mathbf{p p m})\end{array}$ & $\begin{array}{c}\text { Difference from } \\
\text { Target }(\%)\end{array}$ \\
\hline & & 3,000 & 2,950 & -2 \\
\hline & & 10,000 & 9,960 & 0 \\
\hline & & 10,000 & 9,880 & -1 \\
\hline
\end{tabular}

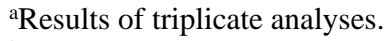

${ }^{\mathrm{b}}$ Animal room samples.

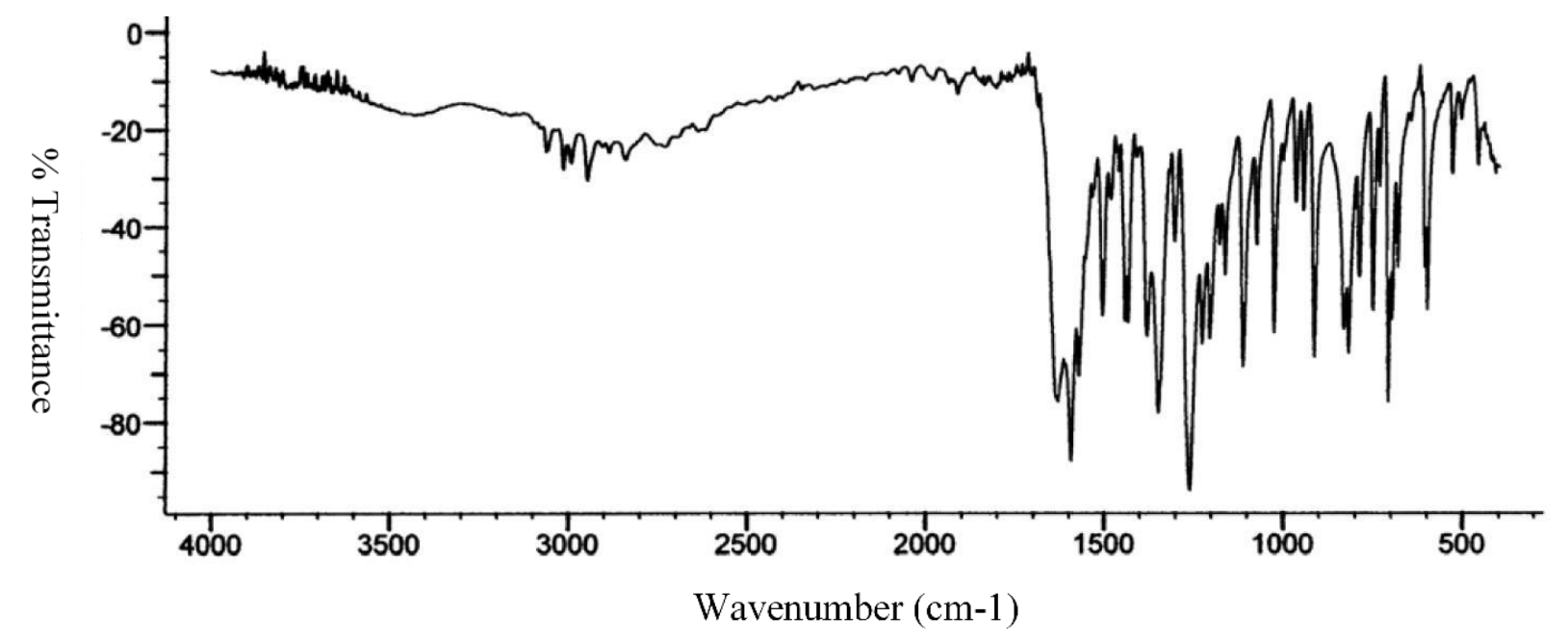

Figure B-1. Infrared Absorption Spectrum of 2-Hydroxy-4-methoxybenzophenone 


\section{Appendix C. Ingredients, Nutrient Composition, and Contaminant Levels in NTP-2000 Rat and Mouse Ration}

\section{Tables}

Table C-1. Ingredients of NTP-2000 Rat and Mouse Ration

Table C-2. Vitamins and Minerals in NTP-2000 Rat and Mouse Ration

Table C-3. Nutrient Composition of NTP-2000 Rat and Mouse Ration ...

Table C-4. Contaminant Levels in NTP-2000 Rat and Mouse Ration C-5 
Table C-1. Ingredients of NTP-2000 Rat and Mouse Ration

Ingredients

Ground Hard Winter Wheat

Ground \#2 Yellow Shelled Corn

Wheat Middlings

Oat Hulls

Alfalfa Meal (Dehydrated, 17\% Protein)

Purified Cellulose

Soybean Meal (49\% Protein)

Fish Meal (60\% Protein)

Corn Oil (without Preservatives)

Soy Oil (without Preservatives)

Dried Brewer's Yeast

Calcium Carbonate (USP)

Vitamin Premix ${ }^{\mathrm{a}}$

Mineral Premix ${ }^{\mathrm{b}}$

Calcium Phosphate, Dibasic (USP)

Sodium Chloride

Choline Chloride (70\% Choline)

Methionine

USP = United States Pharmacopeia.

${ }^{a}$ Wheat middlings as carrier.

${ }^{\mathrm{b}}$ Calcium carbonate as carrier.

\section{Percent by Weight}

22.26

22.18

15.0

8.5

7.5

5.5

5.0

4.0

3.0

3.0

1.0

0.9

0.5

0.5

0.4

0.3

0.26

0.2 
Table C-2. Vitamins and Minerals in NTP-2000 Rat and Mouse Ration ${ }^{\text {a }}$

\begin{tabular}{|c|c|c|}
\hline & Amount & Source \\
\hline \multicolumn{3}{|l|}{ Vitamins } \\
\hline Vitamin A & 4,000 IU & Stabilized vitamin A palmitate or acetate \\
\hline Vitamin D & $1,000 \mathrm{IU}$ & D-activated animal sterol \\
\hline Vitamin $\mathrm{K}$ & $1.0 \mathrm{mg}$ & Menadione sodium bisulfite complex \\
\hline$\alpha$-Tocopheryl Acetate & $100 \mathrm{IU}$ & - \\
\hline Niacin & $23 \mathrm{mg}$ & - \\
\hline Folic Acid & $1.1 \mathrm{mg}$ & - \\
\hline$\alpha$-Pantothenic Acid & $10 \mathrm{mg}$ & $\alpha$-Calcium pantothenate \\
\hline Riboflavin & $3.3 \mathrm{mg}$ & - \\
\hline Thiamine & $4 \mathrm{mg}$ & Thiamine mononitrate \\
\hline B12 & $52 \mu \mathrm{g}$ & - \\
\hline Pyridoxine & $6.3 \mathrm{mg}$ & Pyridoxine hydrochloride \\
\hline Biotin & $0.2 \mathrm{mg}$ & $\alpha$-Biotin \\
\hline \multicolumn{3}{|l|}{ Minerals } \\
\hline Magnesium & $514 \mathrm{mg}$ & Magnesium oxide \\
\hline Iron & $35 \mathrm{mg}$ & Iron sulfate \\
\hline Zinc & $12 \mathrm{mg}$ & Zinc oxide \\
\hline Manganese & $10 \mathrm{mg}$ & Manganese oxide \\
\hline Copper & $2.0 \mathrm{mg}$ & Copper sulfate \\
\hline Iodine & $0.2 \mathrm{mg}$ & Calcium iodate \\
\hline Chromium & $0.2 \mathrm{mg}$ & Chromium acetate \\
\hline
\end{tabular}

aPer kg of finished product.

Table C-3. Nutrient Composition of NTP-2000 Rat and Mouse Ration

\begin{tabular}{lccc}
\hline \multicolumn{1}{c}{ Nutrient } & $\begin{array}{c}\text { Mean } \pm \text { Standard } \\
\text { Deviation }\end{array}$ & Range & Number of Samples \\
\hline Protein (\% by weight) & $14.8 \pm 0.516$ & $14.2-16.8$ & 28 \\
Crude Fat (\% by weight) & $8.69 \pm 0.357$ & $8.0-9.7$ & 28 \\
Crude Fiber (\% by weight) & $9.47 \pm 0.594$ & $8.34-11.6$ & 28 \\
Ash (\% by weight) & $5.25 \pm 1.76$ & $4.6-14.2$ & 28 \\
\hline
\end{tabular}




\begin{tabular}{|c|c|c|c|}
\hline Nutrient & $\begin{array}{c}\text { Mean } \pm \text { Standard } \\
\text { Deviation }\end{array}$ & Range & Number of Samples \\
\hline \multicolumn{4}{|c|}{ Amino Acids (\% of Total Diet) } \\
\hline Arginine & $0.802 \pm 0.075$ & $0.67-0.97$ & 28 \\
\hline Cystine & $0.220 \pm 0.022$ & $0.15-0.25$ & 28 \\
\hline Glycine & $0.703 \pm 0.038$ & $0.62-0.80$ & 28 \\
\hline Histidine & $0.342 \pm 0.071$ & $0.27-0.68$ & 28 \\
\hline Isoleucine & $0.549 \pm 0.041$ & $0.43-0.66$ & 28 \\
\hline Leucine & $1.097 \pm 0.064$ & $0.96-1.24$ & 28 \\
\hline Lysine & $0.700 \pm 0.106$ & $0.31-0.86$ & 28 \\
\hline Methionine & $0.410 \pm 0.042$ & $0.26-0.49$ & 28 \\
\hline Phenylalanine & $0.623 \pm 0.047$ & $0.47-0.72$ & 28 \\
\hline Threonine & $0.512 \pm 0.042$ & $0.43-0.61$ & 28 \\
\hline Tryptophan & $0.155 \pm 0.027$ & $0.11-0.20$ & 28 \\
\hline Tyrosine & $0.420 \pm 0.066$ & $0.28-0.54$ & 28 \\
\hline Valine & $0.666 \pm 0.040$ & $0.55-0.73$ & 28 \\
\hline \multicolumn{4}{|c|}{ Essential Fatty Acids (\% of Total Diet) } \\
\hline Linoleic & $3.95 \pm 0.234$ & $3.49-4.55$ & 28 \\
\hline Linolenic & $0.31 \pm 0.031$ & $0.021-0.368$ & 28 \\
\hline \multicolumn{4}{|l|}{ Vitamins } \\
\hline Vitamin A (IU/kg) & $378 \pm 79.35$ & $203-529$ & 28 \\
\hline Vitamin D (IU/kg) & $1,000^{\mathrm{a}}$ & - & - \\
\hline$\alpha$-Tocopherol (ppm) & $2,543 \pm 13,044$ & $27.0-69,100$ & 28 \\
\hline Thiamine (ppm)b & $8.39 \pm 1.87$ & $3.9-12.5$ & 28 \\
\hline Riboflavin (ppm) & $8.06 \pm 2.83$ & $4.20-17.50$ & 28 \\
\hline Niacin (ppm) & $78.6 \pm 8.26$ & $66.4-98.2$ & 28 \\
\hline Pantothenic Acid (ppm) & $26.6 \pm 11.22$ & $17.4-81.0$ & 28 \\
\hline Pyridoxine (ppm)b & $9.78 \pm 2.08$ & $6.44-14.3$ & 28 \\
\hline Folic Acid (ppm) & $1.58 \pm 0.44$ & $1.15-3.27$ & 28 \\
\hline Biotin (ppm) & $0.32 \pm 0.09$ & $0.20-0.704$ & 28 \\
\hline $\mathrm{B} 12(\mathrm{ppb})$ & $50.6 \pm 35.5$ & $18.3-174.0$ & 28 \\
\hline Choline (as Chloride) (ppm) & $2,615 \pm 635$ & $1,160-3,790$ & 28 \\
\hline
\end{tabular}




\begin{tabular}{|c|c|c|c|c|}
\hline Nutrient & $\begin{array}{c}\text { Mean } \pm \text { Standard } \\
\text { Deviation }\end{array}$ & \multicolumn{2}{|c|}{ Range } & Number of Samples \\
\hline \multicolumn{5}{|l|}{ Minerals } \\
\hline Calcium (\%) & $0.913 \pm 0.046$ & \multicolumn{2}{|c|}{$0.831-1.03$} & 28 \\
\hline Phosphorus (\%) & $0.550 \pm 0.099$ & \multicolumn{2}{|c|}{$0.053-0.613$} & 28 \\
\hline Potassium (\%) & $0.667 \pm 0.030$ & \multicolumn{2}{|c|}{$0.626-0.733$} & 28 \\
\hline Chloride (\%) & $0.393 \pm 0.045$ & \multicolumn{2}{|c|}{$0.300-0.517$} & 28 \\
\hline Sodium (\%) & $0.197 \pm 0.026$ & \multicolumn{2}{|c|}{$0.160-0.283$} & 28 \\
\hline Magnesium (\%) & $0.217 \pm 0.055$ & \multicolumn{2}{|c|}{$0.185-0.490$} & 28 \\
\hline Sulfur $(\%)$ & $0.170 \pm 0.029$ & \multicolumn{2}{|c|}{$0.116-0.209$} & 14 \\
\hline Iron (ppm) & $191.6 \pm 36.8$ & \multicolumn{2}{|c|}{$135-311$} & 28 \\
\hline Manganese (ppm) & $50.1 \pm 9.59$ & \multicolumn{2}{|c|}{$21.0-73.1$} & 28 \\
\hline Zinc (ppm) & $57.4 \pm 26.0$ & \multicolumn{2}{|c|}{$23.3-184.0$} & 28 \\
\hline Copper (ppm) & $7.53 \pm 2.53$ & \multicolumn{2}{|c|}{$3.21-16.3$} & 28 \\
\hline Iodine (ppm) & $0.531 \pm 0.201$ & \multicolumn{2}{|c|}{$0.158-0.972$} & 28 \\
\hline Chromium (ppm) & $0.916 \pm 0.908$ & \multicolumn{2}{|c|}{$0.330-3.97$} & 27 \\
\hline Cobalt (ppm) & $0.225 \pm 0.154$ & \multicolumn{2}{|c|}{$0.086-0.964$} & 26 \\
\hline \multicolumn{5}{|l|}{$\begin{array}{l}\text { aFrom formulation. } \\
{ }^{\mathrm{b}} \text { As hydrochloride. }\end{array}$} \\
\hline \multicolumn{5}{|c|}{ Table C-4. Contaminant Levels in NTP-2000 Rat and Mouse Ration ${ }^{a}$} \\
\hline & \multicolumn{2}{|c|}{ Mean \pm Standard Deviation ${ }^{b}$} & Range & Number of Samples \\
\hline \multicolumn{5}{|l|}{ Contaminants } \\
\hline Arsenic (ppm) & 0.223 & & $0.149-0.385$ & 28 \\
\hline Cadmium (ppm) & 0.053 & & $0.038-0.094$ & 28 \\
\hline Lead (ppm) & 0.138 & & $0.064-0.474$ & 28 \\
\hline Mercury $(\mathrm{ppm})^{\mathrm{a}}$ & 0.014 & & $0.01-0.049$ & 28 \\
\hline Selenium (ppm) & 0.162 & & $0.029-0.209$ & 28 \\
\hline Aflatoxins (ppb) ${ }^{\mathrm{a}}$ & $5 \pm$ & & $5.0-5.0$ & 28 \\
\hline Nitrate Nitrogen $(\mathrm{ppm})^{\mathrm{b}}$ & 15.62 & & $10.0-35.1$ & 28 \\
\hline Nitrite Nitrogen (ppm) $)^{\mathrm{a}, \mathrm{b}}$ & $0.61 \pm$ & & $0.60-0.61$ & 28 \\
\hline BHA (ppm) $)^{\mathrm{a}, \mathrm{c}}$ & $1 \pm$ & & $1.0-1.0$ & 28 \\
\hline $\mathrm{BHT}(\mathrm{ppm})^{\mathrm{a}, \mathrm{c}}$ & 1.08 & & $1.0-3.14$ & 28 \\
\hline
\end{tabular}


2-Hydroxy-4-methoxybenzophenone, NTP TR 597

\begin{tabular}{|c|c|c|c|}
\hline & Mean \pm Standard Deviation ${ }^{b}$ & Range & Number of Samples \\
\hline Aerobic Plate Count (CFU/gm) & $10 \pm 0.00$ & $10.0-10.0$ & 28 \\
\hline Coliform (MPN/gm) & $3.0 \pm 0.00$ & $3.0-3.0$ & 28 \\
\hline E. $\operatorname{coli}(\mathrm{MPN} / \mathrm{gm})^{\mathrm{a}}$ & $10 \pm 0.00$ & $10.0-10.0$ & 28 \\
\hline Salmonella (MPN/gm) & Negative & - & - \\
\hline Total Nitrosamines $(\mathrm{ppb})^{\mathrm{d}}$ & $11.1 \pm 5.55$ & $3.2-24.5$ & 28 \\
\hline N-Ndimethylamine $(\mathrm{ppb})^{\mathrm{d}}$ & $2.5 \pm 1.6$ & $1.0-6.8$ & 28 \\
\hline N-Npyrrolidine $(\mathrm{ppb})^{\mathrm{d}}$ & $8.7 \pm 5.1$ & $2.1-20.0$ & 28 \\
\hline \multicolumn{4}{|l|}{ Pesticides (ppm) } \\
\hline$\alpha-\mathrm{BHC}^{\mathrm{a}}$ & $<0.01$ & - & 28 \\
\hline$\beta-\mathrm{BHC}^{\mathrm{a}}$ & $<0.02$ & - & 28 \\
\hline$\gamma-\mathrm{BHC}^{\mathrm{a}}$ & $<0.01$ & - & 28 \\
\hline$\delta-\mathrm{BHC}^{\mathrm{a}}$ & $<0.01$ & - & 28 \\
\hline Heptachlor $^{\mathrm{a}}$ & $<0.01$ & - & 28 \\
\hline Aldrin $^{\mathrm{a}}$ & $<0.01$ & - & 28 \\
\hline Heptachlor Epoxide ${ }^{\mathrm{a}}$ & $<0.01$ & - & 28 \\
\hline $\mathrm{DDE}^{\mathrm{a}}$ & $<0.01$ & - & 28 \\
\hline $\mathrm{DDD}^{\mathrm{a}}$ & $<0.01$ & - & 28 \\
\hline DDT $^{\mathrm{a}}$ & $<0.01$ & - & 28 \\
\hline $\mathrm{HCB}^{\mathrm{a}}$ & $<0.01$ & - & 28 \\
\hline $\operatorname{Mirex}^{\mathrm{a}}$ & $<0.01$ & - & 28 \\
\hline Methoxychlor ${ }^{\mathrm{a}}$ & $<0.05$ & - & 28 \\
\hline Dieldrin $^{\mathrm{a}}$ & $<0.01$ & - & 28 \\
\hline Endrin $^{\mathrm{a}}$ & $<0.01$ & - & 28 \\
\hline Telodrin ${ }^{\mathrm{a}}$ & $<0.01$ & - & 28 \\
\hline Chlordane $^{\mathrm{a}}$ & $<0.05$ & - & 28 \\
\hline Toxaphene $^{\mathrm{a}}$ & $<0.10$ & - & 28 \\
\hline Estimated PCBs ${ }^{\mathrm{a}}$ & $<0.20$ & - & 28 \\
\hline Ronnel $^{\mathrm{a}}$ & $<0.01$ & - & 28 \\
\hline Ethion $^{\mathrm{a}}$ & $<0.02$ & - & 28 \\
\hline Trithion $^{\mathrm{a}}$ & $<0.05$ & - & 28 \\
\hline Diazinon $^{\mathrm{a}}$ & $<0.10$ & - & 28 \\
\hline
\end{tabular}


2-Hydroxy-4-methoxybenzophenone, NTP TR 597

\begin{tabular}{lccc}
\hline & Mean \pm Standard Deviation $^{\mathbf{b}}$ & Range & Number of Samples \\
\hline Methyl Chlorpyrifos & $0.09 \pm 0.073$ & $0.02-0.315$ & 28 \\
Methyl Parathion $^{\mathrm{a}}$ & $<0.02$ & - & 28 \\
Ethyl Parathion $^{\mathrm{a}}$ & $<0.02$ & - & 28 \\
Malathion & $0.1 \pm 0.093$ & $0.02-0.355$ & 28 \\
Endosulfan I $^{\mathrm{a}}$ & $<0.01$ & - & 28 \\
Endosulfan II $^{\mathrm{a}}$ & $<0.01$ & - & 28 \\
Endosulfane Sulfate $^{\mathrm{a}}$ & $<0.03$ & - & 28 \\
\hline
\end{tabular}

$\overline{\mathrm{CFU}}=$ colony-forming units; $\mathrm{MPN}$ = most probable number; $\mathrm{BHC}=$ hexachlorocyclohexane or benzene hexachloride; $\mathrm{PCB}=$ polychlorinated biphenyl.

${ }^{a}$ All values were less than the detection limit. The detection limit is given as the mean.

${ }^{b}$ Sources of contamination include alfalfa, grains, and fish meal.

'Sources of contamination include soy oil and fish meal.

${ }^{\mathrm{d}}$ All values were corrected for percent recovery. 


\section{Appendix D. Sentinel Animal Program \\ Table of Contents}

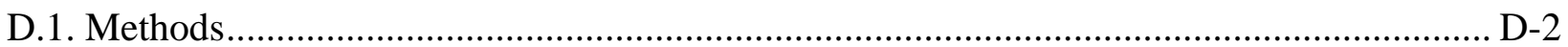

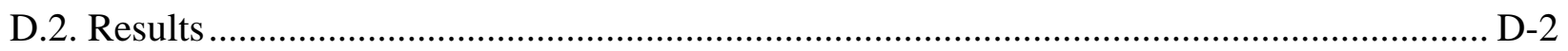

\section{Tables}

Table D-1. Methods and Results for Sentinel Animal Testing ........................................... D-2 


\section{D.1. Methods}

Rodents used in the National Toxicology Program are produced in optimally clean facilities to eliminate potential pathogens that may affect study results. The Sentinel Animal Program is part of the periodic monitoring of animal health that occurs during the toxicologic evaluation of test compounds. Under this program, the disease state of the rodents is monitored via sera or feces from extra (sentinel) or exposed animals in the study rooms. The sentinel animals and the study animals are subject to identical environmental conditions. Furthermore, the sentinel animals come from the same production source and weanling groups as the animals used for the studies of test compounds.

For these toxicology and carcinogenesis studies, blood samples were collected from the rodents and allowed to clot, and the serum was separated. Additionally, fecal samples were collected and tested for Helicobacter species. All samples were processed appropriately with serology testing and sent to IDEXX BioResearch (formerly Rodent Animal Diagnostic Laboratory [RADIL], University of Missouri), Columbia, MO, for determination of the presence of pathogens. The laboratory methods and agents for which testing was performed are tabulated below; the times at which samples were collected during the studies are also listed.

Blood was collected per the following:

- Rats: 10 females at end of quarantine, and 4 weeks postarrival; 5 animals per sex at 6 , 15 , and 18 months, and study termination

- $\quad$ Mice: 5 animals per sex per time period

\section{D.2. Results}

Rats: Positive for pinworms (Syphacia spp.) All other test results were negative. Mice: All test results were negative.

Table D-1. Methods and Results for Sentinel Animal Testing

\begin{tabular}{ll}
\multicolumn{1}{c}{ Method and Test } & \multicolumn{1}{c}{ Time of Collection } \\
\hline Rats & \\
Multiplex Fluorescent Immunoassay & \\
Kilham Rat Virus & $\begin{array}{l}\text { End of quarantine }{ }^{\mathrm{a}} ; 4 \text { weeks postarrival } ; \text {; } 6,15, \text { and } 18 \text { months; stud } \\
\text { termination }\end{array}$ \\
Mycoplasma Pulmonis & $\begin{array}{l}\text { End of quarantine; } 4 \text { weeks postarrival; } 6,15, \text { and } 18 \text { months; study } \\
\text { termination }\end{array}$ \\
Pneumonia Virus of Mice & $\begin{array}{l}\text { End of quarantine; } 4 \text { weeks postarrival; } 6,15, \text { and } 18 \text { months; study } \\
\text { termination }\end{array}$ \\
Rat Coronavirus/Sialodacryoadenitis Virus & $\begin{array}{l}\text { End of quarantine; } 4 \text { weeks postarrival; } 6,15, \text { and } 18 \text { months; study } \\
\text { termination }\end{array}$ \\
Rat Minute Virus & $\begin{array}{l}\text { End of quarantine; } 4 \text { weeks postarrival; } 6,15, \text { and } 18 \text { months; study } \\
\text { termination }\end{array}$
\end{tabular}




\section{Method and Test}

Rat Parvo Virus

Rat Theilovirus

Sendai

Toolan's H-1

Immunofluorescence Assay

Pneumocystis carinii

Mice

\section{Multiplex Fluorescent Immunoassay}

Ectromelia Virus

Epizootic Diarrhea of Infant Mice

Lymphocytic Choriomeningitis Virus

Mycoplasma Pulmonis

Mouse Hepatitis Virus

Mouse Norovirus

Mouse Parvovirus

Minute Virus of Mice

Pneumonia Virus of Mice

Reovirus

Sendai

Theiler's Murine Encephalomyelitis Virus GDVII

\section{Immunofluorescence Assay}

Ectromelia Virus

Epizootic Diarrhea of Infant Mice

Mouse Hepatitis Virus

Mouse Norovirus

\section{Polymerase Chain Reaction}

Helicobacter species

${ }^{a}$ Age-matched nonpregnant females.

bTime-mated females that did not have a litter.

\section{Time of Collection}

End of quarantine; 4 weeks postarrival; 6, 15, and 18 months; study termination

End of quarantine; 4 weeks postarrival; 6, 15, and 18 months; study termination

End of quarantine; 4 weeks postarrival; 6, 15, and 18 months; study termination

End of quarantine; 4 weeks postarrival; 6, 15, and 18 months; study termination

6 months

6 weeks postarrival; 6,12 , and 18 months; study termination 6 weeks postarrival; 6,12 , and 18 months; study termination 6 weeks postarrival; 6,12 , and 18 months; study termination 6 weeks postarrival; 6,12 , and 18 months; study termination 6 weeks postarrival; 6,12 , and 18 months; study termination 6 weeks postarrival; 6,12 , and 18 months; study termination 6 weeks postarrival; 6,12 , and 18 months; study termination 6 weeks postarrival; 6,12 , and 18 months; study termination 6 weeks postarrival; 6,12 , and 18 months; study termination 6 weeks postarrival; 6,12 , and 18 months; study termination 6 weeks postarrival; 6,12 , and 18 months; study termination 6 weeks postarrival; 6,12 , and 18 months; study termination

6 months

6 weeks postarrival; 6 months

Study termination

6 and 12 months

18 months 


\section{Appendix E. Microarray Analysis}

\section{Table of Contents}

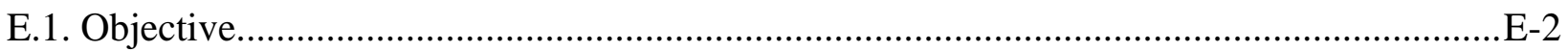

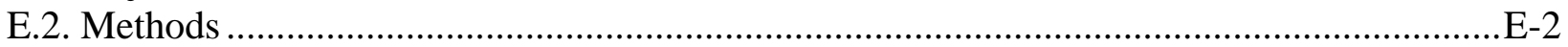

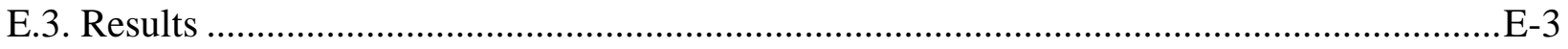

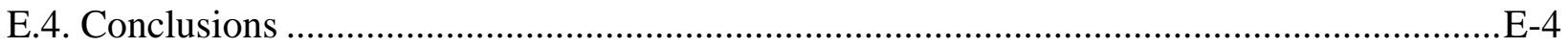

\section{Tables}

Table E-1. Top Five Up- and Down-regulated Probesets in the Liver of Male Sprague Dawley Rats Administered 10,000 ppm 2H4MBP in Feed for 14 Weeks

Table E-2. Ingenuity Pathway Analysis Enriched Disease and Biological/Toxicity Functions that Exhibit Activation/Inhibition in the Liver of Male Sprague Dawley Rats Administered 10,000 ppm 2H4MBP in Feed for 14 Weeks

Table E-3. Ingenuity Pathway Analysis Enriched Canonical Pathways that Exhibit Activation/Inhibition in the Liver of Male Sprague Dawley Rats Administered 10,000 ppm 2H4MBP in Feed for 14 Weeks

Table E-4. Ingenuity Pathway Analysis Enriched Upstream Regulators that Exhibit Activation/Inhibition in the Liver of Male Sprague Dawley Rats Administered 10,000 ppm 2H4MBP in Feed for 14 Weeks 


\section{E.1. Objective}

The objective of the microarray study was to evaluate the transcriptional changes in liver from rats exposed to 0 or $10,000 \mathrm{ppm} 2 \mathrm{H} 4 \mathrm{MBP}$. At the 14 -week interim evaluation, livers were analyzed from male Sprague Dawley rats.

\section{E.2. Methods}

\section{E.2.1. RNA Isolation, cDNA Synthesis, and Array Hybridization}

Liver tissues were excised from five vehicle control $F_{1}$ male rats and five 10,000 ppm $F_{1}$ male rats from the 14-week interim evaluation performed as a part of the 2-year carcinogenicity study. Tissues were immediately frozen in liquid nitrogen at collection and transported to the Battelle Biomedical Research Center (Columbus, $\mathrm{OH}$ ). The liver tissues were removed and added to lysis buffer, and each sample was then homogenized using OmniTip ${ }^{\mathrm{TM}}$ plastic disposable probes (Omni International, Marietta, GA). Following homogenization samples were centrifuged and the RNA was extracted from the supernatant using the Qiagen RNeasy Midi Kit (Qiagen, Valencia, CA). RNA concentration and purity were determined by UV analysis using a NanoDrop 1000 spectrophotometer (NanoDrop Technologies, Wilmington, DE). All samples were assessed for RNA integrity using an RNA 6000 Nano Chip kit with an Agilent 2100 Bioanalyzer (Agilent, Santa Clara, CA). Total RNA (100 ng) was used to synthesize singlestranded DNA, which was subsequently converted into a double stranded eDNA template for transcription. An in vitro transcription (IVT) reaction, which incorporates biotinylated ribonucleotide analogs, was then used to create labeled amplified RNA (aRNA). This RNA target preparation was performed using the Affymetrix GeneChip ${ }^{\circledR}$ 3' IVT Express Kit (Affymetrix Inc., Santa Clara, CA) according to the manufacturer's protocol. All incubation steps during this preparation were completed using an Eppendorf Mastercycler ${ }^{\circledR}$ thermal cycler (Eppendorf, Hamburg, Germany). Labeled aRNA was fragmented and hybridized to the Affymetrix Rat Genome 2302.0 Array (31,099 probe sets) using an Affymetrix GeneChip Hybridization Oven 640. Washing and staining of the arrays were completed using the Affymetrix GeneChip Hybridization Wash and Stain kit and performed using the Fluidics Station 450 according to the Affymetrix recommended protocol (FS450_0001). After washing and staining, the arrays were scanned using an Affymetrix GeneChip Scanner $30007 \mathrm{G}$ and the raw microarray data (.CEL files) were acquired using Affymetrix GeneChip Command Console ${ }^{\circledR}$ Software (AGCC).

\section{E.2.2. Microarray Analysis}

\section{E.2.2.1. Analysis of GeneChip Data Quality}

Quality control (QC) measurements from each Affymetrix GeneChip array were evaluated to determine the quality of the microarray data generated. Affymetrix recommended guidelines for evaluating quality were used to evaluate the output files for each GeneChip array using the R/Bioconductor package, Simpleaffy. ${ }^{117}$ The following QC parameters were evaluated for each chip: average background, scale factor, percent of genes scored as present, 3 ' to 5 ' ratios for the internal control genes beta-actin and glyceraldehyde-3-phosphate dehydrogenase (GAPDH), values for hybridization control transcripts, and values for poly (A) controls. In addition, the data were visually assessed outliers using intensity distribution histograms and principal component 
analysis. These assessments contributed to the determination that the quality of the GeneChip array data obtained from all 10 RNA samples is sufficient to proceed with statistical analysis and biological interpretation.

\section{E.2.2.2. Statistical Analysis}

The 10 .CEL files representing the 10 liver samples from the study were normalized using the robust multiarray algorithm (RMA) ${ }^{118}$ using Patek Genomics Suite v 6.6 (Partek, Inc, St. Louis, MO) using the commented settings in the software. Probe sets showing differential expression between the two dose groups were identified using an ANOVA $(\mathrm{p}<0.05)$ combined with a fold change of $>|1.5|$.

\section{E.2.2.3. Biological Interpretation}

Ingenuity Pathway Analysis ${ }^{\mathrm{TM}}$ (IPA) (Ingenuity Systems ${ }^{\circledR}$, Inc., Redwood City, CA) was used to facilitate biological interpretation of the transcriptional changes produced by $2 \mathrm{H} 4 \mathrm{MBP}$ treatment.

The IPA Core Analysis was performed on June 11, 2019. Enrichment and activation analysis was carried out for IPA disease/biological/toxicity functions. In addition, an IPA Upstream Analysis was performed. Enrichment p values were calculated using a right-tailed Fisher's Exact Test combined with a Benjamini-Hochberg method of multiple testing correction. The $\mathrm{p}$ value $(\mathrm{p}<0.05)$ was determined by how many differentially expressed genes (DEGs) overlapped that are annotated into gene groups (e.g., canonical pathways, biological functions).

Activation/inhibition analysis was performed using the annotation in the IPA Knowledge Base. To determine if there was plausible activation/inhibition of disease/biological/toxicity functions, transcription factors, and chemical signaling signatures, a Z-score was calculated. The Z-score was determined by concordance of observed patterns of regulation (up or down) with known effects on biological functions or effects of transcription factors/chemicals (activation or inhibition of target genes) as annotated in the Ingenuity Knowledge Base. A gene set was deemed to be activated (Z-score $>2$ ), inhibited (Z-score $<-2$ ), or not affected on the basis of the Z-score.

\section{E.3. Results}

\section{E.3.1. Differential Gene Expression}

Whole-rat genome Affymetrix 2302.0 microarrays were used to assess the effect of 10,000 ppm of $2 \mathrm{H} 4 \mathrm{MBP}$ in the diet for 14 weeks on male Sprague Dawley rat liver. Treatment with 2H4MBP led to the differential expression of 357 probe sets (67 up-regulated, 290 downregulated) that mapped to 273 unique genes. Overall the effect on the transcriptome was deemed to be weak relative to high-dose studies that are typical of most toxicogenomics assessments. Notably Cyp2b1/2, Cyplal, and Cyp4al were all moderately up-regulated along with other biotransformation-related genes such as Gsta2, Aldh1a7, and Abcc3. Up-regulation of these genes suggests the liver was adapting to the presence of chemical stressor by up-regulating metabolic pathways to facilitate clearance. The top five up- and down-regulated probe sets as determined by fold change are shown in Table E-1. 
Five hundred twenty-seven IPA disease/biological/toxicity functions showed significant enrichment, however only a small set were also determined to be activated or inhibited by 2H4MBP treatment. Those that were activated include hepatic steatosis, hypoplasia of organ, and G2 phase. Several functions, all primarily related to cell cycle and growth, were inhibited by 2H4MBP treatment. The enriched and activated/inhibited functions are listed in Table E-2.

Twenty-six IPA canonical pathways showed significant enrichment following 2H4MBP treatment. Of the 26 pathways, only a small subset showed inhibition and all were related to cell cycle/proliferation. The enriched and activated/inhibited pathways are listed in Table E-3.

The IPA Upstream Analysis identified > 700 enriched regulatory agents, however, only 32 showed patterns that were suggestive of activation of inhibition. A sizable number of the regulatory agents were prototype chemicals that effect specific processes (e.g., PXR activation) and lead to specific patterns of transcriptional response (i.e., signatures). Identification of these patterns in the $2 \mathrm{H} 4 \mathrm{MBP}$ transcriptional response data suggests that $2 \mathrm{H} 4 \mathrm{MBP}$ may be interacting with the same biological targets as the prototype agents. Caution must be used when interpreting these results because genes are often shared across the signatures, hence differentiating between highly redundant upstream regulatory processes that are driving transcriptomic changes is challenging.

Findings for 2H4MBP are suggestive of effects on glucocorticoid (dexamethasone) and vitamin $\mathrm{D}$ (calcitriol) signaling and potentially on estrogen signaling (raloxifene). Other potential regulatory features in the $2 \mathrm{H} 4 \mathrm{MBP}$ signaling cascade include miR-30c-5p and let-7 microRNAs and some inhibitory effects on cytokine signaling (i.e., TNF, IL1 $\beta$, and IFN $\beta 1$ ). Notably, there is a suggestion that estrogen receptor (Esrl) signaling was inhibited by $2 \mathrm{H} 4 \mathrm{MBP}$, although an effect on Esrl is unlikely based on additional analysis that was performed (see the Other Notable Findings section in this appendix, below). The enriched and activated/inhibited pathways are listed in Table E-4.

\section{E.3.2. Other Notable Findings}

Due to the potential estrogenic properties of $2 \mathrm{H} 4 \mathrm{MBP}$, a specific analysis of estrogen response genes was performed. A subset of genes is known to be strongly up-regulated in male rat liver by pharmacological estrogens. The up-regulation of these genes in response to estrogens has been documented in both the DrugMatrix and TG-Gates data sets, ${ }^{119 ; 120}$ which are accessible through the Illumina Correlation Engine. ${ }^{121}$ The up-regulated genes include Rbp7, Lifr, Cited4, Ksr1, and Ctr9. None of these genes was identified as differentially expressed in the liver of male rats following $2 \mathrm{H} 4 \mathrm{MBP}$ exposure. This observation suggests that it is unlikely that $2 \mathrm{H} 4 \mathrm{MBP}$ produced a systemic estrogenic effect within the context of the 14-week study.

\section{E.4. Conclusions}

The overall transcriptomic response of rat liver to 14 weeks of exposure to $10,000 \mathrm{ppm} 2 \mathrm{H} 4 \mathrm{MBP}$ was weak. This is consistent with the absence of pathological findings in the liver following 2 years of exposure at this dose. The biological interpretation suggests there may be marginal, nonspecific effects on steroid hormone homeostasis that may be related findings in the adrenal cortex, testis, uterus, and ovary in the 2-year study. Notably, these effects do not appear to be related to direct effects on the estrogen receptor as opposed to other potential mechanisms that 
have yet to be characterized. One generally consistent observation was the inhibition of cell cycle-related processes, which could potentially be related to the decreased body weight observed in the 10,000 ppm groups from the 14-week interim evaluation. Finally, the weak induction of some of the nuclear receptor regulated P450s (e.g., Cyp2b1/2) are likely associated with microsomal enzyme induction and the observed liver weight increase at 10,000 ppm 2H4MBP.

Table E-1. Top Five Up- and Down-regulated Probesets in the Liver of Male Sprague Dawley Rats Administered 10,000 ppm 2H4MBP in Feed for 14 Weeks

\begin{tabular}{lccc}
\hline \multicolumn{1}{c}{ Probeset ID } & Gene Symbol & Entrez Gene & Fold Change \\
\hline Up-regulated & & & \\
1368718_at & Aldh1a7 & 29651 & 21.9409 \\
1378249_x_at & LOC102554740/// LOC103693750 & $102554740 / / / 103693750$ & 2.83937 \\
1371076_at & Cyp2b1///Cyp2b2 & $24300 / / / 361523$ & 2.63343 \\
1368321_at & Egr1 & 24330 & 2.43895 \\
1394541_at & Unknown & Unknown & 2.37995 \\
Down-regulated & & & \\
1390317_at & RGD1561849 & 500393 & -2.6521 \\
1369415_at & Bhlhe40 & 79431 & -3.11306 \\
1395255_at & Onecut1 & 25231 & -3.16945 \\
1387760_a_at & Onecut1 & 25231 & -3.77045 \\
1371034_at & Onecut1 & 25231 & -3.98444 \\
\hline
\end{tabular}

Table E-2. Ingenuity Pathway Analysis Enriched Disease and Biological/Toxicity Functions that Exhibit Activation/Inhibition in the Liver of Male Sprague Dawley Rats Administered 10,000 ppm 2H4MBP in Feed for 14 Weeks

\begin{tabular}{lccc}
\hline \multicolumn{1}{c}{ Diseases or Biological/Toxicity Functions } & $\begin{array}{c}\text { Enrichment P } \\
\text { Value }\end{array}$ & $\begin{array}{c}\text { Predicted } \\
\text { Activation Z-Score }\end{array}$ & $\begin{array}{c}\text { Activation } \\
\text { State }\end{array}$ \\
\hline Hepatic Steatosis & 0.00116 & 2.327 & Activate \\
Hypoplasia of Organ & 0.00299 & 2.138 & Activate \\
G2 Phase & 0.00229 & 2 & Activate \\
Increased Levels of Red Blood Cells & 0.00139 & -2 & Inhibited \\
S Phase & 0.00183 & -2.01 & Inhibited \\
Vasculogenesis & 0.00665 & -2.092 & Inhibited \\
Mitosis & 0.00373 & -2.098 & Inhibited \\
Formation of Gonadal Cells & 0.00475 & -2.169 & Inhibited \\
\hline
\end{tabular}




\begin{tabular}{lccc}
\hline \multicolumn{1}{c}{ Diseases or Biological/Toxicity Functions } & $\begin{array}{c}\text { Enrichment P } \\
\text { Value }\end{array}$ & $\begin{array}{c}\text { Predicted } \\
\text { Activation Z-Score }\end{array}$ & $\begin{array}{c}\text { Activation } \\
\text { State }\end{array}$ \\
\hline Maturation of Myeloid Cells & 0.00096 & -2.181 & Inhibited \\
Development of Genitourinary System & 0.00114 & -2.189 & Inhibited \\
Angiogenesis & 0.00172 & -2.221 & Inhibited \\
Development of Vasculature & 0.00178 & -2.223 & Inhibited \\
Hyperplasia of Exocrine Gland & 0.00395 & -2.236 & Inhibited \\
Genitourinary Tumor & 0.00313 & -2.358 & Inhibited \\
Cell Cycle Progression & $6.54 \mathrm{E}^{-06}$ & -2.376 & Inhibited \\
Development of Genital Organ & 0.000931 & -2.376 & Inhibited \\
Transactivation of RNA & 0.00258 & -2.399 & Inhibited \\
Cell Proliferation of Tumor Cell Lines & 0.00153 & -2.595 & Inhibited \\
Development of Reproductive System & 0.000378 & -2.91 & Inhibited \\
Growth of Organism & 0.00696 & -3.468 & Inhibited \\
\hline
\end{tabular}

Table E-3. Ingenuity Pathway Analysis Enriched Canonical Pathways that Exhibit Activation/Inhibition in the Liver of Male Sprague Dawley Rats Administered 10,000 ppm 2H4MBP in Feed for 14 Weeks

\begin{tabular}{lccc}
\hline \multicolumn{1}{c}{ Ingenuity Canonical Pathways } & $\begin{array}{c}\text { Enrichment P } \\
\text { Value }\end{array}$ & Activation Z-Score & $\begin{array}{c}\text { Predicted } \\
\text { Activation } \\
\text { State }\end{array}$ \\
\hline Acute Myeloid Leukemia Signaling & 0.0355 & -2.236 & Inhibition \\
ERK5 Signaling & 0.0372 & -2 & Inhibition \\
Melanocyte Development and Pigmentation Signaling & 0.0380 & -2.236 & Inhibition \\
ErbB2-ErbB3 Signaling & 0.0490 & -2 & Inhibition \\
Mouse Embryonic Stem Cell Pluripotency & 0.0490 & -2.236 & Inhibition \\
\hline
\end{tabular}

Table E-4. Ingenuity Pathway Analysis Enriched Upstream Regulators that Exhibit Activation/Inhibition in the Liver of Male Sprague Dawley Rats Administered 10,000 ppm 2H4MBP in Feed for 14 Weeks

\begin{tabular}{llccc}
\hline \multicolumn{1}{c}{ Upstream Regulator } & Molecule Type & $\begin{array}{c}\text { Enrichment } \\
\text { P Value }\end{array}$ & $\begin{array}{c}\text { Activation } \\
\text { Z-Score }\end{array}$ & $\begin{array}{c}\text { Predicted } \\
\text { Activation } \\
\text { State }\end{array}$ \\
\hline $\begin{array}{l}\text { MiR-30c-5p (and Other MiRNAs w/ } \\
\text { Seed GUAAACA) }\end{array}$ & Mature microRNA & 0.000422 & 2.828 & Activated \\
\hline
\end{tabular}




\begin{tabular}{|c|c|c|c|c|}
\hline Upstream Regulator & Molecule Type & $\begin{array}{l}\text { Enrichment } \\
\text { P Value }\end{array}$ & $\begin{array}{l}\text { Activation } \\
\text { Z-Score }\end{array}$ & $\begin{array}{c}\text { Predicted } \\
\text { Activation } \\
\text { State } \\
\end{array}$ \\
\hline Let-7 & MicroRNA & 0.019 & 2.763 & Activated \\
\hline U0126 & Chemical - kinase inhibitor & 0.0368 & 2.314 & Activated \\
\hline Sulindac Sulfide & Chemical drug & $1.92 \mathrm{E}-05$ & 2.209 & Activated \\
\hline Calcitriol & Chemical drug & 0.0411 & 2.173 & Activated \\
\hline Dexamethasone & Chemical drug & 0.000916 & 2.096 & Activated \\
\hline LY294002 & Chemical - kinase inhibitor & 0.00632 & 2.058 & Activated \\
\hline Cigarette Smoke & Chemical toxicant & 0.00578 & 2.007 & Activated \\
\hline ZBED6 & Transcription regulator & 0.000273 & 2 & Activated \\
\hline Ursolic Acid & Chemical drug & 0.00175 & 2 & Activated \\
\hline Salirasib & Chemical drug & 0.00961 & 2 & Activated \\
\hline $\begin{array}{l}\text { MiR-199a-5p (and Other MiRNAs w/ } \\
\text { Seed CCAGUGU) }\end{array}$ & Mature microRNA & 0.0245 & 2 & Activated \\
\hline EHHADH & Enzyme & 0.000111 & -2 & Inhibited \\
\hline HSD17B4 & Enzyme & 0.000718 & -2 & Inhibited \\
\hline NORAD & Other & 0.0027 & -2 & Inhibited \\
\hline Esr1 & $\begin{array}{l}\text { Ligand-dependent nuclear } \\
\text { receptor }\end{array}$ & 0.0136 & -2.04 & Inhibited \\
\hline Lipopolysaccharide & Chemical drug & 0.000845 & -2.12 & Inhibited \\
\hline Tgf Beta & Group & 0.0234 & -2.126 & Inhibited \\
\hline IFNB1 & Cytokine & 0.036 & -2.162 & Inhibited \\
\hline Bucladesine & Chemical toxicant & 0.0481 & -2.19 & Inhibited \\
\hline $\mathrm{E} 2 \mathrm{~F} 1$ & Transcription regulator & 0.0453 & -2.191 & Inhibited \\
\hline TGFB2 & Growth factor & 0.00702 & -2.205 & Inhibited \\
\hline CSHL1 & Growth factor & 0.00302 & -2.207 & Inhibited \\
\hline $\mathrm{E} 2 \mathrm{~F} 3$ & Transcription regulator & 0.0292 & -2.219 & Inhibited \\
\hline Tributyrin & Chemical drug & 0.00418 & -2.236 & Inhibited \\
\hline Mycophenolic Acid & Chemical drug & 0.00949 & -2.236 & Inhibited \\
\hline IL1B & Cytokine & 0.00709 & -2.36 & Inhibited \\
\hline PDGF BB & Complex & 0.00181 & -2.381 & Inhibited \\
\hline Raloxifene & Chemical drug & 0.0272 & -2.433 & Inhibited \\
\hline Insulin & Group & 0.000964 & -2.446 & Inhibited \\
\hline TNF & Cytokine & 0.00658 & -2.672 & Inhibited \\
\hline HGF & Growth factor & 0.0154 & -2.745 & Inhibited \\
\hline
\end{tabular}




\section{Appendix F. Endocrine Disruptor Screening Panel Studies}

\section{Table of Contents}

F.1. Competitive Estrogen Receptor Binding Assay

F.2. Estrogen Receptor Transcriptional Activation in a Human Cell Line (HeLa-9903)............F-4

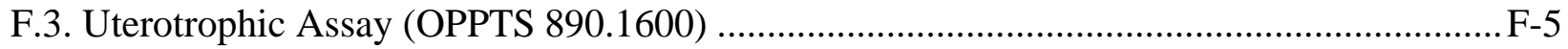

F.4. Competitive Androgen Receptor Binding (Rat Prostate Cytosol) ....................................F-6

F.5. Androgenic Transactivation Activity in MDA-kb2 Reporter Cells: Agonist and Antagonist Modes

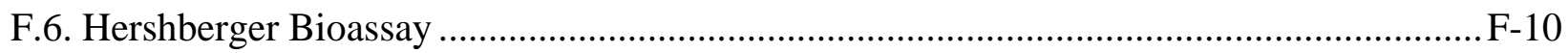

F.7. Human Recombinant Aromatase Assay .............................................................F-11

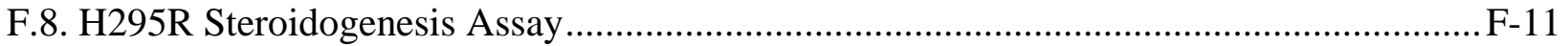

\section{Tables}

Table F-1. Uterine Estrogen Receptor Binding Assay Parameters and Curve Fit ${ }^{\mathrm{a}}$..................F-13

Table F-2. Estrogen Receptor Transcriptional Activation, Assay Parameters, and Curve Fit .. F-15

Table F-3. Uterine and Body Weights of Ovariectomized Sprague Dawley Rats

Administered UV Sunscreen Ingredients via Gavage for Three Days ....................F-16

Table F-4. Prostate Androgen Receptor Binding Assay Parameters and Curve Fit ..................F-16

Table F-5. Androgen Receptor Transactivation: Antagonist Mode Parameters and Curve Fit. F-18

Table F-6. Reproductive Organ and Body Weights of Rats Administered 2H4MBP or EHMC via Gavage for 10 Days (Agonist Assessment)......................................F-19

Table F-7. Reproductive Organ and Body Weights of Rats Administered 2H4MBP or EHMC via Gavage for 10 Days (Antagonist Assessment).

\section{Figures}

Figure F-1. Uterine Estrogen Receptor Binding

Figure F-2. Estrogen Receptor $\alpha$ Transcriptional Activation Assay ....

Figure F-3. Prostate Androgen Receptor Binding .

Figure F-4. Androgen Receptor Transactivation - Agonist Mode

$\mathrm{F}-24$

Figure F-5. Androgen Receptor Transactivation - Antagonist Mode

F-25 


\section{F.1. Competitive Estrogen Receptor Binding Assay}

\section{F.1.1. Methodology}

All procedures were conducted in accordance with the U.S. Environmental Protection Agency (EPA) guideline Office of Prevention, Pesticides and Toxic Substances (OPPTS) 890.1250. ${ }^{40}$

Briefly, 7-day postovariectomy uterine tissue from 12- to 13-week old Sprague Dawley rats was procured from Harlan Laboratories (now Envigo, Indianapolis, IN) and shipped overnight on dry ice. Uterine tissue was inspected for signs of residual ovarian tissue, and, if present, that tissue was discarded. Cytosolic fractions were prepared, pooled, and either used immediately or frozen at $-80^{\circ} \mathrm{F}$. If frozen, once subsequently thawed, unused aliquots were discarded. Three saturation bindings assays to support each run of the respective sunscreen ingredient were performed according to OPPTS 890.1250 and were shown to be acceptable. ${ }^{40}$

Radioactivity was assessed via a scintillation counter (PerkinElmer Tri-Carb 2910TR Liquid Scintillation Analyzer Model B2910) and each vial was counted for at least one minute with quench correction for determination of disintegrations per minute (DPM) per vial. Standards $\left({ }^{3} \mathrm{H}\right.$, ${ }^{14} \mathrm{C}$, and background) were used to verify accurate counting. For competitive binding, $1 \mathrm{nM}$ of $\left[{ }^{3} \mathrm{H}\right]-17 \beta$-estradiol was prepared on the day of assay and the specific activity was adjusted for decay over time prior to performing dilutions. The concentration of estrogen receptor (ER) was sufficient to bind $10-15 \%$ of the radioligand, and the incubation time was $16-20$ hours at $4{ }^{\circ} \mathrm{C}$. The competitive binding assay was determined to be functioning correctly on the basis of criteria set forth in OPPTS 890.1250; specifically, increasing concentrations of unlabeled 17 $\beta$-estradiol displaced $\left[{ }^{3} \mathrm{H}\right]-17 \beta$-estradiol from the receptor in a manner consistent with one-site competitive binding. ${ }^{40}$

The curve fit to the radio-inert estradiol data points using nonlinear regression descended from $90 \%$ to $10 \%$ over approximately an 81 -fold increase in the concentration of the test chemicals. Ligand depletion was minimal - the ratio of total binding in the absence of competitor to the total amount of $\left[{ }^{3} \mathrm{H}\right]-17 \beta$-estradiol added per assay tube was no greater than $15 \%$. The parameter values (Top, Bottom, and Hill slope) for 17 $\beta$-estradiol and 19-norethindrone (positive control) were within the tolerance bounds outlined in the OPPTS guideline. ${ }^{40}$ The dimethyl sulfoxide (DMSO) solvent control did not alter the sensitivity or reliability of the assay- the acceptable limit of ethanol concentration in the assay tube-was 3\%, the acceptable limit of DMSO concentration was $\leq 10 \%$, and all tubes contained the same amount of solvent. The negative control substance, octyltriethoxysilane, did not displace more than $25 \%$ of the radioligand from the ER on average across all concentrations.

The sunscreen ingredients were assessed over a concentration range that fully defined the top of the curve (i.e., a range that showed that a top plateau was achieved) and the top was within $25 \%$ of either the solvent control or the value for the lowest concentration of the $17 \beta$-estradiol 1 standard for that run. The classification of a chemical as a binder or nonbinder was made on the basis of the average results of three nonconcurrent runs, each of which met the performance criteria and, taken together, were consistent with each other, as per OPPTS guideline 890.1250. ${ }^{40}$ Each run was classified as "interactive," "not interactive," "equivocal," or "equivocal up to the limit of the concentrations tested." A run was classified as "interactive" with the ERs if the lowest point on the fitted response curve within the range of the data was less than $50 \%$. 
"Percent" (\%) refers to binding of the radiolabeled estradiol. Thus, "less than $50 \%$ " means that less than $50 \%$ of the radiolabeled estradiol was bound, or, equivalently, that more than $50 \%$ of the radiolabeled estradiol had been displaced from the receptor. A run was classified as "equivocal up to the limit of concentrations tested" if there were no data points at or above sunscreen ingredient concentration of $10^{-6} \mathrm{M}$ and one of the two following conditions held: (1) a binding curve could be fit but $50 \%$ or less of the radiolabeled estradiol was displaced by a concentration of $10^{-6} \mathrm{M}$; or (2) a binding curve could not be fit and the lowest average percent binding among the concentration groups in the data was above $50 \%$. A run was classified as "not interactive" if there were usable data points at or above $10^{-6} \mathrm{M}$ and either: (1) the lowest point on the fitted response curve within the range of the data was above $75 \%$; or (2) a binding curve could not be fit and the lowest average percent binding among the concentration groups in the data was above $75 \%$. A run was classified as "equivocal" if it fell in none of these categories.

After each run was classified, the chemical was classified by assigning the following values to each run and averaging across runs: interactive $=2$, equivocal $=1$, and not interactive $=0$. The chemical classification, based on the average of all the runs performed for a chemical, was calculated as: interactive (average $\geq 1.5)$, equivocal $(0.5 \leq$ average $<1.5)$, and not interactive (average < 0.5). Data points were plotted using GraphPad curve fit for:

$$
\begin{gathered}
\text { IC }_{\mathbf{5 0}}: \mathrm{Y}=\text { Bottom }+(\text { Top }- \text { Bottom }) /\left(1+10^{\wedge}\left(\left(\log \mathrm{IC}_{50}-\mathrm{X}\right) * \text { Hillslope }+\log ((\text { Top }- \text { Bottom }) /\right.\right. \\
(50-\text { Bottom })-1)))
\end{gathered}
$$

The Bottom was constrained to $>0$ for $2 \mathrm{H} 4 \mathrm{MBP}$ and 2-Ethylhexyl p-methoxycinnamate (EHMC).

\section{F.1.2. Results}

In each of the three independent ER binding experiments, the maximal mean specific binding was $>75 \%$ at every soluble $2 \mathrm{H} 4 \mathrm{MBP}$ and EHMC concentration assessed, categorizing them as "not interactive" (Figure F-1). When the specific binding was averaged using the scoring system as described in the OPPTS guideline, 2 H4MBP and EHMC were classified as "not interactive." 40

The half maximal inhibitory concentration $\left(\mathrm{IC}_{50}\right), \log \mathrm{IC}_{50}$, Top, Bottom, and Hill slopes of the curves were determined using the Hill model for 2H4MBP, EHMC and the reference agents (Table F-1). In general, the sunscreen ingredient-specific binding data could be fit to $\mathrm{IC}_{50}$ models but were often ascribed a fit of "ambiguous" by the software, likely due to the weakness of response. The $\mathrm{IC}_{50 \mathrm{~s}}$ for the "not interactive" sunscreen ingredients, $2 \mathrm{H} 4 \mathrm{MBP}$ and EHMC, ranged from approximately $2.3 \times 10^{-4}$ to $14.8 \times 10^{-4} \mathrm{M}$ and approximately $1.9 \times 10^{-3}$ to $4.6 \times 10^{4} \mathrm{M}$, respectively.

The weak positive control 19-norethindrone exhibited a $\log \mathrm{IC}_{50}$ of approximately -5.5 to $-5.6 \mathrm{M}$, whereas $17 \beta$-estradiol displayed a $\log \mathrm{IC}_{50}$ of approximately -8.8 to $-9.0 \mathrm{M}$. The Hill slope for these reference agents was between approximately -0.7 and -1.1 . 


\section{F.2. Estrogen Receptor Transcriptional Activation in a Human Cell Line (HeLa-9903)}

\section{F.2.1. Methodology}

All procedures were conducted in accordance with EPA guideline OPPTS 890.1300..$^{41}$ Briefly, the stably transfected hER $\alpha$-HeLa-9903 cell line was obtained from the Japanese Collection of Research Bioresources (JCRB) Cell Bank (Osaka, Japan). This cell line is derived from a human cervical tumor and has two stably inserted constructs - the hER $\alpha$ expression construct (encoding the full-length human receptor) and a firefly luciferase reporter construct bearing five tandem repeats of a vitellogenin estrogen-responsive element driven by a mouse metallothionein (MT) promoter TATA element. Consequently, the hER $\alpha$-HeLa-9903 cell line can measure the ability of a test substance to induce hER $\alpha$-mediated transactivation of luciferase gene expression and consequently can be used to assess the ability of a test substance to act as an agonist of $\mathrm{hER} \alpha$.

The cell line was certified to be free of mycoplasma, was passage 21 for the assay, and was maintained on phenol-red free media. The functional stability of the cell line was monitored using the following reference chemicals: $17 \beta$-estradiol, $17 \alpha$-estradiol, $17 \alpha$-methyltestosterone, and corticosterone. A complete concentration response curve for each reference compound was run each time the transcriptional activation assay was performed and the $\log \mathrm{PC}_{50}, \log \mathrm{PC}_{10}$, $\log \mathrm{EC}_{50}$, Hill slope, and fold induction values calculated, compared, and deemed consistent with guideline acceptable range values.

Cell viability was monitored by a two-read propidium iodide uptake assay using a Packard Fusion fluorescence plate reader at an excitation wavelength of $544 \mathrm{~nm}$ and an emission wavelength of $612 \mathrm{~nm}$. The first read was taken 24 hours after the addition of the control and test substances. The measured fluorescence indicates spontaneous cell death and control/test material induced cytotoxicity. The cells were then lysed, and a second read was taken, indicating $100 \%$ cell death. The first read is then subtracted from the second read and the results of the subtracted reads are directly proportional to the viability of the cells. As a positive control for inducing cell death, $125 \mu \mathrm{M}$ digitonin was used. Dose groups were normalized to vehicle control to generate percent cell viability.

DMSO was selected as a suitable vehicle for 2H4MBP and EHMC. 2H4MBP and EHMC solutions up to $10^{-4.5} \mathrm{M}$ (the limit concentration for the assay) can be prepared while limiting the final concentration of DMSO in the assay medium to $0.1 \%(\mathrm{v} / \mathrm{v}) .17 \alpha$-methyltestosterone,

$17 \alpha$-estradiol, corticosterone, and $17 \beta$-estradiol. The limit of solubility was determined by visual inspection of the test materials and controls after preparation of the final $1 \mathrm{x}$ dosing solutions in culture media. A sample of the 1x dosing solution was placed into wells of a clear 96-well plate and an endoscope was used to assess precipitation in each sample. Cytotoxicity and test article precipitation were assessed at $10^{-6.5}, 10^{-6}, 10^{-5.5}, 10^{-5}, 10^{-4.5}, 10^{-4}, 10^{-3.5}$, and $10^{-3} \mathrm{M}$. If a dose level of sunscreen ingredient produced cytotoxicity or precipitation, that dose level was not used. Cytotoxicity was observed at $10^{-3} \mathrm{M} 2 \mathrm{H} 4 \mathrm{MBP}$ or EHMC. The final concentrations of $2 \mathrm{H} 4 \mathrm{MBP}$ and EHMC tested in replicate in the ER transcriptional activation assay were $10^{-12}, 10^{-11}, 10^{-10}$, $10^{-9}, 10^{-8}, 10^{-7}, 10^{-6}$, and $10^{-5} \mathrm{M}$. Data points were plotted using GraphPad curve fit for: 


$$
\mathbf{E C}_{\mathbf{5 0}}: \mathrm{Y}=\text { Bottom }+(\text { Top}- \text { Bottom }) /\left(1+10^{\wedge}\left(\left(\log \mathrm{IC}_{50}-\mathrm{X}\right) * \text { Hillslope }\right)\right)
$$

The Bottom was constrained to zero.

\section{F.2.2. Results}

$2 \mathrm{H} 4 \mathrm{MBP}$ at $10^{-5} \mathrm{M}$ induced relative luciferase activity of $14.9 \%$ and $20.9 \%$ in each respective run (Table F-2; Figure F-2). 2H4MBP was considered a "positive" agent as per OPPTS 890.1300 because it exceeded $10 \%$ of the response of the positive control. ${ }^{41}$ In neither run of the ER transcriptional activation assay did EHMC exceed an increase in luciferase activity greater than $5 \%\left(\mathrm{RPC}_{\max }\right)$ at any of the viable concentrations assessed. The $\mathrm{EC}_{50}$ (and log thereof) and Hill slopes of the curves using the Hill model constrained at 0 were generated if possible. The top of the curve was constrained to $<100 \%$ for corticosterone, $17 \alpha$-methyltestosterone, and the sunscreen ingredients, as they did not exhibit a full response (Table F-2). The reference agents and $2 \mathrm{H} 4 \mathrm{MBP}$-specific luciferase data could be fit to the $\mathrm{EC}_{50}$ model. The $\log \mathrm{EC}_{50}$ for $2 \mathrm{H} 4 \mathrm{MBP}$ was -3.2 and $-4.0 \mathrm{M}$, respectively, for runs 1 and 2 . The $\log \mathrm{PC}_{10}$ for $2 \mathrm{H} 4 \mathrm{MBP}$ was calculated to be $-5.6 \mathrm{M}$ for each respective individual run.

The weak positive control $17 \alpha$-methyltestosterone exhibited $\log \mathrm{EC}_{50 \mathrm{~S}}$ of -8.8 and $-8.6 \mathrm{M}$ and Hill slopes of $>1$. $17 \beta$-estradiol displayed $\log \mathrm{EC}_{50}$ of -10.5 and $-10.3 \mathrm{M}$ and Hill slopes of $\sim 1.2$ to 1.5 . $17 \alpha$-estradiol displayed $\log \mathrm{EC}_{50 \mathrm{~s}}$ of -8.8 and $-8.6 \mathrm{M}$ and Hill slopes of 1.5 to 2.0 (Table F-2).

\section{F.3. Uterotrophic Assay (OPPTS 890.1600)}

\section{F.3.1. Methodology}

All procedures were conducted in accordance with OPPTS 890.1600 and were in compliance with the Animal Welfare Act Regulations. ${ }^{122 ;} 123$ Animals were handled and maintained according to the Guide for the Care and Use of Laboratory Animals. ${ }^{124}$ Briefly, 80 ovariectomized Sprague Dawley $\left(\mathrm{Crl}: \mathrm{CD}^{\circledR}(\mathrm{SD})\right.$ IGS) rats, 7 weeks of age, were procured from Charles River Laboratories (Raleigh, NC). Rats were acclimated to the study room for 7 days prior to randomization (body weight stratification to an $\mathrm{N}$ of 8/group), and initiation of dosing. Dose formulations of $2 \mathrm{H} 4 \mathrm{MBP}$, EHMC ( 320 or $1,000 \mathrm{mg} / \mathrm{kg} / \mathrm{day}$ ) and reference agent $17 \alpha$-ethinyl estradiol (EE) $(0.1 \mathrm{mg} / \mathrm{kg} / \mathrm{day})$ were prepared in corn oil. Concentrations and homogeneity were confirmed; mean concentrations were within $10 \%$ of the target concentration and the homogeneity coefficient of variation was $\leq 5 \%$ of the target concentration.

Rats were administered a dose volume of $5 \mathrm{~mL} / \mathrm{kg}$ via oral gavage for 3 consecutive days and then humanely euthanized by carbon dioxide (followed by secondary method to confirm death). Body weights and clinical observations were performed at least once daily. At termination, uteri (with cervix) were excised. Uterine wet and blotted weights were recorded to the nearest $0.0001 \mathrm{~g}$. Terminal body weight and body weight gain were analyzed by ANOVA. Uterine and blotted uterine weights were analyzed using a General Linearized Model (JMP, version 12.0.1) with terminal body weight and exposure concentration as model effects. If the probability of the $\mathrm{p}$ value was $\leq 0.05$, then potential differences in least square means were identified by Dunnett's test (compared to control). EE was compared to the vehicle using the Student's t-test. 


\section{F.3.2. Results}

Rats administered $0.1 \mathrm{mg} / \mathrm{kg}$ EE or $1,000 \mathrm{mg} / \mathrm{kg} 2 \mathrm{H} 4 \mathrm{MBP}$ displayed statistically significant body weight loss, as well as significant decreases in body weight gain, over the 3-day dosing interval. Terminal body weights of rats exposed to EE were significantly lower than control by $6.4 \%$ (Table F-3). Administration of $0.1 \mathrm{mg} / \mathrm{kg}$ EE also resulted in statistically significant (2.8and 2.3-fold) increases in uterine wet and blotted weights, respectively, demonstrating appropriate responsiveness of the system. Neither exposure concentrations of 2H4MBP nor EHMC significantly altered uterine wet or blotted weights.

\section{F.4. Competitive Androgen Receptor Binding (Rat Prostate Cytosol)}

\section{F.4.1. Methodology}

DMSO is one of the recommended solvents (OPPTS 890.1150) and was selected as a suitable vehicle. ${ }^{125} 2 \mathrm{H} 4 \mathrm{MBP}$ and EHMC solutions were prepared with concentrations up to $10^{-4} \mathrm{M}$ (the limit concentration for the assay) while limiting the final concentration of DMSO in the assay media to $\sim 3.2 \%(\mathrm{v} / \mathrm{v})$. DMSO was kept at the same concentration for the controls and for the test substance and was tested as a vehicle control with the reference chemical and reference controls for the run as well. Serial dilutions were prepared in DMSO to yield the final assay concentrations of $1 \times 10^{-3}$ to $1 \times 10^{-10} \mathrm{M}$. Precipitation of $2 \mathrm{H} 4 \mathrm{MBP}$ and EHMC was observed at final assay concentrations of $1 \times 10^{-3} \mathrm{M}$. The positive control, R1881, strongly binds androgen receptors (ARs) and was included to ensure that the run was properly performed and to allow an assessment of variability in the conduct of the assay across time. R1881 stock (10 $\mathrm{mM})$ was diluted 1:10 and then serial diluted. Final concentrations of unlabeled R1881 were $1 \times 10^{-6}$ to $1 \times 10^{-11} \mathrm{M}$. The weak positive control was dexamethasone prepared from a $30 \mathrm{mM}$ stock solution in DMSO and then serially diluted to final concentrations of $1 \times 10^{-3}$ to $1 \times 10^{-10} \mathrm{M}$. DMSO concentrations were kept at $3.2 \%$. Visual observation determined the limit of test chemical solubility, and initial compound solubility was determined in solvent. In addition, the solutions were watched closely when added to the experiment tube, as the test compound may precipitate upon addition to the assay tube mixtures.

Cytosol was collected, processed, and validated per EPA OPPTS 890.1150 for use in this study. ${ }^{125}$ Briefly, for the three independent runs, ventral prostates from SD rats (90 days old and castrated <1 day prior to collection) were removed, weighed, and sent via overnight carrier on dry ice. Upon receipt, prostates were thawed, inspected for fibrous, inflamed, edematous, or other abnormal appearance, and, if present, the organ was discarded. Prostates were trimmed of excess fascia, weighed, minced with a scalpel blade and fine scissors, and immediately homogenized with a Polytron PT 2100 at $4^{\circ} \mathrm{C}$ in TEDG buffer. The homogenates were centrifuged at 30,000 g for 30 minutes using a Sorvall RC5B centrifuge, cooled to $4^{\circ} \mathrm{C}$. The supernatant from a given run was pooled and protein concentration was determined by the Bradford method (BioRad) typical values are 1-4 mg/mL. Samples were frozen and maintained at $-70^{\circ} \mathrm{C}$ until use. Once thawed on ice and diluted to the predetermined optimal protein concentration, they were immediately used. Triamcinolone acetonide was used to prevent progesterone-specific binding.

$\left[{ }^{3} \mathrm{H}\right] \mathrm{R} 1881$ was prepared on the day of assay. The specific activity was adjusted for decay over time prior to performing dilutions, and siliconized tubes were used for the assay. Saturation AR 
binding assays were performed for each independent run of the assay. Increasing concentrations of unlabeled R1881 displaced $\left[{ }^{3} \mathrm{H}\right] \mathrm{R} 1881$ from the receptor in a manner consistent with one-site competitive binding; the ligand depletion was held below 15\%, and was acceptable as per EDSP OPPTS 890.1150. ${ }^{125}$ DMSO at the concentrations used did not alter assay sensitivity or reliability. Resulting data were normalized to \% specific binding and plotted. Data were curve fit by weighted least squares nonlinear regression analysis with weights equal to $1 / \mathrm{Y}$ according to:

$$
\begin{gathered}
\mathrm{Y}=\text { Bottom }+(\text { Top }- \text { Bottom }) /\left(1+10^{\wedge}((\operatorname{logIC} 50-\mathrm{X}) * \text { Hillslope }+\log ((\text { Top }- \text { Bottom }) /\right. \\
(50-\text { Bottom })-1))) .
\end{gathered}
$$

Relative binding activity (RBA) was calculated by dividing the $\mathrm{IC}_{50}$ of the positive control R1881 by the $\mathrm{IC}_{50}$ of the respective sunscreen ingredient.

\section{F.4.2. Results}

The suitable top concentration of 2H4MBP and EHMC for use in all three independent AR competitive binding assays was $10^{-4} \mathrm{M}$, as precipitation was seen with both at $10^{-3} \mathrm{M}$. In the presence of $10^{-4} \mathrm{M} 2 \mathrm{H} 4 \mathrm{MBP},\left[{ }^{3} \mathrm{H}\right]-\mathrm{R} 1881$ specific binding was $64.9 \%, 62.6 \%$, and $61.2 \%$ for each independent experiment, with a mean of $62.9 \%$. When fitted to the $1 / \mathrm{Y}$ weighted Hill model, the $\log \mathrm{IC}_{50}$ ranged from -3.7 to $-1.2 \mathrm{M}$. Collectively, $2 \mathrm{H} 4 \mathrm{MBP}$ tested up to $10^{-4} \mathrm{M}$ did not displace more than $50 \%$ of the $\left[{ }^{3} \mathrm{H}\right]-\mathrm{R} 1881$, categorizing $2 \mathrm{H} 4 \mathrm{MBP}$ as "equivocal" (Table F-4; Figure F-3), as per OPPTS Guidance. ${ }^{125}$

In each of the three AR competitive binding assays and the averaged competition curve, the $\left[{ }^{3} \mathrm{H}\right]-\mathrm{R} 1881$ specific binding at every soluble EHMC concentration tested was $>75 \%$, with $\log \mathrm{IC}_{50}$ values ranging from -2.2 to $5.0 \mathrm{M}$. Therefore, EHMC was classified as a "nonbinder." The weak positive control dexamethasone exhibited $\log \mathrm{IC}_{50}$ values of -4.3 to $-4.6 \mathrm{M}$, whereas R1881-1 displayed $\log \mathrm{IC}_{50 \mathrm{~S}}$ of -8.9 to $-9.9 \mathrm{M}$. The Hill slopes for these reference agents were approximately -1 . The mean RBA for the "equivocal" 2 H4MBP UV filter was $>0.0002 \%$. The mean RBA for the weak reference agent dexamethasone was $0.0024 \%$.

\section{F.5. Androgenic Transactivation Activity in MDA-kb2 Reporter Cells: Agonist and Antagonist Modes}

\section{F.5.1. Methodology}

DMSO was selected as a suitable vehicle for the test substances. Therefore, solutions with a test substance concentration of up to $10^{-3} \mathrm{M}$ (the highest concentration assessed) can be prepared while limiting the final concentration of DMSO in the assay medium to $0.5 \%(\mathrm{v} / \mathrm{v})$. Each test substance was prepared for addition to the cell system by making a $400 \mathrm{mM}$ stock. Dilutions were prepared in DMSO up to 400x, the final target concentration. Dihydrotestosterone (DHT), nilutamide (Nil), dichlorodiphenyldichloroethylene (p,p'-DDE, or DDE), 2H4MBP, and EHMC were all prepared on the day of dosing. Considering the short-term nature of studies of this type, no analyses of stability, homogeneity, or achieved concentration(s) were carried out on preparations of the test substance or positive control chemicals, either before or after the treatment phase. Solubility limits were determined by visual observation or particulate light scattering via nephelometry with Nepheloskan. Stably transfected MDA-kb2 cell line was obtained from ATCC and confirmed to be mycoplasma-free. The MDA-kb2 cell line is derived 
from the MDA-MB-453 breast cancer cell line by stable transfection with a mouse mammary tumor virus luciferase-neo reporter construct containing the androgen response element. The transcriptional stability was monitored by the use of the following reference chemicals: DHT, Nil, and p,p'-DDE. A complete concentration response curve for each reference compound was run each time the transcriptional activation assay was performed. Cells were maintained in Leibovitz's L-15 culture medium containing 10\% fetal bovine serum, in an incubator at approximately $37^{\circ} \mathrm{C}$. The MDA-kb2 cell line is not contact inhibited and can be grown to confluence. Cells were subcultivated at a 1:2 to 1:8 subcultivation ratio. The cells were suspended with complete medium and plated into wells of a 96-well cell culture plate at a density of approximately $1 \times 10^{4}$ cells/100 $\mu \mathrm{L} /$ well. The cells were then placed into an incubator at approximately $37^{\circ} \mathrm{C}$ overnight prior to chemical exposure.

After adding the reference chemicals/test substances, the plates were incubated in an incubator at approximately $37^{\circ} \mathrm{C}$ for approximately 24 hours. For the agonism plates, all concentrations were tested in replicates of 6/plate. In addition, for each concentration, two replicates/plate were prepared that incorporated the AR antagonist Nil. Replicates incorporating an AR antagonist allow for the identification of nonspecific (i.e., non-AR-mediated) induction of the luciferase gene as true AR-mediated induction is inhibited by addition of an antagonist whereas nonspecific induction is not. For the antagonism plates, all concentrations were tested in replicates of 4/plate. Four replicates were co-administered $1 \mathrm{nM}$ DHT and test article at each concentration. Four replicates were co-administered 1,000 nM DHT and test article at each concentration. Replicates incorporating 1,000 nM DHT allowed for the identification of assay interference. Cell viability was monitored by a two-read propidium iodide (PI) uptake assay conducted under low light conditions. Cells were seeded and exposed as described above in a black-walled 96-well cell culture plate.

Digitonin $(125 \mu \mathrm{M})$ was used as a cell death positive control. Following chemical exposure, the growth medium was removed and $50 \mu \mathrm{L}$ of a PI working solution ( $44 \mu \mathrm{M}$ in phosphate buffered saline) was added to each well. Background fluorescence was evaluated by measuring fluorescence immediately on a Packard Fusion fluorescence plate reader at an excitation wavelength of $544 \mathrm{~nm}$ and an emission wavelength of $612 \mathrm{~nm}$. Following this determination, $50 \mu \mathrm{L}$ of a $2 \%(\mathrm{v} / \mathrm{v})$ Triton X-100 solution was added to each well and the plate was incubated at room temperature for approximately 15 minutes to fully lyse all cells in the wells before measuring fluorescence at the same wavelengths. The background-corrected fluorescence was calculated for each well by subtracting the results of the first read from the results of the second read. The change in cell viability was determined by comparing treated wells to the vehicle control wells. A $\geq 20 \%$ reduction in cell viability was considered evidence of cytotoxicity.

Luciferase activity was determined as described by Wilson ${ }^{116}$. Acceptance criteria included: (1) background value ratio of vehicle control to antagonist control should be $<10 \mathrm{X}$, and (2) the ratio of positive control to vehicle control should be $>3 \mathrm{X}$. Each data point was normalized to the average of the vehicle-only treated control (fold induction). Where appropriate, $\log \mathrm{PC}_{50}$, $\log \mathrm{PC}_{10}, \log \mathrm{EC}_{50}$, and Hill slope values were calculated. For the test substance, the maximum response relative to the positive control $\left(\mathrm{RPC}_{\max }\right)$ was determined. In each individual run of the transcriptional activation assay, if $\mathrm{RPC}_{\max }$ was less than $20 \%$, the test substance was considered a negative response for AR agonism. For each individual run of the transcriptional activation assay, the acceptability of the data was evaluated using the following criteria: (1) the mean 
normalized luciferase signal of the PC (10 nM DHT) should be at least fourfold that of the mean vehicle control on each plate, and (2) the results of the reference compounds, Nil and DHT, should be within the acceptable ranges. If the acceptability criteria outlined above were met, that run of the transcriptional activation assay was considered definitive. The test substance was considered negative if $\mathrm{RPC}_{\max }$ was $<20 \%$ in at least two definitive runs of the transcriptional activation assay. The test substance was considered positive if $\mathrm{RPC}_{\max }$ was $\geq 20 \%$ in at least two definitive runs of the transcriptional activation assay.

To determine the relative transcriptional activity as compared to the PC (10 nM DHT), the luminescence data from each plate were analyzed as follows: wells incorporating $1 \mathrm{nM} \mathrm{DHT}$ were analyzed in an identical fashion to wells incorporating 1,000 nM DHT, except that the data were normalized to the induced control with $1 \mathrm{nM}$ DHT or 1,000 nM DHT, respectively. Any cytotoxic concentrations were excluded from data analysis. The mean value for the vehicle control wells was calculated and subtracted from each well to normalize the data. The mean value for the induced control with $1 \mathrm{nM}$ or 1,000 $\mathrm{nM}$ DHT was calculated. The wells dosed with test or control substance and $1 \mathrm{nM}$ or 1,000 $\mathrm{nM}$ DHT were normalized to the mean value for the induced control with $1 \mathrm{nM}$ or 1,000 nM DHT, respectively. Averages of antagonist or high agonist control \% maximal induction were calculated (test or control substance with $1 \mathrm{nM}$ or 1,000 nM DHT, respectively). Differentials were calculated (averages of high agonist \% maximal induction control minus averages of antagonist \% maximal induction control). Where appropriate, $\mathrm{RIC}_{\max }, \mathrm{IC}_{50}$, and Hill slope values were calculated. If the differential between the high antagonism and the low antagonism was greater than $50 \%$ and had a dose response (more than one data point) in two of two runs, then the test substance was considered positive. If the differential between the high antagonism and the low antagonism was less than $50 \%$ and did not have a dose response (more than one data point) in two of two runs, than the test substance was considered negative. For each individual run of the transcriptional activation assay, the acceptability of the data was evaluated using the following criteria: the mean normalized luciferase signal of the PC (10 nM DHT) should have been at least fourfold that of the negative control on each plate. If the acceptability criteria outlined above were met, that run of the transcriptional activation assay was considered to be definitive.

\section{F.5.2. Results}

In all independent runs of the agonist transcriptional activation assay, neither $2 \mathrm{H} 4 \mathrm{MBP}$ nor EHMC resulted in an increase in luciferase activity at any of the viable soluble concentrations tested; $\mathrm{RPC}_{\max }<20 \%$ (Figure F-4).

In two of three runs the decrease in DHT-induced luciferase activity resulting from $2 \mathrm{H} 4 \mathrm{MBP}$ exposure was approximately $25 \%$ at the highest feasible dose of $-4.5 \mathrm{M}$, with the first run exhibiting a luciferase activity of $72.2 \%$ of maximal (Figure F-5). EHMC had no apparent inhibitory effect on DHT-induced AR transcriptional activity. The $\mathrm{EC}_{50}, \mathrm{IC}_{50}$ (and logs thereof), and Hill slopes of the curves using the unconstrained Hill model were determined (Table F-5). Curves could be fit for two of the three $2 \mathrm{H} 4 \mathrm{MBP}$ runs and both EHMC runs. The $\log \mathrm{IC}_{50} \mathrm{~S}$ and Hill slopes for Nil and DDE were approximately -6.4 and $-4.8 \mathrm{M},-1.3$ and -1 , respectively. 


\section{F.6. Hershberger Bioassay}

\section{F.6.1. Methodology}

All procedures were conducted in accordance with OPPTS 890.1400 and in compliance with the Animal Welfare Act Regulations. ${ }^{122 ;} 126$ Animals were handled and maintained according to the Guide for the Care and Use of Laboratory Animals. ${ }^{124}$ Briefly, 208 (total) Sprague Dawley $\mathrm{Crl}$ :CD(SD) IGS rats were procured from Charles River Laboratories (Raleigh, NC) one week after PND 45 castration surgery. Rats were acclimated to the study room for 7 days prior to randomization (body weight stratification; $\mathrm{N}=8$ /group) and initiation of dosing. This assessment was done as two separate studies (with respective controls). For the androgen agonist assessment, $0.4 \mathrm{mg} / \mathrm{kg} / \mathrm{day}$ of testosterone propionate (TP) was used as the positive inducer of maximal androgenic response, whereas $3 \mathrm{mg} / \mathrm{kg} /$ day of flutamide (FT) (in combination with $0.4 \mathrm{mg} / \mathrm{kg} /$ day TP) was used to induce maximal inhibition of the TP-induced androgenic response. Dose formulations of 2H4MBP, EHMC, TP, and flutamide were prepared in corn oil.

In the first study, the vehicle (corn oil) and two exposure concentrations of 2H4MBP and EHMC were used (320 and 1,000 mg/kg/day) for the assessment androgen agonism, and three exposure concentrations $(100,320$, and $1,000 \mathrm{mg} / \mathrm{kg} /$ day) were used to assess potential sunscreen ingredient antagonism of TP-induced androgen action. Respective controls (vehicle, TP, TP and FT) were included in each study. OPPTS 890.1400 specifies to select doses that ensure animal survival and that are without significant toxicity or distress to the animals after 10 consecutive days of chemical administration, and the highest dose should not cause a reduction in the final body weight of the animals greater than $10 \%$ of control weight. ${ }^{126} 2 \mathrm{H} 4 \mathrm{MBP}$ and EHMC were evaluated up to the limit exposure concentration $(1,000 \mathrm{mg} / \mathrm{kg} / \mathrm{day})$. The test substance, FT, or corn oil dose formulations were administered by oral gavage at a dose volume of $5 \mathrm{~mL} / \mathrm{kg}$ body weight. TP dose formulations were administered by subcutaneous injection into the dorsoscapular region at a dose volume of $0.5 \mathrm{~mL} / \mathrm{kg}$ body weight. In co-administered animals, oral gavage preceded subcutaneous injections. Dosing occurred 24 hours ( \pm 2 hours) from the previous dose. Dose volume was determined on individual animal daily body weight. The dosing sequence was stratified across dose groups - one animal from each group and then repeated until all animals were dosed. Selection of the route of administration was in accordance with OPPTS 890.1400 and OECD Guideline 441. ${ }^{127 ;} 126$

Samples were collected for confirmation of concentration and homogeneity. Mean concentrations were within $10 \%$ of the target concentration, and the homogeneity coefficient of variation was less than $\leq 5 \%$ of the target concentration. Rats were orally gavaged at a dose volume of $5 \mathrm{~mL} / \mathrm{kg}$ for 10 consecutive days. Body weights and clinical observations were performed at least once daily. At study termination, rats were humanely euthanized by $\mathrm{CO}_{2}$ asphyxiation and death confirmed by a second method in the same order as they were dosed.

Gross observations were recorded for the ventral prostate, seminal vesicle and coagulating gland with fluid, levator ani/bulbocavernosus muscle, Cowper's gland, and glans penis. The tissues were excised, trimmed of excess adhering tissue and fat, and weighed to the nearest $0.0001 \mathrm{~g}$.

Terminal body weight and body weight gain were analyzed by ANOVA. Organ weights were tested (by dose) and assumed to be normally distributed and analyzed by General Linearized Model (JMP version 12.0.1) with terminal body weight and exposure concentration as model 
effects. If the probability of the $p$ value (versus the respective control) was $\leq 0.05$ then potential differences in least square means were identified by Dunnett's test. TP was compared to vehicle using the Student's t-test.

\section{F.6.2. Results}

In the absence of androgenic action, neither 2H4MBP nor EHMC had any effect on androgen dependent organ weights, demonstrating that 2H4MBP and EHMC do not exhibit any in vivo androgenic activity (Table F-6; Table F-7). In the presence of TP, EHMC did not attenuate the expected androgen-mediated increase in organ weights, demonstrating that EHMC does not exhibit any antiandrogenic activity in vivo under the exposure concentrations assessed. Rats coadministered 1,000 mg/kg/day of 2H4MBP and TP displayed statistically lower day 10 body weight and body weight gain ( 7 and $28 \%$, respectively) relative to control. The mean weights of the glans penis and ventral prostate were also statistically lower (6 and 17\%, respectively). The weight of the seminal vesicles was also slightly lower. However, when concurrent body weight is used as a covariate, the magnitude of the response is decreased and no longer attains statistical significance. Given that these organ weight changes only occurred in the presence of lower body weights at the highest dose assessed, these organ weight changes are likely secondary to effects on body weight.

\section{F.7. Human Recombinant Aromatase Assay}

\section{F.7.1. Methodology}

The potential for 2H4MBP and EHMC to as act as inhibitors of aromatase activity was assessed using human CYP19 (aromatase) and P450 reductase Supersomes ${ }^{\mathrm{TM}}$ (Gentest ${ }^{\mathrm{TM}}$ ). The substrate for the assay was $\left[1 \beta-{ }^{3} \mathrm{H}\right]$-Androstenedione (ASDN), which is then converted by aromatase to estrone. Estrone was extracted via aqueous phase and quantified utilizing liquid scintillation counting, Final concentrations of EHMC and 2H4MBP in the aromatase assay were $10^{-10}, 10^{-9}$, $10^{-8}, 10^{-7}, 10^{-6}, 10^{-5}, 10^{-4.5}, 10^{-4}$, and $10^{-3} \mathrm{M}$. Three independent runs of the aromatase assay were conducted. In each independent run, each concentration of test substance was tested in triplicate. In addition, the positive control inhibitor 4-hydroxyandrostenedione (4OH-ASDN) was included each time the aromatase assay was performed. Increasing concentrations of $4 \mathrm{OH}-\mathrm{ASDN}$ decrease the aromatase activity in a concentration dependent manner.

\section{F.7.2. Results}

According to the data interpretation procedure outlined by the EPA (OPPTS 890.1200), EHMC was classified as a noninhibitor, with mean aromatase activity of $100 \%$ ( $\pm 6 \% \mathrm{SD}) .{ }^{128} 2 \mathrm{H} 4 \mathrm{MBP}$ was classified as equivocal, as it produced a mean aromatase activity level of $51 \%( \pm 13 \%$ SD) of control activity at the highest soluble test concentration of $10^{-4} \mathrm{M}$.

\section{F.8. H295R Steroidogenesis Assay}

\section{F.8.1. Methodology}

The ability of $2 \mathrm{H} 4 \mathrm{MBP}$ or EHMC to affect the steroidogenic pathway, beginning with the sequence of reactions occurring after the gonadotropin hormone receptors through the production of testosterone and estradiol/estrone was assessed using the H295R human adrenocarcinoma cell 
line. The final concentrations of each compound tested in the steroidogenesis assay were: 0.0001 , $0.001,0.01,0.1,1,10$, and $100 \mu \mathrm{M}$. Four independent runs of the steroidogenesis assay were conducted. Three of the four assays were analyzed for each compound. All test chemicals, reference chemicals, and solvent controls were tested in replicates of 3/plate, with the exception of the solvent controls on the quality control (QC) plate. Six solvent control wells were analyzed on the QC plate. The H295R supplemented medium used in the assay at the time of plating, dosing, and harvest contained $10 \mu \mathrm{M} 22 \mathrm{R}$-hydroxycholesterol. The duration of exposure was 48 hours. A QC plate containing two doses of reference chemicals forskolin and prochloraz was run each time the assay was performed. Cell viability was assessed after the 48-hour exposure using the MTT assay. Testosterone and estradiol concentrations were measured using HPLC/MS-MS by OpAns, LLC (Durham, NC). All concentrations that exhibited greater than $20 \%$ cytotoxicity in the MTT cell viability assay were excluded from the statistical analysis of testosterone and estradiol concentrations.

\section{F.8.2. Results}

The highest concentration of $2 \mathrm{H} 4 \mathrm{MBP}$ that could be tested in the assays was $100 \mu \mathrm{M}$, according to apparent solubility and cytotoxicity results. Statistically significant induction of testosterone was observed at the $100 \mu \mathrm{M}$ concentration in all three runs of the assay. Statistically significant estradiol induction was observed at 10 and $100 \mu \mathrm{M}$ in three runs, and at $0.1,1,10$, and $100 \mu \mathrm{M}$ in one run. Although statistically significant results were identified at the $100 \mu \mathrm{M} 2 \mathrm{H} 4 \mathrm{MBP}$ concentration in all three runs, precipitation was noted under the microscope after the 48-hour exposure period at this concentration. Nonetheless, $2 \mathrm{H} 4 \mathrm{MBP}$ would be classified as positive in the steroidogenesis assay for effects on estradiol on the basis of the data interpretation criteria outlined in the OECD test guideline for the assay. Induction of testosterone production was apparently observed at $100 \mu \mathrm{M}$, concomitant with precipitation $2 \mathrm{H} 4 \mathrm{MBP}$. The criteria outlined in the OECD test indicate that the effects of $2 \mathrm{H} 4 \mathrm{MBP}$ on testosterone in each run would be classified as equivocal.

The highest concentration of EHMC that could be tested in the assays was $0.1 \mu \mathrm{M}$ in run 1 and $100 \mu \mathrm{M}$ in all runs 2 and 3, as per solubility results. Precipitation was observed prior to exposure in run 1 at the 1,10, and $100 \mu \mathrm{M}$ concentrations. Cytotoxicity greater than $20 \%$ was not observed in any of the three runs at any of the concentrations tested. No statistically significant effects were observed on testosterone or estradiol production at any of the concentrations that were analyzed in any of the three runs. According to the data interpretation criteria outlined in the OECD test guideline, EHMC is negative in the steroidogenesis assay. 
Table F-1. Uterine Estrogen Receptor Binding Assay Parameters and Curve Fit ${ }^{a}$

\begin{tabular}{|c|c|c|c|c|c|}
\hline & \multicolumn{3}{|c|}{ Reference Agents } & \multicolumn{2}{|c|}{ UV Filter } \\
\hline & 17ß-Estradiol & 19-Norethindrone & Octyltriethoxysilane & 2H4MBP & EHMC \\
\hline \multicolumn{6}{|c|}{$\mathbf{R P C}_{\max }$} \\
\hline Exp. 1 & $0.0 \pm 0.4$ & $0.9 \pm 0.1$ & $94.1 \pm 1.8$ & $83.2 \pm 0.9$ & $89.2 \pm 2.9$ \\
\hline Exp. 2 & $0.0 \pm 0.2$ & $0.8 \pm 0.1$ & $88.6 \pm 1.4$ & $76.5 \pm 0.6$ & $93.4 \pm 0.8$ \\
\hline Exp. 3 & $0.0 \pm 0.1$ & $1.6 \pm 0.6$ & $90.9 \pm 1.6$ & $77.2 \pm 0.4$ & $93.1 \pm 2.1$ \\
\hline Mean & $0.0 \pm 0.0$ & $1.1 \pm 0.3$ & $91.2 \pm 1.6$ & $79.0 \pm 2.1$ & $91.9 \pm 1.4$ \\
\hline \multicolumn{6}{|c|}{$\mathbf{P C}_{\max }(\mathbf{M})$} \\
\hline Exp. 1 & $10^{-7}$ & $10^{-4}$ & $10^{-6.5}$ & $10^{-4}$ & $10^{-4}$ \\
\hline Exp. 2 & $10^{-7}$ & $10^{-4}$ & $10^{-4.5}$ & $10^{-4}$ & $10^{-4}$ \\
\hline Exp. 3 & $10^{-7}$ & $10^{-4}$ & $10^{-4.5}$ & $10^{-4}$ & $10^{-4}$ \\
\hline \multicolumn{6}{|l|}{$\mathbf{R}^{2}$} \\
\hline Exp. 1 & 0.9987 & 0.9993 & Ambiguous 0.2727 & $\begin{array}{c}\text { Ambiguous } \\
0.9915\end{array}$ & $\begin{array}{c}\text { Ambiguous } \\
0.8190\end{array}$ \\
\hline Exp. 2 & 0.9973 & 0.9981 & Ambiguous 0.1109 & 0.8872 & $\begin{array}{c}\text { Ambiguous } \\
0.5173\end{array}$ \\
\hline Exp. 3 & 0.9953 & 0.9998 & Ambiguous 0.3306 & $\begin{array}{c}\text { Ambiguous } \\
0.9843\end{array}$ & $\begin{array}{c}\text { Ambiguous } \\
0.3545\end{array}$ \\
\hline \multicolumn{6}{|l|}{ Top } \\
\hline Exp. 1 & $94.7 \pm 1.9$ & $93.1 \pm 0.9$ & $\sim 7,305$ & $95.3 \pm 0.3$ & $97.8 \pm 2.2$ \\
\hline Exp. 2 & $92.5 \pm 2.8$ & $96.6 \pm 2.1$ & $91.8 \pm 2.2$ & $97.2 \pm 1.8$ & 844,702 \\
\hline Exp. 3 & $95.7 \pm 4.0$ & $100.3 \pm 0.5$ & $98.9 \pm 2.7$ & $98.6 \pm 0.6$ & $98.7 \pm 1.4$ \\
\hline \multicolumn{6}{|l|}{ Bottom } \\
\hline Exp. 1 & $-0.5 \pm 2.0$ & $-0.7 \pm 1.5$ & $\sim 40$ & $\sim 49$ & $\sim 50$ \\
\hline Exp. 2 & $-1.1 \pm 2.9$ & $-7.8 \pm 4.5$ & $\sim 50$ & $<0$ & $\sim 41$ \\
\hline Exp. 3 & $-5.0 \pm 5.0$ & $-1.0 \pm 0.8$ & $\sim 50$ & $\sim 49$ & $\sim 50$ \\
\hline \multicolumn{6}{|c|}{$\operatorname{LogIC} C_{50}$} \\
\hline Exp. 1 & $-9.0 \pm 0.0$ & $-5.5 \pm 0.0$ & $\sim 296.6$ & $\sim-3.6$ & $\sim 4.7$ \\
\hline Exp. 2 & $-9.0 \pm 0.0$ & $-5.5 \pm 0.0$ & $\sim-2.6$ & $-2.9 \pm 4.0$ & $\sim-116.6$ \\
\hline Exp. 3 & $-8.8 \pm 0.1$ & $-5.6 \pm 0.0$ & $\sim-2.7$ & $\sim-2.8$ & $\sim-2.7$ \\
\hline
\end{tabular}




\begin{tabular}{|c|c|c|c|c|c|}
\hline & \multicolumn{3}{|c|}{ Reference Agents } & \multicolumn{2}{|c|}{ UV Filter } \\
\hline & 17 $\beta$-Estradiol & 19-Norethindrone & Octyltriethoxysilane & 2H4MBP & EHMC \\
\hline \multicolumn{6}{|l|}{$\mathrm{IC}_{50}$} \\
\hline Exp. 1 & $9.9 \times 10^{-10}$ & $2.7 \times 10^{-6}$ & $3.7 \times 10^{297}$ & $\sim 2.3 \times 10^{-4}$ & $4.6 \times 10^{4}$ \\
\hline Exp. 2 & $8.8 \times 10^{-10}$ & $2.2 \times 10^{-6}$ & $\sim 2.5 \times 10^{-3}$ & $11.4 \times 10^{-4}$ & $\sim 0$ \\
\hline Exp. 3 & $1.3 \times 10^{-9}$ & $2.3 \times 10^{-6}$ & $\sim 1.9 \times 10^{-3}$ & $\sim 14.8 \times 10^{-4}$ & $\sim 1.9 \times 10^{-3}$ \\
\hline \multicolumn{6}{|c|}{ Hill Slope } \\
\hline Exp. 1 & $-1.1 \pm 0.1$ & $-1.1 \pm 0.1$ & $\sim 0$ & $\sim-5.6$ & $-0.4 \pm 1.0$ \\
\hline Exp. 2 & $-1.0 \pm 0.1$ & $-0.7 \pm 0.1$ & $\sim-4.4$ & $-0.5 \pm 0.9$ & $\sim 0$ \\
\hline Exp. 3 & $-0.8 \pm 0.1$ & $-0.9 \pm 0.0$ & $\sim-4.5$ & $\sim-1.6$ & $\sim-4.7$ \\
\hline \multicolumn{6}{|c|}{ Log Relative Binding Affinity } \\
\hline Exp. 1 & - & 1.6 & NS & 2.5 & -1.9 \\
\hline Exp. 2 & - & 1.6 & 3.5 & 3.1 & 0.1 \\
\hline Exp. 3 & - & 1.6 & 3.3 & 3.2 & 3.3 \\
\hline \multicolumn{6}{|c|}{ Relative Binding Affinity (\%) } \\
\hline Exp. 1 & - & 0.0385 & - & 0.0004 & 0.0000 \\
\hline Exp. 2 & - & 0.0409 & 0.0001 & 0.0001 & - \\
\hline Exp. 3 & - & 0.0565 & 0.0002 & 0.0001 & 0.0001 \\
\hline
\end{tabular}


Table F-2. Estrogen Receptor Transcriptional Activation, Assay Parameters, and Curve Fit ${ }^{\mathrm{a}}$

\begin{tabular}{|c|c|c|c|c|c|c|}
\hline & \multicolumn{4}{|c|}{ Reference Agents } & \multicolumn{2}{|c|}{ UV Filters } \\
\hline & 17 $\beta$-Estradiol & $\begin{array}{c}\text { 17a-Ethynyl } \\
\text { Estradiol }\end{array}$ & Corticosterone & 17a-Methyltestosterone & 2H4MBP & EHMC \\
\hline \multicolumn{7}{|l|}{$\mathbf{R P C}_{\max }$} \\
\hline Exp. 1 & $125.8 \pm 9.4$ & $103.8 \pm 11.6$ & $2.3 \pm 0.5$ & $43.9 \pm 8.0$ & $14.9 \pm 1.1$ & $4.1 \pm 0.8$ \\
\hline Exp. 2 & $135.3 \pm 10.4$ & $101.5 \pm 7.0$ & $0.0 \pm 0.0$ & $35.4 \pm 4.0$ & $20.9 \pm 3.1$ & $3.2 \pm 0.4$ \\
\hline \multicolumn{7}{|l|}{$\mathbf{P C}_{\max }$} \\
\hline Exp. 1 & $10^{-8}$ & $10^{-7}$ & $10^{-7}$ & $10^{-5}$ & $10^{-5}$ & $10^{-8}$ \\
\hline Exp. 2 & $10^{-9}$ & $10^{-8}$ & $10^{-7}$ & $10^{-5}$ & $10^{-5}$ & $10^{-8}$ \\
\hline \multicolumn{7}{|l|}{$\mathbf{R}^{2}$} \\
\hline Exp. 1 & 0.9966 & 0.9962 & Not converged & 0.9588 & 0.8897 & Interrupted \\
\hline Exp. 2 & 0.9930 & 0.9959 & Not converged & 0.9602 & 0.9062 & Interrupted \\
\hline \multicolumn{7}{|l|}{ Top } \\
\hline Exp. 1 & $120.8 \pm 2.9$ & $99.0 \pm 2.5$ & - & - & - & - \\
\hline Exp. 2 & $129.3 \pm 4.6$ & $115.0 \pm 3.0$ & - & - & - & - \\
\hline \multicolumn{7}{|c|}{$\operatorname{LogEC}_{50}$} \\
\hline Exp. 1 & $-10.5 \pm 0.1$ & $-8.8 \pm 0.1$ & - & $-4.9 \pm 0.1$ & $-3.2 \pm 0.5$ & $\sim-6.6 \times 10^{5}$ \\
\hline Exp. 2 & $-10.3 \pm 0.1$ & $-8.6 \pm 0.1$ & - & $-4.6 \pm 0.1$ & $-4.0 \pm 0.3$ & $\sim-4 \times 10^{5}$ \\
\hline \multicolumn{7}{|l|}{$\mathbf{E C}_{50}$} \\
\hline Exp. 1 & $3.3 \times 10^{-11}$ & $1.6 \times 10^{-9}$ & - & $1.4 \times 10^{-5}$ & $6.4 \times 10^{-4}$ & $\sim 0$ \\
\hline Exp. 2 & $4.6 \times 10^{-11}$ & $2.6 \times 10^{-9}$ & - & $2.3 \times 10^{-5}$ & $1.0 \times 10^{-4}$ & $\sim 0$ \\
\hline \multicolumn{7}{|c|}{ Hill Slope } \\
\hline Exp. 1 & $1.5 \pm 0.2$ & $2.0 \pm 0.8$ & - & $0.9 \pm 0.2$ & $0.4 \pm 0.1$ & $\sim 0$ \\
\hline Exp. 2 & $1.2 \pm 0.2$ & $1.5 \pm 0.2$ & - & $0.7 \pm 0.1$ & $0.6 \pm 0.2$ & $\sim 0$ \\
\hline \multicolumn{7}{|c|}{$\operatorname{LogPC}_{10}$} \\
\hline Exp. 1 & -11.5 & -9.7 & $\mathrm{NC}$ & -6.0 & -5.6 & $\mathrm{NC}$ \\
\hline Exp. 2 & -11.6 & -9.7 & $\mathrm{NC}$ & -6.0 & -5.6 & $\mathrm{NC}$ \\
\hline \multicolumn{7}{|l|}{$\mathrm{PC}_{10}$} \\
\hline Exp. 1 & $7.6 \times 10^{-12}$ & $4.8 \times 10^{-10}$ & $\mathrm{NC}$ & $1.1 \times 10^{-6}$ & $2.6 \times 10^{-6}$ & $\mathrm{NC}$ \\
\hline Exp. 2 & $6.6 \times 10^{-12}$ & $6.4 \times 10^{-10}$ & $\mathrm{NC}$ & $1.1 \times 10^{-6}$ & $2.6 \times 10^{-6}$ & $\mathrm{NC}$ \\
\hline
\end{tabular}

2H4MBP = 2,4-dihydroxy-4-methoxybenzophenone; EHMC = 2-ethylhexyl p-methoxycinnamate; NC = Not calculated. ${ }^{\text {a }}$ Values reported as average $\pm \mathrm{SEM}$.

Curve Fit: $\mathrm{Y}=$ Bottom $+($ Top-Bottom $) /\left(1+10^{\wedge}\left(\left(\log \mathrm{EC}_{50}-\mathrm{X}\right)^{*}\right.\right.$ Hillslope $\left.)\right)$. Constrained at 0 (17 $\beta$-estradiol, $17 \alpha$-ethynyl estradiol) or 0 and 100 (corticosterone, 17 $\alpha$-methyltestosterone, 2H4MBP, EHMC). 
Table F-3. Uterine and Body Weights of Ovariectomized Sprague Dawley Rats Administered UV Sunscreen Ingredients via Gavage for Three Days ${ }^{\text {a }}$

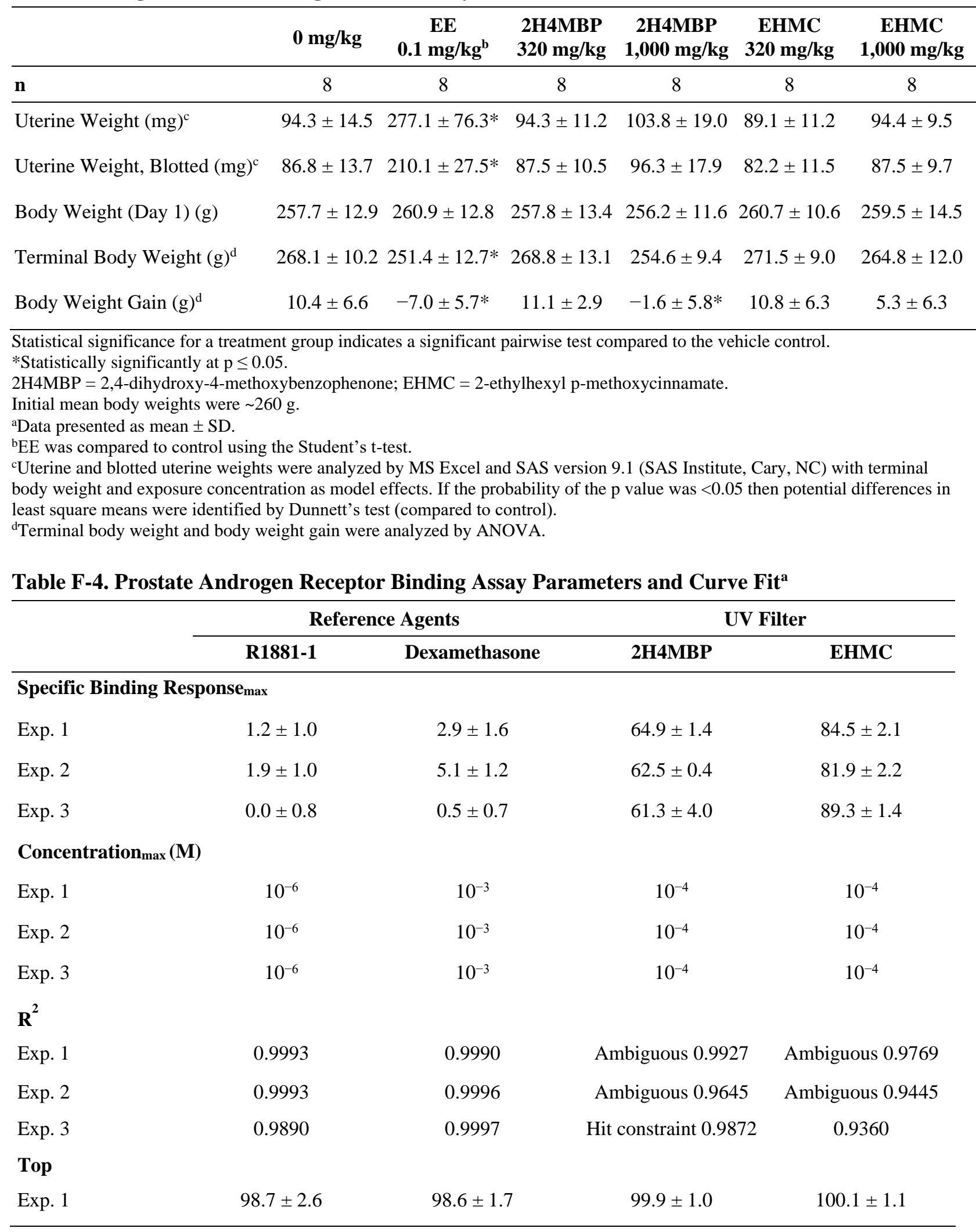




\begin{tabular}{|c|c|c|c|c|}
\hline & \multicolumn{2}{|c|}{ Reference Agents } & \multicolumn{2}{|c|}{ UV Filter } \\
\hline & R1881-1 & Dexamethasone & 2H4MBP & EHMC \\
\hline Exp. 2 & $113.3 \pm 4.9$ & $98.7 \pm 0.9$ & $92.6 \pm 1.4$ & $95.8 \pm 0.8$ \\
\hline Exp. 3 & $99.0 \pm 11.5$ & $94.0 \pm 1.0$ & $100.4 \pm 1.2$ & $100.0 \pm 0.9$ \\
\hline \multicolumn{5}{|l|}{ Bottom } \\
\hline Exp. 1 & $1.2 \pm 0.3$ & $-2.9 \pm 2.1$ & $\sim 50.0$ & $\sim 50.0$ \\
\hline Exp. 2 & $1.8 \pm 0.2$ & $-0.1 \pm 1.2$ & $\sim 50.0$ & $\sim 50.0$ \\
\hline Exp. 3 & $-0.3 \pm 0.4$ & $-2.0 \pm 0.5$ & $\sim 0$ & $\sim 0$ \\
\hline \multicolumn{5}{|l|}{$\operatorname{LogIC} C_{50}$} \\
\hline Exp. 1 & $-8.9 \pm 0.0$ & $-4.4 \pm 0.0$ & $\sim-1.2$ & $\sim 5.0$ \\
\hline Exp. 2 & $-9.9 \pm 0.0$ & $-4.3 \pm 0.0$ & $\sim-3.1$ & $\sim-0.7$ \\
\hline Exp. 3 & $-9.1 \pm 0.1$ & $-4.6 \pm 0.0$ & $-3.7 \pm 0.5$ & $-2.2 \pm 9.5$ \\
\hline \multicolumn{5}{|l|}{$\mathrm{IC}_{50}$} \\
\hline Exp. 1 & $1.3 \times 10^{-9}$ & $3.8 \times 10^{-5}$ & $6.7 \times 10^{-2}$ & $\sim 9.5 \times 10^{4}$ \\
\hline Exp. 2 & $1.1 \times 10^{-10}$ & $4.7 \times 10^{-5}$ & $8.1 \times 10^{-4}$ & $\sim 0.2$ \\
\hline Exp. 3 & $0.9 \times 10^{-9}$ & $2.5 \times 10^{-5}$ & $1.8 \times 10^{-4}$ & $\sim 6.2 \times 10^{-3}$ \\
\hline \multicolumn{5}{|l|}{ Hill Slope } \\
\hline Exp. 1 & $-0.9 \pm 0.1$ & $-0.9 \pm 0.1$ & $-1.1 \pm 0.2$ & $-0.4 \pm 0.1$ \\
\hline Exp. 2 & $-0.9 \pm 0.0$ & $-1.0 \pm 0.1$ & $\sim-3.1$ & $\sim-1.2 \pm 1.7$ \\
\hline Exp. 3 & $-0.9 \pm 0.2$ & $-1.0 \pm 0.1$ & $-0.8 \pm 0.8$ & $-0.5 \pm 0.3$ \\
\hline \multicolumn{5}{|l|}{$\log R B A$} \\
\hline Exp. 1 & - & 2.0 & 7.4 & -1.8 \\
\hline Exp. 2 & - & 2.3 & 3.2 & 14.1 \\
\hline Exp. 3 & - & 2.0 & 2.4 & 4.1 \\
\hline Mean (Exp. 1-3) & - & 2.1 & 4.3 & 5.5 \\
\hline \multicolumn{5}{|l|}{ RBA $(\%)$} \\
\hline Exp. 1 & - & 0.0034 & $<0.0000$ & $<0.0000$ \\
\hline Exp. 2 & - & 0.0002 & $<0.0000$ & $<0.0000$ \\
\hline Exp. 3 & - & 0.0036 & 0.0005 & $<0.0000$ \\
\hline Mean (Exp. 1-3) & - & 0.0024 & 0.0002 & $<0.0000$ \\
\hline
\end{tabular}

2H4MBP = 2,4-dihydroxy-4-methoxybenzophenone; EHMC = 2-ethylhexyl p-methoxycinnamate.

aData presented mean \pm SEM.

Curve Fit: $\mathrm{Y}=$ Bottom $+($ Top-Bottom $) /\left(1+10^{\wedge}\left(\left(\log \mathrm{IC}_{50}-\mathrm{X}\right) *\right.\right.$ Hillslope $+\log (($ Top-Bottom $) /(50-$ Bottom $\left.\left.)-1)\right)\right) .1 / \mathrm{Y}$ weighed; constrained at Bottom $>0$ for $2 \mathrm{H} 4 \mathrm{MBP}$ and EHMC. 
Table F-5. Androgen Receptor Transactivation: Antagonist Mode Parameters and Curve Fit

\begin{tabular}{|c|c|c|c|c|}
\hline & \multicolumn{2}{|c|}{ Reference Agents } & \multicolumn{2}{|c|}{ UV Filter } \\
\hline & DDE & Nilutamide & 2H4MBP & EHMC \\
\hline \multicolumn{5}{|l|}{$\mathbf{R P C}_{\min }$} \\
\hline Exp. 1 & $10.3 \pm 0.3$ & $-1.9 \pm 0.0$ & $72.2 \pm 4.6$ & $98.5 \pm 7.9$ \\
\hline Exp. 2 & $13.2 \pm 1.0$ & $-2.1 \pm 0.0$ & $89.0 \pm 2.8$ & $83.3 \pm 5.2$ \\
\hline Exp. 3 & $13.9 \pm 1.0$ & $-1.0 \pm 0.4$ & $75.6 \pm 5.0$ & - \\
\hline \multicolumn{5}{|l|}{$\mathbf{P C}_{\max }$} \\
\hline Exp. 1 & $10^{-4}$ & $10^{-4}$ & $10^{-4.5}$ & $10^{-4.5}$ \\
\hline Exp. 2 & $10^{-4}$ & $10^{-4}$ & $10^{-4.5}$ & $10^{-4.5}$ \\
\hline Exp. 3 & $10^{-4}$ & $10^{-4}$ & $10^{-4.5}$ & - \\
\hline \multicolumn{5}{|l|}{$\mathbf{R}^{2}$} \\
\hline Exp. 1 & 0.9992 & 0.9979 & Ambiguous 0.7991 & Ambiguous 0.3451 \\
\hline Exp. 2 & 0.9795 & 0.9960 & Not converged & Ambiguous 0.3581 \\
\hline Exp. 3 & 0.9808 & 0.9879 & Ambiguous 0.5396 & - \\
\hline \multicolumn{5}{|l|}{ Top } \\
\hline Exp. 1 & $111.8 \pm 1.1$ & $97.8 \pm 2.6$ & $108.6 \pm 11.6$ & $114.4 \pm 22.0$ \\
\hline Exp. 2 & $94.6 \pm 3.2$ & $101.5 \pm 3.7$ & - & $94.3 \pm 4.4$ \\
\hline Exp. 3 & $110.8 \pm 4.1$ & $116.1 \pm 15.3$ & $110.6 \pm 7.7$ & - \\
\hline \multicolumn{5}{|c|}{ Bottom } \\
\hline Exp. 1 & $8.4 \pm 2.3$ & $2.0 \pm 1.4$ & $\sim 50.0$ & $\sim 50.0$ \\
\hline Exp. 2 & $14.7 \pm 7.4$ & $1.6 \pm 2.0$ & - & $\sim 50.0$ \\
\hline Exp. 3 & $11.2 \pm 10.7$ & $2.3 \pm 3.8$ & $\sim 50.0$ & - \\
\hline \multicolumn{5}{|c|}{$\operatorname{LogIC}_{50}$} \\
\hline Exp. 1 & $-4.9 \pm 0.0$ & $-6.4 \pm 0.0$ & $\sim-3.2$ & $\sim-1.2$ \\
\hline Exp. 2 & $-4.9 \pm 0.1$ & $-6.3 \pm 0.0$ & - & $\sim-1.9$ \\
\hline Exp. 3 & $-4.8 \pm 0.1$ & $-6.5 \pm 0.1$ & $\sim-4.3$ & - \\
\hline \multicolumn{5}{|l|}{$\mathrm{IC}_{50}$} \\
\hline Exp. 1 & $1.4 \times 10^{-5}$ & $4.3 \times 10^{-7}$ & $\sim 0.7 \times 10^{-4}$ & $\sim 6.7 \times 10^{-2}$ \\
\hline Exp. 2 & $1.3 \times 10^{-5}$ & $4.6 \times 10^{-7}$ & - & $\sim 1.2 \times 10^{-2}$ \\
\hline Exp. 3 & $1.5 \times 10^{-5}$ & $3.1 \times 10^{-7}$ & $\sim 5.1 \times 10^{-5}$ & - \\
\hline \multicolumn{5}{|c|}{ Hill Slope } \\
\hline Exp. 1 & $-1.6 \pm 0.1$ & $-1.6 \pm 0.2$ & $-2.6 \pm 3.9$ & $-1.2 \pm 4.8$ \\
\hline Exp. 2 & $-2.1 \pm 0.8$ & $-1.7 \pm 0.2$ & - & $-1.6 \pm 3.4$ \\
\hline Exp. 3 & $-1.5 \pm 0.5$ & $-1.0 \pm 0.3$ & $\sim-16.7$ & - \\
\hline
\end{tabular}


Table F-6. Reproductive Organ and Body Weights of Rats Administered 2H4MBP or EHMC via Gavage for 10 Days (Agonist Assessment) ${ }^{a}$

\begin{tabular}{|c|c|c|c|c|c|c|}
\hline & 0 mg/kg & $\begin{array}{c}\mathrm{TP} \\
0.4 \mathrm{mg} / \mathrm{kg}\end{array}$ & $\begin{array}{c}2 \mathrm{H} 4 \mathrm{MBP} \\
320 \mathrm{mg} / \mathrm{kg}\end{array}$ & $\begin{array}{c}2 \mathrm{H} 4 \mathrm{MBP} \\
1,000 \mathrm{mg} / \mathrm{kg}\end{array}$ & $\begin{array}{c}\text { EHMC } \\
320 \mathrm{mg} / \mathrm{kg}\end{array}$ & $\begin{array}{c}\text { EHMC } \\
1,000 \mathrm{mg} / \mathrm{kg}\end{array}$ \\
\hline $\mathbf{n}$ & $7^{\mathrm{b}}$ & 8 & 8 & 8 & 8 & 8 \\
\hline \multicolumn{7}{|c|}{ Organ Weight (mg) } \\
\hline Glans Penis ${ }^{\mathrm{c}}$ & $47.4 \pm 6.1$ & $92.7 \pm 5.0^{*}$ & $52.4 \pm 7.3$ & $50.7 \pm 5.2$ & $49.4 \pm 7.0$ & $50.4 \pm 5.9$ \\
\hline Cowper's Gland ${ }^{\mathrm{d}}$ & $5.4 \pm 1.5$ & $39.0 \pm 5.6^{*}$ & $5.2 \pm 2.6$ & $5.1 \pm 1.6$ & $4.6 \pm 1.5$ & $5.6 \pm 2.0$ \\
\hline $\mathrm{LABC}^{\mathrm{d}}$ & $133.4 \pm 34.9$ & $384.5 \pm 51.7 *$ & $133.4 \pm 19.1$ & $123.4 \pm 32.0$ & $143.3 \pm 28.9$ & $129.1 \pm 25.6$ \\
\hline Ventral Prostate ${ }^{c}$ & $15.8 \pm 3.1$ & $186.2 \pm 57.2^{*}$ & $15.2 \pm 3.0$ & $14.0 \pm 1.6$ & $16.1 \pm 2.4$ & $15.6 \pm 2.8$ \\
\hline Seminal Vesicles ${ }^{\mathrm{c}}$ & $31.1 \pm 5.3$ & $542.5 \pm 63.2^{*}$ & $39.2 \pm 9.0$ & $33.6 \pm 9.6$ & $34.1 \pm 6.4$ & $33.9 \pm 7.6$ \\
\hline \multicolumn{7}{|l|}{ Body Weight (g) } \\
\hline Day 1 & $255.5 \pm 14.3^{\mathrm{e}}$ & $259.3 \pm 11.9$ & $255.9 \pm 17.7$ & $258.7 \pm 12.4$ & $256.8 \pm 14.4$ & $257.4 \pm 9.3$ \\
\hline Day 11 & $302.2 \pm 24.9$ & $335.1 \pm 24.1 *$ & $299.0 \pm 27.7$ & $298.0 \pm 20.3$ & $313.6 \pm 29.4$ & $298.3 \pm 14.0$ \\
\hline Weight Gain & $47.3 \pm 16.6$ & $75.8 \pm 16.7 *$ & $43.1 \pm 10.6$ & $39.4 \pm 11.2$ & $56.8 \pm 17.6$ & $40.9 \pm 10.4$ \\
\hline
\end{tabular}

Statistical significance for a treatment group indicates a significant pairwise test compared to the vehicle control group.

*Statistically significant at $\mathrm{p}<0.05$ when compared to the respective vehicle control group.

${ }^{\wedge}$ Statistically significant at $\mathrm{p}<0.05$ when compared to the respective TP control.

$2 \mathrm{H} 4 \mathrm{MBP}=2$,4-dihydroxy-4-methoxybenzophenone; EHMC = 2-ethylhexyl p-methoxycinnamate; LABC = levator ani/bulbocavernosus muscle; $\mathrm{TP}=$ testosterone propionate.

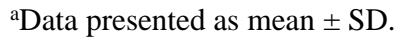

${ }^{b}$ Decrease in $\mathrm{N}$ due to animal removal.

'Statistical analysis performed by ANOVA. If significant, the means were subjected to Dunnett's test (compared to vehicle control) using JMP version 12.0.1.

dStatistical analysis performed using Kruskal Wallace nonparametric analyses. If significant, the means were subjected to Dunn's test (compared to vehicle control).

${ }^{\mathrm{e}}$ Average weight of all eight animals in the $0 \mathrm{mg} / \mathrm{kg}$ group at study initiation. 
Table F-7. Reproductive Organ and Body Weights of Rats Administered 2H4MBP or EHMC via Gavage for 10 Days (Antagonist Assessment) ${ }^{\mathrm{a}}$

\begin{tabular}{|c|c|c|c|c|c|c|c|c|}
\hline & $\begin{array}{l}\text { 0 mg/kg } \\
(+ \text { TP }) b\end{array}$ & $\begin{array}{c}\text { FT } \\
3 \mathrm{mg} / \mathrm{kg} \\
(+\mathrm{TP})\end{array}$ & $\begin{array}{c}2 \mathrm{H} 4 \mathrm{MBP} \\
100 \mathrm{mg} / \mathrm{kg} \\
(+\mathrm{TP})\end{array}$ & $\begin{array}{c}2 \mathrm{H} 4 \mathrm{MBP} \\
320 \mathrm{mg} / \mathrm{kg} \\
(+\mathrm{TP})\end{array}$ & $\begin{array}{c}2 \mathrm{H} 4 \mathrm{MBP} \\
1,000 \mathrm{mg} / \mathrm{kg} \\
(+\mathrm{TP})\end{array}$ & $\begin{array}{c}\text { EHMC } \\
100 \mathrm{mg} / \mathrm{kg} \\
(+\mathrm{TP})\end{array}$ & $\begin{array}{c}\text { EHMC } \\
320 \mathrm{mg} / \mathrm{kg} \\
(+\mathrm{TP})\end{array}$ & $\begin{array}{c}\text { EHMC } \\
1,000 \mathrm{mg} / \mathrm{kg} \\
(+\mathrm{TP})\end{array}$ \\
\hline $\mathbf{n}$ & 8 & 8 & 8 & 8 & 8 & 8 & $6^{c}$ & 8 \\
\hline \multicolumn{9}{|c|}{ Organ Weight (mg) } \\
\hline Glans Penis ${ }^{\mathrm{d}}$ & $92.7 \pm 5.0 *$ & $62.5 \pm 3.8^{\wedge d}$ & $95.6 \pm 4.7$ & $94.0 \pm 4.5$ & $87.5 \pm 3.8^{\wedge}$ & $94.7 \pm 7.8$ & $94.6 \pm 3.2$ & $91.6 \pm 5.0$ \\
\hline Cowper's Gland & $39.0 \pm 5.6^{*}$ & $12.2 \pm 3.9^{\wedge}$ & $38.1 \pm 5.2$ & $37.2 \pm 5.6$ & $37.3 \pm 9.8$ & $39.4 \pm 5.7$ & $36.7 \pm 7.7$ & $32.1 \pm 5.0$ \\
\hline $\mathrm{LABC}^{\mathrm{e}}$ & $384.5 \pm 51.7 *$ & $181.7 \pm 25.6^{\wedge}$ & $419.5 \pm 41.9$ & $428.0 \pm 55.1$ & $387.9 \pm 41.1$ & $415.9 \pm 46.3$ & $419.1 \pm 42.6$ & $359.4 \pm 47.3$ \\
\hline Ventral Prostate $^{\mathrm{d}}$ & $186.2 \pm 57.2^{*}$ & $37.0 \pm 7.7^{\wedge}$ & $206.2 \pm 38.6$ & $195.8 \pm 32.1$ & $155.0 \pm 21.3^{\wedge}$ & $182.4 \pm 47.6$ & $176.9 \pm 47.2$ & $147.6 \pm 39.7$ \\
\hline Seminal Vesicles $^{\mathrm{d}}$ & $542.5 \pm 63.2 *$ & $58.5 \pm 16.7^{\wedge}$ & $594.7 \pm 54.5$ & $618.8 \pm 97.3$ & $506.5 \pm 39.9$ & $562.3 \pm 74.4$ & $610.1 \pm 99.1$ & $465.5 \pm 80.2$ \\
\hline \multicolumn{9}{|l|}{ Body Weight (g) } \\
\hline Day 1 & $259.3 \pm 11.9$ & $258.1 \pm 14.4$ & $257.9 \pm 14.2$ & $260.8 \pm 9.5$ & $256.8 \pm 13.4$ & $259.9 \pm 14.7$ & $259.4 \pm 11.1$ & $259.3 \pm 13.3$ \\
\hline Day 11 & $335.1 \pm 24.1 *$ & $324.0 \pm 24.3$ & $338.1 \pm 17.7$ & $339.2 \pm 15.9$ & $311.2 \pm 16.7^{\wedge}$ & $330.2 \pm 42.3$ & $343.7 \pm 26.5$ & $319.7 \pm 24.8$ \\
\hline Weight Gain & $75.8 \pm 16.7^{*}$ & $65.9 \pm 14.2$ & $80.2 \pm 9.0$ & $78.4 \pm 10.1$ & $54.4 \pm 12.4^{\wedge}$ & $70.3 \pm 30.9$ & $85.2 \pm 23.9$ & $60.4 \pm 16.4$ \\
\hline
\end{tabular}

Statistical significance for a treatment group indicates a significant pairwise test compared to the vehicle control group.

* Statistically significant at $\mathrm{p}<0.05$ when compared to the respective vehicle control group.

${ }^{\wedge}$ Statistically significant at $\mathrm{p}<0.05$ when compared to the respective TP control.

$2 \mathrm{H} 4 \mathrm{MBP}=2$,4-dihydroxy-4-methoxybenzophenone; EHMC = 2-ethylhexyl p-methoxycinnamate; LABC = levator ani/bulbocavernosus muscle; TP = testosterone propionate;

FT = flutamide.

a Data presented as mean $\pm \mathrm{SD}$.

${ }^{\mathrm{b}}$ For the androgen antagonist assessment, all exposure groups were co-administered $0.4 \mathrm{mg} / \mathrm{kg} / \mathrm{day} \mathrm{TP}$.

'Decrease in $\mathrm{N}$ due to animal removal.

${ }^{\mathrm{d} S}$ Statistical analysis performed by ANOVA. If significant, the means were subjected to Dunnett's test (compared to vehicle control) using JMP version 12.0.1. mean \pm SD.

'Statistical analysis performed using Kruskal Wallace nonparametric analyses. If significant, the means were subjects to Dunn's test (compared to vehicle control). 
2-Hydroxy-4-methoxybenzophenone, NTP TR 597

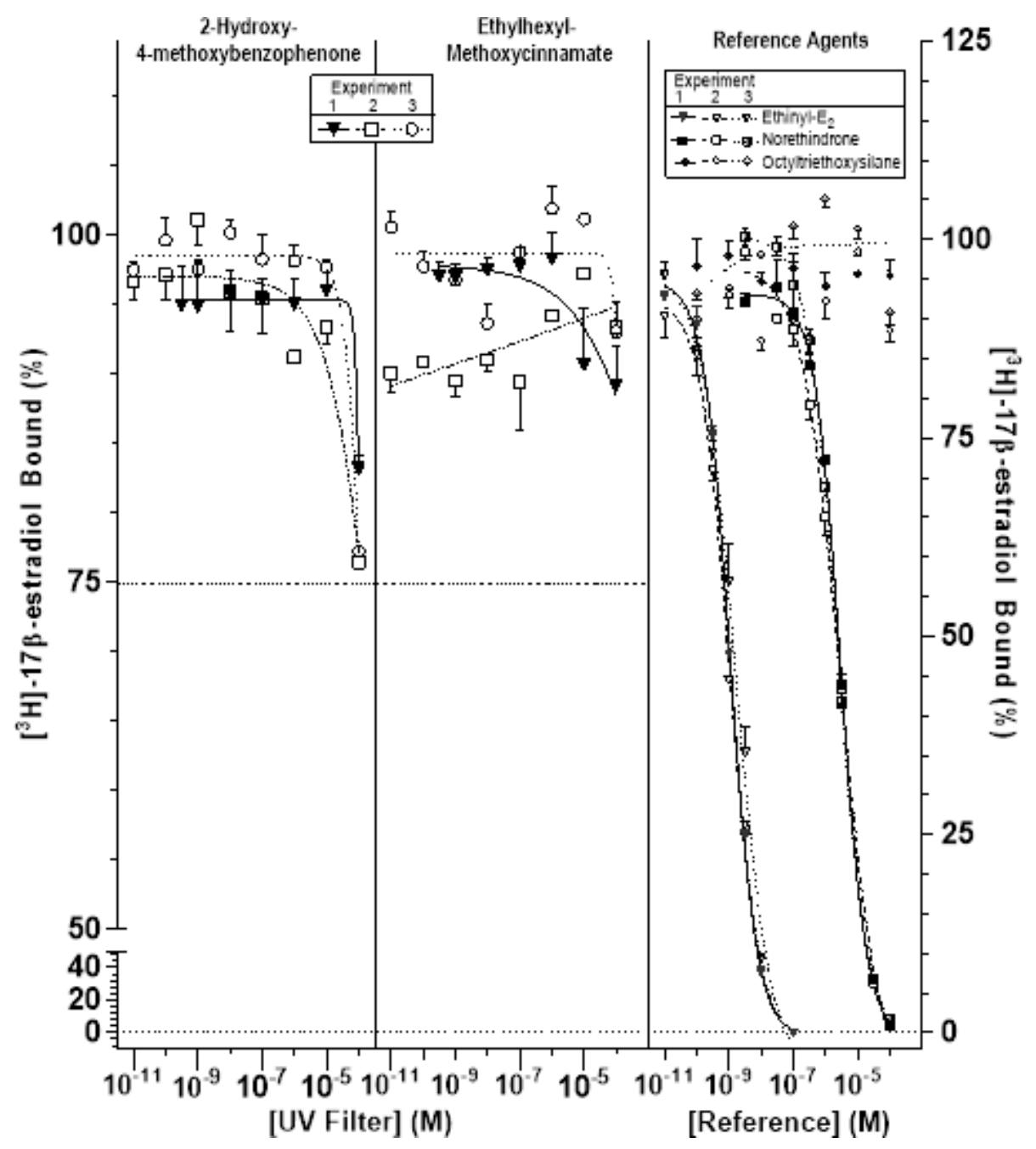

Figure F-1. Uterine Estrogen Receptor Binding 
2-Hydroxy-4-methoxybenzophenone, NTP TR 597

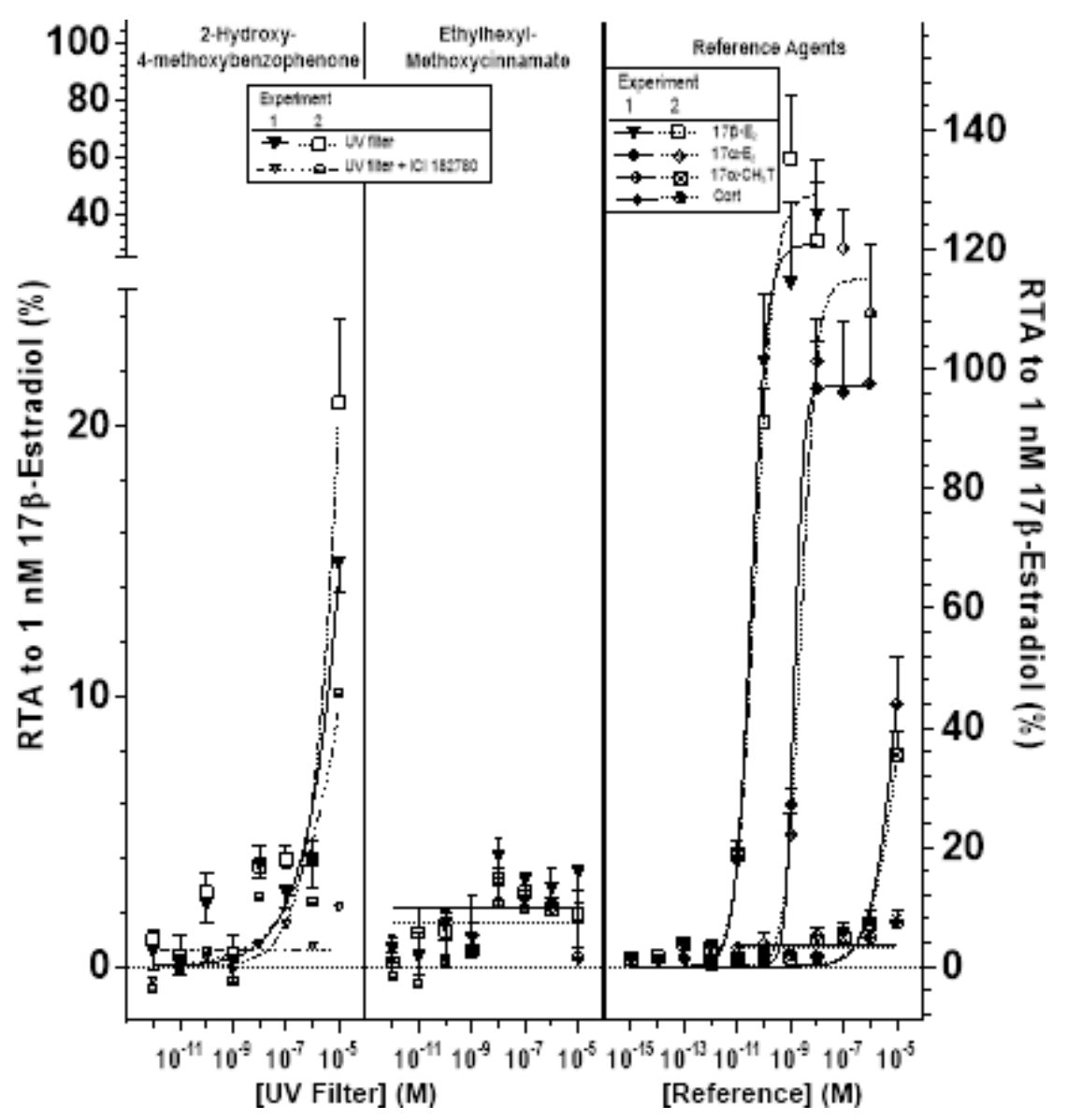

Figure F-2. Estrogen Receptor $\alpha$ Transcriptional Activation Assay 


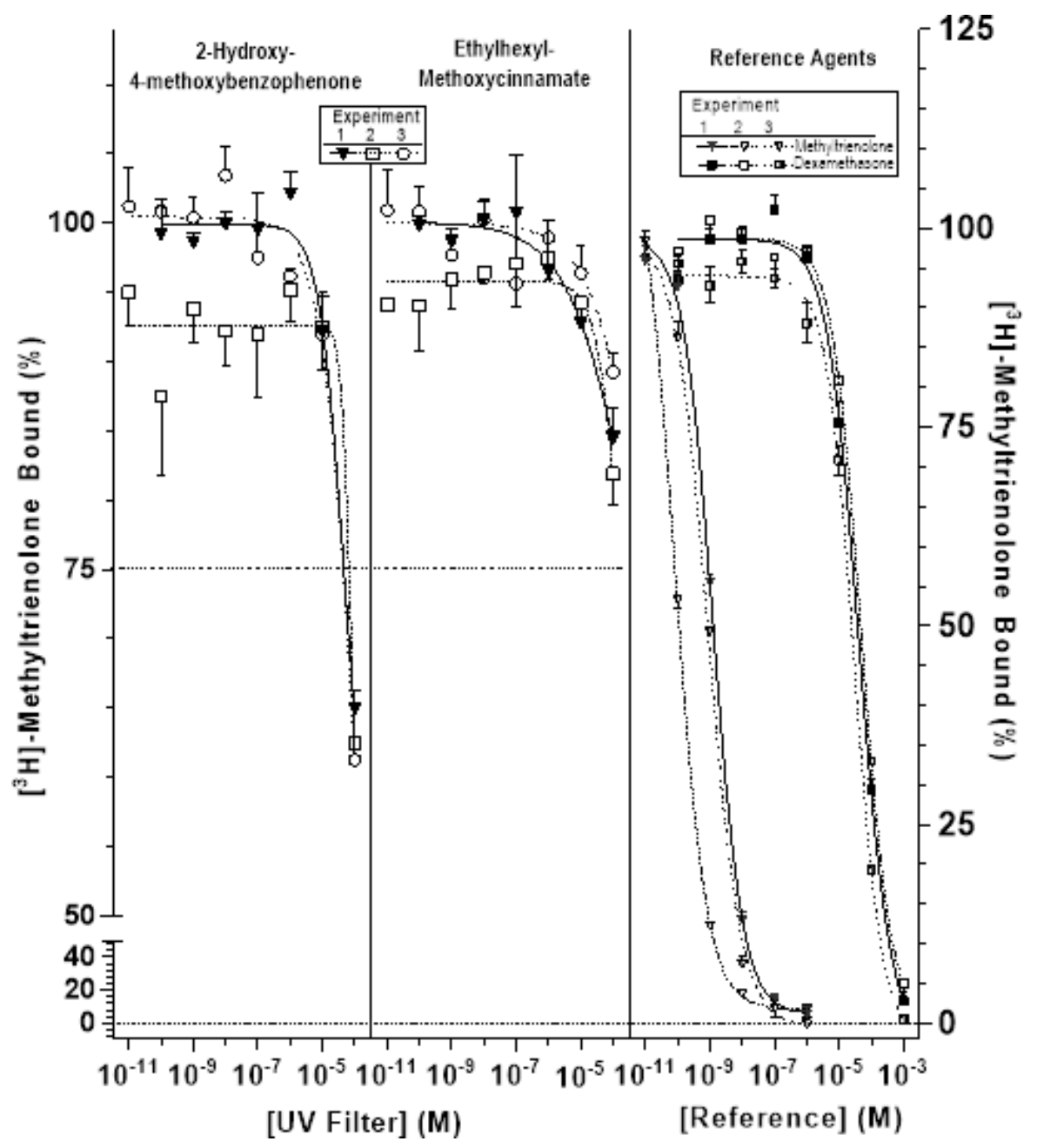

Figure F-3. Prostate Androgen Receptor Binding 


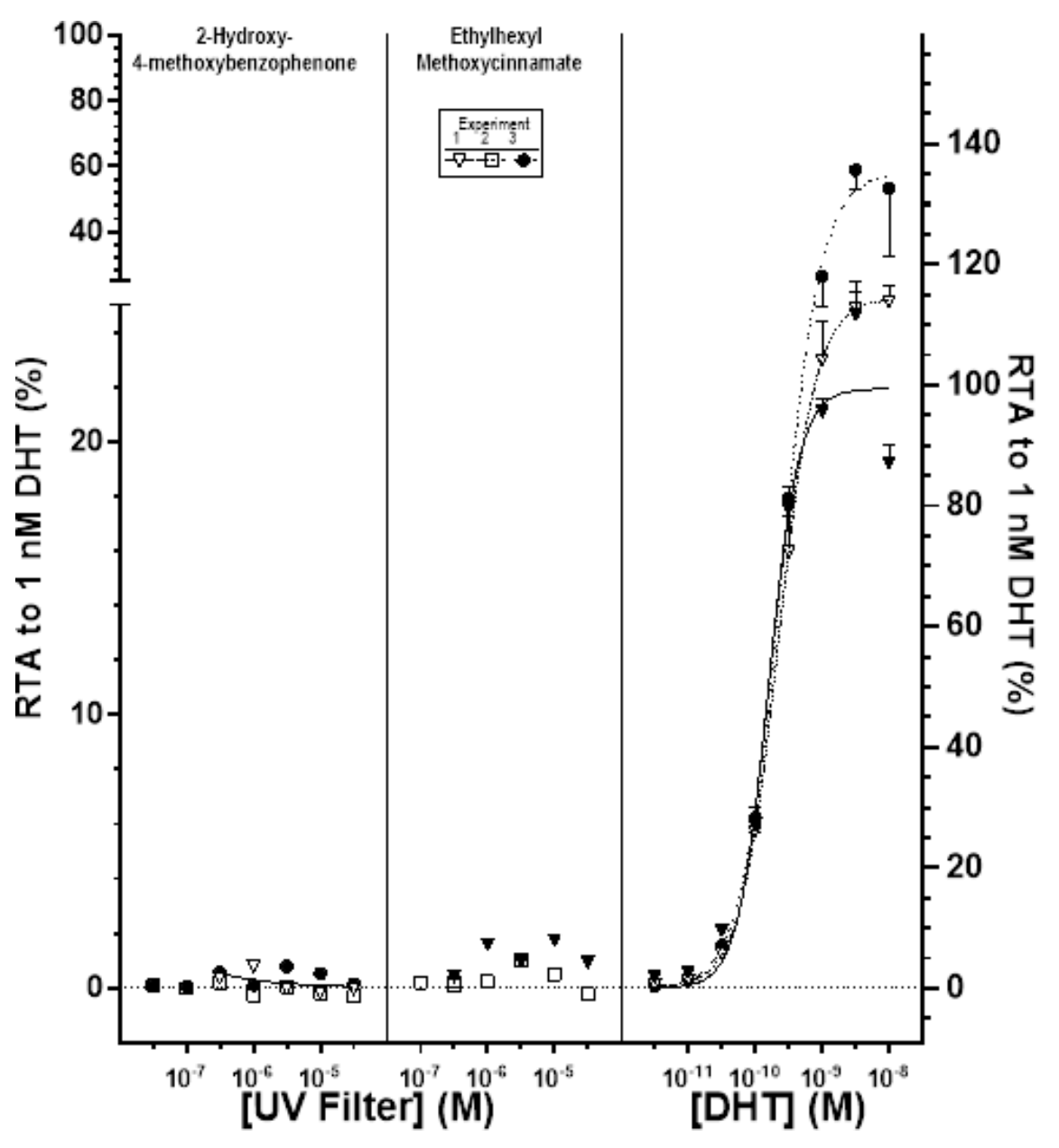

Figure F-4. Androgen Receptor Transactivation - Agonist Mode 
2-Hydroxy-4-methoxybenzophenone, NTP TR 597

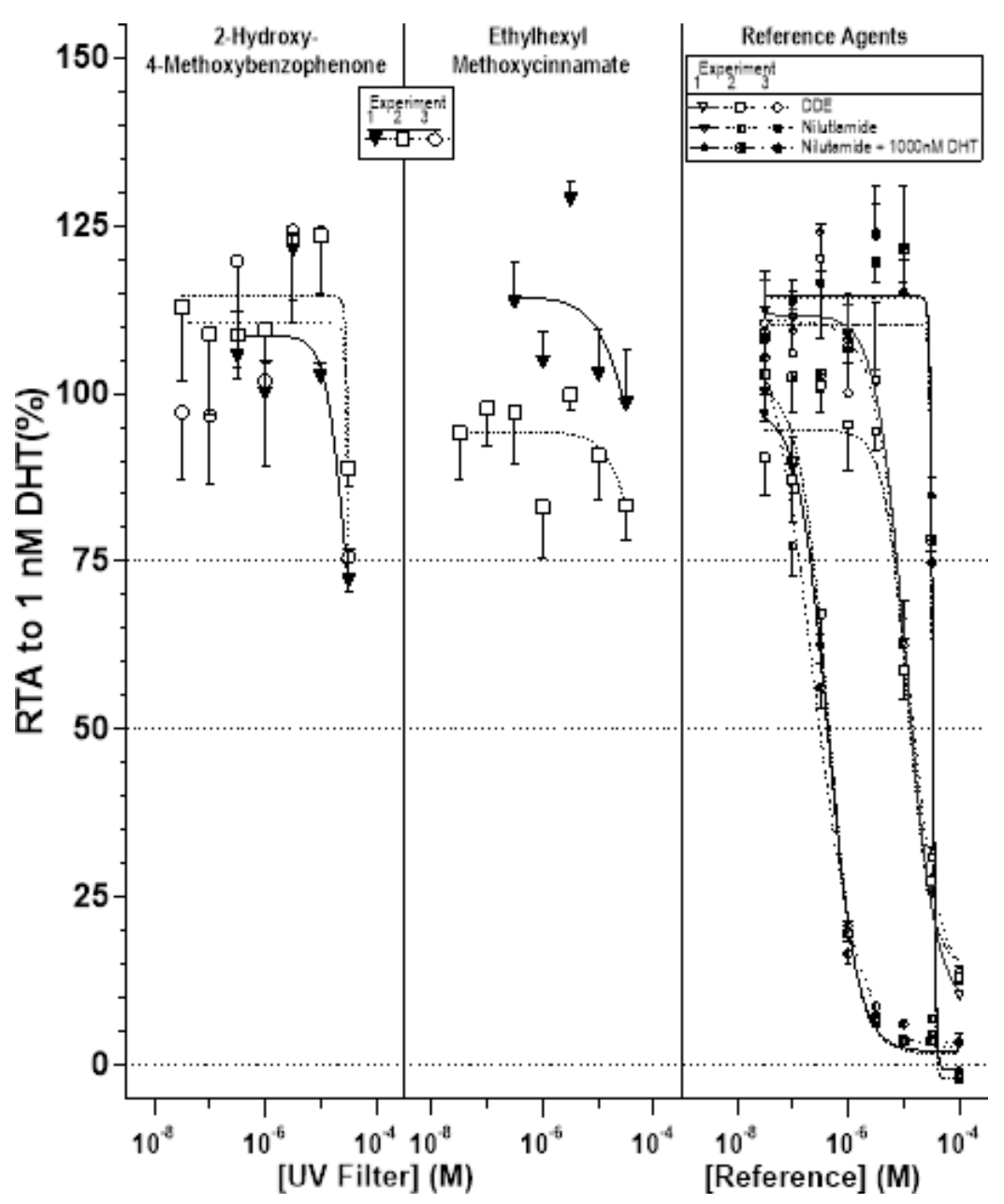

Figure F-5. Androgen Receptor Transactivation - Antagonist Mode 


\section{Appendix G. Summary of Peer Review Panel Comments}

\section{Table of Contents}

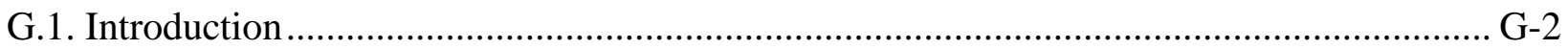

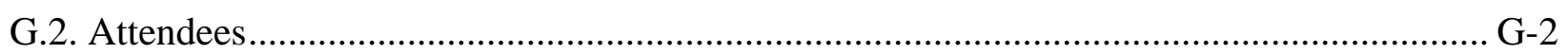

G.3. Peer Review of the Draft NTP Technical Report on the Toxicology and Carcinogenesis Studies of 2-Hydroxy-4-methoxybenzophenone and

Perfluorooctanoic Acid. G-3 


\title{
G.1. Introduction
}

The National Toxicology Program (NTP) convened the NTP Technical Reports Peer Review Panel via webcast on December 12, 2019, to peer review the draft NTP Technical Reports on the Toxicology and Carcinogenesis Studies of 2-Hydroxy-4-methoxybenzophenone and Perfluorooctanoic Acid. Meeting information, including the draft reports, actions, and presentations is currently archived under NTP's "Past Events."

The panel peer reviewed the draft reports and provided its opinion on NTP's preliminary conclusions regarding the level of evidence of carcinogenic activity of 2-hydroxy-4methoxybenzophenone and perfluorooctanoic acid. The panel's comments for the draft NTP Technical Report on the Toxicology and Carcinogenesis Studies of 2-Hydroxy-4methoxybenzophenone begin at Section G.3.3. The panel's recommendations do not necessarily represent the opinion of NTP.

\section{G.2. Attendees}

\section{Peer Review Panel Chair}

Russell Cattley, Auburn University

\section{Peer Review Panel}

Michael Elwell, APEX TOXPATH, LLC

Wendy Halpern, Genentech, Inc.

Gabriele Ludewig, University of Iowa

Kristini Miles, Venture Chemical Consulting, LLC

Karen Regan, Regan Pathology/Toxicology Services, Inc. (2-hydroxy-4-methoxybenzophenone only)

\author{
National Institute of Environmental Health Sciences Staff \\ Brian Berridge \\ Chad Blystone \\ Michelle Cora \\ Stephen Ferguson \\ Shawn Harris \\ Angela King-Herbert \\ Ron Herbert \\ Dave Malarkey \\ Elizabeth Maull, Designated Federal Official \\ Barry McIntyre \\ Georgia Roberts \\ Sheena Scruggs \\ Keith Shockley \\ Robert Sills \\ Matthew Stout \\ Suramya Waidyanatha \\ Nigel Walker \\ AtLee Watson
}


Kristine Witt

Mary Wolfe

Other Federal Agency Staff

Gonçalo Gamboa, FDA (by WebEx)

Contract Support Staff

Amy Brix, EPL, Inc.

Canden Byrd, ICF

Josh Cleland, ICF

Katherine Duke, ICF

Sophie Hearn, ICF

Ernie Hood, Bridport Services

Kyathanahalli Janardhan, ILS

Kelly Shipkowski, ICF

Samantha Snow, ICF

Jessica Wignall, ICF

\section{G.3. Peer Review of the Draft NTP Technical Report on the Toxicology and Carcinogenesis Studies of 2-Hydroxy-4-methoxybenzophenone and Perfluorooctanoic Acid}

\section{G.3.1. Introductions and Welcome}

The National Toxicology Program (NTP) convened a peer-review panel for the Draft NTP Technical Reports on the Toxicology and Carcinogenesis Studies of 2-Hydroxy-

4-methoxybenzophenone and Perfluorooctanoic Acid on December 12, 2019 via webcast.

- Dr. Russell Cattley, panel chair, called the meeting to order at 10:00 a.m., welcomed everyone to the meeting, asked all attendees to introduce themselves, and reviewed the peer-review meeting format for the panel and audience.

- Dr. Brian Berridge, NTP Associate Director, welcomed all participants to the meeting.

- Dr. Elizabeth Maull read the conflict of interest policy statement and briefed the attendees on meeting logistics.

\section{G.3.2. Background and Charge to the Panel}

Dr. Chad Blystone gave a brief presentation on NTP draft technical reports, including information about the levels of evidence for the potential carcinogenic activity of the chemicals tested. He also described the NTP's historical controls, which are categorized by route of exposure and rodent strains. He then gave the charge to the panel for the individual peer reviews:

- Review and evaluate the scientific and technical elements of the study and its presentation.

- Determine whether the study's experimental design, conduct, and findings support NTP's conclusions regarding the hypothesis under the conditions of this study. The peer-review meeting materials can be found on the NTP website. 


\section{G.3.3. Toxicology and Carcinogenesis Studies of 2-Hydroxy- 4-methoxybenzophenone}

\section{G.3.3.1. Presentation and Clarifying Questions}

Dr. Barry McIntyre summarized the studies and conclusions reported in the Draft NTP Technical Report on the Toxicology and Carcinogenesis Studies of 2-Hydroxy-4-methoxybenzophenone (CAS No. 131-57-7) Administered in Feed to Sprague Dawley (Hsd:Sprague Dawley ${ }^{\circledR}$ SD $\left.^{\circledR}\right)$ Rats and B6C3F1/N Mice.

2-Hydroxy-4-methoxybenzophenone is an ultraviolet (UV) filter used in sunscreens and cosmetics to protect the wearer from solar erythema. 2-Hydroxy-4-methoxybenzophenone is also an indirect food additive as it is added to acrylic and modified acrylic plastics that encounter food to prevent UV-mediated degradation. NTP chose to study 2-hydroxy-

4-methoxybenzophenone due to widespread human exposure and lack of carcinogenicity data.

Dr. McIntyre first presented a summary of results from the 2-hydroxy-4-methoxybenzophenone Endocrine Disruptor Screening Panel studies reported in Appendix F of the technical report.

Genetic toxicology studies conducted in Salmonella typhimurium strains TA98 and TA100 as well as Escherichia coli strain uvrA pKM101 with and without S9 were negative.

NTP conducted a perinatal toxicity/carcinogenicity study in time-mated female Hsd:Sprague Dawley ${ }^{\circledR} \mathrm{SD}^{\circledR}$ rats, with exposure concentrations of $0,1,000,3,000$, and 10,000 ppm in the diet. Exposure began on gestation day (GD) 6 through lactation in the dams. In the offspring, exposure continued after weaning on postnatal day (PND) $21(\mathrm{n}=50 / \mathrm{dose})$ for 2 years. In addition, there was a 14-week interim necropsy for the 0 and 10,000 ppm groups $(n=10 /$ sex/dose). Dr. McIntyre presented a summary of results from the 2-hydroxy4-methoxybenzophenone perinatal toxicity/carcinogenicity study.

NTP also conducted a standard chronic bioassay in male and female B6C3F1/N mice, with exposure concentrations of 0,1,000,3,000, and 10,000 ppm in the diet for 2 years. Dr. McIntyre presented a summary of findings from the standard chronic bioassay.

Under the conditions of these 2-year studies, NTP's draft conclusions were:

- Equivocal evidence of carcinogenic activity of 2-hydroxy-4-methoxybenzophenone exposure in male Hsd:Sprague Dawley ${ }^{\circledR} \mathrm{SD}^{\circledR}$ rats based on the occurrence of brain and spinal cord malignant meningiomas.

- Exposure to 2-hydroxy-4-methoxybenzophenone resulted in increased incidences of nonneoplastic lesions of the testis and pancreas in male rats.

- Equivocal evidence of carcinogenic activity of 2-hydroxy-4-methoxybenzophenone exposure in female Hsd:Sprague Dawley ${ }^{\circledR} \mathrm{SD}^{\circledR}$ rats based on the increased incidence of thyroid C-cell adenomas and the increased incidence of uterine stromal polyps.

- Exposure to 2-hydroxy-4-methoxybenzophenone resulted in increased incidences of nonneoplastic lesions of the uterus and adrenal cortex in female rats.

- No evidence of carcinogenic activity in male or female B6C3F1/N mice at exposure concentrations of 1,000, 3,000, and 10,000 ppm 2-hydroxy-4-methoxybenzophenone. 
- Exposure to 2-hydroxy-4-methoxybenzophenone resulted in increased incidences of nonneoplastic lesions of the bone marrow, spleen, and kidney in male and female mice, and liver in male mice.

There were no clarifying questions or comments about the presentation.

\section{G.3.3.2. Public Comments}

Dr. Cattley acknowledged the receipt of written public comments from private citizen Mr. Joe DiNardo. He noted that the panel did not receive requests for oral public comments on the draft technical report.

\section{G.3.3.3. Peer-Review Comments and Panel Discussion}

\section{G.3.3.3.1. First Reviewer - Dr. Karen Regan}

Dr. Karen Regan said that the studies were well-written and well-conducted. She requested clarification on how the dose used in the studies compared to human exposure. She asked for more information on the historical control data used for this study and whether there were any data available from the same strain of rat exposed from GD 6. Dr. Regan questioned why NTP did not evaluate spinal cords for all animals in the study. Dr. Regan asked whether there were any tables that showed the overall incidence of multiplicity for thyroid tumors in female rats, and whether there were any animals with multiple tumors.

- Dr. McIntyre indicated that the plasma levels found in the rodents following exposure were comparable to levels recently reported in human blood (JAMA 2019).

- Dr. Blystone reported that the historical controls used in this study include all exposure start times with most of these studies starting at GD 6.

- Dr. Amy Brix stated that only animals with clinical neuropathological signs had their spinal cords examined and indicated that NTP would consider adding a sentence to the report to clarify this point. She noted that it is possible that they did not observe additional occurrences of malignant meningiomas in the spinal cords. Dr. Brix noted that there were no occurrences of these type of tumors in the historical controls or control group. Even without the single occurrence in the spinal cord, NTP considered the occurrence of malignant meningioma in the brain of adult rats to be equivocal evidence of carcinogenicity.

- Dr. Brix noted that only one female in the highest dose group had bilateral C-cell adenomas in the thyroid, with the rest of the adenomas being unilateral. She remarked that NTP only counted an animal once if it had both a thyroid adenoma and carcinoma, which occurred in only one rat. She stated that they will explain these methods further in the report.

\section{G.3.3.3.2. Second Reviewer - Dr. Kristini Miles}

Dr. Kristini Miles stated that the study was well-designed and executed. She noted that NTP chose sufficient doses for the rats and mice as they were based on previously conducted studies. Dr. Miles noted that 2-hydroxy-4-methoxybenzophenone has been reported in the literature to be a persistent environmental contaminant, specifically in water sources, and there are reports that traditional wastewater treatment processes may not eliminate the contaminant. She asked whether NTP tested 2-hydroxy-4-methoxybenzophenone in the municipal tap water used in the 
study. Dr. Miles inquired whether there was any information available on 2-hydroxy-4methoxybenzophenone concentrations in synthetic resins and plastics, and how it might leach out of such containers. She asked that NTP include the information in the report. Regarding Table 8 in the report, Dr. Miles asked whether the trend test referred to historical controls or something else.

- Dr. McIntyre stated that they did not examine the municipal water used for the presence of 2-hydroxy-4-methoxybenzophenone; however, all rodents received the same water supply.

- Dr. McIntyre indicated that NTP provided information on leachates in plastics, and they would consider adding this information to the report.

- Dr. Keith Shockley noted that they based the trend test on experimental data, not historical controls.

\section{G.3.3.3.3. Third Reviewer - Dr. Michael Elwell}

Dr. Michael Elwell indicated that he had no comments on the study design or dose selection and the results and figures were clearly presented by the NTP. He concurred with the neoplastic and nonneoplastic findings listed in the draft report for the male rats. Regarding the data and discussions of the meningioma and interstitial cell hyperplasia, Dr. Elwell requested confirmation that NTP examined spinal cords from only one or two animals per group. He asked whether it was correct to combine the spinal cord and brain data as the study staff did in Table 11 to perform statistical analysis on the occurrence of these tumors. Dr. Elwell noted that there was one meningioma present in the spinal cord but three in the brain in male rats exposed to $1,000 \mathrm{ppm}$. He remarked that one of these animals (Animal 151) also had a meningioma recorded in the trigeminal nerve. He asked whether NTP should report that meningioma separately and include it in the discussion. He questioned whether NTP should mention the occurrence of granular cell tumors in the meninges in the report as part of the assessment of the meningiomas since NTP Technical Report 573 discussed the relationship between granular cell tumors and meningiomas, with an indication that they had similar morphologies and a common progenitor cell type. Dr. Elwell recommended that the NTP report the increased incidence of interstitial cell hyperplasia of the testes in the discussion section since they included it in the abstract and results section. Dr. Elwell agreed in principle with the conclusion of no evidence of carcinogenicity in the male mice. He suggested clarifying the wording that described the cytoplasmic alteration of the kidneys that occurred. Dr. Elwell stated that the incidence of lymphocyte infiltrates and nephropathy in the kidney listed in the abstract appeared to be very minor given the minimal severity and common background occurrence of these findings.

Dr. Elwell remarked that prior studies with ethylbenzene reported no association of syncytial cell alterations in the liver with hepatocellular neoplasia. He suggested this would be worth mentioning in the discussion since ethylbenzene has a similar structure to 2-hydroxy4-methoxybenzophenone.

In response to Dr. Elwell's comments, Dr. Brix indicated that:

- While NTP examined the brains of all animals, only animals with clinical neurological signs had their spinal cords examined. NTP will update the table to reflect this. NTP will also consider removing the spinal cord data from this analysis. 
- There was an error in the table reporting two meningiomas in Animal 151 (one should have been recorded as a metastasis of the other) and they would update the table to reflect this. NTP will also consider adding language to the discussion section regarding malignant meningiomas.

- NTP will consider adding to the discussion section that meningiomas and granular cell tumors may have a common progenitor.

- NTP will consider adding text to the report that there was no effect on interstitial cell adenomas reported in male rats. NTP will also consider adding text to the discussion regarding interstitial cell hyperplasia.

- There was an error in describing the cytoplasmic alteration in the kidneys in male mice. NTP will update the report to reflect this.

- NTP will consider adding language to the results section downplaying the importance of the chronic progressive nephropathy and lymphocytic infiltrates in the kidneys of male mice and will remove mentions of these findings from the discussion.

- NTP would consider adding language to the report regarding the lack of association between syncytial cell alteration in the liver and exposure to ethylbenzene.

In a follow-up question, Dr. Elwell described his confusion regarding the statistical approaches for the non-neoplastic kidney findings in this report, which seemed to take severity into account.

Dr. Shockley replied that the statistical analysis did not take severity into account but was instead based on incidence. However, this method did account for differential survival.

\section{G.3.3.4. Panel Discussion}

Dr. Gabriele Ludewig stated that the report was clear and well-written. She wondered whether the number of incidences of meningiomas indicated a relationship to exposure and whether NTP should report this as clear evidence instead of equivocal. Dr. Ludewig asked for comment on why they used rats and not hamsters since they metabolize this compound differently, which may make it genotoxic. Dr. Ludewig noted that ER and AR binding is only one way a compound can be an endocrine disruptor. She noticed in the report that NTP reported findings in the adrenal gland which could lead to serotonin disruption and suggested adding that point to the report. Dr. Ludewig observed that only the highest exposure group had female rats that were not pregnant and suggested adding a statement regarding this point.

- Dr. Brix stated that it is always challenging to make a call on uncommon tumors without statistical support, dose response, a change in latency, or supporting evidence from other sex, species, or preneoplastic lesions. Therefore, NTP decided there was equivocal evidence based on the presence of meningiomas.

- Dr. McIntyre noted that NTP no longer used the hamster S9 assay under Organisation for Economic Co-operation and Development (OECD) guidance and that performing those tests would be outside the scope of this report.

- Dr. McIntyre indicated that NTP has done extensive work in relation to testing for hormonal activity and is in the process of reporting on reproductive performance as well as markers of altered endocrine action in another technical report. 
- Dr. McIntyre noted that they examined the animals that did not deliver for implantation sites and they were not pregnant. Since exposure began after implantation, they were not concerned that this was an exposure-related effect.

In a follow-up statement, Dr. Ludewig concluded that she was between some and equivocal evidence regarding the presence of meningiomas.

Dr. Wendy Halpern noted that other reviewers addressed most of her comments. She asked the panel to comment on whether it was a common observation that there were fewer potentially exposure-related tumors identified at the highest dose where the animals had lower body weight.

- Dr. Blystone reported that the influence of lower body weight on the cancer response has been characterized for only a few tumor types (e.g., mammary gland tumors) and that we do not have the information for the other tumor types to include in the report.

Dr. Cattley questioned why there had been a separate peer review conducted on the uterus in the rats.

- Dr. Brix reported that over the past several years, NTP had changed its procedure from doing cross-sectional evaluations to more comprehensive analyses of the uterus.

- Dr. Brix reported that NTP would consider adding language to the report to clarify this point.

\section{G.3.3.5. Vote on NTP Conclusions}

\section{G.3.3.5.1. Male Hsd:Sprague Dawley ${ }^{\circledR} S D^{\circledR}$ rats}

Dr. Cattley called for a motion from the panel to approve the conclusions as written. The panel did not offer a motion. Dr. Regan moved that NTP delete the reference to spinal cord malignant meningiomas from the conclusion. Dr. Ludewig seconded the motion. The panel voted unanimously ( 5 yes, 0 no, 0 abstentions) to approve the new conclusion.

\section{G.3.3.5.2. Female Hsd:Sprague Dawley ${ }^{\circledR} S D^{\circledR}$ rats}

Dr. Cattley called for a motion from the panel to approve the conclusions as written. Dr. Regan so moved, and Dr. Elwell seconded the motion. The panel voted unanimously ( 5 yes, 0 no, 0 abstentions) to approve the conclusions as written.

\section{G.3.3.5.3. Male B6C3F1/N mice}

Dr. Cattley called for a motion from the panel to approve the conclusions as written. Dr. Regan so moved and Dr. Ludewig seconded the motion. The panel voted unanimously (5 yes, 0 no, 0 abstentions) to approve the conclusions as written.

\section{G.3.3.5.4. Female B6C3F1/N mice}

Dr. Cattley called for a motion from the panel to approve the conclusions as written. Dr. Regan so moved, and Dr. Ludewig seconded the motion. The panel voted unanimously (5 yes, 0 no, 0 abstentions) to approve the conclusions as written.

Following the voting, Dr. Cattley noted that Dr. Regan would sign off from the session. 


\section{G.3.4. Toxicology and Carcinogenesis Studies of Perfluorooctanoic Acid}

\section{G.3.4.1. Presentation and Clarifying Questions}

Dr. Blystone summarized the studies and conclusions reported in the Draft NTP Technical Report on the Toxicology and Carcinogenesis Studies of Perfluorooctanoic Acid (CAS No. 335-67-1) Administered in Feed to Sprague Dawley (Hsd:Sprague Dawley ${ }^{\circledR} S D^{\circledR}$ ) Rats.

Perfluorooctanoic acid is a perfluoroalkyl substance (PFAS) used for decades in creating nonstick properties in a variety of products. Manufacturers agreed to discontinue use due to widespread exposure and health concerns. Due to a long half-life measured in years and resistance to environmental degradation, exposure has continued but declined. Perfluorooctanoic acid is the second most abundant PFAS measured in the human population, including children and pregnant women.

Human exposure to perfluorooctanoic acid can occur during early development. It is unknown whether exposure during gestation and lactation alters the carcinogenic response induced by perfluorooctanoic acid. NTP tested the hypothesis that including perinatal exposure with postweaning exposure would quantitatively or qualitatively alter the perfluorooctanoic acid response compared to postweaning exposure only.

NTP conducted a perinatal and postweaning toxicity/carcinogenicity study in Hsd:Sprague Dawley ${ }^{\circledR} \mathrm{SD}^{\circledR}$ rats. In Study \#1, they exposed time-mated female rats to 0, 150, or $300 \mathrm{ppm}$ perfluorooctanoic acid during the perinatal period. NTP provided $\mathrm{F}_{1}$ female rats with 0,300 , or $1,000 \mathrm{ppm}$ perfluorooctanoic acid during the postweaning period (i.e., perinatal/postweaning exposures of $0 / 0,0 / 300,0 / 1,000,150 / 300$, or $300 / 1,000 \mathrm{ppm}$ ) while they provided $\mathrm{F}_{1}$ male rats with 0,150 , or $300 \mathrm{ppm}$ perfluorooctanoic acid during the postweaning period (i.e., perinatal/postweaning exposures of $0 / 0,0 / 150,0 / 300,150 / 150$, or 300/300 ppm) $(\mathrm{n}=50 / \mathrm{sex} /$ dose $)$. Female rats have a lower systemic exposure than males due to a faster perfluorooctanoic acid elimination rate, so NTP provided a higher feed exposure concentration to female rats postweaning. In addition, they conducted a 16-week (19 weeks of age) interim necropsy $(\mathrm{n}=10 / \mathrm{sex} /$ dose $)$.

Due to observed unanticipated toxicity in males during the interim necropsy, NTP removed males from Study \#1 at week 21. In Study \#2, they exposed time-mated female rats to 0 or $300 \mathrm{ppm}$ perfluorooctanoic acid during the perinatal period. They provided $\mathrm{F}_{1}$ male rats 0,20 , 40 , or $80 \mathrm{ppm}$ perfluorooctanoic acid during the postweaning period (i.e., perinatal/postweaning exposures of $0 / 0,0 / 20,0 / 40,0 / 80,300 / 0,300 / 20,300 / 40$, or 300/80 ppm) (n=50/sex/dose).

Dr. Blystone presented a summary of results from the perinatal and postweaning toxicity/carcinogenicity study.

Under the conditions of these 2-year studies, NTP's draft conclusions were:

- Clear evidence of carcinogenic activity of perfluorooctanoic acid in male Hsd:Sprague Dawley ${ }^{\circledR} \mathrm{SD}^{\circledR}$ rats based on the increased incidences of hepatocellular neoplasms (predominately hepatocellular adenomas) and increased incidences of acinar cell neoplasms (predominantly acinar cell adenomas) of the pancreas.

- Exposure to perfluorooctanoic acid resulted in increased incidences of nonneoplastic lesions in the liver and pancreas of male rats. The additional effect of combined 
perinatal and postweaning exposure was limited to a higher incidence of hepatocellular carcinomas compared to postweaning exposure alone.

- Some evidence of carcinogenic activity of perfluorooctanoic acid in female Hsd:Sprague Dawley ${ }^{\circledR} \mathrm{SD}^{\circledR}$ rats based on the increased incidences of pancreatic acinar cell adenoma or adenocarcinoma (combined) neoplasms.

- The higher incidence of hepatocellular carcinomas and higher incidence of adenocarcinomas of the uterus may have been related to perfluorooctanoic acid exposure.

- Exposure to perfluorooctanoic acid resulted in increased incidences of nonneoplastic lesions in the liver, kidney, forestomach, and thyroid gland.

- The combined perinatal and postweaning exposure was not observed to change the neoplastic or nonneoplastic response compared to postweaning exposure alone.

There were no clarifying questions or comments about the presentation.

\section{G.3.4.2. Public Comments}

Dr. Cattley acknowledged the receipt of three written public comments from Dr. Oyebode A. Taiwo on behalf of the 3M Company, Dr. Alexis Temkin on behalf of the Environmental Working Group, and Mr. Jason Dadakis from the Orange County Water District. Dr. Cattley noted that there was one oral public comment from Mr. Steve Risotto on behalf of the American Chemistry Council (ACC).

Mr. Risotto said the ACC believed the peer-review committee should carefully consider NTP's conclusion that there is "some evidence of carcinogenic activity" in female rats, requested additional analysis of the pancreatic tumor data for male rats, and asked whether a conclusion could be reached about the sensitivity of fetal rats to perfluorooctanoic acid exposure. Regarding the evidence for carcinogenicity in female rats, Mr. Risotto observed that there was a nonsignificant increase of combined acinar cell adenomas and adenocarcinomas at 1,000 ppm. He noted that while the increased incidence of acinar cell neoplasms in males increased NTP's confidence that neoplasms in females were related to perfluorooctanoic acid exposure, NTP did not observe acinus hyperplasia in the female rats, which was significantly increased in the male rats. If this hyperplasia is a potentially preneoplastic lesion as NTP suggests, Mr. Risotto stated that this finding should also have been observed in the female rats. Mr. Risotto also noted that the survival rate in the female rats was quite low, which might raise concerns about the general animal husbandry practices of the study since survival was depressed in both the control and exposed animals. Regarding the incidence of acinar cell neoplasms in the male rats, Mr. Risotto noted that the control group had significantly elevated acinus hyperplasia, a possible preneoplastic lesion, affecting nearly $40 \%$ of the control animals. The high background rate observed in the study confirmed the higher sensitivity of the Hsd:Sprague Dawley ${ }^{\circledR} \mathrm{SD}^{\circledR}$ rats compared to other rat strains, and more significantly, to humans. Mr. Risotto also observed that NTP used a smaller size criterion for classifying pancreatic acinar cell neoplasms than previous perfluorooctanoic acid studies. He stated that the draft report does not provide an explanation for why NTP reduced the lesion criteria, or the potential impact such a reduction may have on the findings. Mr. Risotto stated that given the flat dose response for acinar cell neoplasms and high rate of preneoplastic hyperplasia in the control group, NTP should further consider the pancreatic results in the male rats, particularly given the likely contribution of peroxisome proliferator- 
activated receptor alpha $(\mathrm{PPAR} \alpha)$ to tumor formation. Mr. Risotto questioned the relevance of the male rat findings to human risk assessment. He said that ACC was unable to find additional information in the draft report on the nature of the toxicity that caused NTP to restart the male portion of the study. He added that it is critically important that the committee understand the nature of the unanticipated toxicity and consider its potential significance to the findings in the draft report. Regarding the conclusion about fetal sensitivity to perfluorooctanoic acid exposure, Mr. Risotto observed that the draft report indicates that there were very few significant differences between the groups of animals exposed postweaning-only versus groups with perinatal and postweaning exposure. He noted that the differences observed were sporadic and that the report does not prove a conclusion regarding the potential impact of perinatal exposure yet that is the stated hypothesis for conducting the study. Given that NTP rarely conducts combined perinatal and postweaning chronic studies, Mr. Risotto said that ACC believes the committee should evaluate whether the study results support NTP's central hypothesis. He stated that the report summary suggests NTP does not support the hypothesis.

\section{G.3.4.3. Peer-Review Comments and Panel Discussion}

\section{G.3.4.3.1. First Reviewer - Dr. Michael Elwell}

Dr. Elwell said that both studies were well-designed, nicely presented, and NTP clearly stated the results. Dr. Elwell requested further discussion of why the proposed level of carcinogenic activity for pancreatic neoplasms in females does not also apply to the liver carcinoma findings. He said the rationale for the pancreas acinar neoplasm increases as "some evidence" in females appears to be based on the current and historical control data, and association with the finding of "clear evidence" in males. He felt that the rationale could apply to the female liver neoplasm conclusion as well. Dr. Elwell requested discussion of why NTP did not consider the uterine carcinomas "equivocal." Dr. Elwell asked about the relationship of the extended and standard evaluations on the incidence of adenoma and adenocarcinoma in the uterus.

In response to Dr. Elwell's comments, Dr. Blystone indicated that:

- NTP applied a call of some evidence of carcinogenic activity to the adenomas and adenocarcinomas in the pancreas in females since they were present in the highest dose group and considered a rare lesion. However, in the liver, there was only a marginal increase in the incidence of hepatocellular carcinomas in females and no change in the incidence of adenomas.

- NTP used a weight of evidence approach to determine that uterine adenocarcinomas might have been related to exposure.

- NTP found most of the uterine adenocarcinomas after the new sectioning and extended evaluation.

\section{G.3.4.3.2. Second Reviewer - Dr. Gabriele Ludewig}

Dr. Ludewig agreed that NTP executed and described the studies very well. She noted that due to the interest in the results for human risk assessment, the introduction should be perfectly clear as to the limitations of the study. Dr. Ludewig suggested that NTP should clearly state the reference to the perfluorooctanoic acid half-life in female rats, which is measured in hours, versus the halflife in humans, which is measured in years, in the introduction to prevent a false assumption of safety from the high dose that was used. Dr. Ludewig recommended clarifying what type of 
"overt toxicity" NTP observed in males in Study \#1. Dr. Ludewig suggested they add a statement to the discussion as to whether they considered/analyzed ossification and changes in bone morphology since regulatory values in the United States are based on these findings. Dr. Ludewig recommended emphasizing in the report that the PPAR $\alpha$ pathway, which NTP mentions in the report, is not relevant to humans. The CAR pathway and any observation of its activation should be discussed. Dr. Ludewig said NTP should clearly state that the adult exposure included some developmental exposure during sexual maturation since the rats do not fully develop until PND 90. She noted this is important since the hypothesis was to test whether there was an influence of developmental exposure. Dr. Ludewig pointed out that NTP did not mention fecal excretion. Dr. Ludewig stressed that they clearly state the study limitations, especially since the short half-life in rodents is thought to be due to specific transporters present in the kidneys and other organs which may have influenced organ-specific concentrations of PFOA. Dr. Ludewig reported that NTP should cite recently published studies on perfluorooctanoic acid, glucose levels, and liver toxicity to support the findings that there is some liver toxicity.

- Dr. Blystone indicated that NTP would consider clarifying some of the language and adding statements to the report based on her suggestions. This may include additional information on the differences in perfluorooctanoic acid elimination between rodents and humans, a statement about bone morphology findings, and highlighting the point that exposure occurred during sexual maturation.

\section{G.3.4.3.3. Third Reviewer - Dr. Wendy Halpern}

Dr. Halpern indicated that NTP clearly presented and described the findings in the draft report. Dr. Halpern suggested adding more information to the discussion section, in a similar manner to the introduction, that highlights the potential mechanisms of these findings. For instance, the discussion could address the fact that previous carcinogenicity studies identified interstitial cell tumors in male rats as potentially related to perfluorooctanoic acid exposure, which NTP did not identify in this study. Dr. Halpern requested more discussion on the potential immunomodulatory activity as indicated by the decreased spleen and thymus weights. Dr. Halpern suggested expansion of the interim necropsy results, particularly the effect on liver weights. She noted that the biggest challenge in interpreting the study results is the exposure differences, both between rats and humans and between male and female rats. For instance, if testosterone is the driver for exposure differences in males, it is hard to interpret the exposure relationship during development when testosterone is still low in male pups and where female pups were given a higher dose based on exposure differences in adult rats. Dr. Halpern agreed that the decreased body weight and hepatic findings in the males in the initial 16-week necropsy warranted a change in dose administration. However, it is difficult to distinguish the sex-related from potential study-related differences in hepatocellular carcinoma incidence, especially with a small absolute magnitude of difference. Dr. Halpern noted that in almost every parameter evaluated, perinatal exposure seemed to have minimal or no effect, with the singular exception of a numerical increase in hepatocellular carcinomas in male rats exposed to 300/80 ppm in Study \#2. She did not think the overall data supports that perinatal exposure drives this finding since there was a numerically similar incidence of hepatocellular carcinomas in the female rats and because of the potential linkage of these neoplasms to PPAR $\alpha$. She noted that she did not see a difference with perinatal exposure in either liver weights, acyl-CoA activation, or any other parameter that would suggest that PPAR $\alpha$ induction was different. She did not think this finding was clearly 
related or dependent on perinatal exposure, which goes back to the hypothesis presented. Dr. Halpern indicated that her main question was whether this was a developmentally sensitive effect given that male rats had the same exposure as female rats based on the kinetic data and these findings were not present in female rats.

In response to Dr. Halpern's comments, Dr. Blystone indicated that:

- NTP phrased the conclusion statements as they were because they limited the response to that one finding and, since perinatal exposure may by an influence, it was not an outright rejection of the hypothesis.

- NTP did not observe differences in liver weights or acyl-CoA oxidase activity. He noted that there might be other mechanisms at play besides increased PPAR $\alpha$ via acyl-CoA activation, such as the constitutive androstane receptor (CAR) pathway. While CAR activity has been shown in other studies, NTP did not evaluate it in this study.

- NTP would consider clarifying various points in the report based on Dr. Halpern's suggestions such as the exposure concentration differences between this study and concentrations used previously, the role sexual maturation may play in the exposure differences, and details regarding spleen and thyroid weights.

In a follow-up statement, Dr. Halpern said it was her impression from reading the report that NTP did not expect that male and female perinatal exposures would have differed, yet they only saw hepatocellular carcinomas in the males, not the females.

- Dr. Blystone confirmed Dr. Halpern's statement.

\section{G.3.4.4. Panel Discussion}

Dr. Cattley expressed concern that there was not sufficient evidence to conclude that there was an influence of perinatal exposure. For instance, the hepatocellular carcinoma response was so weak that there was not much of a window to detect any increase that might occur without any perinatal exposure. In addition, there was no effect on the incidence of hepatocellular adenomas with perinatal exposure. He noted that the report appropriately combined the incidence of hepatocellular adenomas and hepatocellular carcinomas since NTP considered adenomas to be the precursor lesion and can potentially progress to carcinomas. He indicated that he was struggling with the hypothesis about the impact of perinatal exposure on the incidence of hepatocellular neoplasia in the study.

- Dr. Blystone confirmed that the incidence of adenomas did not appear different between animals with and without perinatal exposure. He remarked that although the strength of response was not strong, the rarity of the lesion and the fact that the liver responded to the chemical led NTP to make this conclusion.

In a follow-up statement, Dr. Cattley indicated that he was still hesitant to conclude that there was a perinatal effect in this study. 


\section{G.3.4.5. Vote on NTP Conclusions}

\section{G.3.4.5.1. Male Hsd:Sprague Dawley ${ }^{\circledR} S D^{\circledR}$ rats}

Dr. Cattley called for a motion from the panel to approve the conclusions as written.

Dr. Ludewig so moved, but there was no second to the motion. Dr. Cattley called for a motion from the panel to approve the first two bullets as written and delete the third bullet, and the panel would consider adding a replacement third bullet. Dr. Halpern so moved and Dr. Ludewig seconded the motion. The panel voted unanimously (4 yes, 0 no, 0 abstentions) to approve the first two bullets of the conclusion. Dr. Cattley called for a motion to add a third bullet. Following an extensive discussion, the panel proposed the third bullet read, "The additional effect of perinatal exposure in combination with postnatal exposure was uncertain and limited to the observation of hepatocellular carcinomas." Dr. Halpern moved for the approval of the third bullet. Dr. Ludewig seconded the motion. The panel voted unanimously (4 yes, 0 no, 0 abstentions) to approve the proposed third bullet.

\section{G.3.4.5.2. Female Hsd:Sprague Dawley ${ }^{\circledR} S D^{\circledR}$ rats}

Dr. Cattley called for a motion from the panel to approve the conclusions as written. Dr. Elwell so moved and Dr. Ludewig seconded the motion. The panel voted unanimously (4 yes, 0 no, 0 abstentions) to approve the conclusions as written.

\section{G.3.5. Closing Remarks on the Draft Reports}

Dr. Cattley welcomed additional panel comments on the draft reports. There were no additional comments.

Closing the meeting, Dr. Maull thanked all the peer-review panelists.

Dr. Cattley added his thanks to the NTP staff and the panel members for their efforts.

Dr. Cattley adjourned the meeting at 1:15 p.m. EDT on December 12, 2019. 


\section{Appendix H. Supplemental Data}

Tables with supplemental data can be found here: https://doi.org/10.22427/NTP-DATA-TR-597.

\section{H.1. Fourteen-week Interim Evaluation in Rats}

E03 - Growth Curves

E04 - Mean Body Weights and Survival Table

E05 - Clinical Observations Summary

E08 - Feed Water and Compound Consumption Table

P03 - Incidence Rates of Non-Neoplastic Lesions by Anatomic Site

P04 - Neoplasms by Individual Animal

P05 - Incidence Rates of Neoplasms by Anatomic Sites (Systematic Lesions Abridged)

P08 - Statistical Analysis of Primary Tumors

P09 - Non-Neoplastic Lesions by Individual Animal

P10 - Statistical Analysis of Non-Neoplastic Lesions

P11 - Statistical Analysis of Survival Data

P14 - Individual Animal Pathology Data

P17 - Neoplasms by Individual Animal (Systemic Lesions Abridged)

P18 - Incidence Rates of Non-Neoplastic Lesions by Anatomic Site with Average Severity Grades

P40 - Survival Curves

PA06 - Organ Weights Summary

R02 - Reproductive Performance Summary

\section{H.2. Perinatal and Two-year Study in Rats}

E03 - Growth Curves

E04 - Mean Body Weights and Survival Table

E05 - Clinical Observations Summary

E08 - Feed Water and Compound Consumption Table 
HMB Chronic Perinatal Female Harlan Sprague Dawley Rats Gestational and Lactational Chemical Consumption (mg HMB/kg body weight/day)HMB Chronic Perinatal Female Harlan Sprague Dawley Rats: Gestational and Lactational Food Consumption (g/animal/day)

HMB Chronic Perinatal Female Harlan Sprague Dawley Rats: Lactational Body and Body Weight Gains

HMB Chronic Perinatal Litter Data Analysis in Female Harlan Sprague Dawley Rats: Live Litter Size

HMB Chronic Perinatal Litter Data Analysis in Female Harlan Sprague Dawley Rats: PND1 Data

HMB Chronic Perinatal Litter Data Analysis in Female Harlan Sprague Dawley Rats: Survival

HMB Chronic Perinatal: Summary Pup Body Weights

P03 - Incidence Rates of Non-Neoplastic Lesions by Anatomic Site

P04 - Neoplasms by Individual Animal

P05 - Incidence Rates of Neoplasms by Anatomic Site (Systemic Lesions Abridged)

P08 - Statistical Analysis of Primary Tumors with Rao-Scott

P09 - Non-Neoplastic Lesions by Individual Animal

P10 - Statistical Analysis of Non-Neoplastic Lesions

P11 - Statistical Analysis of Survival Data

P14 - Individual Animal Pathology Data

P17 - Neoplasms by Individual Animal (Systemic Lesions Abridged)

P18 - Incidence Rates of Non-Neoplastic Lesions by Anatomic Site with Average Severity Grades

P40 - Survival Curves

\section{H.3. Two-year Study in Mice}

E03 - Growth Curves

E04 - Mean Body Weights and Survival Table

E05 - Clinical Observations Summary

E08 - Feed Water and Compound Consumption Table

P03 - Incidence Rates of Non-Neoplastic Lesions by Anatomic Site

P04 - Neoplasms by Individual Animal 
P05 - Incidence Rates of Neoplasms by Anatomic Sites (Systemic Lesions Abridged)

P08 - Statistical Analysis of Primary Tumors

P09 - Non-Neoplastic Lesions by Individual Animal

P10 - Statistical Analysis of Non-Neoplastic Lesions

P11 - Statistical Analysis of Survival Data

P14 - Individual Animal Pathology Data

P17 -Neoplasms by Individual Animal (Systemic Lesions Abridged)

P18 - Incidence Rates of Non-Neoplastic Lesions by Anatomic Site with Average Severity Grades

P40 - Survival Curves

\section{H.4. Genetic Toxicology}

Genetic Toxicity Study 613844

G06 - Ames Summary Data

Genetic Toxicity Study 381877

G06 - Ames Summary Data

Genetic Toxicity Study G10260

G06 - Ames Summary Data 


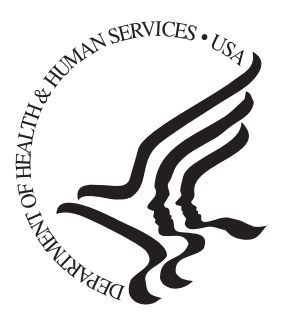

\section{National Toxicology Program}

NTP Central Data Management, MD EC-03

National Institute of Environmental Health Sciences

P.O. Box 12233

Research Triangle Park, NC 27709

http://ntp.niehs.nih.gov 